\title{
A Mixed Methods Analysis of a Single-Course Strategy to Integrate Technology into PETE
}

James D. Wyant

West Virginia University

Follow this and additional works at: https://researchrepository.wvu.edu/etd

\section{Recommended Citation}

Wyant, James D., "A Mixed Methods Analysis of a Single-Course Strategy to Integrate Technology into PETE" (2012). Graduate Theses, Dissertations, and Problem Reports. 264.

https://researchrepository.wvu.edu/etd/264

This Dissertation is protected by copyright and/or related rights. It has been brought to you by the The Research Repository @ WVU with permission from the rights-holder(s). You are free to use this Dissertation in any way that is permitted by the copyright and related rights legislation that applies to your use. For other uses you must obtain permission from the rights-holder(s) directly, unless additional rights are indicated by a Creative Commons license in the record and/ or on the work itself. This Dissertation has been accepted for inclusion in WVU Graduate Theses, Dissertations, and Problem Reports collection by an authorized administrator of The Research Repository @ WVU.

For more information, please contact researchrepository@mail.wvu.edu. 
A Mixed Methods Analysis of a Single-Course Strategy to Integrate Technology into PETE

James D. Wyant

\author{
Dissertation submitted to the \\ College of Physical Activity and Sport Sciences \\ at West Virginia University \\ in partial fulfillment \\ of the requirements for the degree of \\ Doctor of Philosophy \\ in \\ Kinesiology
}

With an emphasis

in

Physical Education Teacher Education

Emily Jones Ph.D., Co-Chair

Sean Bulger Ed.D., Co-Chair

Eloise Elliott, Ph.D

Richard Walls, Ph.D

Pamela Whitehouse, Ed.D

Robert Wiegand, Ph.D

Department of Coaching and Teaching Studies

Morgantown, WV

2012

Keywords: Instructional Technology; Physical Education; Pre-service teachers

Copyright 2012 James D. Wyant 


\section{Abstract \\ A Mixed Methods Analysis of a Single-Course Strategy \\ to Integrate Technology into PETE}

\section{by James D. Wyant}

Background/Purpose: In recent years increased attention has been placed on physical education teachers' use of instructional technology. To date little research has been disseminated regarding the specific strategies physical education teacher education (PETE) programs are employing to prepare pre-service teacher's to use technology. The purpose of this study was to examine the impact of a domain-specific instructional technology course on advancing change in stages of concern and stages of adoption among pre-service teachers. Methods: A mixed methods process involving qualitative (i.e., weekly journal entries and post-course semi-structured interviews) and quantitative (i.e., pre and post course survey) data collection was employed. Participants included 12 undergraduate PETE candidates enrolled at a mid-Atlantic university. Data analysis involved descriptive statistics, inductive analysis, and mixing of qualitative and quantitative data to produce independent case profiles. Data reduction and cross-case synthesis were then used to identify within and across group themes. Analysis/Results: Four dominant themes emerged from participant data: (1) Increased Technological and Technological Pedagogical Knowledge; (2) Persistent First- and Second- Order Barriers to Technology Use; (3) Necessity of Experiential and Hands-on Learning; and (4) Variation in Warrant for Technology Use. The four themes included a total of nine sub-themes that illustrate the benefits and limitations of a single-course strategy in facilitating pre-service teacher use of instructional technology. Conclusions: Faced with the challenge of preparing PETE candidates to effectively integrate technology in their teaching, faculty need to implement a combination of strategies to advance technology perceptions and promote its meaningful application in physical education classrooms. 


\section{Dedications}

I would like to dedicate this dissertation to my parents:

Alanna and Jim Wyant.

It is your love and support that have allowed me to complete this journey.

This dissertation is also dedicated to loving memory of my niece:

Zelah Rose Holbert.

You will forever be in our hearts. 


\section{Acknowledgements}

Dr. Emily Jones and Dr. Sean Bulger served as the driving force behind my accomplishments as a graduate student. I thank you both for your kindness, wisdom, and willingness to assist me through this process.

I also want to thank Dr. Pamela Whitehouse. I appreciate your willingness to serve on my doctoral committee. I will always be grateful for the help you provided me. Your wisdom served as an inspiration for my dissertation work.

I'd also like to extend a thank you to the remaining members of my doctoral committee: Dr. Richard Walls, Dr. Robert Wiegand, and Dr. Eloise Elliott. Dating back to my dissertation proposal you each provided insight that enabled me to successfully complete this project.

Dr. Dan Ziatz has been a constant voice of encouragement throughout my years as a graduate student at West Virginia University. It was the confidence that he expressed in me that helped to get me through my dissertation. I will always be grateful and remember the conversations we have shared.

I would also like to thank my fellow graduate students. Wes Meeteer took me under his wing during my first year. Without his help and advice my years as a doctoral student would have been much more difficult. Will Davis has been a true friend. When I needed someone to talk to he was always there for me. Kiel Illg has been a great friend and a valuable resource. I also will always remember my time during doctoral seminars with my good friends Josh Nelson and Marcus Kinney. I'd also like to thank Camille Ramsey, Kacey DiGiacinto, Han Chen, and Meghan Phillips who have all helped me throughout this process.

Lastly, I'd also like to thank my sisters Jodie and Jamie. I will always be appreciative of your unconditional love and support. 


\section{Table of Contents}

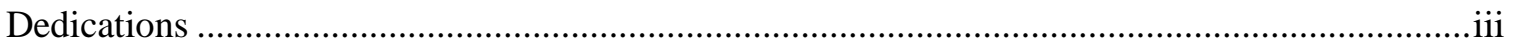

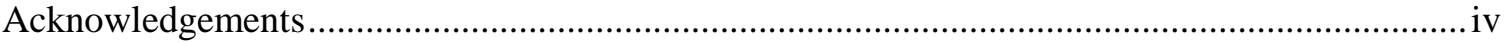

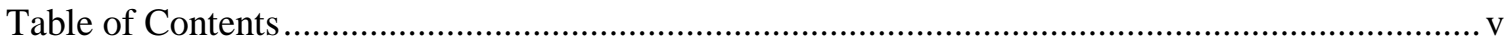

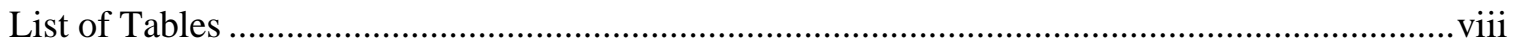

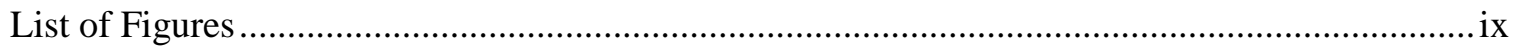

A Mixed Methods Analysis of a Single-Course Strategy to Integrate Technology into PETE ....... 1

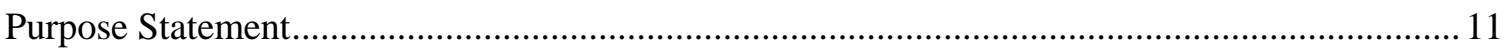

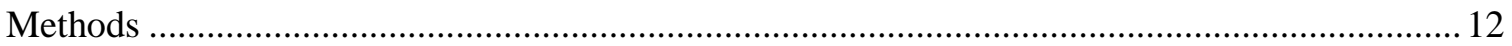

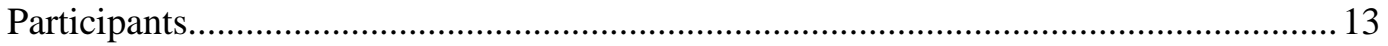

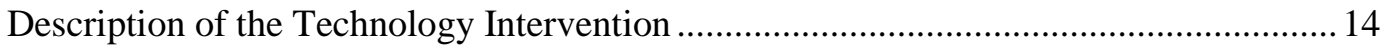

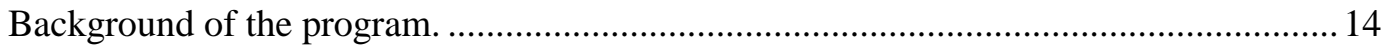

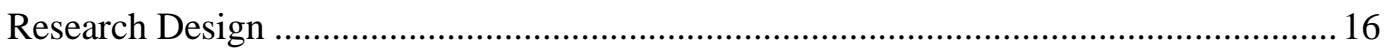

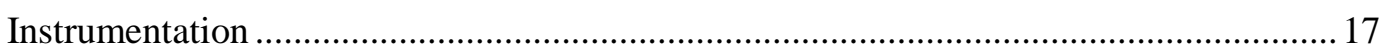

Data Collection Procedures and Analyses ................................................................. 19

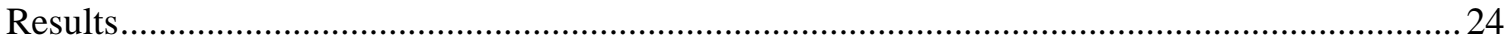

Background Information on Participants .....................................................................2 24

Theme 1: Increased Technological and Technological Pedagogical Knowledge ..............25

Theme 2: Persistent First- and Second-Order Barriers to Technology Use .......................28

Theme 3: Necessity of Experiential and Hands-on Learning ............................................ 31

Theme 4: Variation in Warrant for Instructional Technology Use ................................... 33

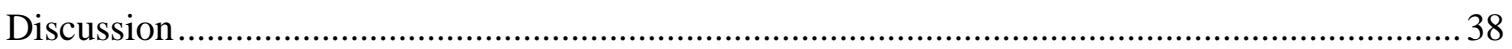

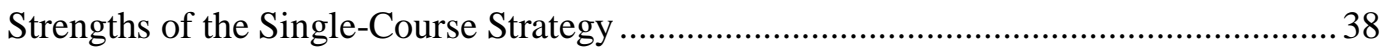

Limitations of the Single-Course Strategy ......................................................................... 40

Improving Pre-Service Teacher Change with Technology ..............................................42

Impediments to Pre-Service Teacher Change with Technology ........................................44

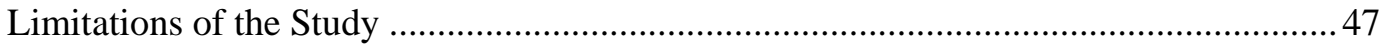

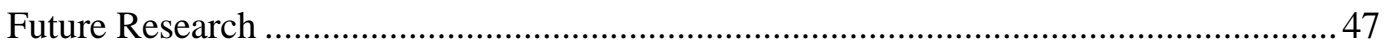

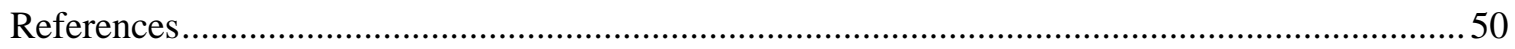

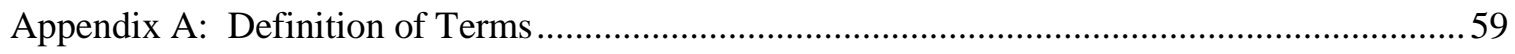




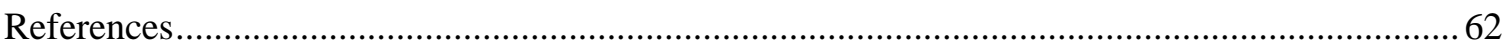

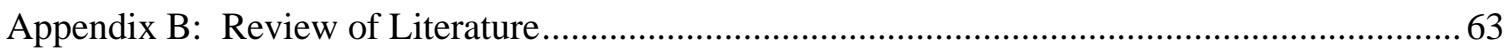

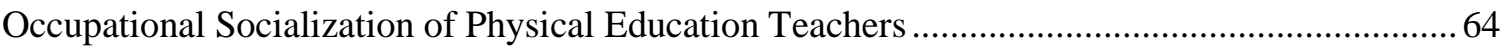

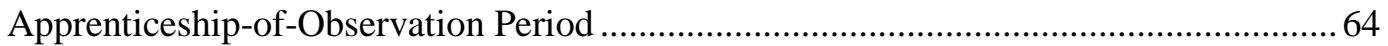

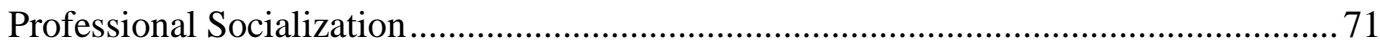

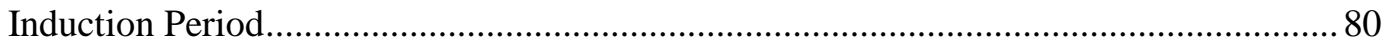

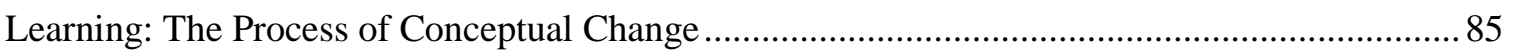

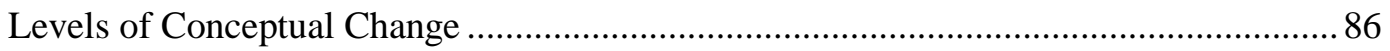

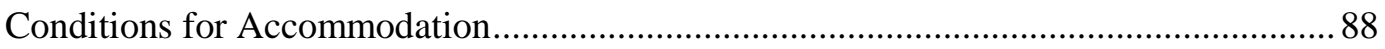

Teachers' Conceptual Change with Technology ….....................................................91

Barriers that Influence Teachers' Conceptual Change with Technology ......................................94

Barriers to Teacher Change with Technology ....................................................................... 95

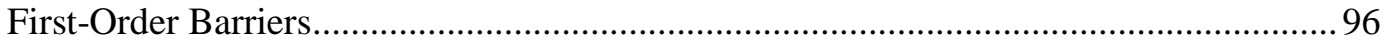

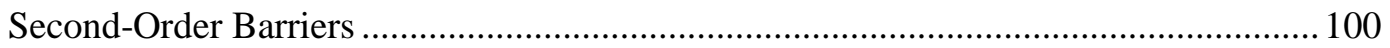

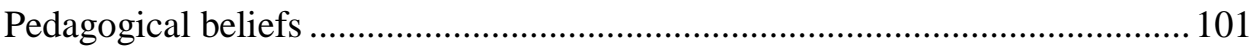

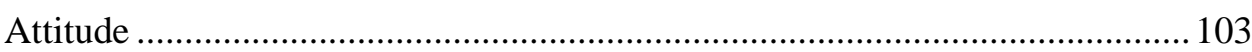

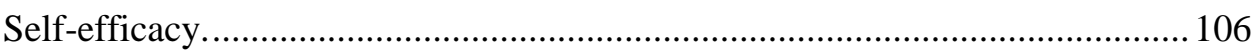

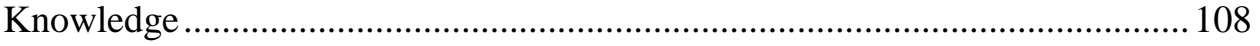

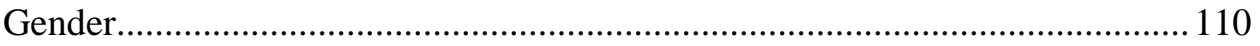

Strategies for Integrating Technology into PETE Curriculum ................................................. 112

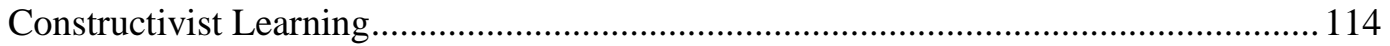

Strategy to Integrate Technology into PETE Curriculum............................................... 119

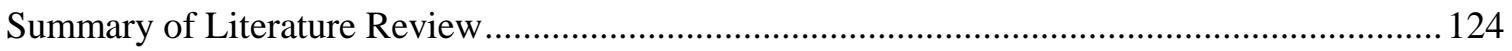

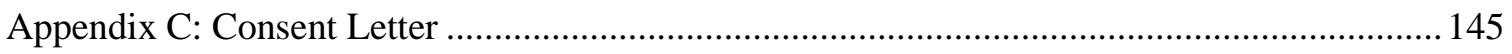

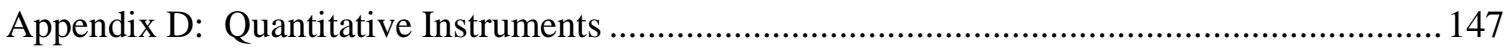

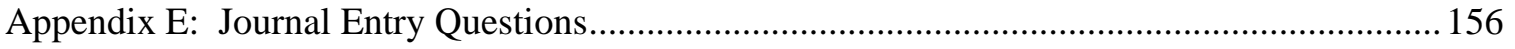

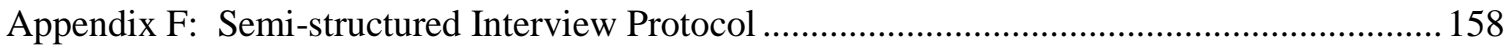

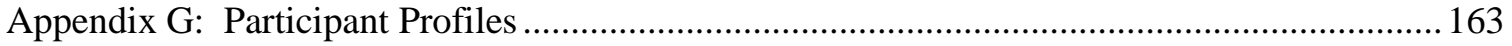

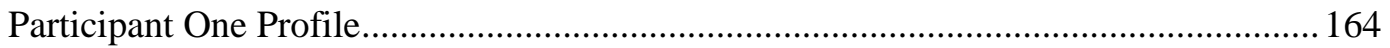

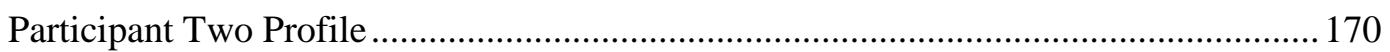

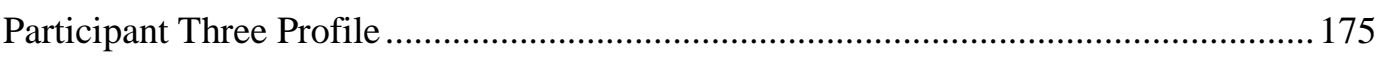

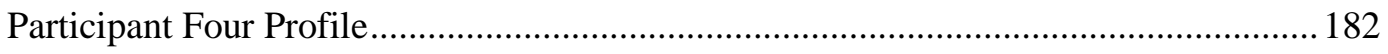

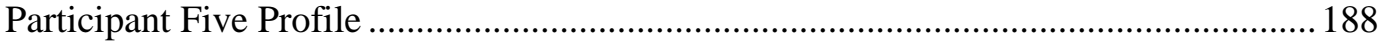




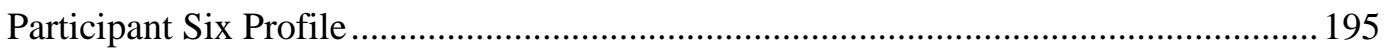

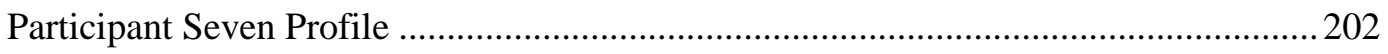

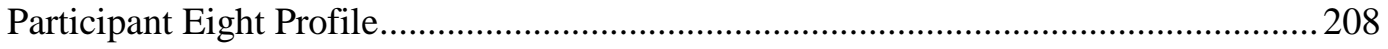

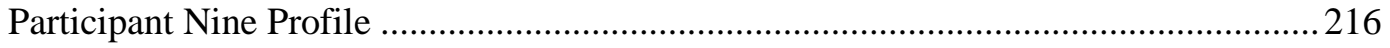

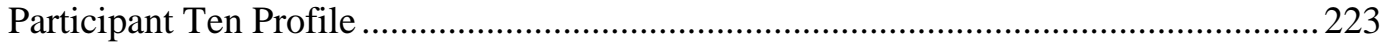

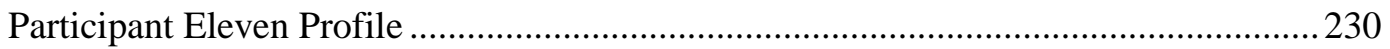

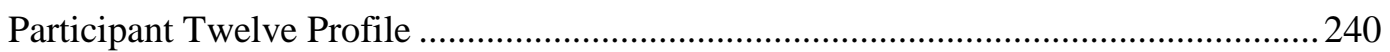

Appendix H: Curriculum Vitae.................................................248 


\section{List of Tables}

Table 1 Stages of Adoption Model Description .................................................... 4

Table 2 Concerns-Based Adoption Model Description ............................................. 6

Table 3 Strategies to Integrate Instructional Technology in Teacher Training ............... 8

Table 4 Research-Based Approaches Embedded within the Technology Intervention.... 15

Table 5 Participant Background and Demographic Information ............................... 25

Table 6 Summary of Theme 1: Increased Technological Knowledge and Technological

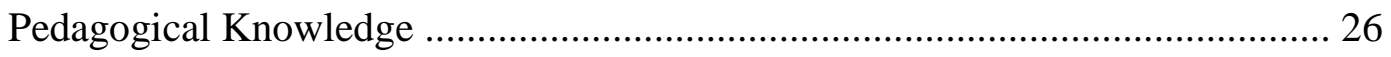

Table 7 Summary of Theme 2: Persistent First- and Second-Order Barriers to

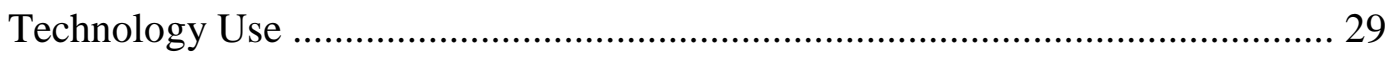

Table 8 Summary of Theme 3: Necessity of Experiential and Hands-on Learning ......... 32

Table 9 Summary of Theme 4: Variation in Warrant for Instructional Technology Use. 37 


\section{List of Figures}

Figure 1 Visual Model of Mixed Methods Research Design 


\section{A Mixed Methods Analysis of a Single-Course Strategy to Integrate Technology into PETE}

In today's constantly changing world, technology has become an important aspect of everyday life and its use is pervasive among children and adolescents (Hersey \& Jordan, 2007; Koc \& Bakir, 2010; Lenhart, 2009). In response to these societal trends, key stakeholders and decision makers in the field of education have recognized the value of technology and made a concerted effort to integrate it as a key dimension of teaching and learning in the schools (Gray, Thomas, \& Lewis, 2010; Quillen, 2011). Accordingly, considerable focus has also been placed on the need to prepare teachers with the competencies required to use technology as a means of preparing young people to function productively within our digital society (National Council for Accreditation of Teacher Education, 2008; International Society for Technology in Education, 2008a). The numerous national entities advocating for technology integration include the governing body of physical education. Recently the National Association for Sport and Physical Education (NASPE) established a standard that addresses technology and a related position statement citing the benefits of technology use within the discipline (NASPE, 2008; NASPE, 2009). Beginning physical education teachers are now expected to develop the competencies that will enable them to integrate technology as a means to enhance student learning in the gymnasium. As a result, physical education teacher education (PETE) programs are challenged to facilitate learning in pre-service teachers relative to their use of technology in the schools (NASPE, 2008). Unfortunately, the challenges associated with this type of curricular innovation and conceptual changes in physical education are well documented.

The occupational socialization literature describes how pre-service physical education teachers develop their beliefs about teaching and why practitioners teach the way they do once employed (Curtner-Smith, 2009; Stroot, Faucette, \& Schwager, 1993; Schempp \& Graber, 1992; 
Templin, Woodford, \& Mulling, 1982). Researchers have observed that PETE programs have limited impact on pre-service teachers because the pre-existing beliefs about teaching formed during their own K-12 school experience are resistant to change (Chu, 1984; Curtner-Smith, Hastie, \& Kinchin, 2008; Jackson, 1968; Lawson, 1983; Lortie, 1975; 2002). The evidence related to the induction of beginning physical educators also demonstrates that they encounter numerous individual, social, and environmental barriers to developmentally and instructionally appropriate practice upon their actual entry into the schools (Millslagle \& Morley, 2004; Ryan, 2008). In these difficult circumstances, the knowledge, attitudes, and skills developed during teacher preparation are washed out and many teachers revert to the belief systems about teaching that were formed and entrenched prior to their entry into a PETE program (Lawson, 1983; Zeichner \& Tabachnick, 1981). These finding are highly relevant to any discussion of innovation regarding technology use in teacher education and the schools because "knowledge about teacher socialization can inform educators as to why recruits are resistant to change and unlikely to incorporate some facets of training into their future teaching practices" (Schempp \& Graber, 1992, p.344).

Meaningful learning or change is difficult to achieve because of the considerable influence of existing knowledge structures (Piaget, 1985; Viennot, 1979). Similar to the occupational socialization literature, research on learning also emphasizes that existing knowledge structures can be highly resistant to change. As Viennot (1979) highlights even when faced with rational contradictions to current knowledge structures, misconceptions can remain largely unaffected by educational training. Posner, Strike, Hewson, and Gertzog’s (1982) research acknowledges the challenge of learning, thus referring to learning as a process of conceptual change. Conceptual change occurs when current misconceptions toward a concept 
are replaced. Posner and colleagues (1982) highlight that first and foremost learners must be dissatisfied with their current knowledge and beliefs about a phenomenon. As with occupational socialization, research on learning reiterates that ultimately the individual has the ability to decide whether or not to internalize concepts or ideas. If new concepts do not align with current knowledge structures or underlying beliefs, they have the autonomy to dismiss the new information. Dole and Sinatra (1998) described that the real challenge in facilitating conceptual change is that individuals can reject new concepts at anytime throughout the learning process.

More specifically, researchers have also investigated the process and challenge of producing meaningful learning in teachers relative to their adoption and use of instructional technology. Two prominent models have been used to help explain teacher's willingness or reluctance to incorporate technology in their instruction: Stages of Adoption (Christensen, Griffin, \& Knezek, 2001; Russell, 1995) and Concerns-Based Adoption Model (CBAM) (Hall, George, \& Rutherford, 1979). The models vary in terminology but focus on the learning process teachers navigate when confronted with the challenge of technology integration. Each model highlights the process of learning and the conditions that must be met for teachers to make progress in their usage of technology.

The Stages of Adoption model outlines the six stages a teacher progresses through when incorporating technology in their teaching (Christensen et al., 2001). The model highlights how teachers progress from a non-adopter (Stage One, Awareness) to an innovative user of technology (Stage Six, Creative Application to New Contexts). Each stage represents the conditions that must be addressed for teachers to advance in their usage of technology (see Table 1). The model bas been cited as an effective tool to measure teachers' adoption of technology 
and has typically been used to inform education and design professional development opportunities to better meet the needs of teachers (Christensen et al., 2001).

Table 1

Stages of Adoption Model Description

\begin{tabular}{lll}
\hline Stage & Name & Description \\
\hline One & Awareness & Individual is aware that technology exists but has not used it. \\
Two & Learning the Process & Individual is trying to learn the basics of technology. \\
Three & $\begin{array}{l}\text { Understanding the Application } \\
\text { of the Process }\end{array}$ & $\begin{array}{l}\text { Individual is beginning to understand the process of using } \\
\text { technology. }\end{array}$ \\
Four & Familiarity and Confidence & Individual is gaining confidence in using technology. \\
Five & $\begin{array}{l}\text { Adaptation to Other } \\
\text { Contexts }\end{array}$ & $\begin{array}{l}\text { Individual feels they can use technology in a variety of } \\
\text { contexts as an instructional tool. }\end{array}$ \\
Six & $\begin{array}{l}\text { Creative Application to New } \\
\text { Contexts }\end{array}$ & $\begin{array}{l}\text { Individual feels they can use technology as an instructional } \\
\text { tool and successfully integrate it into their curriculum. }\end{array}$ \\
\hline
\end{tabular}

Note. Adapted from Christensen, R., Griffin, D., \& Knezek, G. (2001). Measures of Teacher Stages of Tech Integration and Their Correlates with Student Achievement. Paper presented at the Annual Meeting of the American Association of Colleges for Teacher Education, Dallas, TX.

The CBAM provides a more holistic perspective of the different feelings teachers can possess when learning how to integrate technology (Hall et al., 1979). The model consists of seven stages of concern. Table 2 includes a description for each of the seven stages of concern. Awareness (Stage Zero), Informational (Stage One), Personal (Stage Two), and Management (Stage Three) are referred to as internal concerns or low levels of concern. When individuals possess concerns of this nature their attention focused on the innovation comes from within (Hall et al., 1979). Consequence (Stage Four), Collaboration (Stage Five), and Refocusing (Stage Six) are labeled as external concerns or high levels of concern. Individuals who possess external concerns tend to focus on how the innovation will influence other people (Hall et al., 1979). The underlying premise of this model is that concern influences performance; lower level concerns 
have to be addressed before higher level concerns will be considered (Hall et al., 1979). The model also highlights that individuals can possess multiple concerns toward an innovation at the same time (Hall et al., 1979). For example, a teacher could feel knowledgeable about creative application of technology in instructional settings (Refocusing, Stage Six), but have internal concerns about their personal investment of discretionary time and effort required to integrate technology into their teaching (Personal, Stage Two). Due to its relevance to technology integration, the CBAM has been used widely in related research and findings indicate that learners will experience different concerns as a result of beliefs, knowledge, experiences, and comfort with technology (Donovan, Hartley, \& Strudler, 2007; Overbaugh \& Lu, 2008; Rakes \& Casey, 2002).

If pre-service teachers are to successfully move forward along these continuums of change in a desirable direction, the various facilitators and barriers to technology adoption and use in educational settings must also be considered. Ertmer (1999) classified barriers as external or internal factors that impact a teacher's ability to integrate technology into their teaching. External barriers or first-order barriers are those factors that the teacher does not have control over. Typically these barriers include things such as access to technology equipment, training, and support. Research provides that a common barrier faced by teacher education programs is ensuring pre-service teachers and faculty have adequate access to technology (Koc \& Bakir, 2010; Lisowski, Lisowski, \& Nicolia 2007). Once technologies are in place, however it is also important that pre-service teachers, practitioners, and faculty have the needed competencies to effectively use the technology. Therefore, effective training and professional development are critical to meaningful technology integration (ISTE, 2008b). While addressing first-order 
barriers is critical, Ertmer and Ottenbreit-Leftwich (2010) emphasize that even if issues such as access and training are covered it does not ensure teachers will use technology.

Table 2

Concerns-Based Adoption Model Description

\begin{tabular}{|c|c|c|}
\hline Stage & Name & Description \\
\hline Zero & Awareness & Little concern or involvement about the innovation is indicated. \\
\hline One & Informational & $\begin{array}{l}\text { A general awareness of the innovation is indicated and some } \\
\text { interest is expressed (e.g. general characteristics, effects, and } \\
\text { requirements for use). The individual is interested in learning } \\
\text { more about the innovation }\end{array}$ \\
\hline Two & Personal & $\begin{array}{l}\text { Uncertain about the demands of the innovation. Individual is } \\
\text { also not sure about their ability to use the innovation and } \\
\text { potential conflicts with personal pedagogical beliefs. }\end{array}$ \\
\hline Three & Management & $\begin{array}{l}\text { Individual is focused on how to use the innovation. Primary } \\
\text { focus is on organizing, managing, and the time demands of the } \\
\text { innovation. }\end{array}$ \\
\hline Four & Consequence & $\begin{array}{l}\text { Concerned about how the innovation will impact their students. } \\
\text { Specifically concerned about the relevance of the innovation, } \\
\text { how to evaluate student learning, and changes needed to address } \\
\text { student learning. }\end{array}$ \\
\hline Five & Collaboration & $\begin{array}{l}\text { Concerned about how to collaborate with others regarding the } \\
\text { innovation. }\end{array}$ \\
\hline Six & Refocusing & $\begin{array}{l}\text { Individual is concerned about ways to improve use of the } \\
\text { innovation. Individual definitely possesses ideas about the } \\
\text { innovation. }\end{array}$ \\
\hline
\end{tabular}

Note. Hall, G. E., George, A. A., \& Rutherford, W. L. (1979). Measuring stages of concern about the innovation: A manual for the use of the SOC questionnaire. Austin, TX: The University of Texas at Austin. The Research and Development Center for Teacher Education.

A significant reason teachers choose not to make technology an integral component of their teaching is because they do not value technology (Ertmer \& Ottenbreit-Leftwich, 2010). Barriers that deal with value are considered to be internal factors, which directly relate to teachers' beliefs about teaching, beliefs about technology, and desire to change. Internal barriers are also commonly referred to as second-order barriers (Ertmer, 1999). While, first-order 
barriers are viewed as changeable; second-order barriers are often characterized as static (Ertmer, 1999). Second-order barriers are classified as static because internal variables such as beliefs and knowledge can be highly resistant to change (Ertmer \& Ottenbreit-Leftwich, 2010; Pajares, 1992; Viennot, 1979). As Cuban (1997) highlights, the challenge of getting teachers to use technology is not about resources; instead the real challenge is that many teachers do not believe in technology as an instructional tool. Barriers to teacher change with technology highlights the need for PETE programs to adopt research driven strategies that have been shown to produce meaningful learning in pre-service teachers.

Due to the lack of empirical evidence that currently exists as to what is the best manner to prepare pre-service physical education teachers to use technology, an initial step may be to pull from the knowledge base that currently exists in general education. Kay (2006) identified ten commonly used strategies to integrate technology into general education pre-service programs (see Table 3). Of the ten strategies identified, the one of interest to this study is the singlecourse. Single-course is a strategy in which a pre-service program offers one instructional technology course for its learners. Primary benefits of this strategy include: enhanced selfefficacy using technology (Gunter, 2001), technology skills (Gunter, 2001), and exposure to the role of technology in teaching (McRobbie, Ginns, \& Stein, 2000). An inherent disadvantage to this approach is the lack of authentic experience or application of instructional technology in the K-12 context (Pope, Hare, \& Howard, 2002). 
Table 3

Strategies to Integrate Instructional Technology in Teacher Training

\begin{tabular}{|c|c|c|c|}
\hline Strategy & Key Features & Key Findings & Constraints / Limitations \\
\hline Integrated & $\begin{array}{l}\text { Weaves technology throughout } \\
\text { multiple courses in pre-service } \\
\text { curriculum }\end{array}$ & $\begin{array}{l}\text { - Increases technology confidence and } \\
\text { skills } \\
\text { - Focuses on meaningful problem solving } \\
\text { with technology }\end{array}$ & $\begin{array}{ll}\text { - } & \text { Access to technology } \\
\text { - } & \text { Minimal transfer of learned skills to } \\
\text { - } & \text { Lchool-based field experiences } \\
\text { - } & \text { imited faculty time and expertise }\end{array}$ \\
\hline Multimedia & $\begin{array}{l}\text { Various multimedia-based } \\
\text { technologies are integrated across pre- } \\
\text { service education (e.g., electronic } \\
\text { portfolios, online video, online } \\
\text { courses) }\end{array}$ & - Limited empirical evidence & - Limited empirical evidence \\
\hline $\begin{array}{l}\text { Education of } \\
\text { Faculty }\end{array}$ & $\begin{array}{l}\text { Teaches faculty how to integrate } \\
\text { technology (focused on improving } \\
\text { attitude, ability, and use) }\end{array}$ & $\begin{array}{l}\text { Establishes a cohesive, coordinated } \\
\text { introducing and modeling technology } \\
\text { for pre-service teachers }\end{array}$ & - Faculty buy-in \\
\hline Single-Course & $\begin{array}{l}\text { A stand-alone technology course over } \\
\text { viewing a wide range of technologies } \\
\text { and technology skills (e.g., content, } \\
\text { project, or process-based) }\end{array}$ & $\begin{array}{l}\text { - Enhances technology self-efficacy } \\
\text { - Increases technology skills and } \\
\text { application } \\
\text { - Constrained by limited extension into } \\
\text { field }\end{array}$ & $\begin{array}{l}\text { - } \quad \text { Learning of skills in isolation } \\
\text { - } \quad \text { Minimal transfer of learned skills to } \\
\text { school-based field experiences }\end{array}$ \\
\hline Modeling & $\begin{array}{l}\text { Faculty demonstrate meaningful } \\
\text { technology use in classroom }\end{array}$ & $\begin{array}{l}\text { - Illustrates technology use in "real } \\
\text { world" scenarios }\end{array}$ & $\begin{array}{l}\text { - Faculty ability to provide meaningful } \\
\text { examples of technology use } \\
\text { - Limited hands-on experiences for } \\
\text { pre-service teachers }\end{array}$ \\
\hline
\end{tabular}


Table 3 Continued

\begin{tabular}{|c|c|c|c|}
\hline Strategy & Key Features & Key Findings & Constraints / Limitations \\
\hline Collaboration & $\begin{array}{l}\text { Partnerships between university and } \\
\text { public schools to create rich field- } \\
\text { based technology environments }\end{array}$ & $\begin{array}{l}\text { - Promotes positive relationships between } \\
\text { universities and local schools } \\
\text { - } \quad \text { Provides authentic and supporting } \\
\text { settings to explore technology uses }\end{array}$ & - $\quad$ Requires buy-in from all parties \\
\hline Field-Based & $\begin{array}{l}\text { Requires pre-service teachers to create } \\
\text { and deliver technology-rich lessons } \\
\text { during field experiences }\end{array}$ & $\begin{array}{l}\text { - Provides authentic, hands-on application } \\
\text { of technology } \\
\text { - Focuses on technology's impact on } \\
\text { student learning }\end{array}$ & $\begin{array}{l}\text { - Relies on pre-service teachers' level } \\
\text { of confidence, preparation, and skill }\end{array}$ \\
\hline Workshops & $\begin{array}{l}\text { Short, focused seminars or labs to } \\
\text { introduce technologies and } \\
\text { applications }\end{array}$ & $\begin{array}{l}\text { - Provides time-efficient information } \\
\text { distribution }\end{array}$ & $\begin{array}{l}\text { - Long-term effects on attitude and } \\
\text { technology use in classroom is not } \\
\text { empirically established }\end{array}$ \\
\hline Access & $\begin{array}{l}\text { Provides access to software, hardware } \\
\text { and support }\end{array}$ & $\begin{array}{l}\text { Provides opportunities for technology } \\
\text { use and application }\end{array}$ & $\begin{array}{l}\text { - Is not sufficient as an isolated } \\
\text { strategy }\end{array}$ \\
\hline $\begin{array}{l}\text { Mentor- } \\
\text { Teacher }\end{array}$ & $\begin{array}{l}\text { Places pre-service teachers with } \\
\text { teacher to jointly produce meaningful } \\
\text { technology-rich learning experiences }\end{array}$ & - Limited empirical evidence & - Limited empirical evidence \\
\hline
\end{tabular}

Note. Adapted from Kay, R. (2006). Evaluating strategies used to incorporate technology into preservice education: A review of literature. Journal of Research on Technology in Education, 38(4), 383408 
General education researchers have also suggested instructional approaches to embed within a single-course to enhance learning. One suggestion is to create a constructivist-based learning environment that promotes hands-on learning, collaboration, and modeling (Kang, Choi, \& Chang, 2007). The merits of constructivist-based learning environments include: exposing pre-service teachers to authentic learning tasks (Murphy, 1997), improving pre-service teachers' perception of technology (Vannatta \& Beyerbach, 2000), and enhancing pre-service teachers' understanding of technology (Mai \& Tse-Kian, 2010). At the core of the constructivist approach is that teachers create climates that embrace solving of real world problems and assist learners in deriving new knowledge and understanding (Solomon \& Schrum, 2007).

Another recommended instructional approach to be infused within a single-course is the use of a sound conceptual framework that informs course design and implementation. An example of such a framework is the Technological Pedagogical Content Knowledge (TPACK) model (Mishra \& Koehler, 2006). The TPACK framework is an extension of Lee Shulman's (1986) discussion of pedagogical content knowledge (PCK) by introducing technological knowledge (TK) as a new independent, yet interacting construct within the model. There are three knowledge constructs represented in the TPACK model, these include:(1) content knowledge (CK) which is knowledge of subject matter; (2) pedagogical knowledge (PK) that is knowledge of the methods of teaching; and (3)technological knowledge (TK) which involves knowledge of available technologies and knowing how to operate specific technologies. The independent natures of these constructs represent a solid base of teacher knowledge; while the interactions among the constructs reflect a teacher's ability to design meaningful experiences in aim of student learning. In 1986 Shulman postulated that the interactions among CK and PK, or more commonly referred to as PCK, allowed teachers to blend content and pedagogy to build 
meaningful and accessible learning experiences for students. The interaction new addition of TK to this model produces additional interactions and implications for the teaching and learning environment (Mishra \& Koehler, 2006). For example, when TK and PK intersect, it is referred to as technological pedagogical knowledge (TPK) and is described as the knowledge of existent technologies and their functions, coupled with an understanding of how one's teaching and instruction will change as a result of using a particular technology. The interaction between TK and CK, or technological content knowledge (TCK), is the knowledge of technology and how its application in a classroom setting will change the subject matter being introduced. Lastly, the model offers that at the intersection of all three knowledge constructs exists TPACK, which embodies an understanding and negotiation of the dynamic interactions among content, pedagogical, and technological knowledge that can result in true technology integration. The TPACK model emphasizes that teachers must navigate and negotiate the manners in which technology will influence their content and instructional practices in order to successfully integrate technology into their teaching (Banister \& Reinhart, 2011). Several researches have lauded the positive impact of TPACK on student learning (Chai, Koh, \& Tsai, 2010; ÖzgünKoca, Meagher, \& Edwards, 2010).

\section{Purpose Statement}

In recent years increased attention has been placed on physical education teachers' use of instructional technology. To date little research has been disseminated regarding the specific strategies PETE programs are employing to prepare teacher candidates to use technology though. The purpose of this study was to examine the impact of a domain-specific instructional technology course on advancing change in stages of concern and stages of adoption among preservice teachers. When you combine the increasing role of technology in society and education, 
a climate has been created for PETE programs to prepare pre-service teachers to effectively use technology in their teaching (Kay, 2006; NASPE, 2008). Accordingly, some physical education researchers have cited the need for more inquiry on this matter (Woods, Goc Karp, Hui, \& Perlman, 2008). Therefore, this study sought to examine the impact a research driven technology integration strategy had on advancing change in pre-service teachers relative to instructional technology. More specifically, understanding how pre-service teachers with different concerns toward instructional technology respond to a domain-specific technology course was a central focus. The following research questions were used to guide the study: (1) Does participation in a domain-specific instructional technology class advance change in preservice physical education teachers' stage of concern and stage of adoption of instructional technology? (2) To what extent are the perceptions of instructional technology the same for participants that possess different concerns toward instructional technology?

\section{Methods}

A partially mixed, concurrent equal status mixed-method design was used to collect data. This descriptive study examined the influence a domain-specific instructional technology course had on pre-service teachers' stages of concern and stages of adoption of instructional technology. The first dependent variable for the study was pre-service teachers' stage of concern toward instructional technology. The second dependent variable for the study was pre-service teachers' stage of adoption of technology. To examine change in these variables descriptive statistics, journal entries, and semi-structured interviews were utilized. Concern toward instructional technology was analyzed and interpreted with the Stages of Concern Questionnaire (SoCQ) (Hall et al., 1979) and the stage of adoption of technology was analyzed using the Stages of Adoption of Technology survey (Christensen et al., 2001; Russell, 1995). Journal entries and semi- 
structured interviews were analyzed through application of inductive content analysis (Lincoln \& Guba, 1985; Patton, 2002) and constant comparative analysis (Glaser, 1965).

\section{Participants}

Prior to beginning the study, Institutional Review Board consent was granted (see Appendix C). The study included 12 participants. Participants for the study were junior and senior level pre-service physical education teachers who were one or two semesters away from initiating their physical education student teaching placements. Participants were recruited from a sample of 34 (male $=24$, female $=10)$ students enrolled in a mandatory three credit hour domain-specific instructional technology course taught by a content-specialist. Due to the nature of the single-course strategy and the need to keep a desirable teacher-to-pupil ratio, all participants were not enrolled in the course at the same time. Six participants were enrolled during the first section of the course, while the remaining six participants were enrolled in the second section of the course. All students enrolled in the mandatory instructional technology course were consented to participate in the study and completed the research instruments and activities; however only data from the 12 selected participants were analyzed and used to inform this study.

Two participant sampling techniques were implemented to address the research questions. Since all participants involved in the study were required to take the instructional technology course they served as a convenience sample. A potential weakness of convenience sampling is the possibility of yielding information-poor cases (Patton, 2002). For that reason, a second sampling procedure was implemented. A stratified purposeful sampling procedure was used to identify information rich cases. Specifically, the six participants with the highest scores on the Refocusing (Stage Six) level of concern and the six participants with the highest score on 
the Awareness (Stage Zero) level of concern, measured by the SoCQ, were selected. For the purpose of this study, group placement was based on the pre-service teachers' levels of concern measured by the SoCQ prior to the start of the course.

\section{Description of the Technology Intervention}

Kay (2006) recommends researchers provide a clear description of the teacher education program that is integrating instructional technology strategies or interventions. Specifically Kay indicates the description needs to provide readers with insight into the background of the program including the number of faculty and pre-service teachers, the program's organization in regards to technology, and overview of the duration of the intervention. These recommendations allow for greater understanding of the contextual factors that facilitate and/or inhibit instructional technology integration in pre-service education (Kay, 2006).

Background of the program. This study occurred at a mid-Atlantic, land-grant institution with an approximate enrollment of 29,000 undergraduate and graduate students. In the PETE program, roughly 110 pre-service teachers enroll each academic year and progress through the program of study in cohorts. Serving these pre-service teachers are six PETE faculty members, two part-time faculty members, and nine graduate assistants.

To prepare pre-service teachers to use technology in their teaching, a faculty member with expertise in instructional technology was hired and various technologies were secured. Examples of secured technologies included: handheld computers, FLIP ${ }^{\mathrm{TM}}$ video cameras, GPS units, heart rate monitors, laptop computers, active gaming systems, and relevant software programs such as Polar PE Manager ${ }^{\circledR}$. A computer lab with 20 desktop computers and a technology-equipped classroom was in place and already available for students. 
Domain-specific instructional technology course. The domain-specific instructional technology course was taught in two sections during the summer and offered to pre-service teachers entering their final year of study. The course met Monday through Friday for three hours each day. The course design was influenced by faculty expertise, national standards, and extensive technology integration research. Based on the faculty's assumption that pre-service teachers would have limited experience with domain-specific technologies, the establishment of a positive, non-threatening learning environment was imperative. Use of constructivist-based learning experiences helped to create such an environment. Pre-service teachers were not viewed as passive recipients of knowledge in this course; rather the instructor and guest experts guided pre-service teachers through varied learning experiences that required collaboration, problem solving, hands-on experimentation, and group and individual exploration of ways the technologies could be implemented in the physical education setting. To facilitate such learning, several recommended, research-based approaches were embedded within the course (see Table 4). A fidelity checklist was used to ensure the instructional environments, and experiences across the sections were the same.

Table 4

Research-Based Approaches Embedded within the Technology Intervention

\begin{tabular}{ll}
\hline \multicolumn{1}{c}{ Research-based approaches } & \multicolumn{1}{c}{ Rationale } \\
\hline $\begin{array}{l}\text { Technological Pedagogical Content Knowledge } \\
\text { (TPACK) }\end{array}$ & $\begin{array}{l}\text { TPACK was a guiding framework for the course to } \\
\text { enhance pre-service teachers' knowledge of } \\
\text { technology and methods for integrating technology } \\
\text { into the K-12 context. }\end{array}$ \\
Continuous Modeling of Technology & $\begin{array}{l}\text { Pre-service teachers were provided with accurate } \\
\text { models of the technology to ensure early success. }\end{array}$ \\
Focus on Project-Based Learning & $\begin{array}{l}\text { Pre-service teachers were required to develop } \\
\text { instructional technology projects that could be } \\
\text { implemented into the K-12 context. }\end{array}$ \\
\hline
\end{tabular}


As described earlier, the course occurred over a three week time period, with each week centering on a theme. The themes were inspired by the national ISTE and NASPE standards (ISTE, 2008a; NASPE 2008). Each week learning experiences included lectures, hands-on learning, reading assignments, reflections, and quizzes that addressed the week's theme. Week one's technology-based learning experiences focused on professionalism and advocacy in physical education. All technologies introduced addressed professionalism and advocacy (e.g., blogging applications, electronic portfolio software, publishing software, and use of library research resources). During week two the focus transitioned to planning and implementation. Technologies for this week focused on assisting teachers with planning and implementation in physical education (e.g., Polar PE Manager ${ }^{\circledR}$, handheld computers, GPS land navigation, and podcasting). Assessment and evaluation was the theme for the final week of the course. Technologies this week had functions related to assessing and evaluating student learning in the physical education setting (e.g., heart rate monitors, electronic grade book software, digital imaging tools, and online resources).

\section{Research Design}

To assist in answering the research questions a partially mixed, concurrent equal status mixed-methods design was used, which involved the collection of quantitative and qualitative data at roughly the same points throughout the study (Leech \& Onwuegbuzie, 2009). As the name states, this mixed-methods design places equal importance on quantitative and qualitative data collection procedures. This design not only enabled the researcher to provide a rich description of variables that influenced pre-service teachers' stage of concern and stage of adoption of technology, but also facilitated an understanding as to why pre-service teachers felt the way they did toward technology. 
Quantitative data were collected and analyzed using a descriptive, repeated measures design. Dependent variables for the study were pre-service teachers' stage of concern toward instructional technology and stage of adoption of technology. The design enabled the researcher to use both quantitative and qualitative methods to analyze participant survey responses to inform the dependent variables under investigation: stage of concern and stage of adoption. Quantitative data were collected and analyzed at two points across the course: pre and postcourse. Qualitative data were collected concurrently with the quantitative measures. The aim of the qualitative methodology was to gather information about the perceptions of pre-service teachers within the sample regarding instructional technology. Three journal entries were embedded throughout the course and a semi-structured interview occurred at the end of the course.

\section{Instrumentation}

Two closed-ended survey instruments were used to measure participant change relative to instructional technology: (1) SoCQ, and (2) Stages of Adoption of Technology Instrument. Qualitative data collection included weekly journal entries and end of course semi-structured interview were used to gather information on participants' perceptions of instructional technology.

Stages of Concerns Questionnaire. The SoCQ is based on the work of Hall et al. (1979) and is used to measure participants' concern toward an innovation (e.g., instructional technology) (see Appendix D). The SoCQ was validated over a three year period and has reportedly high internal reliability with a coefficient of reliability ranging from .64 to .83 and test-retest reliability ranging from .65 to .86 . The SoCQ contains 35 items with an eight-point response scale ranging from "not true of me now" to "very true of me now." The 35 items are 
representative of the seven CBAM stages of concern, with five items accounting for each stage. Participants responded to each item by rating their level of concern on the zero to seven response scale. Response scores from the five items corresponding with each stage were summed to generate raw scores and later converted to percentages. The percentage scores represented the level of concern participants had for each stage.

Any score that exceeded $80 \%$ was considered to be a high level of concern. The stages of concern include the following: Awareness (Stage Zero), Informational (Stage One), Personal (Stage Two), Management (Stage Three), Consequence (Stage Four), Collaboration (Stage Five), and Refocusing (Stage Six). Awareness represents the lowest stage of concern, while Refocusing signifies the highest stage of concern. Awareness, Informational, Personal, and Management concerns are characterized as personal/internal concerns, while Consequence, Collaboration, and Refocusing are labeled as external concerns. The SoCQ survey was administered two times during the study: pre and post-course.

Stages of Adoption of Technology survey. This single-item survey, which contains six stages, was used to measure the stage of adoption of technology in pre-service teachers (see Appendix D). Originally created by Russell (1995) the instrument was used to measure adults stages of adoption with e-mail. Russell's stages include: (1) Awareness, (2) Learning the Process, (3) Understanding the Application of the Process, (4) Familiarity and Confidence, (5) Adaption to Other Contexts, and (6) Creative Applications of New Concepts. Since the instrument was created, descriptions of the stages have been modified to generalize and apply to instructional technology (Christensen et al., 2001). The instrument has been found to be a valid indicator of teachers' change with technology with a high test-retest estimate (.91) (Christensen 
\& Knezek, 2000). The instrument was administered twice during the study: pre- and postcourse.

Journal entries. Weekly structured journal entries were designed to gauge the participants' experience during the course, but also to determine prior experiences with technology in the physical education setting (see Appendix E). The weekly instructor-generated prompts instructed participants to reflect on their perceptions relative to current and future contexts. Prompts were structured in a manner to provide participants the opportunity to openly share their perceptions of instructional technology (Patton, 2002). Prior to the study all journal entry prompts were piloted for clarity.

Semi-structured interviews. Semi-structured interview questions were open-ended to allow participants the freedom to share their beliefs, feelings, and opinions (Patton, 2002) (see Appendix F). A primary purpose of the interview was to have the participants reflect on their experience during the instructional technology course. Questions were written in a manner to seek to understand their perceptions of instructional technology going forward. The interview also helped to identify the similarities and differences that existed between pre-service teachers who possessed different stages of concern toward instructional technology. To enhance the reliability of the interview questions an interview protocol was created based on the recommendations of Patton (2002). Prior to the study interview questions were also piloted to check for clarity.

\section{Data Collection Procedures and Analyses}

Due to the nature of the instructional technology course data were collected and analyzed over four phases. (see Figure 1). The research design included the following four phases: (1) 
Pre-Course, (2) Through-Course, (3) Post-Course, and (4) Mixing the Data. This section contains a description for each phase of the research design.

Phase-one: Pre-course. On the first day of the instructional technology course participants completed both quantitative measures: the SoCQ and Stages of Adoption instruments. Analysis of the SoCQ aimed to identify participants' level of concern for each of the seven constructs. This process included converting participants' SoCQ responses to percentage scores for each construct; which allowed the investigator to identify the level of concern for each construct across all participants. The product of the pre-course SoCQ analysis was the identification of the stratified sample $(N=12)$, including participants $(n=6)$ with the highest score on the Refocusing (Stage Six) level of concern and participants $(n=6)$ with the highest score on the Awareness (Stage Zero) level of concern.

Phase-two: Through course. During phase-two qualitative data were collected. Each week of the course participants completed a journal entry. Inductive content analysis was used to analyze the journal entries. This process consisted of three steps: open coding (Elo \& Kyngas, 2007; Lincoln \& Guba, 1985), categorizing (Cavanagh, 1997; Lincoln \& Guba, 1985), and drawing conclusions (Zhang \& Wildemuth, 2009). The product of phase-two was rich, descriptive journal-based qualitative case profiles for each participant $(N=12)$.

Phase-three: Post-course. During phase-three quantitative and qualitative data were collected. On the final day of the course participants completed both quantitative survey instruments. The post-course analysis aimed to identify change in the dependent variables (Stage of Adoption and Stage of Concern) from pre to post-measurement. The SoCQ raw scores were again converted to percentage scores, to produce the level of concern for each construct. Following this, a holistic examination of the post-course quantitative data involved the use of a 
four stage process to produce a pre to post quantitative case profile for each participant. The four step examination process was based upon the recommendations of Hall et al. (1979) and involved examination of: (1) Relative intensity of participant percentage scores for each stage of concern and the change that occurred from pre to post measurement; (2) Participant's highest and lowest stage scores to determine their level of intensity for each stage at both measurement points, this assisted in understanding participant concerns about instructional technology coming into the course and how those feeling changed; (3) Item response trends to ensure participants Qsorted the items according to the different stages and to determine whether the participants were able to accurately distinguish between the stages; (4) Participant's total SoCQ score, which is the average level of concern across all stages, an indication of a user's involvement with the innovation (e.g., if the total score is low this can characterize a user that lacks investment toward instructional technology). Data generated from the SoCQ and Stages of Adoption of Technology survey were used to generate descriptive pre- to post- course quantitative case profiles for each participant. The profiles included a holistic description of trends observed within participant data (e.g., intensities of stage percentage scores, changes in percentage and total scores, and changes in stage of adoption).

On the last day of the course participants engaged in a 20-30 minute semi-structured interview. Audio recordings of each participant interview were transcribed verbatim by the researcher. Transcriptions were then sent to each participant to ensure that data accurately represented their feelings, thoughts, and opinions. Similar to analysis of the journal entries, interview transcripts were analyzed using inductive content analysis (Lincoln \& Guba, 1985). Once conclusions were drawn from the interview data, the investigator built interview-based 
qualitative case profiles for each participant. The products of phase-three were pre to post quantitative case profiles and qualitative case profiles $(N=12)$.

Phase-four: Mixing the data. In a partially mixed concurrent equal status design the data must first be analyzed utilizing appropriate quantitative and qualitative evaluation methods (Leech \& Onwuegbuzie, 2009). For this study, quantitative and qualitative case profiles were then combined to construct mixed-case narratives for each research participant $(N=12)$. Mixing of the data helped to identify similarities and differences in the data, but it also enabled the investigator to provide a richer description of the data (Plano Clark, \& Creswell, 2008). Analysis of the mixed-case narratives followed the guidelines of Constant Comparison Analysis (Glaser, 1965). Constant comparison allowed the investigator to systematically review, reduce, and synthesize the data from research participants' mixed-case narratives into emergent individual themes, stratified group themes, and themes across all participants. To ensure that data interpretation was accurate and unbiased, outsider legitimation was used. This involved the use of an outside experienced social science researcher to systematically review the mixed-data case narratives. Researcher's first agreed on individual participant themes, and then deductive analysis was employed for data reduction and cross-case synthesis of mixed-data case narratives. Pertinent theories and constructs (e.g., occupational socialization, first- and second-order barriers, and TPACK) were used to help confirm salient themes within the data. The product of phase-four was within and across group themes based on mixed-case narratives (see Appendix $\mathrm{G})$. 
Phase

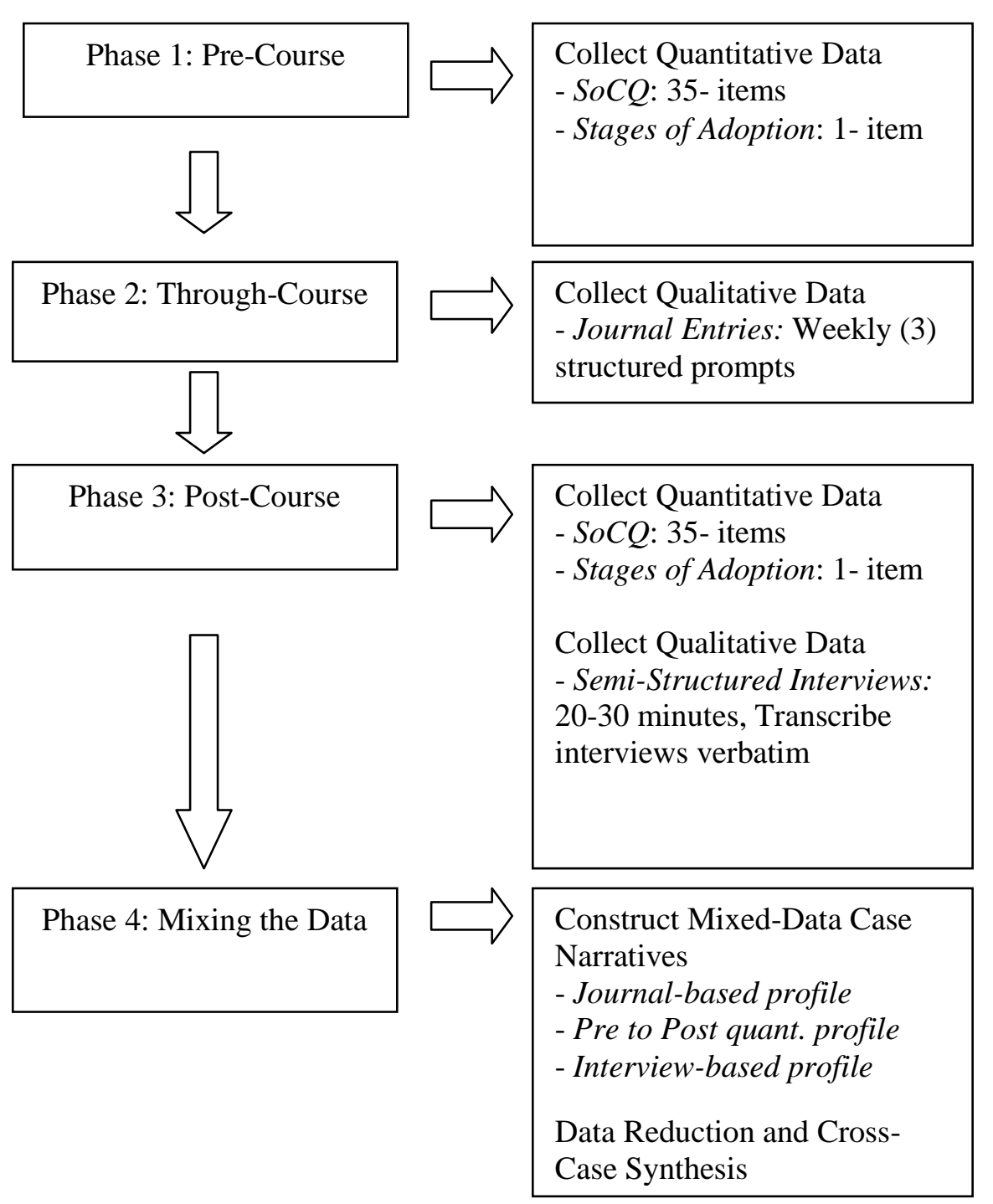

Figure 1. Visual Model of Mixed Methods Research Design

\begin{tabular}{|l|}
\multicolumn{1}{c|}{ Analysis } \\
\hline Analyze Quantitative Data \\
- SoCQ: Raw scores \& \\
percentages per construct \\
- Stages of Adoption: Stage \\
identification
\end{tabular}

\section{Analyze Qualitative Data}

- Inductive Content Analysis

\begin{tabular}{|l|}
\hline Analyze Quantitative Data \\
- SoCQ: Raw scores \& \\
percentages per construct \\
- Stages of Adoption: Stage \\
identification \\
\\
Analyze Qualitative Data \\
- Inductive Content Analysis, \\
Member checks, Outsider check \\
\hline
\end{tabular}

Analyze Independent Cases
- Constant Comparison Analysis
of within-case themes, Identify
outliers, Outsider check

Analyze High and Low Cases
- Constant Comparison Analysis
of within-group themes, Identify
outliers, Outsider check

Product

- Stratified sample of

Highest Awareness ( $n=6$ )

and Refocusing $(n=6)$

level of concern

participants

- Journal-based qualitative case profiles $(N=12)$

- Pre to post quantitative case profiles $(N=12)$

- Interview-based qualitative case profiles $(N=12)$

- Within and across group themes based on mixeddata case narratives $(N=12)$ 


\section{Results}

The mixed-method analysis of these data yielded results and insight to the guiding research questions: (1) Does participation in a domain-specific instructional technology course advance change in pre-service physical education teachers' stage of concern and stage of adoption of instructional technology? (2) To what extent are the perceptions of instructional technology the same for participants that possess different concerns toward instructional technology? Findings revealed four salient themes across participants and data sets, these include: (1) Increased Technological and Technological Pedagogical Knowledge, (2) Persistent First- and Second-Order Barriers to Technology Use, (3) Necessity of Experiential and Hands-on Learning, and (4) Variation of Warrant for Instructional Technology Use. A summary of participant background information and the themes will be described within this section.

\section{Background Information on Participants}

Participants in this study included 12 pre-service teachers (male $=10$; female $=2$; mean age $=22.25$ years $)$ enrolled in a domain-specific instructional technology course at a midAtlantic university. Table 5 provides an overview of research participants' background and demographic information. All 12 participants reported having a home computer and all but one reported attending at least one technology-related course (beyond the one under investigation). Six participants attributed their knowledge of technology prior to the start of the course to their time spent as K-12 students. Half of the participants indicated moderate exposure to technology in physical education as a K-12 student. Upon entry to the course, the SoCQ was used to stratify participants into two groups (e.g., low concern and high concern). To illustrate the difference between the groups upon entry is the average percentage scores on the SoCQ constructs. Relative to Stage Zero (Awareness), the low concern participants averaged a score of 99\%, 
whereas the high concern participants averaged a score of $58 \%$. With respect to Stage Six (Refocusing) the low concern participants averaged $72 \%$ and the high concern participants averaged $92 \%$. The variation across groups indicated that participants possessed different concerns toward instructional technology upon entry into the course.

Table 5

Participant Background and Demographic Information

\begin{tabular}{cccccccc}
\hline $\begin{array}{c}\text { Participant } \\
\text { Code }\end{array}$ & $\begin{array}{c}\text { Stratified } \\
\text { Group }\end{array}$ & Gender & Age & $\begin{array}{c}\text { Technology } \\
\text { Courses } \\
\text { Attended }\end{array}$ & $\begin{array}{c}\text { Home } \\
\text { Computer }\end{array}$ & $\begin{array}{c}\text { Source of } \\
\text { Technology } \\
\text { Knowledge }\end{array}$ & $\begin{array}{c}\text { Exposure to } \\
\text { technology }\end{array}$ \\
\hline P1 & Low & Male & 23 & 1 & Yes & College courses & Minimal \\
P3 & Low & Male & 26 & 2 & Yes & Self-taught & High \\
P4 & Low & Male & 23 & 2 & Yes & Self-taught & Moderate \\
P5 & Low & Male & 23 & 1 & Yes & K-12 & Moderate \\
P6 & Low & Male & 21 & 1 & Yes & K-12 & Moderate \\
P7 & High & Male & 21 & 1 & Yes & K-12 & Minimal \\
P8 & High & Male & 23 & 0 & Yes & K-12 & High \\
P9 & High & Male & 22 & 2 & Yes & Self-taught & Moderate \\
P10 & High & Female & 22 & 3 & Yes & Self-taught & Minimal \\
P11 & High & Male & 22 & 1 & Yes & Family/Friends & Moderate \\
P12 & High & Female & 20 & 1 & Yes & K-12 & Minimal \\
\hline
\end{tabular}

Theme 1: Increased Technological and Technological Pedagogical Knowledge

Across both stratified groups data indicated that the instructional technology course was effective at enhancing pre-service teachers' knowledge of technology. Specifically, participants' operational knowledge and knowledge of technology's role in their teaching increased. Similar 
to other research findings on the standalone technology courses, results of this study showed that participants experienced enhanced knowledge and self-efficacy toward instructional technology (McRobbie et al., 2000; Rochanasmita, Padilla, \& Tunhikorn, 2009). A salient theme that emerged across all participants $(N=12)$ was enhanced TK and TPK (see Table 6$)$. This theme describes (1) how participants' operational knowledge of technology improved and (2) how participants' knowledge for using technology in their teaching increased. Mishra and Koehler's (2006) TPACK framework illustrates how technology interplays with the forms of knowledge that are needed for teachers to successfully integrate technology. Technological knowledge and TPK represent two forms of knowledge that teachers need relative to meaningful integration of instructional technology.

Table 6

Summary of Theme 1: Increased Technological Knowledge and Technology Pedagogical Knowledge

\begin{tabular}{|c|c|c|c|}
\hline Emergent Sub-Theme & Group & $\mathrm{n}$ & Sample Data \\
\hline \multirow[t]{2}{*}{$\begin{array}{l}\text { Increased TK } \\
\text { - Skills required to } \\
\text { operate technologies } \\
\text { - Knowledge of } \\
\text { available technologies }\end{array}$} & $\begin{array}{l}\text { Low } \\
\text { Concern }\end{array}$ & $\begin{array}{l}\text { P1, P2, P3, P4, } \\
\text { P5, P6 }\end{array}$ & $\begin{array}{l}\text { "Before the class I was not comfortable with } \\
\text { technology and using it in my PE classroom } \\
\text { was out of the question. Things have } \\
\text { changed over the previous three weeks" (P5- } \\
\text { J3-L14) }\end{array}$ \\
\hline & $\begin{array}{l}\text { High } \\
\text { Concern }\end{array}$ & $\begin{array}{l}\text { P7, P8, P9, P10, } \\
\text { P11, P12 }\end{array}$ & $\begin{array}{l}\text { "I am more comfortable with using } \\
\text { technology. I also know more about what it } \\
\text { has to offer to the classroom and the extreme } \\
\text { variety there is to choose from" (P11-J3- } \\
\text { L21) }\end{array}$ \\
\hline \multirow{2}{*}{$\begin{array}{l}\text { Increased TPK } \\
\text { - Knowing how to } \\
\text { integrate technology } \\
\text { in teaching } \\
\text { - Knowing how } \\
\text { technology can } \\
\text { influence teaching }\end{array}$} & $\begin{array}{l}\text { Low } \\
\text { Concern }\end{array}$ & $\begin{array}{l}\text { P1, P2, P3, P4, } \\
\text { P5, P6 }\end{array}$ & $\begin{array}{l}\text { "I've expanded my knowledge on ways to } \\
\text { integrate technology into the classroom in a } \\
\text { way that I feel enhances student learning and } \\
\text { overall performance of the students' } \\
\text { abilities" (P6-J30L14) }\end{array}$ \\
\hline & $\begin{array}{l}\text { High } \\
\text { Concern }\end{array}$ & $\begin{array}{l}\mathrm{P} 7, \mathrm{P} 8, \mathrm{P} 9, \\
\mathrm{P} 10, \mathrm{P} 11, \mathrm{P} 12\end{array}$ & $\begin{array}{l}\text { "The most important experience I had in the } \\
\text { class was learning different technologies to } \\
\text { use in lesson delivery" (P12-J3-L2) }\end{array}$ \\
\hline
\end{tabular}


Increased TK is indicative of a user who feels more comfortable with operating various technology tools (Mishra \& Koehler, 2006). Technological knowledge includes knowing how to operate technologies, install software, and what specific technologies can accomplish relative to the teaching setting (e.g., how to create, update, and manage an online grade book). For example, Participant Two stated the following about learning how to use a technology, "I made my YouTube ${ }^{\circledR}$ debut. I was surprised how easy it was to put together” (P2-I-L10). Echoing this sentiment was a statement shared by Participant Eleven, "I have learned that with a little research and determination that these technologies can easily be mastered" (P11-J2-L20). Participant Two, Participant Eleven, and others indicated that the course elevated their selfefficacy and comfort level with technologies that can be used within the physical education context.

Technological pedagogical knowledge represents knowledge that is needed for teachers to apply technology to the teaching setting (Mishra \& Koehler, 2006). Technological pedagogical knowledge reflects not only understanding how to operate technology, but an awareness of how technology can impact the learning environment (e.g., technology's impact on instructional strategies and classroom management). All participants expressed feelings that the course provided them with a better sense of how they could use and apply technology in the physical education setting. For example, a common concept shared across participants was reflected by Participant Six: "I feel that the course really helped me better understand how to use technology in the classroom" (P6-J3-L11). The participants believed themselves to be more capable of integrating technology into their teaching following the course. Participant Eleven's statement captures this sentiment:

Note. $P$ identifies participant, $J$ refers to journal, $I$ refers to Interview, and $L$ refers to its placement in raw data 
A change that I feel I have gone through with this class would be more confidence in implementing the technologies in the classroom. I knew how to use the majority of the technologies, but how to use it (technology) in my instruction was lacking (P9-J3-L9). Increased confidence and knowledge of instructional technology was also present in the quantitative results, specifically within the Stages of Adoption results. Exiting the course, seven participants were Stage Five adopters or higher following the course, whereas only four participants were at this level upon course entry. Further, at course entry there were no Stage Six adopters, but following the course four participants self-identified as Stage Six adopters. Both datasets highlighted a positive change in participants' knowledge and confidence using instructional technology.

\section{Theme 2: Persistent First- and Second-Order Barriers to Technology Use}

Across all participants the persistence of perceived barriers to use instructional technology was a commonality within the data. Collectively the theme on barriers indicated that the single-course was less effective at addressing the barriers to teacher change with technology as compared to the myriad of first-order barriers that participants possessed. These findings support what other scholars have found in relation to the challenge of modifying highly resistant second-order barriers (Ertmer \& Ottenbreit-Leftwich, 2010). Findings also suggested that the participants' barriers, both internal and external, will need to be addressed before meaningful change relative to instructional technology would occur (Hall et al., 1979). Two sub-themes were identified within this theme, they include: (1) Second-Order Barriers (e.g., beliefs, confidence), and (2) First-Order Barriers (e.g., cost, support) that participants reported upon exit of the course (see Table 7). While all participants expressed concern about barriers, there was a distinct difference between the high concern and low concern groups. Both forms of barriers 
were more pronounced within the low concern group. Also, the nature of the second-order barriers expressed by both groups was different.

Table 7

Summary of Theme 2: Persistent First- and Second-Order Barriers to Technology Use Emergent Sub-Theme Group $\mathrm{n} \quad$ Sample Data

\begin{tabular}{llll}
\hline $\begin{array}{l}\text { Second-Order Barriers } \\
\text { - Pedagogical beliefs } \\
\text { - Confidence } \\
\text { - Knowledge } \\
\text { - Value }\end{array}$ & $\begin{array}{l}\text { Low } \\
\text { Concern }\end{array}$ & P1, P2, P3, P4, P5, P6 & $\begin{array}{l}\text { "I just don't really have the desire } \\
\text { to use technology" (P6-I-L68) }\end{array}$ \\
$\begin{array}{lll}\text { High } \\
\text { Concern }\end{array}$ & P7, P8, P9, P11 & $\begin{array}{l}\text { "It is about the students to me I } \\
\text { want to make sure it (technology) } \\
\text { benefits them" (P9-I-L80) }\end{array}$ \\
$\begin{array}{lll}\text { - Support } \\
\text { - Access }\end{array}$ & $\begin{array}{l}\text { Low } \\
\text { Concern }\end{array}$ & P1, P2, P3, P4, P5, P6 & $\begin{array}{l}\text { "I don't think it is ever going to be } \\
\text { cost effective" (P2-I-L104) }\end{array}$ \\
& $\begin{array}{l}\text { High } \\
\text { Concern }\end{array}$ & P10, P12 & $\begin{array}{l}\text { "The biggest thing I am worried } \\
\text { about is not having enough money } \\
\text { to purchase the technology" (P10- } \\
\text { I-L83) }\end{array}$ \\
& &
\end{tabular}

Second-order barriers. The low concern group's second-order barriers dealt primarily with lacking value of technology and technology not aligning with their pedagogical beliefs. For example, Participant Four stated the following about technology, "I think we can still use paper and pencil if we really had to do this stuff technology is supposed to accomplish" (P4-I-L41). In a similar vein, Participant Six provided this statement, "Honestly I just think it is easier to go without technology as opposed to using technology" (P6-I-L20). While low concern participants indicated second-order barriers that were very personal in nature, the high concern participants' second-order barriers focused primarily on technology's impact on their teaching. Participant Eight provided this statement, "I never want technology to trump me, but I would like to have it as a tool to help me when I am teaching" (P8-I-L57). The high concern group also described concerns about technology impacting their students. Participant Nine articulated this concern, "I 
guess my concern is kind of like more toward how to use it (technology) toward an age group. Like which technologies do you use with certain age groups?”(P9-I-L20) Unlike the low concern group, the high concern group had moved past the personal nature of the second-order barriers that were widely described by the low concern group and rather focused on barriers relating to technology's impact on their teaching.

First-order barriers. The low concern participants expressed concerns about first-order barriers. A focus of this sub-theme dealt with the challenge of securing technology due to cost as well as the need for support in the use of technology. Low concern participants frequently described that they felt technology was not realistic for the physical education context (e.g., technology is too expensive, technology is not feasible for physical education). Representing this notion was a statement shared by Participant One,

As far as my concerns regarding the class, they were unfortunately verified. I did not believe technology would be a practical addition to a physical education classroom. This I still believe to be true. Although there are many practical benefits to its usage within a classroom for economic reasons it is most likely impossible to incorporate (P1-J2-L7). The concern about cost was consistent across the low concern group. Low concern participants also expressed a concern that they will need support for their use of technology (e.g., technical assistance). Participant Three stated, "I will have to rely on a lot of people until I am more confident" (P3-I-L24). Unlike low concern participants, the high concern group's focus on firstorder barriers was to a much lesser extent. The high concern group seemed to look past the firstorder barriers that could impede their use of technology (e.g., financial concerns, support). 


\section{Theme 3: Necessity of Experiential and Hands-on Learning}

Irrespective of the stratified group many of the participants cited the importance of experiential learning relative to technology. Specifically, participants across both groups recognized the value of hands-on learning experiences embedded within the course. Findings suggested that hands-on learning experiences contributed to the perceived positive outcomes of the course. Hands-on learning serving as a mechanism of positive change for pre-service teachers supports what other scholars have found (Abbitt \& Klett, 2007). Findings also highlighted the value of experiential learning as reflected in participants' mention of lack of exposure to technology as physical education students and as pre-service teachers. This theme was comprised of two sub-themes: (1) Hands-on learning as a facilitator to positive teacher change, and (2) Lack of exposure to technology as a barrier to teacher change with technology (see Table 8). While the importance of hands-on learning was expressed from participants across high and low groups, only participants from the high concern group described the lack of exposure and experience with technology as a concern.

Hands-on learning. Participants across both groups cited that hands-on learning contributed to the perceived positive outcomes they received from the course. Participant Three provided this statement, "I've enjoyed the fact that we have got to use some of the pieces (of technology) outside of the classroom and really get comfortable with the technology" (P3-J2-

L4). Participant Ten shared a similar statement, "It's nice to be able to take some of the different equipment home and really get to experience how it (technology) works" (P10-J2-L9). The value of hands-on learning to technology integration coincides with what other scholars have found, for instance Ertmer and Ottenbreit-Leftwich (2010) explained, "the more experiences students have, the more likely they will be comfortable using technology to facilitate 
learning in their future classrooms" (p. 269). Participant Eight reinforced this as he articulated,

"when you actually get to hands-on use technology it makes you warm-up to the thought of actually being able to use it when you get out there and teach" (P8-I-L32).

Table 8

Summary of Theme 3: Necessity of Experiential and Hands-on Learning

\begin{tabular}{|c|c|c|c|}
\hline Emergent Sub-Theme & Group & $\mathrm{N}$ & Sample Data \\
\hline \multirow[t]{2}{*}{$\begin{array}{l}\text { Hands-on Learning } \\
\text { - Experiment with } \\
\text { technology } \\
\text { - Learn how to operate } \\
\text { technology }\end{array}$} & Low Concern & $\mathrm{P} 1, \mathrm{P} 2, \mathrm{P} 3, \mathrm{P} 5$ & $\begin{array}{l}\text { "Actually sitting down and using } \\
\text { the technology. Having it } \\
\text { (technology) in front of you and } \\
\text { being available was big for me } \\
\text { (P1-I-L78) }\end{array}$ \\
\hline & High Concern & P8, P9, P10 & $\begin{array}{l}\text { "I feel the most important } \\
\text { experience that I had in class was } \\
\text { actually getting to actually do } \\
\text { hands on activities with all of the } \\
\text { technology we learned about" (P8- } \\
\text { J3-L2) }\end{array}$ \\
\hline $\begin{array}{l}\text { Exposure to Technology } \\
\text { - Lack of exposure to } \\
\text { technology in K-12 } \\
\text { setting }\end{array}$ & Low Concern & P6 & $\begin{array}{l}\text { "You know we really haven't used } \\
\text { any of the technology resources } \\
\text { during like our teaching } \\
\text { placements" (P6-I-L31) }\end{array}$ \\
\hline $\begin{array}{l}\text { technology in field- } \\
\text { based experiences } \\
\text { - Modeling of } \\
\text { technology use by } \\
\text { PETE faculty }\end{array}$ & High Concern & $\mathrm{P} 9, \mathrm{P} 10, \mathrm{P} 11$ & $\begin{array}{l}\text { "Because if you base it off of my } \\
\text { education here the majority was } \\
\text { not involved with technology so I } \\
\text { am much more comfortable with } \\
\text { everything else" (P11-I-L101) }\end{array}$ \\
\hline
\end{tabular}

Exposure to technology. The importance of experiential learning was also expressed in relation to lacking exposure and experience with technology as K-12 physical education students and pre-service teachers. This was particularly true for the participants from the high concern group. Participant Ten stated the following about lacking experience, "Really just my lack of experience of applying it (technology) in the field just makes me nervous" (P10-I-L89). Not being able to see or personally use technology in the field created some doubt in these 
participants. Participant Nine's statement further supports this notion, "Because I have not used it (technology) in the classroom at all like maybe if we started using technology earlier I wouldn't have much of a worry about it" (P9-I-L84). Concern about lacking authentic experience with technology supports an inherent weakness of the single-course strategy.

Standalone technology courses typically do not provide learners with opportunities to see or use technology in an authentic setting (Pope et al., 2002).

\section{Theme 4: Variation in Warrant for Instructional Technology Use}

Across both stratified groups individual variation was present relative to the warrant participants possessed toward instructional technology use. Schempp and Graber (1992) emphasized that PETE programs will have pre-service teachers who believe teaching involves planning, providing feedback, and assessing (innovative); while others will believe teaching physical education is about making sure your students have fun (custodial). They also indicate that there will be pre-service teachers who fall in the middle and possess characteristics of innovative and custodial warrants (moderate).Within this theme, it became evident that across the participants there were characteristics of all three types of warrants, thus supporting three sub-themes: (1) Innovative teaching warrants (2) Moderate teaching warrants, and (3) Custodial teaching warrants (see Table 9). Evaluating participants' warrant assisted in identifying similarities and differences relating to feelings toward technology across participants and groups.

Innovative teaching warrant. Participants who were observed to possess innovative teaching warrants expressed value about technology's potential role in teaching and learning settings. Beyond value, innovative oriented participants remained highly positive, optimistic, and open about technology. Representing this sentiment was a statement Participant Three shared, "Technology is growing rapidly which means it needs to play a major role in not only my 
teaching but all teaching" (P3-J1-L7). The belief that technology needed to play a role in physical education was also articulated by Participant Five,

As a result of the course I feel like incorporating technology into my PE classroom is not only a good idea but almost a necessity. Why not use something to encourage students to get out and get moving if it is so easy to use? Students are more prone to be involved if they feel comfortable, and technology is something that most children in the upcoming generation are very comfortable with, so using it is a great motivator (P5-J3-L16).

The positive nature of responses shared by innovative participants toward instructional technology reiterates what Lawson (1983) stressed about innovative teachers being more likely to embrace the culture PETE programs try to promote. Innovative participants believed that instructional technology could positively contribute to their teaching. As Participant Twelve stated, "It is important that all students in the physical education setting learn and technology can help with student learning" (P12-J3-L10).

Moderate teaching warrant. Moderate teaching warrant participants from this study possessed dueling characteristics. First, moderate teachers possessed a commonality with innovative teachers. The shared characteristics included a value and receptivity toward technology. Participant Nine provided this statement about technology, "Teaching resources would be what I got out of the class. Having alternative styles of teaching such as technology, really assist in the teaching progress. It keeps things interesting, fun, and learning will happen as a result" (P9-J3-L11). Participant Seven also cited the value of technology, "There are numerous benefits that technology can bring to the table when teaching and I just want to be aware of all the choice I have" (P7-J1-L30). The notion that technology would be a necessity was discussed widely by this group as well; in large part because participants spoke to 
technology's emerging role in society and young people's lives. Participant Seven stated, “The new generations of students are very tech savvy and I think that technology can help a teacher reach out to some students who don't love physical education as much as the other students" (P7J1-L10). A similar statement was shared by Participant Nine, "Technology is very involved in everyone's lives, even children's. Technology can be used as a motivator to participate in exercise and physical activity" (P9-J1-L9). Participants across both stratified groups who possessed a moderate warrant cited the value of integrating technology into their teaching. This supports what Lawson (1983) and Curtner-Smith (2009) infer of moderately-oriented teachers being more likely to adopt the ideas that preparation programs are trying to promote.

Among participants with moderate and innovative warrants, second-order barriers were more prominent among moderate participants following the course. The concerns of secondorder barriers were more indicative of the custodial participants, this illuminates the dueling characteristics present in moderate participants. Moderate participants saw value in technology, but they also possessed internal concerns. Participant Four's following statements reflected the mixed feelings, "I like heart rate monitors, I like activity watches, and I like the GPS. Anything that is going outside and doing actual physical activity I am all for that" (P4-I-L6)." He also expressed doubt in this statement, "I see where they are going with it (technology). I'm not an avid fan of it yet. I don't see the use for technology now. It is just not for me" (P4-I-L37). Mixed feelings were also articulated by Participant Seven, "I am very concerned about using technology in my classroom. It would be a waste to ignore resources that can help our teaching process" (P7-J1-L14). He too voiced concern about technology, "You should use technology in my opinion, but if you become too reliant on technology it could replace us" (P7-I-L42). 
Custodial teaching warrant. In stark contrast to the other two sub-themes, was the nature of warrants custodial participants possessed. Custodial participants were explicit and consistent with their feelings about technology. The predominant premise threaded throughout these participants was a lack of value toward technology. Participant Two stated, "I am not going to be concentrating on technology. That is going to be the last thing on my mind" (P2-IL116). Building on this sentiment was a statement by Participant Six, "I mean I would be able to do it (use technology) if I wanted to. I know how to use different technologies but it would just be a matter of whether I wanted to apply it to my teaching" (P6-I-L48). Lack of value and desire to use technology was candidly expressed by Participant Eleven, "Well I am not going to use it unless I really feel that it is absolutely necessary" (P11-I-L64). An underlying force that contributed to the custodial participants' resistance to technology was a preference to a traditional approach to teaching physical education. Illustrating this was Participant Eleven's statement, "I will always be more toward the traditional way of physical education" (P11-I-L57). Custodial teachers resisting change supports what other scholars have found because as Crum (1993), stresses teachers who possess a custodial orientation will have a preference toward a traditional approach to physical education.

Most of the physical education research on teacher socialization highlights the impact a teacher's role orientation has on the decisions they make as teachers (Curtner-Smith, 2009; Lawson, 1983; Lortie, 1975, 2002). Results from this study indicated that warrant directly reflected participants' perception of instructional technology: (1) innovative teachers possessed a warrant that embraced instructional technology's potential role in physical education, (2) moderate teachers possessed a warrant of mixed feelings toward instructional technology and 
physical education, and (3) custodial teachers' warrant was characteristic of an individual that did not value instructional technology.

Table 9

Summary of Theme 4: Variation in Warrant for Instructional Technology Use

Emergent Sub-Themes Group N Sample Data

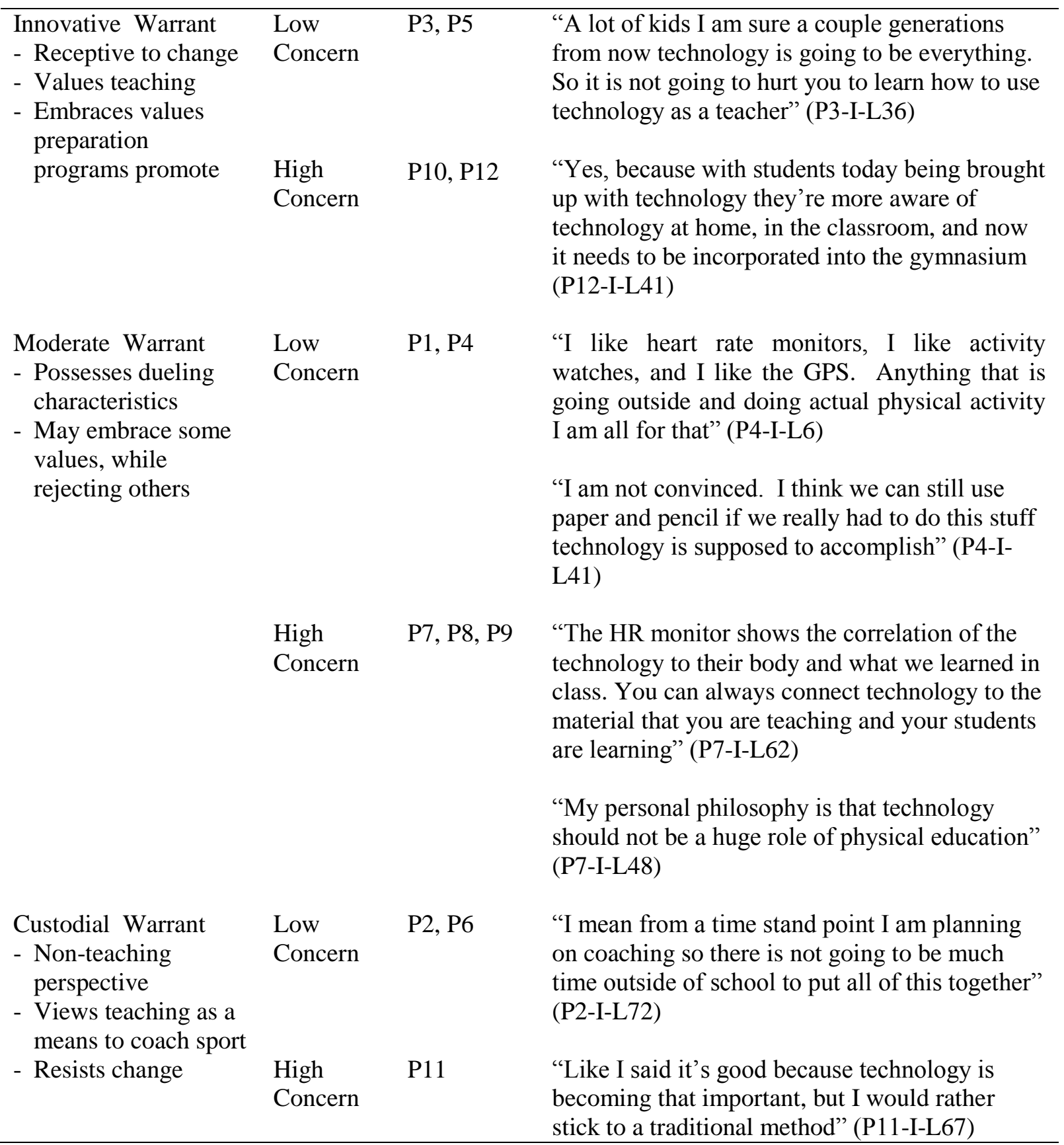




\section{Discussion}

While the importance of instructional technology to the educational experience seems to be well established (NASPE, 2008NCATE, 2008), the best strategy to prepare pre-service teachers to use technology in a meaningful manner continues to be debated (Ertmer \& Ottenbreit-Leftwich, 2010; Kay, 2006). This is particularly true for physical education because little research has been disseminated relative to instructional technology integration into the PETE curriculum. Therefore, from a practical standpoint, findings from this study provide PETE programs with a systematic analysis of a strategy that can be integrated into a curriculum. Further, this study provides PETE programs with an overview of facilitators and barriers to preservice teacher change with technology. To frame the discussion this section contains the following: (1) Strengths of the Single-Course Strategy, (2) Limitations of the Single-Course Strategy, (3) Improving Pre-service Teacher Change with Technology, (4) Impediments to Preservice Teacher Change with Technology, (5) Limitations of the Study, and (6) Future Research.

\section{Strengths of the Single-Course Strategy}

Results of this study demonstrated that a clear strength of a domain-specific instructional technology course is that it can be an effective means to enhance the knowledge and self-efficacy that pre-service teachers possess relative to instructional technology. These findings support what others have cited as strengths of the single-course strategy (McRobbie et al., 2000;

Rochanasmita et al., 2009). All participants, even those that did not value technology, expressed that the course enhanced their knowledge and self-efficacy of instructional technology. Looking at the perceived positive outcomes participants received from the course through the prism of the TPACK framework better illustrates this strength. Evidence suggested that two forms of knowledge were enhanced, TK and TPK, which are critical to meaningful technology integration 
(Mishra \& Koehler, 2006). Increased operational knowledge of technology, understanding how to integrate technology into one's teaching, and knowing how technology can impact the learning environment are clearly desirable outcomes. What may be a more important result as other scholars have suggested is that using the TPACK framework to guide training is valuable to creating meaningful, positive change in pre-service teachers (Allan, Erickson, Brookhouse, \& Johnson, 2010; Chai et al., 2010).

Another strength that emerged from the single-course strategy was the importance of hands-on learning. Many participants cited having the opportunity to "play" with the technology served as a factor that initiated positive change. Being able to use the technologies in a supportive environment was an enjoyable, yet productive experience for participants. As Bandura (1977) pointed out, being able to achieve a level of personal mastery is a key variable to enhancing an individual's self-efficacy. The benefits of enhancing pre-service teachers' access to technology supports what other scholars have found (Koc \& Bakir, 2010; Lisowski et al., 2007), as it appears access to technology is an integral component for advancing positive change in pre-service teachers.

Hands-on learning was an important experience for participants, but what may have been even more important was that participants were in a supportive environment to help ensure success. Early success with technology was a strong emphasis because initial success is critical to enhancing an individual's self-efficacy (Bandura, 1977). To ensure success the instructor established a supportive and positive learning environment. A consistent measure that was used across the course was providing students with accurate models to show step-by-step tutorials for all technologies. The instructor also allowed students to collaborate with peers to promote critical thinking and problem solving. Further, the instructor established consulting hours 
outside of class for students who had questions about technology assignments. The rationale behind the learning environment was to remove first-order barriers. Throughout the course preservice teachers had unlimited access to technology and constant support with their use of technology (e.g., instructor support, peer support). Removing first-order barriers is critical to promoting positive change because barriers of this nature can be frustrating to teachers (Ertmer, 1999).

Beyond enhanced knowledge, self-efficacy, and the importance of hands-on learning as strengths of this strategy, an underlying and driving force that contributed to the positive outcomes observed across participants was the PETE program's commitment to instructional technology. Prior to the first day of the instructional technology course this PETE program took measures to make technology a valuable component of the curriculum. A variety of domainspecific technologies were secured, a knowledgeable faculty member was given the freedom to design the course, and most importantly administration made a commitment to instructional technology. A committed program ensures that measures are in place to provide faculty and preservice teachers with support to move the technology integration process forward (Strudler \& Wetzel, 1999). With commitment from administration and faculty, the pre-service teachers in this PETE programs were exposed to an environment that has placed a relative degree of importance on instructional technology.

\section{Limitations of the Single-Course Strategy}

While the single-course strategy does have the potential to serve an important role within a PETE curriculum, by itself the single-course does not appear to be an effective means to facilitate meaningful change in pre-service teachers. Use of the TPACK framework helps to illustrate inherent limitations of the single-course strategy. The common weakness of the single- 
course strategy is the lack of authentic experience with instructional technology in the K-12 context (Pope et al., 2002). The single-course provided evidence of enhancing TK and TPK, yet one glaring omission was the absence of a more holistic knowledge base indicative of TPACK. Technological pedagogical content knowledge is a form of knowledge that highlights the importance of understanding how technology interplays with content and the subsequent delivery of that content (Mishra \& Koehler, 2006). Technological pedagogical content knowledge not only stresses having a deep understanding of the content matter, but an individual needs to know how a piece of technology will impact their teaching, students, and overall learning environment. Given that pre-service teachers from this study did not use technology in an authentic classroom setting, it is natural that this form of knowledge did not increase. Also, from a practical standpoint expecting pre-service teachers to have a deep understanding of content and a variety of technologies at this point in their professional development may be a bit unrealistic. The nature of TPACK suggests that pre-service teachers need to have opportunities to use technology in an authentic setting, but it also may highlight that this form of knowledge will be difficult to fully address during the professional preparation years. Due to limited curriculum space, clinical hours, and the need to develop other important teaching functions, TPACK is a form of knowledge that may need to be further addressed through professional development, graduate school, and other pertinent training means for practitioners. Ertmer, Addison, Lane, Ross and Woods (2000) support this notion stating that "achieving meaningful technology use is a slow process that is influenced by many factors" (p. 68). As scholars point out meaningful technology use is a long, slow process for teachers. Accordingly, when pre-service teacher's transition into the field as practitioners, all pertinent forms of knowledge related to TPACK will need to continue to develop for meaningful use of technology to occur. 


\section{Improving Pre-Service Teacher Change with Technology}

Building on the weakness of the single-course strategy, an important variable to improving pre-service teacher change with technology may be differentiated learning experiences. As Ertmer and Ottenbreit-Leftwich (2010) emphasize the more experiences preservice teachers have with technology the greater likelihood they will use technology in their teaching. Findings of this study further highlight the need to differentiate learning experiences with technology. Reliance on one strategy to prepare pre-service teachers to use technology will not suffice. If programs are going to appropriate resources to instructional technology, Kay (2006) suggested that the most impactful approach for preparation programs to adopt is a combination of strategies (e.g., single-course and field-based). The jury is still out as to what combination of strategies is most impactful in both general education and PETE settings. Evidence has been provided as to what the strengths and limitations are with a domain-specific instructional technology course, but further research is needed to measure the impact other research-based strategies have on advancing change in pre-service physical education teachers.

In order for PETE programs to adopt a combination of strategies to integrate instructional technology, an important variable will be buy-in from all faculty members. If only one or two faculty members embrace instructional technology it may limit what PETE programs can do from a comprehensive standpoint. This notion is supported by scholars in that "a commonality among exemplary institutions... is their ongoing systematic effort to encourage and support faculty to use technology in their teaching" (Strudler \& Wetzel, 1999, p. 80). If all faculty members meaningfully use and reinforce technology in their teaching, it provides pre-service teachers with effective modeling and differentiated experiences with technology. Further, another product of all faculty members using technology in their teaching is that pre-service 
teachers will be exposed to technology across the curriculum (e.g., foundational courses, PCK courses, field placements). Stranding technology-related learning experiences more comprehensively across the curriculum may help to enhance pre-service teachers' perceived value and usefulness of instructional technology, a notion that is recommended and reinforced by the National Council for Accreditation of Teacher Education (2003). As was stated previously in this discussion section, administrators play an important role in promoting faculty use of technology. If the expectation is for pre-service teachers to use technology in an effective manner, then it should also be expected that PETE faculty integrate instructional technology into their teaching.

Stranding technology related experiences throughout the curriculum may help to enhance pre-service teachers' perceptions of technology. However, as was mentioned previously due to limited curriculum space, clinical hours, and the need to develop other important teaching functions, PETE programs must be pragmatic with technology integration strategies. To help pre-service teachers and faculty members, PETE programs should be intentional with selecting meaningful technologies. Programs should not expect faculty and pre-service teachers to master all forms of technologies. Instead, by reducing the number of technologies pre-service teachers are expected to learn it may help to enhance the likelihood of them developing a sense of mastery. More research is needed to identify the technologies that are most impactful and feasible for PETE programs. However, recent research recommends that teacher education programs identify technologies that support learning objectives, target student learning, and assists learners in reaching the identified goals (Cennamo, Ross, \& Ertmer, 2010). 


\section{Impediments to Pre-Service Teacher Change with Technology}

The impediment to pre-service teacher change with technology is not a novel finding. Occupational socialization helps to explain a prominent threat to teacher change with technology. Similar to what other scholars have found when investigating physical education, PETE, and pre-service teachers: producing meaningful learning and change is challenging (Curtner-Smith, 2009; Lawson, 1983, Schempp \& Graber, 1992). Findings from this study demonstrated that pre-existent beliefs and knowledge structures about physical education are prominent threats to pre-service teacher change with technology. As scholars have emphasized for over 30 years, the beliefs pre-service teachers develop prior to enrollment in a preparation program are highly resistant to change (Curtner-Smith, 2009; Lawson, 1983; Pajares, 1992) and although educators may assume that given technology's emerging role in society that pre-service teachers would naturally gravitate to this teaching tool, findings from this study highlighted that this assumption is true for some individuals, but some will resist. On the surface pre-service teachers' resistance of technology may seem counterintuitive, however this has been seen in previous findings (Russell, Bebell, O’Dwyer, \& O'Connor, 2003). Therefore, educators should not operate under the false pretenses that all younger or future teachers will value technology as an instructional tool. For PETE a possible impediment may be that technology is likely not widely used in K-12 physical education classrooms across the country. As Lortie $(1975 ; 2002)$ emphasized teachers have a tendency to teach the way that they were taught, therefore, if preservice teachers are not exposed to technology in the physical education classroom it is not a stretch for them to resist this instructional tool as pre-service teachers.

Individual differences among pre-service teachers not only make it difficult to advance change relative to instructional technology, but it makes it challenging to advance any type of 
change. Role orientation research highlights the characteristics pre-service teachers possess (Lawson, 1983). Results from this study highlight that some pre-service teachers will embrace, some will sit on the fence, and others will resist the ideals and dispositions PETE programs try to promote relative to instructional technology. What is important regarding role orientation, subjective warrant, and pre-existent beliefs is that PETE programs and faculty understand the individual variation that is present across pre-service teachers. As Schempp and Graber (1992) stated twenty years ago, "understanding the process of teacher socialization allows educators to better reflect on the orientations and practices they incorporate into education classes" (p. 344), and this sentiment still rings true today. Understanding where pre-service teachers fall on the continuum not only helps to inform educators, but it can help guide training. For example, findings from this study indicated that moderate oriented participants were very much on the fence when it came to instructional technology. Yet, if PETE programs are aware of the dueling characteristics that moderate oriented pre-service teachers may possess toward instructional technology it can help inform training that may move these individuals further along the continuum toward qualities that innovators possess.

Closely related to the influence occupational socialization and its impediment to preservice teacher change with technology, is its presence in the K-12 physical education classroom. The K-12 years are inextricably linked to the professional preparation years (Lortie, 1975; 2002). For the field to move toward meaningful use of technology not only does it need to improve at the PETE level, but improvement must also be seen at the K-12 level. If pre-service teachers have little exposure to technology as a K-12 student it certainly does not help PETE programs promote meaningful change. To move the field forward PETE programs, K-12 schools, faculty 
members, and practitioners will need to work together to make instructional technology a valued component of physical education.

From a PETE perspective to help move toward meaningful use of technology, programs need to ensure that resources are in place to assist faculty with technology integration. If faculty are not prepared to use technology or do not embrace technology there may be no greater impediment to pre-service teacher change with technology. As a recent study highlighted, Smith and Owens (2010) found that faculty members feel that they lack the training to integrate technology into their teaching. Researchers in this study also found that teacher education programs are not providing pre-service teachers with enough time to use technology in the classroom and during field experiences. The link may be that if faculty members are not confident in their ability to use technology they may be reluctant to allow their pre-service teachers to use technology. So, while preparation programs are being more proactive there are still many faculty members who do not feel that they have the skills necessary to infuse technology into their teaching. While support for faculty members is an ongoing issue, another important variable that may help correct this problem is creating a culture that promotes technology use.

Within the organizational framework of PETE programs a critical factor that facilitates the integration process is creating a culture that promotes technology use. ISTE (2008b) recommends the following conditions be in place for the technology integration process: (1) a shared vision among stakeholders; (2) proactive leadership that emphasizes the importance of technology in education; (3) established policies that provide incentive for the use of technology; and (4) empowered leaders that aim to be effective leaders that create change. A culture that emphasizes technology use will have a strong correlation with its faculty members 
feeling that they are expected to use technology in their teaching (Lin \& Ha, 2009). Through establishment of policies that encourage use of technology by faculty members it has the possibility to create a supportive network for pre-service teachers and a motivational mechanism for pre-service teachers to use technology.

\section{Limitations of the Study}

The results of this study should be viewed with caution for the following reasons:

1. The investigator only analyzed an instructional technology course at one university.

2. The sample size was limited. There were only twelve participants involved in this study.

3. The study occurred at a large university that had access to a wide array of domainspecific technologies and technology related resources. Different environments may yield different results.

4. The investigator's prior involvement with the participants could have influenced their responses. Since participants knew their responses would be evaluated it could influence how they behaved. To address this potential confound, the investigator assured participants that all information would remain anonymous. In addition, the investigator was not an instructor of record for the instructional technology course.

\section{Future Research}

Results of this study and previously disseminated research have cited the strengths and weaknesses of the single-course strategy (Pope et al., 2002). The first recommendation for future research is for scholars within the field to continue to evaluate the effectiveness of technology integration strategies. Not only is further investigation of the single-course strategy needed, but systematic analysis of other strategies is recommended. To assist scholars, the 
investigator recommends that Kay's (2006) review of technology integration strategies serve as a foundation for framing studies. Future studies on technology integration and the PETE context must also continue to identify the barriers and facilitators to pre-service teacher change with technology. Evidence from this study highlighted the impact of hands-on learning, TPACK, warrant, first-order barriers, and second-order barriers had on pre-service teachers. Given the limited knowledge base that currently exists within PETE, more evidence is needed to identify barriers and facilitators that are present for pre-service physical education teachers.

One finding that emerged from this study is that pre-service teachers need more differentiated experiences with technology. Therefore, scholarly research needs to also investigate different aspects of technology integration. Investigating technology integration through the K-12 context, faculty use of technology, field-based technology usage by pre-service teachers, and other related areas are recommended. A more holistic analysis of technology integration in the physical education context needs to occur. Differentiating the nature of research designs and objectives will help to broaden the knowledge base and discussion of technology integration into the physical education context.

Another recommendation for future research is for investigators to carefully consider the quantitative measures that are used to analyze technology integration. In this study use of the SoCQ proved to be a challenge. Fully understanding the products that quantitative measures produce is recommended. Scholars from general education have produced a variety of quantitative measures that assesses teacher change with technology (see Christensen \& Knezek, 2000). More research is needed to find the quantitative measure(s) that best meet the needs of physical education researchers who are investigating technology integration. Also, the investigator recommends the use of mixed-method research designs to analyze technology 
integration. This notion is supported by Kay (2006). Use of a mixed methodology enabled the investigator to have a deeper understanding of the research objectives and provide a more holistic description of the findings.

According to the position statement released by NASPE (2009) there is a belief that instructional technology can fill a positive role in physical education programming. While technology is a valued instructional tool by decision makers, the problem for physical education is that the importance of technology is currently not reflected in the knowledge base. Therefore, the final recommendation is for scholars within the field of physical education to make a stronger commitment to investigate instructional technology. Countless studies have been published on technology integration from different disciplines within general education (Kay, 2006). As a result, there are a variety of research designs, strategies, lessons learned, and other evidencebased approaches to technology integration for PETE professionals to build on. Given technology's emerging role in society and education the time has come for PETE scholars to also place a relative degree of value toward instructional technology. 


\section{References}

Abbitt, J. T., \& Klett, M. D. (2007). Identifying influences on attitudes and self-efficacy beliefs towards technology integration among pre-service educators. Electronic Journal for the Integration of Technology into Education, 6, 28-42.

Allan, W., Erickson, J., Brookhouse, P., \& Johnson, J. (2010). Teaching professional development through a colloaborative curriculum project: An example of TPACK in Maine. Tech Trends: Linking Research and Practice to Improve Learning, 54(6), 36-43.

Bandura, A. (1977). Social Learning Theory. New York: General Learning Press.

Banister, S., \& Reinhart, R. (2011). TPCK for impact: Classroom teaching practices that promote social justice and narrow the digital divide in an urban middle school. Computers in the Schools, 28(1), 5-26. doi:10.1080/07380569.2011.551086

Cavanagh, S. (1997) Content analysis: concepts, methods and applications. Nurse Researcher, 4, 5-16.

Cennamo, K. S., Ross, J., \& Ertmer, P. E. (2010). Technology integration for meaningful Classroom use: A standards-based approach. Belmont, CA: Wadsworth.

Chai, C., Koh, J., \& Tsai, C. (2010). Facilitating pre-service teachers development of technological, pedagogical, and content knowledge. Educational Technology \& Society, $13(4), 63-73$.

Christensen, R., \& Knezek, G. (2000). Internal consistency reliabilities for 14 computer attitude scales. Journal of Technology and Teacher Education, 8(4), 327-336. 
Christensen, R., Griffin, D., \& Knezek, G. (2001). Measures of Teacher Stages of Tech Integration and Their Correlates with Student Achievement. Paper presented at the Annual Meeting of the American Association of Colleges for Teacher Education, Dallas, TX.

Chu, D. (1984). Teacher/coach orientation and role socialization: A description and explanation. Journal of Teaching in Physical Education, 3(2), 3-8.

Crum, B. J. (1993). Conventional thought and practice in physical education: problems of teaching and implications for change. Quest (00336297),45(3), 339-356.

Cuban, L. (1997). High-tech schools and low-tech teaching. Education Week on the Web. Retrieved March 13, 2011 from http://www.edweek.org/ew/articles/1997/05/21/34cuban.h16.html

Curtner-Smith, M. D., Hastie, P. A., \& Kinchin, G. D. (2008). Influence of occipational socialization on beginning teachers' Interpretation and delivery of sport education. Sport, Education and Society, 13(1), 97-117.

Curtner-Smith, M. D. (2009). Breaking the cycle of non-teaching physical education teachers: Lessons to be learned from occupational socialization literature. In Housner, L. D., Metzler, M. W., Schempp, P. G., \& Templin, T. J. (Eds.), Historic traditions and future directions of research on teaching and teacher education in physical education (pp. 221226). Morgantown, WV: Fitness Information Technology.

Dole, J. A., \& Sinatra, G. M. (1998). Reconceptualizing change in the cognitive construction of knowledge. Educational Psychologist, 33(2/3), 109-128. 
Donovan, L., Hartley, K., \& Strudler, N. (2007). Teacher concerns during initial implementation of a one-on-one laptop initiative at the middle school level. Journal of Research in Technology Education, 39(3), 263-286.

Elo, S., \& Kyngas, H. (2007). The qualitative content analysis process. Journal of Advanced Nursing, 62(1), 107-115.

Ertmer, P. A. (1999). Addressing first and second-order barriers to change: Strategies for technology integration. Educational Technology Research and Development, 47(4), 4761.

Ertmer, P. A., Addison, P., Lane, M., Ross, E., \& Woods, D. (2000). Examining teachers' beliefs about the role of technology in the elementary classroom. Journal of Research on Computing in Education, 32(1), 54-71.

Ertmer, P. A., \& Ottenbreit-Leftwich, A. (2010). Teacher technology change: How knowledge, confidence, beliefs, and culture intersect. Journal of Research on Technology in Education, 42(3), 255-284.

Glaser, B. G. (1965). The constant comparative method of qualitative analysis. Social Problems, 12(4), 436-445.

Gray, L., Thomas, N., and Lewis, L. (2010). Teachers' Use of Educational Technology in U.S. Public Schools: 2009 (NCES 2010-040). National Center for Education Statistics, Institute of Education Sciences, U.S. Department of Education. Washington, DC.

Gunter, G. A. (2001). Making a difference: Using emerging technologies and teaching strategies to restructure an undergraduate technology course for pre-service teachers. Educational Media International, 38(1), 13-20. 
Hall, G. E., George, A. A., \& Rutherford, W. L. (1979). Measuring stages of concern about the innovation: A manual for the use of the SOC questionnaire. Austin, TX: The University of Texas at Austin. The Research and Development Center for Teacher Education.

Hersey, J. C., \& Jordan, A. (2007). Reducing children's TV time to reduce the risk of childhood overweight: The children's media use study. Retrieved November 12, 2010, from http://www.cdc.gov/nccdphp/dnpa/obesity/pdf/TV_Time_Highligts.pdf

International Society for Technology in Education [ISTE]. (2008a). The ISTE national educational standards (NETS-T) and performance indicators for teachers. Eugene, OR: Author Retrieved March 13, 2011 from http://www.iste.org/standards/nets-for-teachers.aspx

International Society for Technology in Education [ISTE]. (2008b). Essential conditions: Necessary conditions to effectively leverage technology for education. Eugene, OR: Author Retrieved March 13, 2011 from http://www.iste.org/Libraries/PDFs/Essential_Conditions_2007_EN.sflb.ashx Jackson, P. (1968). Life in Classrooms. New York, NY: Harper and Row.

Kang, I., Choi, J.I., \& Chang, K. (2007). Constructivist research in educational technology: A retrospective view and future prospects. Asia Pacific Education Review, 8 (3), 397-412.

Kay, R. H. (2006). Evaluating strategies used to incorporate technology into preservice education: A review of the literature. Journal of Research on Technology in Education, 38(4), 384-406. 
Koc, M., \& Bakir, N. (2010). A needs assessment survey to investigate pre-service teachers' knowledge, experiences and perceptions about preparation to using educational technologies. The Turkish Online Journal of Educational Technology, 9(1), 13-22.

Lawson, H. A. (1983). Toward a model of teacher socialization in physical education: The subjective warrant, recruitment, and teacher education. Journal of Teaching in Physical Education, 2(3), 3-16.

Leech, N. L., \& Onwuegbuzie, A. J. (2009). A typology of mixed methods research designs. Quality and Quantity: International Journal of Methodology, 43, 265-275.

Lenhart, A. (2009). Teens and mobile phones over the past five years: Pew internet looks back. Pew Internet \& American Life Project. Retrieved June 22, 2011 from http://epirev.oxfordjournals.org/content/32/1/56.full.pdf + html

Lin, C., \& Ha, L. (2009). Subcultures and use of communication information technology in higher education institutions. The Journal of Higher Education, 80(5), 564-590.

Lincoln, Y. S., \& Guba, E. G. (1985). Naturalistic inquiry. Newbury Park, CA: Sage Publications.

Lisowski, L. R., Lisowski, J. R., \& Nicolia, S. (2007). Infusing technology into teacher education: Doing more with less. Computer in the Schools, 23(3), 71-92.

Lortie, D. C. (1975). School-teacher: A sociological study. Chicago, IL: The Univerity of Chicago Press.

Lortie, D. C. (2002). School-teacher: A sociological study ( $2^{\text {nd }}$ ed.). Chicago, IL: The University of Chicago Press. 
Mai, N., \& Tse-Kian, N. (2010). Students' perceptions in developing a multimedia project within a constructivist learning environment: A Malaysian experience. Turkish Online Journal of Educational Technology, 9(1), 176-184.

McRobbie, C. J., Ginns, I. A., \& Stein, S. J. (2000). Preservice teachers' thinking about technology and technology education. International Journal of Technology and Design Education, 10, 81-101.

Millslagle, D., \& Morley, L. (2004). Investigation of role retreatism in the teacher/coach. Physical Educator , 61(3), 120-130.

Mishra, P., \& Koehler, M. J. (2006). Technological pedagogical content knowledge: A framework for teacher knowledge. Teachers College Record, 108(6), 1017-1054.

Murphy, E. (1997). Constructivism: From theory to practice. Retrived January 22, 2011 from http://www.vccaedu.org/inquiry/inquiry-spring-2007/i-12-Carwile.html

National Association for Sport in Physical Education (2008). National initial physical education teacher education standards. Retrieved March 12, 2011 from http://www.aahperd.org/naspe/grants/accreditation/upload/2008-National-Initial-PETE$\underline{\text { Standards.pdf }}$

National Association for Sport in Physical Education. (2009). Appropriate use of instructional technology in physical education [Postion Statement]. Reston, VA: Author

National Council for Accreditation of Teacher Education (2003). International Technology Education Association/Council on Technology Teacher Education (ITEA/CTTE). Retrieved March 12, 2011 from http://www.ncate.org/standard/programstds.htm 
National Council for Accreditation of Teacher Education (2008). Professional standards for the accreditation of schools, colleges, and departments of education. Retrieved March 12, 2011, from http://www.ncate.org/LinkClick.aspx?fileticket=P2KEH2wR4Xs\%3d\&tabid=107

Overbaugh, R., \& Lu, R. (2008). The impact of a federally funded grant on a professional development program: Teachers' stages of concern toward technology integration. Journal of Computing in Teacher Education, 25(2), 45-55.

Özgün-Koca, S., Meagher, M., \& Edwards, M. (2010). Preservice teachers' emerging TPACK in a technology-rich methods Class. Mathematics Educator, 19(2), 10-20

Pajares, M. (1992). Teachers' beliefs and educational research: Cleaning up a messy construct. Review of Educational Research, 62(3), 307-332.

Patton, M. Q. (2002). Qualitative research \& evaluation methods. ( $3^{\text {rd }}$ ed.). Thousand Oaks, CA: Sage Publications.

Piaget, J. (1985). The equilibrium of cognitive structures: The central problem of intellectual development. Chicago, IL: The University of Chicago Press.

Plano Clark, V.L., \& Creswell, J.W. (2008) The mixed methods reader. Thousand Oaks, CA: Sage Publications.

Pope, M., Hare, D., \& Howard, E. (2002). Technology integration: Closing the gap between what preservice teachers are taught to do and what they can do. Journal Of Technology And Teacher Education, 10(2), 191-203.

Posner, G. J., Strike, K. A., Hewson, P. W., \& Gertzog, W. A. (1982). Accommodation of a scientific conception: Toward a theory of conceptual change. Science Education, 66(2), 211-227. 
Quillen, I. (2011). ISTE: Without EETT, progress 'cannot be achieved.' Education Week on the Web. Retrieved March 13, 2011 from

http://blogs.edweek.org/edweek/DigitalEducation/2011/01/iste_without_eett_progress_ca $\underline{\text { n.html }}$

Rakes, G. C., \& Casey, H. B. (2002). An analysis of teacher concerns toward instructional technology. International Journal of Educational Technology, 3(1), Retrieved March 14, 2011 from

http://www.ed.uiuc.edu.www.libproxy.wvu.edu/ijet/v3n1/v3n1articles.html

Rochanasmita, A., Padilla, M. J., \& Tunhikorn, B. (2009). The development of pre-service science teachers' professional knowledge in utilizing ict to support professional lives. Eurasia Journal of Mathematics, Science \& Technology, 5(2), 91-101.

Russell, A. L. (1995). Stages in learning new technology: Naive adult email users. Computers in Education, 25(4), 173-178.

Russell, M., Bebell, D., O’Dwyer, L., \& O’Connor, K. (2003). Teachers’ beliefs about and use of technology: Enchancing the use of technology for new and veteran teachers. Boston, MA: Boston College, Technology and Assessment Study Collaborative.

Ryan, T. (2008). Antecedents for interrole conflict in the high school teacher/coach. Physical Educator, 65(2), 58-67.

Schempp, P. G., \& Graber, K. C. (1992). Teacher socializatoin from a dialectal perspective: Pretraining through induction. Journal of Teaching in Physical Education, 11, 329-348.

Shulman, L. S. (1986). Those who understand: Knowledge growth in teaching. Educational Researcher, 15(2), 4-14. 
Smith, P. A., \& Owens Jr., E. W. (2010). Examining barriers to integrate technology in elementary teacher education programs. Journal of Technology Integration, 2(1), 59-74.

Solomon, G., \& Schrum, L. (2007). Web 2.0 new tool, new schools. Eugene: International Society for Technology in Education.

Stroot, S. A., Faucette, N., \& Schwager, S. (1993). In the beginning: The induction of physical educators. Journal of Teaching in Physical Education, 12, 375-385.

Strudler, N., \& Wetzel, K. (1999). Lessons from exemplary colleges of education: Factors affecting technology integration in preservice programs. Educational Research Research and Development , 47(4), 63-81.

Templin, T. J., Woodford, R., \& Mulling, C. (1982). On becoming a physical educator: Occupational choice and the anticipatory socialization process. Quest, 34(2), 119-133.

Vannatta, R. A., \& Beyerbach, B. (2000). Facilitating a contructivist vision of technology integration among education faculty and preservice teachers. Journal of Research on Computing in Education, 33(2), 132-148.

Viennot, L. (1979). Spontaneous reasoning in elementary dynamics. European Journal of Science in Education, 1(2), 205-221.

Woods, M. L., Goc Karp, G., Hui, M., \& Perlman, D. (2008). Physical educators' technology competencies and usage. Physical Educator, 65(2), 82-99.

Zeichner, K. M., \& Tabachnick, B. R. (1981). Are the effects of university teacher education “washed out” by school experience? Journal of Teacher Education, 32(3), 7-11.

Zhang, Y., \& Wildemuth, B.M. (2009). Qualitative analysis of content. In B. Wildemuth (Ed.), Applications of Social Research Methods to Questions in Information and Library. Retrieved January 2, 2012 from http://ils.unc.edu/ yanz/Content_analysis.pdf 
Appendix A

Definition of Terms 
1. Occupational Socialization - "Socialization involves pressures to change, to influence neophytes in socially desirable directions, to drop previous patterns of behavior and accept new norms held by the socializing agent or significant other" (Edgar \& Warren, 1969, p. 387).

2. Apprenticeship-of-Observation - Highlights the influence of the socialization period pre-service teachers spend prior to enrollment in a professional preparation program. Lortie (2002) “...participation in school has special occupational effect on those who do move to the other side of the desk" (p. 61).

3. Professional Socialization - Lawson (1983) refers to professional socialization "as the time period when practicing teachers acquire and maintain the values, sensitivities, skills, and knowledge that are deemed ideal for teaching physical education" (p. 9).

4. Subjective Warrant - Individual's perceptions of the skills needed to work in a given profession (Dewar \& Lawson, 1984).

5. Conceptual Change - Conceptual change is the process of restructuring and organizing currently held conceptions (Jonassen, Strobel, \& Gottdenker, 2005).

6. Instructional Technology - "The theory and practice of design, development, utilization, management, and evaluation of processes and resources for learning” (Seels \& Richey, 1994, p. 1).

7. First-Order Barriers - Barriers that are external to the teacher that influence technology integration (e.g. access, resources, support) (Ertmer, 1999).

8. Second-Order Barriers - Barriers that are internal to the teacher that influence technology integration. (e.g. confidence, beliefs, attitude) (Ertmer, 1999). 
9. Single-Course - A stand alone course that aims to teach pre-service teachers a variety of technology skills (Kay, 2006). 


\section{References}

Dewar, A. L., \& Lawson, H. A. (1984). The subjective warrant and recruitment into physical education. Quest, 36, 15-25.

Edgar, D., \& Warren, R. (1969). Power and autonomy in teacher socialization. Sociology of Education, 42(4), 386-399.

Ertmer, P. A. (1999). Addressing first and second-order barriers to change: Strategies for technology integration. Educational Technology Research and Development, 47(4), 4761.

Jonassen, D., Strobel, J., \& Gottdenker, J. (2005). Model building for coneptual change. Interactive Learning Enviornments, 13(1-2), 15-37.

Kay, R. H. (2006). Evaluating strategies used to incorporate technology into preservice education: A review of the literature. Journal of Research on Technology in Education, 38(4), 384-406.

Lawson, H. A. (1983). Toward a model of teacher socialization in physical education: The subjective warrant, recruitment, and teacher education. Journal of Teaching in Physical Education, 2(3), 3-16.

Lortie, D. C. (2002). School-teacher: A sociological study ( $2^{\text {nd }}$ ed.). Chicago, IL: The University of Chicago Press.

Seels, B. B. \& Richey, R. C. (1994) Instructional technology: The definition and domains of the field. Bloomington, IN: Association for Educational Communications and Technology. 
Appendix B

Review of Literature 


\section{Occupational Socialization of Physical Education Teachers}

Researchers have investigated the socialization of teachers for over 50 years (Jackson, 1968; Lortie, 1975; Scribner \& Akiba, 2010). Edgar and Warren (1969) defined socialization as involving "pressures to change, to influence neophytes in socially desirable directions, to drop previous patterns of behavior and accept new norms held by the socializing agent or significant other" (p. 387). In physical education, research concerning socialization's impact on teachers dates back to the late 1970's and early 1980's (Lawson, 1983a, 1983b; Templin, 1979). The three periods of socialization of interest to this study are the (a) prior experiences of pre-service teachers during their K-12 years, (b) professional preparation in a teacher education program, and (c) induction into the school setting as a beginning teacher. It is necessary to explore the impact these three socializing periods may have on pre-service teachers' beliefs toward technology's role in physical education. To date researchers have not examined how pre-service physical education teachers are socialized to view technology's role in teaching and learning in physical education.

\section{Apprenticeship-of-Observation Period}

Researchers have used a variety of names to describe the time pre-service teachers spend in schools prior to enrollment in a professional preparation program such as recruitment (Dewar, 1989, Lawson, 1983a), pre-training, (Zeichner \& Gore, 1990), and apprenticeship-of-observation (Lortie, 1975). Regardless of the specific name used, it is clear that the apprenticeship period serves as a significant socializing agent. Apprenticeship has been defined as the process when an individual acquires the expertise, knowledge, and skills for a specific occupation - in a sense the person develops their occupational identity (Fuller \& Unwin, 2009). The occupational identity of a future teacher begins to grow when they are a student during the K-12 years. Some 
researchers have even suggested that this time spent prior to enrollment in formal preparation is the most influential socializing agent in the development of a teacher (Jackson, 1968; Lortie, 1975, 2002).

By identifying the apprenticeship years as the most significant socializing agent, these researchers suggest that this is the time period when future teachers actually learn how to teach in many respects. For that reason being a student during the K-12 years is analogous to serving an apprenticeship for teaching (Lortie, 1975, 2002). Students typically can spend over 10 continuous years in close contact with teachers before beginning a career in education. Lortie equated these continuous years in the K-12 setting to roughly 13,000 hours in the classroom. One constant over these years in the school setting is the relationship that exists between the student and teacher. For students who want to be successful in school the relationship with the teacher takes on a different dynamic. This is especially true for students who aspire to attend college. Students with high ambitions will make a concerted effort to be viewed favorably by their teachers. Lortie suggested that students who wish to be seen in a positive light by teachers participate in role playing in an attempt to ensure that their behaviors are seen favorably. Role playing can become even more significant when students have a desire to become a teacher. Students begin to imagine what they think it is like to be a teacher. Lortie (1975) stated "first, the student sees the teacher from a specific vantage point; second, the student's participation is usually imaginary rather than real" (p. 62). This is a critical point because unlike typical apprenticeships students never actually teach.

In spite of never assuming the duties of a teacher, students use the apprenticeship years to gain familiarity with teaching (Lawson, 1983a, Schempp, 1989). Based on past experiences in school students evaluate effectiveness of instruction using criteria they have personally 
developed. Unfortunately, criteria that students create typically are not rooted in sound pedagogical theory. Instead prospective teachers base perceptions of teacher effectiveness on their own personal likes and dislikes (Lortie, 1975, 2002).

Researchers in the field of physical education have also concluded that the apprenticeship years are highly influential for pre-service teachers. Dewar and Lawson (1984) conducted a study that investigated 10 high school seniors. A significant finding from this study was that the apprenticeship years led these students to view a career in physical education as a way to remain involved with sport. The implication being that students did not aspire to be a physical educator to teach young people to be skillful movers; instead they had an affinity for physical education because they viewed it as a profession to further their interest in sport. Hutchinson (1993) also investigated prospective physical education teachers. She studied 10 prospective physical education teachers who believed teaching physical education was characterized by the following: students should have fun, instruction was not needed because students should already know the skills, teachers should adopt a multi-activity curriculum, noncompliant behavior should result in low grades, and lesson plans do not always have to be written down. This research is consistent with other studies that found students often underestimate the difficulty of teaching (Lortie, 1975, 2002; Schempp \& Graber, 1992). This faulty perception of teaching perpetuates the notion that anyone can teach (Lortie, 1975, 2002). Due to students' limited vantage point they are not privy to the science of teaching; however, in spite of this it is evident that students learn a great deal about the profession, for better or worse, as a result of the apprenticeship-ofobservation period.

Teaching is unlike any other profession because of the extended exposure future professionals already have to the field. For example, students who enter dentistry school 
typically have not had continuous years of exposure to the field. For prospective teachers this simply is not the case. Students are not removed from most teaching activities (Lortie, 1975, 2002) and therefore view how teachers instruct, handle management issues, assess student learning, among other teaching functions. This informal training process that students engage in during the K-12 years has considerable impact on how an individual views teaching. Schempp's (1989) study of 49 pre-service physical education teachers illustrates the impact of this exposure. One significant finding of the study showed that the apprenticeship years provide pre-service teachers with a multitude of instructional strategies that are internalized based on personal likes and dislikes.

The internalizing of instructional approaches based on personal taste has serious implications for teacher education programs. The apprenticeship years result in prospective teachers creating a filter or a lens that all future experiences are viewed through. If prospective teachers already believe they know how to be an effective teacher it may limit the impact professional training can have on them. As Lortie (1975) described," unless beginning teachers undergo training experiences which offset their individualistic and traditional experiences, the occupation will be staffed by people who have little concern with building a shared technical culture" (p. 67). It is critical for teacher education programs to acknowledge that the apprenticeship-of-observation period that prospective teachers complete exerts significant developmental influence on their receptiveness to new concepts and ideas. Teacher educators must understand that pre-service teachers have already experienced a substantial amount of informal training when they enter a professional preparation program (Graber, 1989). Knowledge of a prospective teacher's biography may enable the teacher education program to have greater impact on teacher dispositions and behaviors. Schempp and Graber (1992) 
suggested that gaining a better understanding of the teacher socialization periods enables teacher educators to become more aware of pre-service teachers' thinking and dispositions toward the profession, which then prepares teacher educators for interactions with teacher candidates enrolled in their program.

One distinct outcome of the apprenticeship years is the development of a subjective warrant. People naturally participate in self-selection when they are thinking about different professions (Lortie, 1975). Self-selection means that they will test their knowledge, skill, and ability against what are perceived to be the needed competencies for a profession. In a similar vein, Dewar and Lawson (1984) characterized the subjective warrant as an individual's perceptions of the skills needed to work in a profession. It is against these perceived competencies that individual's make the decision to enter a profession or not. Individuals pursue occupations in which they feel that they have the ability to succeed. Every occupational field has distinct recruitment variables associated with it. Recruitment is the process when an individual develops an affinity for a specific field (Dewar \& Lawson, 1984). Lortie (1975) identified two types of recruitment variables that he labeled as attractors and facilitators. Attractors are the perceived benefits of working in a given occupation, which can range from material rewards, time compatibility, and ability to perform a service to the community. Facilitators are the influential variables that enable an individual to enter an occupation.

Lortie's $(1975,2002)$ research offers a useful framework for evaluating the variables that draw individuals to enter the profession of physical education. Teachers are attracted to physical education for a variety of reasons, one of which is that individuals view teaching as an occupation that enables them to work closely with young people. Lortie $(1975,2002)$ identified this attractor as the interpersonal theme. Working with young people is one of the defining 
characteristics of teaching. Data from physical education entry studies have shown that an opportunity to work with young people is an influential attractor (Templin, Woodford, \& Mulling, 1982). Woods and Rhoades (2010) found this sentiment to remain true in a recent study of 334 in-service physical education teachers. Results of the study showed that a significant motivator for the participants to enter physical education was the joy they received from working with children. Teachers also view the occupation as providing an important public service. Lortie $(1975,2002)$ labeled this attractor as the service theme. Teaching is viewed as providing a great service to society (Templin et al., 1982). Working with young people and providing a service to society are two highly influential attractors to teaching. Another distinct attractor of teaching is the ability to continue in a field that the individual is comfortable with. Lortie $(1975,2002)$ labeled this attractor as the continuation theme. Prior to entry into a PETE program individuals have spent years in the school setting. Individuals become so comfortable with the school setting they have a desire to continue this connection by becoming a teacher (Templin et al., 1982). For individuals who have a desire to enter physical education it could stem from their positive experience as a student in physical education. Some pre-service teachers select physical education because they view it as a means to continue their association with sport (Curtner-Smith, 2009; Chu, 1984; Dewar \& Lawson, 1984; Templin et al., 1982).

Lawson (1983a) offered two examples of why pre-service teachers' attraction to physical education may be less than ideal for the field. First, entering physical education to teach is not a primary motivation for many who enter the field. Second, individuals are attracted to physical education because it allows them to continue their relationship with sport; specifically it enables them to coach. Building on this research Dewar (1989) concluded that students attracted to the field saw physical education as a means to "reproduce the kinds of experiences they had as 
students" (p. 47). Unfortunately, Dewar's research showed that the individual's who had a subjective warrant that attracted them to the field saw physical education as a curriculum that promoted learning how to play games. Another defining attractor of teaching is having a summer vacation. Lortie $(1975,2002)$ labeled this attractor as time compatibility. There is little argument that the working schedules of teachers are a strong attractor to the profession. However, for physical education time compatibility may not be as strong of an attractor because physical education teachers often coach. Coaching takes a considerable amount of leisure time that is afforded to teachers. Therefore, time compatibility may not be a realistic attractor for many individuals who choose to enter physical education.

Lortie $(1975,2002)$ identified ease of entry as a significant facilitator that attracts individuals to the teaching profession as well. Individuals view teaching as a profession that is relatively easy to gain entry into. Factors such as admission standards, time required for training, intellectual rigor, and the money required to matriculate through a program are all variables that impact an individual's decision to select physical education (Templin et al., 1982). Relative ease of entry into physical education programs has led some researchers to conclude that the field does not attract the strongest candidates. Templin et al. (1982) found evidence that physical education students had mediocre academic records. Griffin (1989) further validated this notion in a study that looked at 93 student teachers, 89 cooperating teacher, and 17 university supervisors in physical education. Results of the study found that the student teachers' vocabulary level ranked in the fifteenth percentile, with cooperating teachers and university supervisors not faring much better. This suggests that physical education may not be a student's first choice of major. However, when you couple mediocre academic records and relative ease of entry physical education, it is viewed as an attractive choice for many prospective teachers. 


\section{Professional Socialization}

The second socialization period occurs when prospective teachers enter formal training programs. This time period is referred to as professional socialization. Lortie (1975) identified that a primary goal of this time period is to create a shared technical culture for teachers. Shared technical culture refers to the skills and knowledge that are necessary for being successful in a profession. Similarly, Lawson (1983a) described professional socialization "as the time period when practicing teachers acquire and maintain the values, sensitivities, skills, and knowledge that are deemed ideal for teaching physical education" (p. 9). This is the time when pre-service teachers learn the science of teaching. Many researchers have argued that professional socialization has low impact on pre-service teachers however (Chu, 1984; Curtner-Smith, Hastie, \& Kinchin, 2008; Jackson, 1968; Lawson, 1983b; Lortie, 1975). Professional socialization is thought of as a low impact enterprise because practicing teachers' subjective warrants are resistant to the change that teacher education programs try to facilitate.

A contributing factor to pre-service teachers being resistant to adopting the shared technical culture is the orientation they have toward the profession. Lortie (1975) found that students may enter teaching because they view it as a gateway to other professions as previously described. Research in physical education has shown that the influence of sport and coaching leads many students to choose physical education because they primarily want to coach. Two common orientations that have been identified as being present for future physical education teachers relates to those who are oriented toward coaching or teaching. Chu (1984) emphasized teachers that posses a coaching orientation will not be committed to teaching, instead will view physical education as a means to coach. 
Similarly, Hutchinson (1993) studied 10 high school students who had a desire to become physical education teachers. In her study she found that all 10 prospective teachers viewed physical education as a field that would enable them to coach sport. Hutchinson's study also showed that high school students believed physical education should focus on ensuring that students have fun, lesson planning was not needed, and grading should be centered on complying with the teacher's rules. Research of this nature indicates that the subjective warrant practicing teachers' posses in physical education may be in direct conflict with the shared technical culture PETE programs are trying to develop.

Individuals who enter programs lacking a commitment to the occupation have little incentive to learn the pedagogical skills, knowledge, and dispositions taught throughout the program (Chu, 1984). Similarly, Schempp and Graber (1992) state "if students expect to be trained as coaches but encounter almost exclusive emphasis on teacher training, a sharp violation of expectations mediates the acquisition of the orientation that the training program hopes to instill" (p. 335). This provides further indication that students oriented toward coaching can be problematic for PETE programs.

Lawson (1983a) hypothesized that "students with extensive involvement in organized sport will be attracted to coaching, not teaching" (p. 8). Coaching oriented teachers view physical education as a means to continue their relationship with sport. Lawson also hypothesized that "students with limited involvement in sport, but more extensive involvement in physical activity and physical education will be attracted to teaching, not coaching" (p. 8). Teaching oriented students will not select physical education because they have a desire to coach. Woods and Rhoades' (2010) study of 334 in-service physical education teachers that were aspiring to become Nationally Board Certified Physical Education supported Lawson's 
hypotheses. From the 334 participants, 65 were selected to participate in follow-up interviews, of which only four acknowledged that they chose to enter physical education to coach. The implication may be that individuals who are aspiring to reach the highest status that physical education practitioners can attain do not possess coaching orientations.

Coaching oriented teachers are also closely connected to being custodial in their teaching beliefs. Teachers that possess custodial coaching orientation are likely to perpetuate the status quo (Lawson, 1983a). Similarly, Crum (1993) characterized custodial oriented teachers as possessing a warrant that does not embrace teaching. Crum's work captures the problematic cycle that has plagued the field of physical education. Custodial teachers graduate from PETE programs and enter the school system only to provide poor examples for future physical education teachers, which then instills prospective teachers with faulty warrants on what physical education is all about. On the other end of the continuum, research has indicated that individuals who possess a teaching orientation are more likely to be innovative in their approach to instruction (Lawson, 1983a). Innovative teachers are more apt to change the status quo and adopt the shared technical culture that PETE programs are trying to instill (Curtner-Smith, 2009; Lawson, 1983a).

For those students that fall in the middle, meaning they are not categorized as being custodial or innovative, there is possibility for change. Curtner-Smith (2009) found that preservice teachers who possess a moderate custodial orientation can be changed. Research on orientations highlights the importance for PETE programs to understand the orientation that preservice teachers enrolled in their programs posses. As Schempp and Graber (1992) described, PETE programs will have students at one extreme that have been socialized to believe a good teacher plans, teaches, and assesses students learning, while at the other extreme there will be 
students that have been socialized to believe physical education is about having fun. Knowing the two extremes, custodial and innovative, is critical when preparing these individuals to be effective novice physical educators.

Field placements also serve as a significant socializing force during the professional period. As Dodds (1989) pointed out pre-service teachers' perspective remain a fluid entity during field placements. Curtner-Smith's (1996) study of 28 pre-service teachers found positive results with implementation of early field experiences. Specifically by adopting and adhering to the following strategies: (a) place pre-service teachers in sites that reinforce programmatic goals; (b) pre-service teachers are supervised by trained PETE faculty and cooperating teachers; (c) field placement emphasizes what is being taught in methods courses; (d) content taught to pre-service teachers in methods courses is practical in nature; and (e) train pre-service teachers to collect data and reflect on their teaching episodes. While early field experiences have potential to influence so does the student teaching placement, which is seen as the most important field placement for pre-service teachers (Schempp \& Graber, 1992). During field placements preservice teachers are in between two worlds, the university and public schools.

This is why Freibus (1977) suggested that cooperating teachers are a key socializing agent because they serve as pivotal and influential figures during field placements for pre-service teachers (Dodds, 1989). Pre-service teachers are exposed to a variety of instructional practices, management routines, and other pertinent teaching functions during field placements. When cooperating teachers and universities do not share the same ideology, problems can arise for preservice teachers because of the mixed signals they receive. 
To combat this issue some scholars recommend providing cooperating teachers with formal training programs to help prepare them to be an effective role model for pre-service teachers (Horton \& Harvey, 1979; Siedentop, 1981). In addition to the influence cooperating teachers have on pre-service teachers, the pupils in the K-12 setting also serve as socializing agents (Dodds, 1989). A study by Freibus (1977) illustrated the power pupils can have on preservice teachers during field placements. In this study of pre-service teachers the most influential socializing force was the pupils. It was found that pre-service teachers had a strong desire to appease the pupils in their classrooms. Furthermore, Mohr's (2000) dissertation study of five beginning physical education teachers showed the influence pupils can have on teachers as well. The teachers in his study employed teaching behaviors that aimed to keep the students happy instead of focusing on effective instructional behaviors.

Behaviors that pre-service teachers employ to appease other people also applies within the teacher education program. Preparation programs intend to impart meaningful change on pre-service teachers, however, when practicing teachers possess subjective warrants that are in direct conflict with the shared technical culture a PETE program possesses it should come of little surprise that resistance may occur. Resistant behavior highlights studentship, which is the process when students react to professional socialization (Graber, 1989). Work on studentship indicates that students are not passive recipients of information they receive. Instead, students are active in the learning process. Upon entry into a preparation program, students have expectations of what they should learn. Some expectations will be shared by teacher educators and students. When the expectations for teacher preparation conflict with those of pre-service the teachers, resistance to socialization may occur. 
Studentship empowers students to adopt the components of the shared technical culture they perceive as relevant, while ignoring the components they view as irrelevant (Graber, 1989). Students know that in order to matriculate through a preparation program they must, at the very least, appease faculty members. The behaviors that compromise studentship enable students to progress through the program with less effort. In what Schempp and Graber (1992) call the dialectal process of socialization, which refers to the decision process between pre-service teachers' beliefs toward physical education and the shared technical culture PETE programs try to instill. The dialectal process further represents the autonomy pre-service teachers have when it comes to deciding what information they feel is relevant.

When students resist the forces of professional socialization they may participate in a variety of behaviors. Graber (1991) performed a study of 62 physical education pre-service teachers. The study revealed a range of behaviors that pre-service teachers participate in. Preservice teachers that had a strong desire to perform well in courses would find ways to gain an edge on the instructor to get the desired grade. In order to gain insight into a professor's expectation for what it takes to achieve good grades, students may participate in psyching-out. Psyching-out is a student's attempt to gain more insight into the nature of faculty demands so less effort must be put forth in studying or completing a course assignment (Graber, 1989, 1991). Students will bargain, persuade, and plead with teachers so they better know what they have to do to be successful. When resisting the forces of professional socialization students also project an image that they feel will be viewed in a positive light by the PETE instructor. Graber referred to this process as fronting. Fronting behaviors can range from pretending to take notes, using professional terminology, or showing interest in teaching. Students may be displaying behaviors or beliefs just to please faculty members (Graber, 1989, 1991). While some studentship 
behaviors are overt, others are intentionally more covert. An example of a covert studentship behavior is cheating or short cuts (Graber, 1989, 1991). Cheating unlike fronting can have serious consequences for students so these behaviors must be done in a discrete manner. Graber's research found that pre-service teachers viewed cheating as wrong, but readily admitted taking advantage of short-cuts. For example, if students could use work from previous courses to assist them in current courses they would do so. Some short cuts may be harmless while others can seriously undermine the intended learning outcomes of the preparation program.

Doolittle, Placek, and Dodds (1993) longitudinal study of 16 pre-service physical education teachers, highlights cases of three students that pushed back against the forces of socialization. The study revealed that the program had minimal impact on changing the beliefs pre-service teachers toward teaching physical education. Matanin and Collier (2003) conducted a longitudinal study on three pre-service physical education teachers. Results from this study supported the notion that pre-service teachers do push back against professional socialization. Specifically, this study cited how a pre-service teacher's biography stimulates the resistance to professional socialization.

All studentship behaviors are not necessarily negative. Student participation in the dialectal process is a natural occurrence. Simply put, students are not passive recipients of knowledge. Students are going to fight back against knowledge that they view as lacking relevance. This resistance will lead to students participating in studentship behaviors. One example where studentship can have a positive outcome is fronting. Fronting professional behaviors that students feel faculty view favorably may have a positive outcome. Fronting may result in students internalizing the shared technical culture programs are trying to instill in them (Graber, 1989). Knowledge of studentship behaviors sheds light on the hidden dialectic that 
occurs during the preparation years (Schempp \& Graber, 1992). A major implication of this line of research for PETE programs is that pre-service teachers are very much active participants in the learning process.

Given what is currently known about the influence a pre-service teacher's biography has on the professional socialization period, one might wonder how the products of the apprenticeship years should be dealt with from the teacher education standpoint. Fortunately there is a knowledge base that provides PETE programs with strategies to address the influences of the apprenticeship-of-observation period. For programs to have impact on pre-service teachers they must first recognize that they do not enter college campuses as a blank canvas (Lortie, 1975, 2002). Instead, pre-service teachers enter programs with a pre-conceived understanding of how to teach.

Beginning the process of challenging misconceptions that pre-service teachers have toward the profession is critical in facilitating the process of creating a shared technical culture within and throughout professional programming (Lawson, 1983a). To create such a culture it means that all faculty members must be on the same page so pre-service teachers receive a consistent message throughout. Graber (1989) offered a series of suggestions for programs to help deal with the forces of socialization. Programs must assist pre-service teachers in critically examining and challenging their beliefs toward the profession. It is also recommended that programs attempt to determine the level of commitment pre-service teachers possess toward the profession. If individuals have a desire to enter physical education for reasons other than they want to be effective teachers this should serve as a red flag. If pre-service teachers are not committed to the profession this will contribute to their resistance to positive socialization during the professional period. Graber also urged programs to gauge pre-service teachers' expected 
outcomes of the professional period. If a program understands the knowledge and skills preservice teachers expect from the professional period it enhanced the program's impact. It is also recommended that programs have an understanding of studentship behaviors. Graber suggested that programs make expectations explicit and assure students that if they meet the set criteria they will receive the desired reward. Another important implication for programs is the need to critically examine what pre-service teachers actually learn during the professional period (Graber, 1989). Adopting formative assessment enables the program to critically examine what the curriculum is teaching its learners. Collectively the suggestions by Graber offer programs a framework to address the products of the apprenticeship years and to enhance the impact the professional period has on pre-service teachers.

Schempp and Graber (1992) also provided programs with suggestions to deal with the forces of the apprenticeship years including the need to challenge the beliefs pre-service teachers possess. If beliefs are not challenged minimal impact could occur, or as Schempp and Graber state "recruits may leave their preparation programs untouched by new knowledge and insights" (p. 337). Hutchinson (1993) stressed that pre-service teachers enter programs with robust beliefs toward the profession, thus emphasizing the need for programs to challenge these beliefs. Curtner-Smith (1996) recognized that a pre-service teachers' orientation is an influential force during the professional period. However, his study of 28 pre-service physical education teachers found that early field experiences were successful in changing the beliefs participants had toward the profession.

O’Sullivan (1996) based on a review of the occupational socialization literature and its impact on learning, recommended that programs provide pre-service teachers with multiple opportunities to challenge the misconceptions they may have toward the profession. Wideen, 
Mayer-Smith, and Moon (1998) reinforced previous research findings in that they also described that successful teacher education programs build on the beliefs pre-service teachers already possess. Curtner-Smith (2009) emphasized the role prior beliefs and teacher orientation has on the potential impact programs can have on pre-service teachers' beliefs during the professional period. He stressed the need for programs to recruit innovative oriented teachers and reject preservice teachers that possess custodial orientations. Programs not only need to acknowledge that beliefs play an influential role in the development of pre-service teachers during the professional period, but programs need to make a concerted effort to challenge pre-existent misconceptions.

\section{Induction Period}

The socialization of teachers does not end once they graduate from a preparation program; instead it follows them into their first teaching position. Completion of the professional socialization period leads teacher to the induction socialization period. When a new teacher enters a school, they are entering an organization. Lawson (1983b) highlighted that organizational socialization is when teachers try to transition from being an "outsider" to an "insider" that is accepted by their peers (p. 7). Entry into schools exposes novice teachers to different personalities, expectations, and challenges. Every beginning teacher works to understand what it means to be a teacher in that school (Lawson \& Stroot, 1993) and since no two schools have the same culture (Schempp \& Graber, 1992) the socialization process they are about to embark upon can be quite difficult.

Highlighting the uniqueness of the socialization process for beginning teachers is the fact that on the first day of teaching they are expected to assume the same duties as a professional who has been in the business for 25 years, unlike other occupations such as nursing where new professionals remain under the tutelage of a veteran nurse for up to a year before shouldering all 
the responsibilities of the job (Lortie, 1975, 2002). Like it or not, in teaching from day one they are likely be the only teacher in front of the class. It is the hope that the professional socialization period adequately prepares the beginning teacher to successfully assume the duties of teaching in an effective manner (Lawson, 1983b). Problems can arise when beginning teachers do not feel well prepared to meet the considerable number of demands placed on them. The demands placed on beginning teachers often force them to make decisions that enable mere survival in their current situation.

Survival is a word that a few researchers have used to characterize the induction process (Lortie, 1975; Schempp \& Graber, 1992). Survival is particularly relevant for beginning physical education teachers. One variable that fuels beginning physical education teachers to resort to survival mode is the shock that they feel when assuming the duties of teaching. The surprise felt by beginning teachers is referred to as reality shock (Stroot, Faucette, \& Schwager, 1993). Reality shock occurs when a teacher perceives that the competencies received from their preparation program did not enable them to meet the demands of teaching, thus forcing teachers into survival mode. Smyth's (1995) study of a first year physical education teacher's transition into assuming the duties of a teacher helps to illustrate reality shock. One emergent implication of this study was that the first year teacher had no idea how rigorous his work schedule was going to be. Another force that contributed to the first year teacher's reality shock was the lack of expectations from others within the school. The overall lack of expectations created a culture that supported a less than ideal physical education curriculum, one that emphasized students being busy, happy, and good. Curtner-Smith (2001) later found similar results. In his study of a first-year physical education teacher, Curtner-Smith found that the teacher grew very frustrated with the lack of status physical education had in his school. The frustrations the teacher 
experienced in this study highlight what other researchers have found in that physical education is often marginalized within the school curriculum (O'Sullivan, 1989; Sparkes, Templin, \& Schempp, 1993).

Reality shock and marginalization are not the only forces physical education teachers must confront. Another variable that awaits beginning physical education teachers is a feeling of professional isolation (O’Sullivan, 1989; Stroot, Faucette, \& Schwager, 1993). Many researchers have examined the impact isolation can have on beginning physical education teachers. Smyth (1995) found that a first year teacher was surprised by the amount of autonomy he had in making decisions for his program. This autonomy also required the beginning teacher to make a lot of decisions without being able to share ideas or collaborate with other professionals. Curtner-Smith's (2001) study also found that the participant in his study found it quite difficult to get to know other teachers in his school. He cited a major impediment that prevented him from having meaningful interaction with other professionals was the gym being isolated within the school. Another commonality in these studies that contributed to the isolation of beginning professionals was not having other like-minded teachers in the building to talk to, seek advice from, and in some cases vent.

The isolation experienced during the school day is a negative socialization force beginning physical education teachers have to confront. When the school bell sounds many teachers' day ends, while the work day for a considerable number of physical education teachers is just beginning as they also fulfill the role of a coach. Role conflict often arises for physical education teachers because they place more value on being a coach, which can be traced back to their internal motivation for entering the profession (Chu, 1984). Once physical education teachers have entered the work environment and received a coaching position, the value placed 
on coaching is reinforced because the related accomplishments are praised, while the physical education program is often ignored (Stroot et al., 1993). Naturally this reward system is problematic for the establishment and delivery of quality physical education. It also provides another example of the dialectic process that physical education teachers face: Do I want to be an effective teacher or coach? Based on the reward system that permeates the profession it is not a surprise why so many physical educators make the decisions they do. This highlights the teacher-coach role conflict that many physical educators face. The teacher-coach role conflict is highly relevant to physical education because it is assumed that physical education teachers can easily perform both duties due to the inherent similarities (Figone, 1994). The ability of physical educators to effectively fulfill both sets of responsibilities is not supported in the literature though.

Curtner-Smith (2001) found that a first year teacher's experience of teaching and coaching was extremely difficult to manage because of the stress it placed on him. Millslagle and Morley (2004) conducted a study of 129 teachers who also coached. One emergent theme identified through their research was that the time spent on teaching physical education decreased when they became involved in coaching. This suggests that the perceived notion that teachers can fill both roles may be faulty. It may even indicate that when it comes to filling both the coaching and teaching role that something has to give. Millslagle and Morley (2004) referred to this as retreatism, which means that the teacher retreats from the duties of teaching and embraces the coaching role. Again, another example of the dialectic process physical education teachers face: Should I invest my energy into coaching or teaching? Ryan (2008) conducted a study on the teacher/coach role conflict as well. This study of 135 teachers who coached further highlighted how the role conflict can lead to a great deal of stress. The teacher/coach role 
conflict is a prime example of the difficult decisions physical education teachers sometimes have to make to survive.

Reality shock, marginalization, isolation, and role conflict highlight some of the impediments that beginning teachers must overcome to survive in the schools. It should come as no surprise when you combine these negative socializing forces that it produces few positive outcomes for teachers. One of the most problematic results of the negative socializing culture in physical education is washout. Washout occurs when all of the competencies learned during the professional period are deemed not useful by the physical education teacher (Zeichner \& Tabachnick, 1981). Essentially the teacher makes a decision that the outcomes received from the professional period do not align with the realities of the job.

Stroot et al. (1993) discussed the experiences of three first year physical education teachers and found that the school environment did not support quality physical education. Instead it created a climate that caused the beginning teachers to revert back to behaviors they never imagined they would employ such as teaching without lesson plans and a curriculum that focused on playing games. However, all is not lost when it comes to the study of washout in physical education teachers. Curtner-Smith (2001) determined that beginning teachers with an innovative orientation found that they were able to successfully navigate the murky waters that physical educators face in the schools. The implication from his line of research is that teachers who are innovatively oriented are better equipped to push back against the negative socialization forces.

So what can be done to help beginning physical education teachers successfully navigate the first few years of teaching? Based on a review of the occupational socialization literature, 
Stroot and Whipple (2003) offered a series of suggestions to help physical education teachers successfully transition from teacher preparation programs to the school setting. First it is recommended that beginning teacher actively seek out a mentor. Ideally beginning teachers should try to identify a mentor who is also a physical education specialist. Other researchers have also identified mentoring as a critical component in assisting beginning teachers (Stroot et al., 1993). Second, physical education teachers also have a responsibility to be continual learners. Stroot and Whipple (2003) recommended beginning teachers accomplish this by staying up-to-date with published resources. As Armour, Makopoulou and Chambers (2009) argued, teachers have a professional responsibility to keep their knowledge current to better meet the needs of their learners. This means that learning cannot stop when teachers graduate from professional preparation programs. A third recommendation is for beginning teachers to develop into reflective practitioners. Critical examination of one's teaching enables them to identify potential areas for improvement. Attard and Armour (2005) stated, "the reflective process should eventually help the teacher change, adapt and modify his/her teaching to the particular context" (p. 197). The fourth suggestion is that beginning teachers actively network. It is important for beginning teachers to try to be an advocate for their programs, network with others, and don't settle for the status quo. Stroot et al. (1993) emphasized that beginning teachers need to get outside of their gyms so they can counter the negative effects of professional isolation as well.

\section{Learning: The Process of Conceptual Change}

Research on the periods and products of occupational socialization tell us that learning can be a complicated process. This is particularly true for individuals in the field of education due to the access future teachers have to individuals in the profession prior to entry into formal 
teacher training (Lortie, 1975, 2002). Conceptual change is characterized by a change in knowledge structures during the learning process (Posner, Strike, Hewson, \& Gertzog, 1982). Research on conceptual change further highlights the challenges that are present when it comes to knowledge acquisition (Posner et al., 1982; Vosniadou, 1992). Due to the nature of research on conceptual change this section will be further divided into the following sub-sections: (a) levels of conceptual change; (b) conditions for accommodation; and (c) conceptual change with technology.

\section{Levels of Conceptual Change}

Dating back to the early work of Jean Piaget scientists have studied the impact of learners' existent knowledge structures on how they interpret new information. Piaget's (1985) work highlights that learning represents the interactions between the information students are taught and their current knowledge structure. Due to the robust knowledge structures that exist, teaching may not always be as effective as teachers perceive it to be for their learners (Viennot, 1979). As Viennot described even when faced with rational contradictions to current knowledge structures, misconceptions can remain largely unaffected by teaching. Research on misconceptions supports what researchers in the field of physical education have determined regarding the impact the apprenticeship-of-observation period and subjective warrant has on the professional socialization of teachers (Lawson, 1983a; Schempp \& Graber, 1992).

Viennot's (1979) work indicated that learning can vary for individuals depending on the robustness of their knowledge structures. The variance in learning illustrates the different levels that exist in the conceptual change process. Piaget (1985) identified the first level of knowledge acquisition as assimilation. Assimilation is characterized as the integration of new information 
into knowledge structures that are already present. Posner et al. (1982) referred to assimilation as the first stage of conceptual change because it is a rather easy process that does not require the learner to dramatically change knowledge structures and new information can be integrated with little difficulty. Posner et al. (1982) stated that "inquiry and learning occur against the background of the learner's concepts" (p. 212). Thus, when new information does not conflict with a learner's background, knowledge acquisition is not impeded. Assimilation also suggests that the learner does not greatly adjust their existing knowledge structures, which in some cases could be problematic. The absence of meaningful change is also referred to as weak restructuring (Vosniadou \& Brewer, 1987). Weak restructuring has been heavily linked with the difference between a novice and expert. Weak restructuring is prevalent in novices because they are less able to make connections with their existing knowledge structure when compared to an expert (Vosniadou \& Brewer, 1987). In addition, research on assimilation shows that when new information does not align with current knowledge structures it will not be easily assimilated by the learner (Dole \& Sinatra, 1998). These findings provide further evidence that new information is filtered based on a learner's current knowledge structures or subjective warrant.

Assimilation is referred to as an easy process for the learner, but the second level of conceptual change is much more difficult to achieve. The next level of acquisition is identified as accommodation (Piaget, 1985). Accommodation is characterized as the restructuring of current knowledge structures. Research on accommodation suggests that the role of prior experience is not as important as it is in assimilation (Vosniadou \& Brewer, 1987). This is true largely because accommodation is a change in conception or a shift away from a previously held understanding of a topic. For example, if a physical education teacher possessed a traditional conception toward assessment of student learning, then adoption of heart rate monitors in a 
physical education setting would require accommodation of their knowledge structures.

Naturally this is why this form of conceptual change is classified as a more radical alteration in knowledge structures (Dole \& Sinatra, 1998; Posner et al., 1982). Vosniadou and Brewer (1987) stated that, "this type of change is postulated by investigators to account for radical changes in knowledge that appear to occur with age or expertise" (p. 52). Vosniadou and Brewer suggested that with age and expertise it is much easier for accommodation to occur. However, age and expertise still does not ensure that accommodation is going to come to fruition.

The difficult nature of accommodation is why the innovation adoption process is typically a slow one (Rogers, 1983). Ennis (2007) pointed out that a change of this level requires an individual to make profound changes to their life. For example, changes of this magnitude are often made by individuals after they make a visit to a doctor when they are told they need to improve their diet or else. As Ennis also described, "from this perspective, it is not surprising that instructional environments designed to foster simple knowledge accretion are often ineffective in stimulating and sustaining major behavioral changes" (p. 140).

\section{Conditions for Accommodation}

Posner and colleagues' (1982) seminal work provided a list of conditions that must be present for meaningful knowledge acquisition to occur in learners. From their work they created the Conceptual Change Model (CCM) (see Figure 1). In the CCM researchers described a series of conditions and steps that learners progress through in the process of change. Even before the condition of accommodation can be addressed the learner must first view the new conception as logical (Posner et al., 1982). The implication for teachers is that learners' current conceptions have formed because they make sense, therefore new material must be presented in a manner that 
is logical for it to even be considered. Once that hurdle is overcome the progression for conceptual change can continue. The first condition that must be met is that an individual must be dissatisfied with their existing conception(s). The second condition is that a learner must view the new conception as intelligible. The next condition is that a learner must view the new conception as plausible. The final condition is that the learner must view the new conception as being fruitful, meaning they see it as being worthwhile.

The CCM provides a framework that individuals must progress through when they are confronted with new conceptions. For example, let's say a physical education teacher is confronted with technology integration. First, they must be dissatisfied with their current pedagogical beliefs and practice. Once this condition is met the teacher must now view technology integration as an intelligible concept. They have to be able to grasp the concept and have the ability to explore the ways technology could be integrated into their teaching. Once technology is viewed as an intelligible concept they must now see it as feasible. The teacher has to believe that they have the resources to make technology an integral component of their teaching. Finally, the teacher has to view making technology an integral aspect of their teaching as an effort that is worth pursuing. What makes accommodation difficult is if any point a condition is not fulfilled they will return to their currently held conceptions (Posner et al., 1982). Dole and Sinatra (1998) emphasized the difficultly in facilitating conceptual change is that it takes a considerable amount of work. So, if the individual believes that a currently held conception will get the job done they are less likely to put the work in to achieve the conceptual change. 


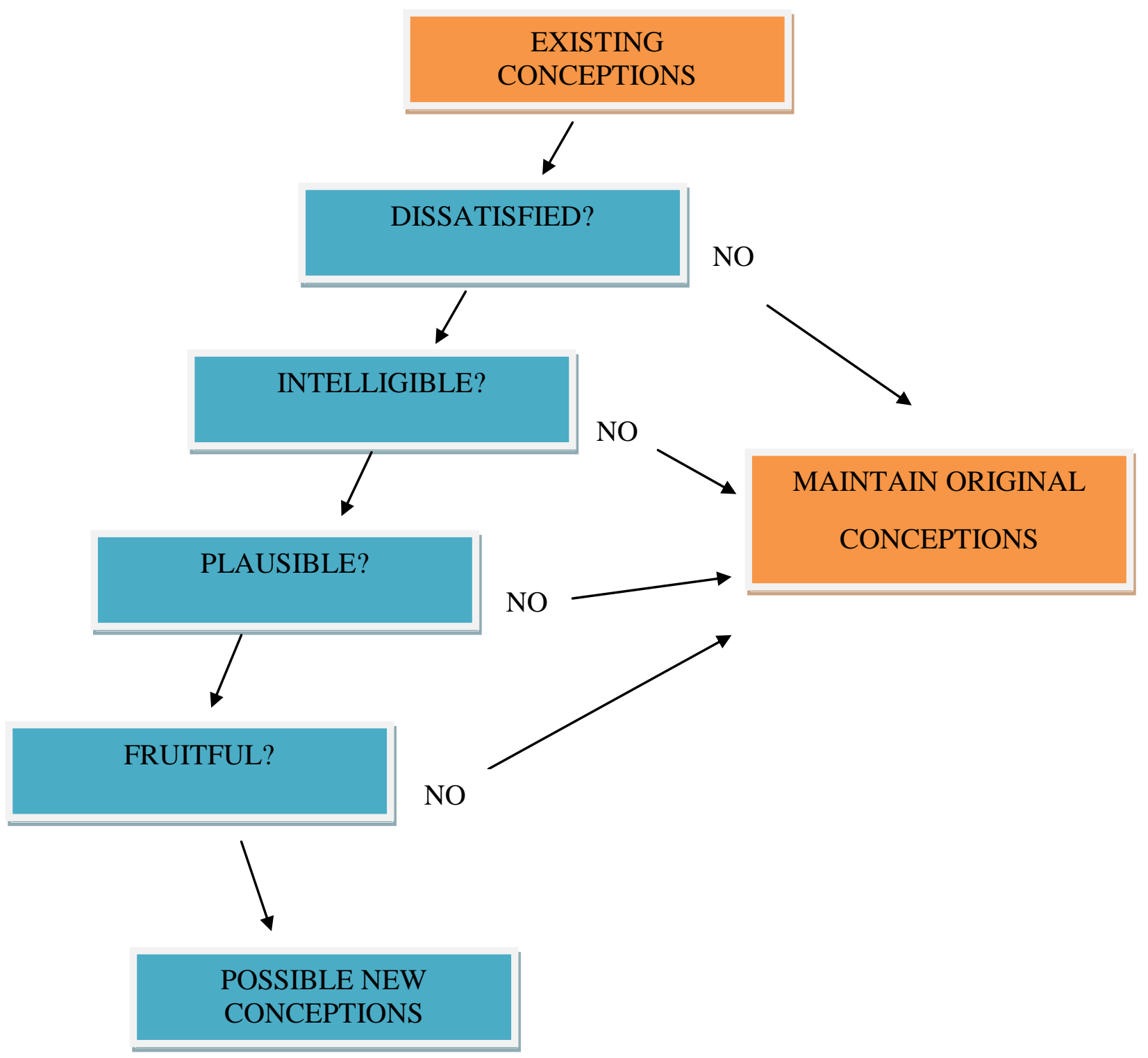

Figure 1. Conceptual Change Model adapted from Posner et al. (1982)

Posner and colleagues (1982) also offered teachers suggestions for moving learners toward conceptual change. First, teachers should design learning experiences that challenge currently held conceptions toward the content being introduced. Additionally, teachers should make a concerted effort to pay special attention to learners that are making an effort to resist 
accommodation. Teachers should also try to adopt strategies over time to help move learners to accommodation. Finally, teachers should create an evaluative technique that tracks their learners' conceptual change. These strategies provide PETE programs with strategies to manage the considerable challenge of achieving accommodation in learners. The challenges in changing conceptions could be particularly problematic when it comes to integrating technology into a teacher's repertoire.

\section{Teachers' Conceptual Change with Technology}

The terminology used to describe conceptual change within instructional technology may vary slightly, but the emphasis on change in knowledge structures remains consistent. Two prominent models that have been used to analyze technology integration are the Stages of Adoption (Russell, 1995) and Concerns-Based Adoption Model (CBAM) (Hall, George, \& Rutherford, 1979). The models vary in nature; however the focus is on the process teachers endure when they move toward technology integration. In addition, the models highlight teachers' current view of technology's role in their teaching. Russell's (1995) Stages of Adoption Model outlines six stages teachers progress through in terms of technology usage in their teaching: (1)Awareness, (2) Learning the Process, (3) Understanding and Application of the Process, (4) Familiarity and Confidence, (5) Adaption to Other Contexts, and (6) Creative Application to New Contexts

This model highlights how teachers move from being a non-adopter of technology to a meaningful user of technology. The model was validated in an initial study of 30 pre-service teachers and follow-up studies with 300 teachers. Christensen, Griffin, and Knezek (2001) used the Stages of Adoption Model in 12 school districts with 428 teachers and found that the most 
common stage was 4.4. After the intervention, which exposed teachers to professional development from instructional designers, the most common stage progressed to 4.86 .

The CBAM (Hall et al., 1979) is slightly different in that it seeks to measure the level of concern a teacher has in integrating an innovation into their teaching. Hall et al. stated the following in terms of concern, "the composite representation of the feelings, preoccupation, thought, and consideration given to a particular issue or task is called concern" (p. 5). The CBAM consists of seven stages of concern with stage zero representing the lowest level of concern and stage six the highest level of concern (see Table 1). The theory behind this model is that concern influences performance; lower level concerns have to be addressed before higher level concerns will be considered (Hall et al., 1979). The implication for teacher educators is that depending on the individual's prior experience with the innovation the stage of concern could vary. However, it is predictable that individuals will experience different stages of concerns at the same time. Key variables that determine the intensity of the stage of concern a person experiences is their current knowledge structure relative to the innovation, if involvement with the innovation is new, or if they have had previous experience with the innovation (Hall et al., 1979). Awareness of where learners fall on the continuum of concerns has the potential to provide educators with invaluable feedback to inform training. 
Table 1

Concerns-Based Adoption Model Description

\begin{tabular}{|c|c|c|}
\hline Stage & Name & Description \\
\hline Zero & Awareness & Little concern or involvement about the innovation is indicated. \\
\hline One & Informational & $\begin{array}{l}\text { A general awareness of the innovation is indicated and some interest is } \\
\text { expressed (e.g. general characteristics, effects, and requirements for } \\
\text { use). The individual is interested in learning more about the } \\
\text { innovation }\end{array}$ \\
\hline Two & Personal & $\begin{array}{l}\text { Uncertain about the demands of the innovation. Individual is also not } \\
\text { sure about their ability to use the innovation and potential conflicts } \\
\text { with personal pedagogical beliefs. }\end{array}$ \\
\hline Three & Management & $\begin{array}{l}\text { Individual is focused on how to use the innovation. Primary focus is } \\
\text { on organizing, managing, and the time demands of the innovation. }\end{array}$ \\
\hline Four & Consequence & $\begin{array}{l}\text { Concerned about how the innovation will impact their students. } \\
\text { Specifically concerned about the relevance of the innovation, how to } \\
\text { evaluate student learning, and changes needed to address student } \\
\text { learning. }\end{array}$ \\
\hline Five & Collaboration & $\begin{array}{l}\text { Concerned about how to collaborate with others regarding the } \\
\text { innovation. }\end{array}$ \\
\hline Six & Refocusing & $\begin{array}{l}\text { Individual is concerned about ways to improve use of the innovation. } \\
\text { Individual definitely possesses ideas about the innovation. }\end{array}$ \\
\hline
\end{tabular}

Note. Hall, G. E., George, A. A., \& Rutherford, W. L. (1979). Measuring stages of concern about the innovation: A manual for the use of the SOC questionnaire. Austin, TX: The University of Texas at Austin. The Research and Development Center for Teacher Education.

Due to the relevance of CBAM to technology integration it has been applied in several studies. For example, Christensen et al.'s (2001) study of 428 teachers found that following professional development the average level of concern increased from 5.36 to 5.80. The increase in level of concern was compatible with an increase in stage of adoption. In Rakes and Casey's (2002) study of 658 teachers the most common concern was stage two. They suggested that the teachers in this sample had numerous personal concerns about integrating technology into their teaching. Donovan, Hartley, and Strudler (2007) also implemented the CBAM to measure 17 teachers' level of concern and again determined that stage two was the most commonly voiced 
concern. The implication of this study was that the researchers recommended that professional development opportunities be designed to address the concerns that teachers possess regarding instructional technology use. Overbaugh and Lu's (2008) study of 377 teachers found that there was a difference in level of concern between male and females. The results suggested that males voiced lower level concerns, meaning that they were more worried about how technology would impact them personally.

Donovan and Green (2010) studied the integration of technology in pre-service teacher education using CBAM to measure the level of concern of faculty. The results showed that faculty members need to be prepared to integrate technology to ensure program success. The implication for PETE programs are that indirectly the level of concern that faculty possess could impact the experience pre-service teachers receive regarding instructional technology. Collectively the research on conceptual change in technology highlights that stage of adoption and that stages of concern have an impact on the actual use of technology in teaching.

\section{Barriers that Influence Teachers' Conceptual Change with Technology}

The variables that influence teachers' beliefs and intention to use technology are of interest to any discussion that addresses technology integration (Ertmer \& Ottenbreit-Leftwich, 2010). For PETE programs to prepare pre-service teachers to effectively use technology in their teaching, there must first be a discussion of the variables that influence teachers' adoption of technology. Therefore, this section is further divided into the following sub-sections: (a) barriers to teacher change with technology; (b) first-order barriers; and (c) second-order barriers. 


\section{Barriers to Teacher Change with Technology}

Despite the exponential growth of technology in society, research has indicated that education has yet to integrate technology in a meaningful manner in the K-12 setting. Researchers have identified many barriers, including access to technology and support for technology use (Office of Technology Assessment, 1995), while others have explored the impact of beliefs, confidence, and knowledge (Ertmer, 1999; Ertmer \& Ottenbreit-Leftwich, 2010). The emergence of technology in society, however, has increased access to technology in the public schools. In fact, data show that $97 \%$ of teachers have reported a moderate to high degree of access to technology (Gray, Thomas, \& Lewis, 2010). In conjunction with the growth of technology in the K-12 setting, teacher education programs have also developed plans to integrate technology into the curriculum (Kay, 2006). Even with increased access and educational opportunities many teachers still report using technology primarily for low-level tasks such as word processing and internet research (Ertmer \& Ottenbreit-Leftwich, 2010). Many pre-service teachers also report feeling unprepared to integrate technology into their instruction (Gunter, 2001; Liang, Walls, Hicks, Clayton, \& Yang, 2006). Moving all teachers toward more meaningful use of technology requires that the related barriers are addressed during the conceptual change process.

Ertmer (1999) classified barriers as external or internal factors that impact a teacher's ability to integrate an innovative strategy into their teaching. External barriers are those factors that the teacher does not have control over. Typically these barriers are referred to as access to technology equipment, training, and support. Barriers considered internal are directly related to teachers' beliefs about teaching and technology and the desire to bring about change (Ertmer, 1999). Addressing first-order and second-order barriers is necessary to move the field toward 
more meaningful use of technology in the classroom for the purpose of enhancing student learning.

\section{First-Order Barriers}

As described above first-order barriers refer to influential factors that are external to the teacher. When insufficient resources are in place it makes it difficult to successfully integrate technology into the routines of teachers (Means \& Olson, 1997). First-order barriers refer to access to technology and support for technology use (Ertmer, 1999; Ertmer, Addison, Lane, Ross, \& Woods, 2000). Given that these barriers are out of the control of the teacher, there is little that teachers can do to address them. The implication for pre-service teachers is that they must rely on external entities to help address these barriers. In the case of pre-service physical education teachers, they must rely on PETE programs. It would be difficult to integrate technology into the curriculum in a meaningful manner without addressing first-order barriers from a programmatic standpoint.

This is especially true when beginning the process of technology integration. Teachers may become frustrated when they are faced with first-order barriers (Ertmer, 1999). It can be frustrating because teachers are sometimes asked to integrate technology when they perceive there to be a lack of resources in place to help them navigate the process. However, teachers frequently point to first-order barriers as the reason behind their non-use of technology when in reality it is second-order barriers that are the real inhibitors (Ertmer, 1999; Ertmer, Addison, Lane, Ross, \& Woods 2000). Even though addressing second-order barriers may take precedence, the problems first-order barriers create should not be minimized. By addressing first-order barriers it may remove some of the uncertainty teachers feel when they are asked to address technology in their teaching. 
A critical factor that facilitates a teacher education program's integration of technology is access to technology (Strudler $\&$ Wetzel, 1999). This includes access for pre-service teachers and faculty members. Insufficient access to technology for either party limits a program's ability to address technology appropriately. Lisowski, Lisowski, and Nicolia (2007) studied technology integration in teacher education and found that one of the most significant barriers was ensuring that there was adequate technology in place. Similarly, Goktas, Yildirim, and Yildirim (2009) identified lack of technology as one of the main barriers in pre-service education. Koc and Bakir's (2010) study also found that lack of technology equipment was a barrier for pre-service teachers in relation to integrating technology into their teaching. Collectively these studies highlight how important it is for pre-service programs to secure a sufficient amount of technologies to facilitate the integration process.

One factor that must be taken into consideration for PETE programs is the uniqueness of the domain-specific technologies used in physical education. Many of the technologies that physical educators use in their unique instructional context are not found in a typical computer lab. Fiorentino and Castelli (2005) outlined some of the technologies that can be used in the physical education setting. Some of the unique technologies they described for physical educators include: heart rate monitors, accelerometers, pedometers, gaming systems and software, and handheld computers. The implication for PETE programs is the additional monetary support that has to be in place to appropriately prepare pre-service teachers to use technology in physical education. Further exacerbating the potential financial strain on PETE programs is that the International Society for Technology in Education (ISTE) (2008a) cites that consistent and adequate financial support is a necessary condition to facilitate the technology integration process. 
Once technologies are in place it is also recommended that pre-service programs update them on a two to three year basis (Strudler \& Wetzel, 1999). A primary reason that updates are recommended is that technologies are continually evolving, thus creating a need for programs to remain current. For programs to consistently secure the necessary resources, there needs to be a firm commitment from administrators and faculty leaders (ISTE, 2008b; Strudler \& Wetzel, 1999). Once technologies are secured first-order barriers are still not completely overcome because there needs to be measures in place to provide technical support for all parties.

A committed program makes sure that measures are in place to provide faculty and preservice teachers with support to move the technology integration process forward (Strudler \& Wetzel, 1999). Once programs have secured technologies there needs to be systems in place that support the use of these technologies. Silverman (1997) highlighted that a potential impediment for PETE programs is that faculty members need to know how to use the technologies in order to better prepare pre-service teachers. Often decision-makers mistakenly assume that just by purchasing technologies and providing access, faculty use of technology immediately follows (Ertmer, 1999).

However, without providing adequate support for use of technology it may impede the integration process. Strudler and Wetzel's (1999) study of pre-service programs found that exemplary colleges provided support for faculty in the form of group training and one-on-one technical support. Groves and Zemel (2000) discovered that faculty rated technical support as the most important variable that promotes technology integration. The ISTE (2008b) also emphasize the importance of consistent and reliable technical support being in place to ensure successful technology integration in the educational setting. Building on this thought Orr, Williams, and Pennington (2009) found that colleges are being more proactive in providing 
support for faculty, and cited its importance in enhancing the ability to effectively use technology in their teaching. However, Smith and Owens' (2010) study of 1,200 higher education institutions demonstrated that faculty members still perceive they lack the training to integrate technology into their teaching. The researchers also found that teacher education programs are not providing pre-service teachers with enough time to use technology in the classroom and field experiences. The problem is that if faculty members are not confident in their ability to use technology, they may be reluctant to allow their pre-service teachers to apply it as well. So, while schools, colleges, and departments of education are being more proactive, there still are a considerable number of faculty members who do not feel that they have the skills necessary to infuse technology into their teaching. While support for faculty is an ongoing issue, one suggestion that may help correct this is creating a shared culture that promotes technology use.

The ISTE (2008b) recommend that the following conditions be put in place to inform the technology integration process: (a) shared vision among stakeholders, (b) proactive leadership that emphasizes the importance of technology in education, (c) policies that provide incentive for the use of technology, and (d) empowered leaders who aim to be effective at facilitating change. A culture that emphasizes technology has a strong correlation with faculty members' feelings that they are expected to use technology in their teaching (Lin \& Ha, 2009). Through the establishment of policies that encourage use of technology, it is possible to create a supportive and motivational mechanism for pre-service teachers.

The related data suggest that pre-service teachers who attend programs with a strong technology emphasis have a desire to integrate technology into their teaching. Strudler and Wetzel (1999) found that students from exemplary programs had greater intention to integrate 
technology into their teaching. Similarly, Ertmer and Ottenbreit-Leftwich (2010) suggested that pre-service teachers benefit from a program that has a strong emphasis on technology.

A significant factor that contributes to creating a technology culture is the experience preservice teachers have observing the technologies used by faculty members in their classes. Vicarious experience in relation to modeling of technology by faculty members can instill a greater sense of efficacy within pre-service teachers so that they too can use technology without adverse consequences (Bandura, 1977). When pre-service teachers do not see faculty members use technology in their teaching it may result in them being less inclined to integrate it into their own (Zehr, 1997). Therefore, the benefit of faculty members using technology cannot be understated. Faculty members who use technology have the ability to serve as models, support mechanisms, and motivational forces for pre-service teachers.

\section{Second-Order Barriers}

While first-order barriers are viewed as dynamic, second-order barriers are characterized as more static (Ertmer, 1999). Similar to the outcomes of the apprenticeship-of-observation period, second-order barriers are the result of lived experience. A primary product of the apprenticeship-of-observation period is subjective warrant. Research on subjective warrant closely mirrors the characteristics that comprise second-order barriers. Second-order barriers are intrinsic to the teacher and include beliefs about teaching, classroom practices, and resistance to change (Ertmer, 1999). Socialization and second-order barriers both illustrate that pre-service teachers do not enter preparation programs as empty vessels. Instead, pre-service teachers enter with beliefs about teaching, physical education, and other relevant behaviors. The extended exposure pre-service teachers have to the profession prior to entry into a preparation program is 
why some scholars have argued that these intrinsic variables are so difficult to change (Ertmer, 1999; Lortie, 1975; Pajares, 1992).

The resistance to change that characterizes second-order barriers is the primary reason they may be more significant than first-order barriers. As Cuban (1997) highlights the challenge of getting teachers to use technology is not about resources, instead the real challenge is that many teachers do not believe in technology as an instructional tool. For PETE programs to impart meaningful change in pre-service students' perceptions toward technology, it is necessary to consider the practical implications of second-order barriers that pre-service teachers commonly possess.

Pedagogical beliefs. All teachers possess beliefs about their responsibilities, subject matter, and teaching (Pajares, 1992). This is true for pre-service teachers as well. By the time pre-service teachers enter a teacher education program, beliefs about teaching are already well established (Lawson, 1983a; Lortie, 1975). Research on pre-service teacher beliefs has been well-documented (Curtner-Smith, 2001, Lawson, 1983a, 1983b, 1986; Lawson \& Stroot, 1993; Schempp \& Graber, 1992; Templin et al., 1982). Work by these scholars and others highlights the impact years of being a student in the K-12 setting has on pre-service teachers.

Upon entry into a professional preparation program, pre-service teachers experience an environment that is not vastly different than the one they observed as a K-12 student. Pajares (1992) referred to this familiarity as pre-service teachers being insiders. Unlike other fields preservice teachers do not enter an environment that is totally foreign, PETE students have been in gymnasiums and classrooms for many years. The implication for PETE programs is that the beliefs pre-service teachers possess toward education may remain largely unchanged by higher 
education (Pajares, 1992). This research demonstrates that the pre-service years could have low impact on changing students' pedagogical beliefs. The pre-service years may have low impact because pre-existent beliefs tend to persevere even against time, reason, and education (Lortie, 1975; Pajares, 1992).

This limited impact on pre-service teachers' pedagogical beliefs could have significant implications for technology integration in the PETE curriculum. If pre-service teachers enter programs with a negative disposition toward technology's role in education, progress toward the standard established by NASPE might be hampered. Research from general education has revealed that pedagogical beliefs are highly influential on how teachers view technology integration related to their teaching (Dexter, Anderson, \& Becker, 1999; Ertmer et al., 2000; Ertmer \& Ottenbreit-Leftwich, 2010; Hermans, Tondeur, van Braak, \& Valcke 2008). This research again highlights how the prior experiences of teachers can influence the decisions they make.

Research on technology integration has shown that teachers who possess a traditional belief system toward education may not view technology integration favorably (Hermans et al., 2008). The outcomes of this research are quite similar to the field of physical education.

Occupational socialization literature has shown that the role orientation a teacher possesses is a significant influence on their pedagogical beliefs (Curtner-Smith, 2001, 2009; Lawson, 1983a; Schempp \& Graber, 1992). The traditional belief system Hermans et al. (2008) described is similar to that of physical education teachers who possess a custodial, coaching orientation. Both viewpoints indicate that these teachers are comfortable perpetuating the status quo (Lawson, 1983a; Hermans et al. 2008). 
Working to identify the pedagogical beliefs a pre-service teacher possesses may be a critical factor for PETE programs to consider during the technology integration process. Acknowledgement that pre-service teachers already have beliefs about physical education is important. Since beliefs are strong indicators of the decisions that teachers make in the classroom, programs must not ignore this variable in the area of technology integration (Teo, Chai, Hung, \& Lee, 2008). It is necessary to challenge and require pre-service teachers to reflect on the pedagogical beliefs they possess regarding technology's role in education (Ertmer \& Ottenbreit-Leftwich, 2010). If pre-service teachers are not required to reflect on the beliefs that they maintain, it could translate to beliefs remaining unchanged. Furthermore, pre-service teachers need to see how technology can enhance their instructional effectiveness (Ertmer \& Ottenbreit-Leftwich, 2010). Programs must show pre-service teachers the usefulness of technology. Beginning the process of belief revision in the pre-service stage is critical because research has shown that it can take up to five years for teachers to get to a point where they can integrate technology into their teaching in a meaningful way (Ertmer \& Ottenbreit-Leftwich, 2010; Sandholtz, Ringstaff, \& Dwyer, 1997).

Attitude. In addition to beliefs, another construct that has been heavily researched regarding technology use in education is attitude (Christensen et al., 2001; Gibbone, Rukavina, \& Silverman, 2010; Shoffner, 2009). Beliefs are the foundation on which attitudes are built (Pajares, 1992, Dole \& Sinatra, 1998). This means that an attitude consists of an interrelated set of beliefs. In Eagly and Chaiken's (1993) seminal work, they define attitude as “a psychological tendency that is expressed by evaluating a particular entity with some degree of favor or disfavor" (p. 1). This definition is shared by other researchers in that attitude can be placed on a continuum, with a positive attitude on one side and a negative attitude on the other side (Dole \& 
Sinatra, 1998). Eagly and Chaiken $(1993,2007)$ also go onto to discuss three factors that influence attitude: evaluation, attitude object, and tendency. Evaluation is characterized by a person doing just that, evaluating a piece of technology, a teacher, or a curriculum model. Attitude object is the object or entity that elicits the response. For example, a person will hold an attitude toward constructivism, motorcycles, politicians, or sport teams. Attitude objects can be abstract, concrete, an individual, or a group of individuals (Dole \& Sinatra, 1998; Eagly \& Chaiken, 2007). Tendency is the final component of attitude in that people will have a tendency to respond to an attitude object based on prior experience. For example, if a person has experienced trouble with technology previously they will likely have an unfavorable response when they see a piece of technology. However, the attitude object can have the ability to elicit a response in the individual that is implicit or explicit.

A person's attitude may remain implicit especially when a context dictates such a response (Eagly \& Chaiken, 2007). One example of this would be a pre-service teacher that possesses a poor evaluation of technology who may not let their feelings be known around instructors because it is not the socially desirable response. This harboring of an attitude is similar in nature to the studentship behaviors that Graber $(1989,1991)$ found in her study of preservice physical education teachers. Both researchers suggested that an attitude can still endure even if it is not explicit. Eagly and Chaiken's (2007) framework is useful when applied to the evaluations teachers make when integrating technology in their teaching.

Research on technology in education has found that attitude is a key determinant of use (Teo, Lee, \& Chai, 2008; Zhao \& Frank, 2003). Zhao and Frank (2003) stated, "unless a teacher holds a positive attitude toward technology, it is not likely that he or she will use it in their teaching" (p. 809). This claim is substantiated by their study of four school districts that 
contained 19 schools that previously made a significant investment in technology. A critical implication of this study is that if technology did not align with the teachers' pedagogical beliefs then it was unlikely to be integrated into their teaching in a meaningful manner. Teo et al.'s (2008) study of 239 pre-service teachers found that those who possessed positive attitudes toward technology were more likely to view it as a tool that could be usefully integrated into their teaching. Another finding of the study was that a significant contributor to the pre-service teachers' attitude toward technology was their prior experience with it.

Teo (2008) continued this line of research with another study on pre-service teachers. In this study of 139 pre-service teachers the findings were similar to others in that the more positive experience individuals had with technology the more likely they are to possess a positive attitude toward technology (Al-Zaidiyeen, Mei, \& Fook, 2010; Shoffner, 2009). The study also revealed overall that regardless of gender, pre-service teachers possessed a positive attitude toward technology. A recent study in the field of physical education produced similar results. Gibbone et al. (2010) found that despite facing various barriers physical education practitioners maintained a positive attitude toward the potential role technology could play in their teaching. These studies support the notion that students entering pre-service programming may have a positive attitude toward technology due to the increasing prevalence of technology in society (Prensky, 2001; Solomon \& Schrum, 2007).

Prensky (2001) referred to the influx of current pre-service teachers as digital natives. The term digital native implies that these individuals have grown up with technology as an integral component of their lives. Although pre-service teachers have grown up in a culture that embraces technology it does not necessarily mean they envision technology as being an integral component of their teaching or curriculum. Russell, Bebell, O’Dwyer and O'Connor (2003) 
investigated 2,894 teachers' use of technology. One of the interesting findings of this study was that beginning teachers felt comfortable with technology, but they also thought that technology had a negative impact on education.

Similarly, Lei’s (2009) study of 70 pre-service teachers found that they had reservations about technology in education. The pre-service teachers readily admitted that technology was a significant part of their life, but when it came to teaching they still had a preference for traditional approaches to teaching. Another finding showed that students feared that emphasizing technology too much could create problems. Specifically, individuals in this study worried that people were becoming too dependent on technology. Findings from these studies highlight the role implicit attitudes can have on technology use. In these studies, even though the pre-service teachers and beginning teachers liked technology in their personal lives, they had an enduring negative attitude toward the role technology could play in their teaching. The potential implication could be that the prevalence of technology use during their K-12 and professional experience could have been minimal, thus exposing them to more traditional approaches to teaching. This further substantiates the claim that teachers prefer to teach the way they were taught (Lortie, 1975, 2002).

Self-efficacy. Addressing beliefs and attitude is not the only concern because teachers must also have confidence in their ability to use technology. Self-efficacy refers to an individual's belief in their ability to accomplish a specific task (Bandura, 1977). Bandura also described that self-efficacy is a great predictor of behavior. Meaning that if an individual has greater self-efficacy they are more likely to participate in performing a given behavior. Bandura (2004) stated that: 
The stronger the perceived self-efficacy, the higher the goals people set for themselves and the firmer their commitments to them. Self-efficacy beliefs shape the outcomes people expect their efforts to produce. Those of high efficacy expect realize favorable results. Those of low efficacy expect their efforts bring poor outcomes. People of low efficacy are easily convinced of the futility of effort in the face of difficulties. They quickly give up trying (p. 145).

What Bandura's research highlights is how influential self-efficacy is when an individual attempts a task. This could especially be true when teachers are asked to use technology in their instruction. Preparing pre-service teachers to use various technologies must also be considered because self-efficacy is context dependent (Browne, 2009). Meaning a pre-service teacher may have high self-efficacy with a specific technology but that confidence may not necessarily transfer to another technology. However, Perkmen, and Pamuk's (2010) study of 117 preservice teachers identified self-efficacy as a strong predictor of performance regarding general technology use. Results of this study illustrate that there is a positive relationship between a preservice teachers' self-efficacy and their performance with a technology.

If PETE programs must work to enhance pre-service teachers' confidence with various technologies, then programs must identify what technologies need to be addressed. Currently research of this nature has not occurred in PETE. However, recent research by Cennamo, Ross, and Ertmer (2010) recommended identifying technologies that support learning objectives, target student learning, and assists learners in reaching identified goals. In spite of the lack of research regarding the technologies that should be included in PETE programs, considerable research has been performed that highlights the preferred methods to enhance self-efficacy. To date the one 
the most effective strategies to enhance an individual's self-efficacy is personal mastery (Ertmer, Ottenbreit-Leftwich, 2010).

Personal mastery is attained by providing individuals with successful experiences. Bandura (1977) stated, "success raises mastery expectations; repeated failures lower them, particularly if the mishaps occur early in the course of events" (p. 195). Therefore, ensuring that pre-service teachers experience success early in the technology integration process is critical. Vicarious experience is also an important variable that should be addressed during the technology integration process. By seeing others perform the task individuals can persuade themselves to think that if others can do it that they can also experience success (Bandura, 1977). Therefore, effective modeling of technologies to pre-services teachers during the integration process can also increase self-efficacy. A recent study by Abbitt and Klett (2007) investigated the impact four technology courses had on pre-service teachers' self-efficacy for using technology in their teaching. Researchers concluded that effective modeling of technology positively contributed to enhanced self-efficacy among learners. Coupling successful experiences and effective modeling of technology are two tactics programs can use to enhance the self-efficacy of pre-service teachers (Bandura, 1977; Ertmer \& Ottenbreit-Leftwich, 2010).

Knowledge. While beliefs are seen as static, knowledge is more fluid (Pajares, 1992). Pajares goes on to describe that knowledge is fluid by nature, changing with new experiences. For this reason knowledge is a variable PETE programs should address when it comes to technology integration. Knowledge should also be of concern because of the influence it has on teachers' decisions (Borko \& Putnam, 1995). Pierson (2001) stated, “this knowledge would not only include basic technology competency but also an understanding of the unique characteristics of particular types of technologies that would lend themselves to particular 
aspects of the teaching and learning processes" (p. 427). Pierson's research highlighted that teachers must have knowledge of the subject matter, knowledge of technologies, and knowledge how to effectively integrate both of them together.

The knowledge structure Pierson describes that teachers should aspire to reach highlights the need to address two forms of knowledge. Anderson $(1985,2004)$ characterized two forms of knowledge as procedural and declarative. Procedural knowledge is characterized by knowing how things work. For example, pre-service teachers need to know how specific technologies work or how to integrate a given technology into their teaching effectively. Declarative knowledge is characterized by knowing what something is. For example, pre-service teachers must know what a technology is or what makes it work. The implication for PETE programs is that pre-service teachers must have both procedural and declarative knowledge to effectively use technology. Knowing what a technology is without knowledge of how to integrate it effectively into their teaching is not productive. Therefore, as Pierson (2001) described we must build technological knowledge in pre-service teachers. By building procedural and declarative knowledge structures that address technology it will help to create technological knowledge in pre-service teachers.

Creating a technological knowledge base does not ensure that teachers will use technology in a meaningful manner. Zeichner and Tabachnick (1981) indicated that knowledge learned during the preparation period can be washed out. Pajares (1992) also explained this phenomenon when he suggested that knowledge learned is typically not used. What this research tells us is that when teachers are faced with the realities of the job, much of the knowledge previously gained is washed out. Stroot and Whipple (2003) described washout as, "sometimes the reality of the school context does not support the goals and philosophies adopted 
by beginning teacher during the teacher preparation program” (pp 316-317). This can lead to teachers feeling overwhelmed with their situation. Therefore, in order to deal effectively with the environment, teachers revert to practices that allow them to simply survive.

Washout highlights why biography or the apprenticeship-of-observation has been labeled as more influential on a teacher than formal preparation (Lortie, 1975). This is one reason why two teachers with similar knowledge structures teach differently (Pajares, 1992). The individuality that characterizes teaching highlights the influence beliefs, specifically pedagogical beliefs, have on the decisions teachers make. As Ertmer (2005) pointed out ultimately it is up to the teacher in how they use technology in their teaching. The freedom a teacher has in deciding how to use technology highlights the dialectal process that occurs in teaching. Therefore, the impetus is on preparation programs to instill within pre-service teachers a positive perception, enhanced knowledge, and increased confidence toward their ability to use technology meaningfully. Working to promote meaningful use of technology in the classroom setting is paramount. The NASPE (2009) believes that meaningful use of technology will enable a teacher to increase their instructional effectiveness, store student data electronically, and provide opportunities for all students to use technology. In order to prepare pre-service physical education teachers to reach this goal programs must work to address first and second-order barriers that pre-service teachers encounter.

Gender. One additional barrier observed throughout the literature on technology use is gender. In review of the literature on technology integration, Kay (2006) recommended that studies look for potential differences that may exist in gender relative to technology. However, recent research results vary as to whether or not gender played a significant role when it comes to technology. 
Ozden, Aktay, Yilmaz, and Ozdemir's (2007) study of pre-service teachers’ perceptions toward technology investigated whether there was any difference between females and males. The study included 125 pre-service teachers, 71 females and 54 males. It was found that there were no significant differences relative to gender when it came to technology. A recent study by Teo et al. (2008) demonstrated that there were not significant differences related to technology use when it came to gender. In the field of physical education, a recent study by Woods, Goc Karp, Hui, and Perlman (2008), with 75 females and 38 males, also reported that there were no significant differences by gender when it came to technology competency. However, one interesting finding was that male teachers reported feeling more confident in their ability to use technology. The researchers in this study also cited the need for more research of physical education teachers' views of technology relative to gender. In a more recent study by Lambert and Gong (2010), with 50 females and 50 males, researchers found that gender did not influence how the participants interpreted an instructional technology course.

While these studies found that gender is not an influential variable, other researchers have suggested that gender can play a role when it comes to technology. Zhou and Xu (2007) looked at gender differences toward technology in a group of faculty members. Similar to Woods et al. (2008), the females in this investigation were not as confident with technology compared to their male counterparts. Birol, Bekirogullari, Etci, and Dagli's (2009) study of 157 college students also showed that gender differences existed. In this examination of 77 females and 80 males, it was found that males were significantly more confident in their ability to use technology. Another important implication of this study is that the researchers suggested that females require more self-confidence and motivation to use technology. Coklar and Odabasi's (2010) study of 2,566 pre-service teachers, with 1,070 males and 1,496 females, also found gender differences. 
In this sample male teachers reported feeling more competent in using technology, while females felt more confident in their ability to use technology for productivity and professional practices. Findings of this study are important because they indicate that male and female students may feel more comfortable with technologies that are geared to accomplish different tasks. Kay (2007) also reported that female students prefer to use different instructional approaches when it came to technology.

Collectively the results of these studies illustrate that gender may or may not be a significant barrier to teacher change with technology. This is particularly true for the field of physical education. As Woods and colleagues (2008) suggested, researchers need to further examine the role of gender in technology integration in physical education. Better understanding of the potential differences that may exist could prove beneficial to PETE programs seeking to further strengthen the training of practicing teachers relative to technology.

\section{Strategies for Integrating Technology into PETE Curriculum}

Kay (2006) stated "to date there is no consolidated picture on how to effectively introduce technology to pre-service teachers" (p. 385). However, research has been conducted that has identified, implemented, and evaluated strategies that pre-service programs have used (Bahr, Shaha, Farnsworth, Lewis, \& Benson, 2004; Choy, Wong, \& Gao, 2009; Gunter, 2001; Kay, 2006; Supon \& Ruffini, 2009). In fact, Kay (2006) identified ten strategies used to integrate technology into the pre-service curriculum (see Table 2). All of this research took place outside of physical education. Fiorentino and Castelli (2005) did identify a series of technologies for PETE programs to consider when teaching pre-service teachers to use technology in their teaching, but little is known about the effectiveness of various strategies to embed technology-centered learning experiences. 
Table 2

Strategies to Integrate Instructional Technology in Teacher Training

Strategy Key Features

\begin{tabular}{|c|c|}
\hline Integrated & $\begin{array}{l}\text { Weaves technology throughout multiple courses in pre-service } \\
\text { curriculum }\end{array}$ \\
\hline Multimedia & $\begin{array}{l}\text { Various multimedia-based technologies are integrated across pre- } \\
\text { service education (e.g., electronic portfolios, online video, online } \\
\text { courses) }\end{array}$ \\
\hline Education of Faculty & $\begin{array}{l}\text { Teaches faculty how to integrate technology (focused on improving } \\
\text { attitude, ability, and use) }\end{array}$ \\
\hline Single-Course & $\begin{array}{l}\text { A stand-alone technology course over viewing a wide range of } \\
\text { technologies and technology skills (e.g., content, project, or process- } \\
\text { based) }\end{array}$ \\
\hline Modeling & Faculty demonstrate meaningful technology use in classroom \\
\hline Collaboration & $\begin{array}{l}\text { Partnerships between university and public schools to create rich field- } \\
\text { based technology environments }\end{array}$ \\
\hline Field-Based & $\begin{array}{l}\text { Requires pre-service teachers to create and deliver technology-rich } \\
\text { lessons during field experiences }\end{array}$ \\
\hline Workshops & $\begin{array}{l}\text { Short, focused seminars or labs to introduce technologies and } \\
\text { applications }\end{array}$ \\
\hline Access & Provides access to software, hardware and support \\
\hline Mentor teachers & $\begin{array}{l}\text { Places pre-service teachers with teacher to jointly produce meaningful } \\
\text { technology-rich learning experiences }\end{array}$ \\
\hline $\begin{array}{l}\text { Combination of } \\
\text { strategies }\end{array}$ & $\begin{array}{l}\text { Combines two or more approaches to integrate technology into the } \\
\text { curriculum }\end{array}$ \\
\hline
\end{tabular}

Note. Adapted from Kay, R. (2006). Evaluating strategies used to incorporate technology into preservice education: A review of literature. Journal of Research on Technology in Education, 38(4), 383-408 
Recent research in the field of physical education has identified the need for PETE programs to further explore strategies being used to integrate technology into the curriculum (Woods et al., 2008). The ISTE (2008b) recommend that a curriculum framework be in place to support use of technology and digital-age learning experiences. Based on the scope of this study and the needs identified within the literature, this section will be divided into the following subsections: (a) constructivist learning, and (b) recommended strategies to integrate technology in the PETE curriculum.

\section{Constructivist Learning}

Constructivism's role in enhancing the learning experience relative to technology has been reported heavily in the literature (Neo \& Neo, 2009; Jaramillo, 1996). From this viewpoint, learning is constructed based on the learner's prior experience, beliefs, and knowledge (Jaramillo, 1996). Constructivism, like occupational socialization, also emphasizes that learners do not enter the teaching-learning environment as empty vessels (Jaramillo, 1996; Schempp \& Graber, 1992). Both theories, constructivism and occupational socialization, recognize and value that the prior experience of learners is highly influential to the learning experience. Murphy (1997) created a list of conditions that characterize a constructivist learning environment based on a review of the related literature:

1. Multiple perspectives and representations of concepts and content are presented and encouraged.

2. Goals and objectives are derived by the student or in negotiation with the teacher or system.

3. Teachers serve in the role of guides, monitors, tutors, and facilitators. 
4. Activities, opportunities, tools and environments are provided to encourage metacognition, self-analysis regulation, reflection, $\&$ awareness.

5. The student plays a central role in mediating and controlling learning.

6. Learning situations, environments, skills, content, and tasks are relevant, realistic, authentic, and represent the natural complexities of the 'real world'.

7. Primary sources of data are used in order to ensure authenticity and real-world complexity.

8. Knowledge construction and not reproduction is emphasized.

9. This construction takes place in individual contexts social negotiation, collaboration, and experience.

10. The learner's previous knowledge construction, beliefs, and attitudes are considered in the knowledge construction process.

11. Problem-solving, higher-order thinking skills and deep understanding are emphasized.

12. Errors provide the opportunity for insight into students' previous knowledge constructions.

13. Exploration is a favored approach in order to encourage students to seek knowledge independently and to manage the pursuit of their goals.

14. Learners are provided with the opportunity for apprenticeship learning in which there is an increasing complexity of tasks, skills, and knowledge acquisition.

15. Knowledge complexity is reflected in an emphasis on conceptual interrelatedness and interdisciplinary learning.

16. Collaborative and cooperative learning are favored in order to expose the learner to alternative viewpoints 
17. Scaffolding is facilitated to help students perform beyond the limits of their ability.

18. Assessment is authentic and interwoven with teaching (p. 11-13).

Murphy's conditions for constructivist learning environments are consistent with more recent research as well (Koohang, Riley, Smith, \& Schreurs, 2009; Neo \& Neo, 2009; Shaqour, 2005). Another defining characteristic of a constructivist learning environment is that it shifts away from a traditional approach to learning. According to Solomon and Schrum (2007) traditional learning environments are characterized by teacher-centered instruction, passive learning, and factual-based learning, while constructivist-based environments are described as student-centered, collaborative, and promoting critical thinking.

Another defining characteristic of constructivist-based learning environments is that connections are made to the real world (Murphy, 1997). Fueling this connection is what researchers have identified as situated learning (Lave \& Wenger, 1991). Lave and Wenger described situated learning as occurring when the content learned is highly connected to the context in which it is learned. The significance of situated learning to teacher education is the need to structure learning experiences that reflect what the real world will look like. Anderson, Reder, and Simon (1996) referred to this as abstract teaching. The concept of abstract teaching emphasizes that if you teach content to a learner that is not required in their job, it is perceived as being of little use to them.

Another component of a constructivist-based learning environment that is associated with situated learning is collaboration (Lave \& Wenger, 1991; Murphy, 1997). Lave and Wenger (1991) also referred to collaboration as communities of practice. While, the terminology applied to the concept may vary, the rationale behind it remains the same in that it emphasizes 
individuals of equal status working together to enhance their acquisition of knowledge (Anderson et al., 1996). For example, in the context of a PETE program a community of practice would be a classroom of students because they would be considered of equal status. In that context a focus of situated learning would stress the group working together collectively to learn as much as possible about technology integration into physical education.

Creating a constructivist learning environment has also been correlated with technology because it has shown to provide positive results for learners. Vannatta and Beyerbach (2000) conducted a two year study of 122 pre-service teachers. A focus of the study was to create a constructivist vision of technology integration within pre-service teachers. Results of the study showed that pre-service teachers' vision of technology integration improved and was better aligned with a constructivist approach. A constructivist-based learning environment also provides ample time for hands-on learning. In relation to technology, hands-on learning has proven to be an effective tool for promoting positive change. As Ertmer and Ottenbreit-Leftwich (2010) highlighted, it is critical to provide teachers with personal experiences using technology. Positive results from this study further validate the notion that a constructivist-based learning environment better meets the needs of $21^{\text {st }}$ century learners. As Prensky (2001) described, today's learners' needs are not fulfilled by a traditional approach to teaching and learning. According to Solomon and Schrum (2007), the emergence of technology in the $21^{\text {st }}$ century has fueled this need to transform education. Kang, Choi, and Chang (2007) reiterated this perception in its review of the literature on constructivism's role in technology education by asserting that the social needs of $21^{\text {st }}$ century learners require the creation of a constructivist learning environment. 
Creating such an environment is critical to promote constructivist use of technology by pre-service teachers. Teo et al. (2008) found that when the school environment does not align with constructivist-based learning principles it can have a profound influence. Results of this study indicated that the school environment pre-service teachers taught in were not compatible with a constructivist vision, which then lead participants to employ a traditional approach to technology use. In this study a traditional approach to technology use consisted of drill and practice, web searches, and location of factual information, while a constructivist vision was described as using technology for collaboration, student presentations, and modeling of technology. Koohang et al. (2009) offered suggestions for creating a constructivist learning environment by providing specific examples. Some of the suggestions the researchers offered included: self-reflection, scaffolding, interdisciplinary learning, and authentic assessment.

When a constructivist-based learning environment is developed to facilitate the teaching of technology it has shown to produce positive results in pre-service teachers. Molebash (2002) created a constructivist-based learning environment with an emphasis on technology integration in an elementary methods course. Results showed that the constructivist environment enabled the researcher to effectively demonstrate how pre-service teachers could use technology, which then enabled the pre-service teachers to construct their own knowledge. Neo and Neo's (2009) study provided further evidence of the benefits of a constructivist learning environment with technology integration. A unique element of this study was that the results of the constructivist environment were voiced from the pre-service teachers' viewpoint. Participants in this study voiced that the constructivist learning environment instilled a high sense of motivation, increased understanding of the topic, understanding of the utility of teamwork, and it enhanced success. 
The importance of constructivism to the learning process should not be understated. As Solomon and Schrum (2007) voice their feeling on the value of constructivism, "rather than providing didactic instruction and expecting students to repeat facts on a test, teachers encourage students to think about what they already know about a topic, search for new information, and collaborate with others to solve realistic problems and derive new understanding” (p. 38). The utility of constructivism to the PETE curriculum is of importance too. The impact pre-service physical education teachers' robust beliefs can have on the learning process during the professional period provides a rationale for a new approach to instruction (Lawson, 1983a; 1983b; Schempp \& Graber, 1992). Similarly, the research that has been conducted on technology education demonstrates that beliefs form barriers to the technology integration process (Ertmer, 1999; Ertmer \& Ottenbreit-Leftwich, 2010). Recognition of and value of prior beliefs is also at the core of constructivism (Murphy, 1997). Therefore, adoption and implementation of a constructivist-based learning environment within a PETE curriculum enables teacher educators to have pre-service teachers critically reflect on prior beliefs throughout the learning process.

\section{Strategy to Integrate Technology into PETE Curriculum}

Creating a constructivist-based learning environment is the pedagogically sound approach recommended for technology integration (Teo et al., 2008; Vannatta \& Beyerbach, 2000). The next step for programs is to implement constructivist principles within a strategy that can be integrated into the curriculum. Kay (2006) identified ten common strategies that preservice programs have used to teach technology to pre-service teachers. The most common strategy was for programs to incorporate technology in all courses across the curriculum. This strategy was referred as an integrated approach. The integrated approach to technology is highly 
recommended by national entities (National Council for Accreditation of Teacher Education [NCATE], 2003) and is praised for the positive results it has shown regarding increased student confidence with technology, improved technology skills, and development of meaningful learning experiences for pre-service teachers (Pope, Hare, \& Howard, 2002; Vannatta \& Beyerbach, 2000). While the integrated approach has proven to be an effective strategy it is not the only one programs can adopt to address technology integration.

A single-course is precisely what the name suggests, a standalone course that aims to prepare pre-service teachers to use technology in their teaching. Hargrave and Hsu (2000) identified the single-course as a common approach for pre-service programs to use for addressing technology. Pre-service programs have approached the single-course in different ways. Kay (2006) highlighted how programs have made the single-course content-based, project-based, or process-based. In a content-based course there is a considerable focus on enhancing pre-service teacher's knowledge of relevant technologies. A project-based approach involves a constructivist learning environment (McRobbie, Ginns, \& Stein, 2000). A processbased approach engages pre-service teachers in the process of integrating technology effectively into their teaching. Each design has shown to produce positive results for pre-service teachers. Primary benefits of utilizing a single-based course for technology are to (a) enhance self-efficacy (Gunter, 2001), (b) provide pre-service teachers with a good foundation on how to use technology in their teaching (McRobbie et al., 2000; Rochanasmita, Padilla, \& Tunhikorn, 2009), and (c) increase the technology skills of pre-service teachers (Strudler and Wetzel, 1999).

The single-course strategy has also demonstrated the ability to enhance pre-service teachers' confidence in their ability to use technology. Milman and Molebash (2008) conducted a longitudinal study of 99 teachers, 5-7 years after they attended an instructional technology 
course while they were pre-service teachers. Results of the study showed that participants still had a higher confidence level in their ability to use technology than before they entered the course. Hammond and colleagues (2009) also performed a follow-up study on 40 first year teachers who attributed their use of technology to the learning experiences they received as preservice teachers. Findings indicated that the single-course instilled a level of confidence within the beginning teachers that they could effectively use technology in their teaching. The outcomes of this study help to confirm what similar research endeavors have discovered, a single-course is an effective means for enhancing pre-service teachers' self-efficacy toward technology (Lambert \& Gong, 2010; Wang, Ertmer, \& Newby, 2004a, 2004b).

Another recommended instructional approach to be infused within a single-course is the use of a sound conceptual framework that informs course design and implementation. An example of such a framework is the Technological Pedagogical Content Knowledge (TPACK) model (Mishra \& Koehler, 2006). The TPACK framework is an extension of Shulman's (1986) discussion of pedagogical content knowledge (PCK) by introducing technological knowledge (TK) as a new independent, yet interacting construct within the model (see Figure 2). There are three knowledge constructs represented in the TPACK model, these include:(1) content knowledge (CK) which is knowledge of subject matter,; (2) pedagogical knowledge (PK) that is knowledge of the methods of teaching; and (3)technological knowledge (TK) which involves knowledge of available technologies and knowing how to operate specific technologies. The independent natures of these constructs represent a solid base of teacher knowledge; while the interactions among the constructs reflect a teacher's ability to design meaningful experiences in aim of student learning. In 1986 Shulman postulated that the interactions among CK and PK, or more commonly referred to as PCK, allowed teachers to blend content and pedagogy to build 
meaningful and accessible learning experiences for students. The interaction new addition of TK to this model produces additional interactions and implications for the teaching and learning environment (Mishra \& Koehler, 2006). For example, when TK and PK intersect, it is referred to as technological pedagogical knowledge (TPK) and is described as the knowledge of existent technologies and their functions, coupled with an understanding of how one's teaching and instruction will change as a result of using a particular technology. The interaction between TK and CK, or technological content knowledge (TCK), is the knowledge of technology and how its application in a classroom setting will change the subject matter being introduced. Lastly, the model offers that at the intersection of all three knowledge constructs exists TPACK, which embodies an understanding and negotiation of the dynamic interactions among content, pedagogical, and technological knowledge that can result in true technology integration. Collectively the parts of the TPACK framework emphasize the types of knowledge that teachers need to integrate technology and the complex interplay of the knowledge forms that is needed for meaningful technology integration.

Researchers have conducted studies using the TPACK framework and found success in producing positive outcomes among pre-service teachers. Özgün-Koca, Meagher, and Edwards (2010) conducted a study of 20 pre-service teachers regarding the impact a methods course, with a focus on technology integration, had on changing perceptions about technology's role in mathematics. Results of the study indicated that enhancing pre-service teachers' TK, CK, and TPACK yielded positive results. Specifically, the development of TPACK within the pre-service teachers transformed how they viewed technology's role in their curriculum. Pre-service teachers went from viewing technology as a tool that could assist learning to thinking about technology as a tool that could enhance learning. 


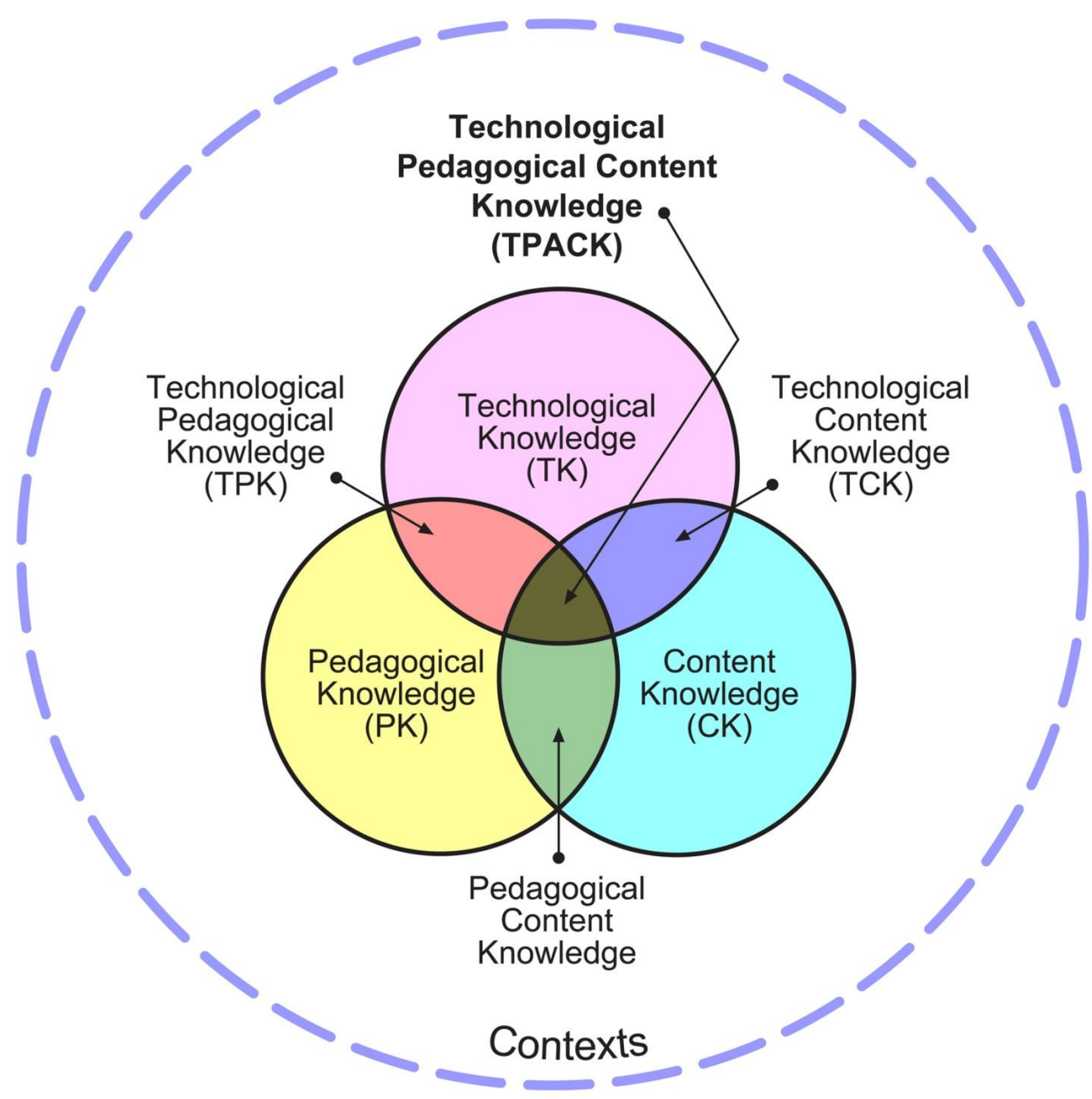

Figure 2. Mishra and Koehler's TPACK Framework and its Knowledge Components.

Retrieved from http://tpack.org/ on June 19, 2012

Building on this study, Chai, Koh, and Tsai (2010) researched the impact a single-course had on increasing a group of pre-service teachers' TPACK. The study looked at a group of 889 pre-service teachers. They found that the course had a positive impact on increasing pre-service 
teachers' perception of their ability to effectively integrate technology into their teaching. Findings from this study highlighted the benefits of single-courses focusing not only learning the technology, but how to effectively integrate technology into teaching. The study also stressed the importance of ensuring that pre-service teachers' CK and PCK are in place before introducing TCK. Meaning once pre-service teachers have a foundational knowledge base it is much easier to teach them how they can apply technology into their teaching. Findings from these studies support what other researchers have found, that TPACK is a useful framework to apply when preparing pre-service teachers to integrate technology (Allan, Erickson, Brookhouse, \& Johnson, 2010; Graham, Burgoyne, Cantrell, Smith, St. Clair, \& Harris, 2009; Jang \& Chen, 2010).

Research on single-based courses has also identified potential limitations of this strategy. Smith and Owens (2010) found that the pre-service teachers may still have reservations about technology's role in the curriculum after attending a single-course. However, the primary concern with programs using the single-based course is the lack of extension in the field that preservice teachers are afforded (Gunter, 2001). The lack of extension in the field, using the technologies with children in the schools, could lead to pre-service teachers learning the technologies in isolation. For this reason Kay (2006) recommended that programs rely on more than one strategy to prepare pre-service teachers to integrate technology into their teaching.

\section{Summary of Literature Review}

To date there is no consolidated picture of what is the most effective way to prepare preservice teachers to use technology (Kay, 2006). This is particularly relevant in physical education because the need to train pre-service teachers to use technology was recently mandated (NASPE, 2008). Therefore, at this point-in-time it is necessary to analyze how the best practices 
in general education transfer to the PETE context (see Table 2). Particularly since the literature base from general education recognizes the influence prior experience, beliefs, and other intrinsic variables has on the technology integration process.

The attention to intrinsic variables is great because they are inextricably linked to the decisions a teacher actually makes in the classroom (Ertmer, 1999; Lortie, 1975, 2002; Pajares, 1992). Research on the beliefs of physical education teachers has told us that many individuals possess less than ideal warrants toward the profession (Curtner-Smith, 2009; Lawson, 1983a; Schempp \& Graber, 1992). The primary culprit that leads to these faulty conceptions is the negative socialization forces during the apprenticeship years and induction (Curtner-Smith, 2009; Lawson, 1983a). The end product of negative socialization is that it creates a filter that all new information must pass through.

The filter that is created by pre-service teachers and teachers relative to technology integration is similar to what is described in the occupational socialization literature. Based on the socialization processes individuals experience they possess different beliefs, confidence, knowledge, and attitudes toward technology integration in physical education. The literature from technology integration into the general education setting confirms this notion (Ertmer, 1999). The literature on the socialization of physical education teachers, conceptual change, and barriers to technology integration all highlight how impactful prior experience is to the learning process (Ertmer, 1999, 2005; Lortie, 1975, 2002; Posner et al., 1982).

Research on learning, socialization and technology tell us that the background characteristics an individual brings with them to the learning environment has the potential to influence the change process (Coklar \& Odabasi, 2010; Curtner-Smith, 2009; Lawson, 1983a). 
Therefore, a primary focus of this investigation will be to explore how research-driven and best practices relative to technology integration from general pre-service education programs transfer to PETE programs. Specifically, can an instructional technology course facilitate conceptual change in pre-service physical education teachers? What concerns do pre-service teachers have relative to technology? What stage of adoption of technology are PETE students? 


\section{References}

Abbitt, J. T., \& Klett, M. D. (2007). Identifying influences on attitudes and self-efficacy beliefs towards technology integration among pre-service educators. Electronic Journal for the Integration of Technology into Education, 6, 28-42.

Allan, W., Erickson, J., Brookhouse, P., \& Johnson, J. (2010). Teaching professional development through a colloaborative curriculum project: An example of TPACK in Maine. Tech Trends: Linking Research and Practice to Improve Learning, 54(6), 36-43.

Al-Zaidiyeen, N. J., Mei, L. L., \& Fook, F. S. (2010). Teachers' attitudes and levels of technology use in classrooms: The case of Jordan schools. International Education Studies, 3(2), 211-218.

Anderson, J. (1985). Cognitive psychology and its implications. San Franciso: Freeman. Anderson, J. (2004). Cogntiive psychology and its implications (6th ed.). New York: Worth.

Anderson, J., Reder, L., \& Simon, H. (1996). Situated learning and education. Educational Researcher, 25(4), 5-11.

Armour, K., Makopoulou, K., \& Chambers, F. (2009). The learning teacher in physical education. In Housner, L. D., Metzler, M. W., Schempp, P. G., \& Templin, T. J. (Eds.), Historic traditions and future directions of research on teaching and teacher education in physical education (pp. 213-220).

Attard, K., \& Armour, K. (2005). Learning to become a learning professional: Reflections on one year of teaching. European Journal of Teacher Education, 28(2), 195-207. 
Bahr, D. L., Shaha, S. H., Farnsworth, B. J., Lewis, V. K., \& Benson, L. F. (2004).

Preparingtomorrow's teachers to use technology: Attitudinal impacts of technologysupported field experiences on pre-service teacher candidates. Journal of Instructional Psychology, 31(2), 88-97.

Bandura, A. (1977). Self-efficacy: Toward a unifying theory of behavioral change. Psychological Review, 84(2), 191-215.

Bandura, A. (2004). Health promotion by social cognitive means. Health Education \& Behavior, 31(2), 143-164.

Birol, C., Bekirogullari, Z., Etci, C., \& Dagli, G. (2009). Gender and computer anxiety, motivation, self-confidence, and computer use. Eurasian Journal of Educational Research (EJER), (34), 185-198.

Borko, H., \& Putnam, R. T. (1995). Expanding a teachers knowledge base: A cognitive psychological perspective on professional development. In T. R. Guskey \& M. Huberman (Eds.), Professional development in education: New paradigms \& practices (pp. 35-66). NY: Teachers College, Columbia University

Browne, J. (2009). Assessing pre-service teacher attitudes and skills with the technology integration confidence scale. Computers in the Schools, 26(1), 4-20.

Cennamo, K. S., Ross, J., \& Ertmer, P. A. (2010). Technology integration for meaningful classroom use: A standards-based approach. Belmont, CA: Wadsworth.

Chai, C., Koh, J., \& Tsai, C. (2010). Facilitating pre-service teachers development of technological, pedagogical, and content knowledge. Educational Technology \& Society, $13(4), 63-73$. 
Choy, D., Wong, A. F., \& Gao, P. (2009). Student Teachers' Intentions and Actions on Integrating Technology into Their Classrooms during Student Teaching: A Singapore Study. Journal of Research on Technology in Education, 42(2), 175-195.

Chu, D. (1984). Teacher/coach orientation and role socialization: A description and explanation. Journal of Teaching in Physical Education, 3(2), 3-8.

Christensen, R., Griffin, D., \& Knezek, G. (2001). Measures of Teacher Stages of Tech Integration and Their Correlates with Student Achievement. Paper presented at the Annual Meeting of the American Association of Colleges for Teacher Education, Dallas, TX.

Coklar, A., \& Odabasi, H. (2010). Are teacher candidates able to use educational technologies effectively? A case study in terms of standards. International Journal of Human Sciences, $7(2), 1-16$.

Crum, B. J. (1993). Conventional thought and practice in physical education: problems of teaching and implications for change. Quest, 45(3), 339-356.

Cuban, L. (1997). High-tech schools and low-tech teaching. Education Week on the Web. Retrieved March 13, 2011 from http://www.edweek.org/ew/articles/1997/05/21/34cuban.h16.html

Curtner-Smith, M. D. (1996). The impact of early field experiences on preservice physical education teachers' conceptions on teaching. Journal of Teaching in Physical Education, $45,224-250$.

Curtner-Smith, M. D. (2001). The occupational socialization of a first-year physical education teacher with a teaching orientation. Sport, Education, and Society, 6(1), 81-105. 
Curtner-Smith, M. D. (2009). Breaking the cycle of non-teaching physical education teachers: Lessons to be learned from occupational socialization literature. In Housner, L. D., Metzler, M. W., Schempp, P. G., \& Templin, T. J. (Eds.), Historic traditions and future directions of research on teaching and teacher education in physical education (pp. 221226). Morgantown, WV: Fitness Information Technology.

Curtner-Smith, M. D., Hastie, P. A., \& Kinchin, G. D. (2008). Influence of occipational socialization on beginning teachers' Interpretation and delivery of sport education. Sport, Education and Society, 13 (1), 97-117.

Dewar, A. L. (1989). Recruitment in physical education teaching: Toward a critical approach. In Templin, T. J., \& Schempp, P. G. (Eds.), Socialization into Physical Education: Learning to Teach (pp. 39-57). Indianapolis, IN: Benchmark Press, Inc.

Dewar, A. L., \& Lawson, H. A. (1984). The subjective warrant and recruitment into physical education. Quest, 36, 15-25.

Dexter, S. L., Anderson, R. E., \& Becker, H. (1999). Teachers' views of computers as catalysts for changes in their teaching practice. Journal Of Research On Computing In Education, 31(3), 221.

Dodds, P. (1989). Trainees, field experiences, and socialization into teaching. In Templin, T. J., \& Schempp, P. G. (Eds.), Socialization into physical education: Learning to teach (pp. 81-104). Indianapolis, IN: Benchmark Press, Inc.

Dole, J. A., \& Sinatra, G. M. (1998). Reconceptualizing change in the cognitive construction of knowledge. Educational Psychologist, 33(2/3), 109-128. 
Doolittle, S. A., Placek, J. H., \& Dodds, P. (1993). Persistence of beliefs about teaching during formal training of Preservice Teachers. Journal of Teaching in Physical Education, $12(4), 355-365$.

Donovan, L., \& Green, T. (2010). One-to-one computing in teacher education: Faculty concerns and implication for teacher educators. Journal of Digital Learning in Teacher Education, 26(4), 140-148.

Donovan, L., Hartley, K., \& Strudler, N. (2007). Teacher concerns during initial implementation of a one-on-one laptop initiative at the middle school level. Journal of Research in Technology Education, 39(3), 263-286.

Eagly, A. H., \& Chaiken, S. (1993). The psychology of attitudes. Fort Worth, TX: Harcourt, Brace, Jovanovich,

Eagly, A. H., \& Chaiken, S. (2007). The advantages of an inclusive definition of attitude. Social Cognition, 25(5). 582-602.

Edgar, D., \& Warren, R. (1969). Power and autonomy in teacher socialization. Sociology of Education, 42(4), 386-399.

Ennis, C. D. (2007). 2006 C.H. McCloy Research Lecture: Defining Learning as Conceptual Change in Physical Education and Physical Activity Settings. Research Quarterly for Exercise \& Sport, 78(3), 138-150.

Ertmer, P. A. (1999). Addressing first and second-order barriers to change: Strategies for technology integration. Educational Technology Research and Development, 47(4), 4761.

Ertmer, P. A. (2005). Teacher pedagogical beliefs: The final frontier in our quest for technology integration? Educational Technology Research \& Development, 53(4). 25-39. 
Ertmer, P. A., Addison, P., Lane, M., Ross, E., \& Woods, D. (2000). Examining teachers' beliefs about the role of technology in the elementary classroom. Journal of Research on Computing in Education, 32(1), 54-71.

Ertmer, P. A., \& Ottenbreit-Leftwich, A. (2010). Teacher technology change: How knowledge, confidence, beliefs, and culture intersect. Journal of Research on Technology in Education, 42(3), 255-284.

Figone, A. (1994). Teacher-coach role conflict: Its impact on student and athletes. Physical Educator, 51(1), 29-34.

Fiorentino, L. H., \& Castelli, D. (2005). Creating a virtual gymnasium. Journal of Physical Education Recreation and Dance JOPERD, 76(4), 16-18.

Freibus, R. J. (1977). Agents of socialization involved in student teaching. Journal of Educational Research, 70, 263-268.

Fuller, A., \& Unwin, L. (2009). Change and continuity in apprenticeship: The resilience of a model of learning. Journal of Education and Work, 22(5), 405-416.

Gibbone, A., Rukavina, P., \& Silverman, S. (2010). Technology Integration in Secondary Physical Education: Teachers' Attitudes and Practice. Journal of Educational Technology Development \& Exchange, 3(1), 27-42.

Goktas, Y., Yildirim, S., \& Yildirim, Z. (2009). Main barriers and possible enablers of ict's integration and pre-service teacher education programs. Educational Technology \& Society, 12(1), 193-204.

Graber, K. C. (1989). Teaching tomorrow's teachers: Professional preparation as an agent of socialization. In Templin, T. J., \& Schempp, P. G. (Eds.), Socialization into physical education: Learning to teach (pp. 59-78). Indianapolis, IN: Benchmark Press, Inc. 
Graber, K. C. (1991). Studentship in preservice teacher education: A qualitative study of undergraduates in physical education. Research Quarterly for Exercise and Sport, 62(1), $41-51$.

Graham, C., Burgoyne, N., Cantrell, P., Smith, L., St. Clair, L., \& Harris, R. (2009).

Diagramming tpack in practice: Using an elaborated model of tpack framework to analyze and depict teacher knowledge. Tech Trends: Linking Research and Practice to Improve Learning, 53(5), 70-79.

Gray, L., Thomas, N., \& Lewis, L. (2010). Teachers' Use of Educational Technology in U.S. Public Schools: (NCES 2010-040). National Center for Education Statistics, Institute of Education Sciences, U.S. Department of Education, Washington, D.C.

Griffin, G. A. (1989). A descriptive study on student teaching. The Elementary School Journal, (89), 343-364.

Groves, M., \& Zemel, P. (2000). Instructional technology adoption in higher education. International Journal of Instructional Media, 27 (1), 57-65.

Gunter, G. A. (2001). Making a difference: Using emerging technologies and teaching strategies to restructure an undergraduate technology course for pre-service teachers. Educational Media International, 38(1), 13-20.

Hall, G. E., George, A. A., \& Rutherford, W. L. (1979). Measuring stages of concern about the innovation: A manual for the use of the SOC questionnaire. Austin, TX: The University of Texas at Austin. The Research and Development Center for Teacher Education.

Hammond, M., Fragkouli, E., Suandi, I., Crosson, S., Ingram, J., Johnston-Wilder, P., Kingston, Y., Pope, M., \& Wray, D. (2009). What happens as student teachers who made very good use of ICT during pre-service teacher training enter their first year of training? Teacher Development, 13(2), 93-106. 
Hargrave, C. P., \& Hsu, Y. (2000). Survey of instructional technology courses for preservice teachers. Journal Of Technology And Teacher Education, 8(4), 303-14.

Hermans, R., Tondeur, J., van Braak, J., \& Valcke, M. (2008). The impact of primary school teachers' educational beliefs on the classroom use of computers. Computers and Education, 51, 1499-1509.

Horton, L., \& Harvey, K. (1979). Preparing cooperating teachers: The role of the unversity supervisor. Peabody Journal of Education, 57, 56-60.

Hutchinson, G. E. (1993). Prospective teachers' perspectives on teaching physical education: An interview study on the recruitment phase of teacher socialization. Journal of Teaching in Physical Education, 12, 344-354.

International Society for Technology in Education [ISTE]. (2008a). The ISTE national educational standards (NETS-T) and performance indicators for teachers. Eugene, OR: Author. Retrieved March 13, 2011 from http://www.iste.org/standards/nets-for-teachers.aspx

International Society for Technology in Education [ISTE]. (2008b). Essential conditions: Necessary conditions to effectively leverage technology for education. Eugene, OR: Author Retrieved March 13, 2011 from http://www.iste.org/Libraries/PDFs/Essential_Conditions_2007_EN.sflb.ashx

Jackson, P. (1968). Life in Classrooms. New York, NY: Harper and Row.

Jaramillo, J. A. (1996). Vygotsky's sociocultural theory and contributions to the development of constructivist curricula. Education, 117(1), 133-140.

Jang, S., \& Chen, K. (2010). From pck to tpck: Developing a transformative model for preservice science teachers. Journal of Science Education and Technology, 19 (6), 553-564. 
Kang, I., Choi, J.I., \& Chang, K. (2007). Constructivist research in educational technology: A retrospective view and future prospects. Asia Pacific Education Review, 8 (3), 397-412.

Kay, R. H. (2006). Evaluating strategies used to incorporate technology into preservice education: A review of the literature. Journal of Research on Technology in Education, 38(4), 384-406.

Kay, R. (2007). A formative analysis of how preserivce teachers learn to use technology. Journal of Computer Assisted Learning, 23, 366-383.

Koc, M., \& Bakir, N. (2010). A Needs Assessment Survey to Investigate Pre-Service Teachers' Knowledge, Experiences and Perceptions about Preparation to Using Educational Technologies. The Turkish Online Journal of Educational Technology, 9 (1), 13-22.

Koohang, A., Riley, L., Smith, T., \& Schreurs, J. (2009). E-learning and constructivism: From theory to application. Interdisciplinary Journal of E-learning and Learning Objectives, 5, 91-109.

Lambert, J., \& Gong, Y. (2010). 21st century paradigms for pre-service teacher technology preparation. Computers in the Schools, 27, 54-70.

Lave, J., \& Wenger, E. (1991). Situated Learning: Legitimate peripheral participation. Cambridge: Cambridge University Press.

Lawson, H. A. (1983a). Toward a model of teacher socialization in physical education: The Subjective warrant, recruitment, and teacher education. Journal of Teaching in Physical Education, 2(3), 3-16.

Lawson, H.A. (1983b). Toward a model of teacher socialization in physical education: Entry into schools, teachers' role orientations, and longevity in teaching. Journal of Teaching in Physical Education, 3(1), 3-15. 
Lawon, H. A. (1986). Occupational socialization and the design of teacher education programs. Journal of Teaching in Physical Education, 5, 107-116.

Lei, J. (2009). Digital natives as preservice teachers: What technology preparation is needed? Journal of Computing in Teacher Education, 25(3), 87-97.

Liang, G., Walls, R. T., Hicks, V. L., Clayton, L. B., \& Yang, L. (2006). Will tomorrow’s physical educators be prepared to teach in the digital age? Contemporary Issues in Technology and Teacher Education, 6(1), 143-156.

Lin, C., \& Ha, L. (2009). Subcultures and use of communication information technology in higher education institutions. The Journal of Higher Education, 80(5), 564-590.

Lisowski, L. R., Lisowski, J. R., \& Nicolia, S. (2007). Infusing technology into teacher education: Doing more with less. Computer in the Schools, 23(3), 71-92.

Lortie, D. C. (1975). School-teacher: A sociological study. Chicago, IL: The Univerity of Chicago Press.

Lortie, D. C. (2002). School-teacher: A sociological study ( $2^{\text {nd }}$ ed.). Chicago, IL: The University of Chicago Press.

Matanin, M., \& Collier, C. (2003). Longitudinal analysis of preservice teachers' beliefs about teaching physical education. Journal of Teaching in Physical Education, 22, 153-168.

McRobbie, C. J., Ginns, I. A., \& Stein, S. J. (2000). Preservice teachers' thinking about technology and technology education. International Journal of Technology and Design Education, 10, 81-101.

Means, B., \& Olson, K. (1997). Technology and education reform: Studies of education reform. Washington, DC: U.S Government Printing Office. 
Milman, N. B. \& Molebash, P. E. (2008). A longitudinal assessment of teacher education students' confidence towards using technology. Journal of Educational Computing Research, 38(2), 183-200.

Millslagle, D., \& Morley, L. (2004). Investigation of role retreatism in the teacher/coach. Physical Educator , 61(3), 120-130.

Mishra, P., \& Koehler, M. J. (2006). Technological pedagogical content knowledge: A framework for teacher knowledge. Teachers College Record, 108(6), 1017-1054.

Mohr, D. J. (2000). Qualitative analysis of the socialization factors experienced by induction phase of physical education teachers from one university (Unpublished Doctoral Dissertation). West Virginia University, Morgantown, WV.

Molebash, P. E. (2002). Constructivism meets technology integration: The CUFA technology Guidelines in an elementary social studies methods course. Theory and Research in Social Education, 30(3), 429-455.

Murphy, E. (1997). Constructivism: From theory to practice. Retrived January 22, 2011 from http://www.vccaedu.org/inquiry/inquiry-spring-2007/i-12-Carwile.html

National Association for Sport in Physical Education (2008). National initial physical education teacher education standards. Retrieved March 12, 2011 from http://www.aahperd.org/naspe/grants/accreditation/upload/2008-National-Initial-PETE$\underline{\text { Standards.pdf }}$

National Association for Sport in Physical Education. (2009). Appropriate use of instructional technology in physical education [Postion Statement]. Reston, VA: Author 
National Council for Accreditation of Teacher Education (2003). International Technology Education Association/Council on Technology Teacher Education (ITEA/CTTE). Retrieved March 12, 2001 from http://www.ncate.org/standard/programstds.htm

National Council for Accreditation of Teacher Education (2008). Professional standards for the accreditation of schools, colleges, and departments of education. Retrieved March 12, 2011, from http://www.ncate.org/LinkClick.aspx?fileticket=P2KEH2wR4Xs\%3d\&tabid=107

Neo, M., \& Neo, T. K. (2009). Engaging students in multimedia-mediated Constructivist learning-Students' perceptions. Educational Technology \& Society, 12(2), 254-266.

Office of Technology Assessment. (1995). Teachers and technology: Making the connection (OTA-EHR-616). Washingtion, DC: Government Printing Office.

Orr, R., Williams, M. R., \& Pennington, K. (2009). Institutional efforts to support faculty in online teaching. Innovative Higher Education, 34, 257-268. Retrieved March 7, 2012, from DOI: $10.1007 / \mathrm{s} 10755-009-9111-6$

O'Sullivan, M. (1989). Failing gym is like failing lunch or recess: Two beginning teachers' struggle for legitmacy. Journal of Teaching in Physical Education, 8(3), 227-242.

O'Sullivan, M. (1996). What do we know about the professional preparation of teachers? In Silverman, S., \& Ennis, C. (Eds.), Student Learning in Physical Education: Applying Research to Enhance Instruction (pp. 315-338).

Overbaugh, R., \& Lu, R. (2008). The impact of a federally funded grant on a professional development program: Teachers' stages of concern toward technology integration. Journal of Computing in Teacher Education, 25(2), 45-55. 
Ozden, M., Aktay, S., Yilmaz, F., \& Ozdemir, D. (2007). The relation between pre-service teachers' computer self-efficacy believes and attitudes towards technology use. The International Journal of Learning, 14(6), 53-60.

Özgün-Koca, S., Meagher, M., \& Edwards, M. (2010). Preservice Teachers' Emerging TPACK in a Technology-Rich Methods Class. Mathematics Educator, 19(2), 10-20.

Pajares, M. (1992). Teachers' beliefs and educational research: Cleaning up a messy construct. Review of Educational Research, 62(3), 307-332.

Perkmen, S., \& Pamuk, S. (2010). Social cognitive theory predictors of pre-service teachers' technology integration performance. Asia Pacific Educational Review .

Piaget, J. (1985). The equilibrium of cognitive structures: The central problem of intellectual development. Chicago, IL: The University of Chicago Press.

Pierson, M. (2001). Technology integration practice as a function of pedagogical expertise. Journal of Research on Computing in Education, 33, 413-429.

Pope, M., Hare, D., \& Howard, E. (2002). Technology integration: Closing the gap between what preservice teachers are taught to do and what they can do. Journal of Technology And Teacher Education, 10(2), 191-203.

Posner, G. J., Strike, K. A., Hewson, P. W., \& Gertzog, W. A. (1982). Accommodation of a scientific conception: Toward a theory of conceptual change. Science Education, 66(2), 211-227.

Prensky, M. (2001). Digital natives, digital immigrants. On the Horizon, 9(5), 1-6.

Rakes, G. C., \& Casey, H. B. (2002). An Analysis of Teacher Concerns toward Instructional Technology. International Journal of Educational Technology, 3(1), Retrieved March 14, 2011 from http://www.ed.uiuc.edu.www.libproxy.wvu.edu/ijet/v3n1/v3n1articles.html 
Rochanasmita, A., Padilla, M. J., \& Tunhikorn, B. (2009). The development of pre-service science teachers' professional knowledge in utilizing ict to support professional lives. Eurasia Journal of Mathematics, Science \& Technology, 5(2), 91-101.

Rogers, E. (1983). Diffusion of Innovations (3rd ed.). New York, NY: The Free Press.

Russell, A. L. (1995). Stages in learning new technology: Naive adult email users. Computers in Education, 25(4), 173-178.

Russell, M., Bebell, D., O'Dwyer, L., \& O'Connor, K. (2003). Examining teacher use of technology: Implications for preservice and inservice teacher preparation. Journal of Teacher Education, 54(4), 297-310.

Ryan, T. (2008). Antecedents for interrole conflict in the high school teacher/coach. Physical Educator, 65(2), 58-67.

Sandholtz, J. H., Ringstaff, C., \& Dwyer, D. C. (1997). Teaching with technology: Creating student-centered classrooms. New York: Teachers College Press.

Schempp, P. G. (1989). Apprenticeship-of-observation and the development of physical education teachers. In Templin, T. J., \& Schempp, P. G. (Eds.), Socialization into Physical Education: Learning to Teach (pp. 39-57). Indianapolis, IN: Benchmark Press, Inc.

Schempp, P. G., \& Graber, K. C. (1992). Teacher socializatoin from a dialectal perspective: Pretraining through induction. Journal of Teaching in Physical Education, 11, 329-348.

Scribner, J., \& Akiba, M. (2010). Exploring the relationship between prior career experience and instructional quality among mathematics and science teachers in alternative teacher certification programs. Educational Policy. 24(4), 602-627. 
Shaqour, A. H. (2005). A model for integrating new technologies into pre-service teacher training programs Ajman University (a case study). Turkish Online Journal Of Educational Technology, 4(3), 18-24.

Shoffner, M. (2009). Personal attitudes and technology: Implications for preservice teacher reflective practice. Teacher Education Quarterly, 36(2), 143-161.

Shulman, L. S. (1986). Those who understand: Knowledge growth in teaching. Educational Researcher, 15(2), 4-14.

Siedentop, D. (1981). The Ohio State University supervision research program summary report. Journal of Teaching in Physical Education, Introductory Issue, 30-33.

Silverman, S. (1997). Technology and physical education: Present, possibilities, and potential problems. Quest, 49, 306-314.

Smith, P. A., \& Owens Jr., E. W. (2010). Examining barriers to integrate technology in elementary teacher education programs. Journal of Technology Integration, 2(1), 59-74.

Smyth, D. M. (1995). First-year physical education teachers' perceptions of their workplace. Journal of Teaching in Physical Education, 14(2), 198-214.

Solomon, G., \& Schrum, L. (2007). Web 2.0 new tool, new schools. Eugene: International Society for Technology in Education.

Sparkes, A., Templin, T., \& Schempp, P. (1993). Exploring dimensions of marginality: Reflecting on the life histories of physical education teachers. Journal of Teaching in Physical Education, 12, 386-398.

Stroot, S. A., Faucette, N., \& Schwager, S. (1993). In the beginning: The induction of physical educators. Journal of Teaching in Physical Education, 12, 375-385. 
Stroot, S. A., \& Whipple, C. (2003). Organizational socialization. In Student learning in physical education. Edited by S. Silverman and C. D. Ennis. Champaign-Urbana, IL: Human Kinetics. 339-365.

Strudler, N., \& Wetzel, K. (1999). Lessons from exemplary colleges of education: Factors affecting technology integration in preservice programs. Educational Research Research and Development , 47(4), 63-81.

Supon, V. , \& Ruffini, M. (2009). Technology integration during student teaching: A case study. College Student Journal, 43(2), 347-351.

Templin, T. (1979). Occupational socialization and the physical education student teacher. Research Quarterly for Exercise and Sport, 50, 482-493.

Templin, T. J., Woodford, R., \& Mulling, C. (1982). On becoming a physical educator: Occupational choice and the anticipatory socialization process. Quest, 34(2), 119-133.

Teo, T. (2008). Pre-service teachers' attitudes toward computer use: A Singapore study. Australasian Journal of Educational Technology, 24(4), 413-424.

Teo, T., Chai, C., Hung, D., \& Lee, C. (2008). Beliefs about teaching and uses of technology among pre-service teachers. Asia-Pacific Journal of Teacher Education, 36(2), 163-174.

Teo, T., Lee, C., \& Chai, T. (2008). Understanding pre-service teachers' computer attitudes: Applying and extending the technology acceptance model. Journal of Computer Assisted Learning, 24, 128-143.

Vannatta, R. A. \& Beyerbach, B. (2000). Facilitating a contructivist vision of technology integration among education faculty and preservice teachers. Journal of Research on Computing in Education, 33(2), 132-148. 
Viennot, L. (1979). Spontaneous reasoning in elementary dynamics. European Journal of Science in Education, 1(2), 205-221.

Vosniadou, S., \& Brewer, W. (1987). Theories of knowledge restructuring in development. Review of Educational Research, 57(1), 51-67.

Vosniadou, S. (1992). Knowledge acquisition and conceptual change. Applied Psychology: An International Review, 41(4), 347-357.

Wang, L., Ertmer, P., \& Newby, T. (2004a). Increasing pre-service teachers' self-efficacy beliefs for technology integration. Journal of Research on Technology in Education, 36(3), 231.

Wang, L., Ertmer, P., \& Newby, T. (2004b). Increasing pre-service teachers' self-efficacy beliefs for technology integration. Journal of Research on Technology in Education, 36(3), 231250.

Wideen, M., Mayer-Smith, J., \& Moon, B. (1998). A critical analysis of the research on learning to teach: Making the case for an ecological perspective on inquiry. Review of Educational Research, 68(2), 130-178. doi:10.2307/1170752

Woods, M. L., Goc Karp, G., Hui, M., \& Perlman, D. (2008). Physical educators' technology competencies and usage. Physical Educator, 65(2), 82-99.

Woods, A. M., \& Rhoades, J. L. (2010). National board certified physical educators: Background characteristics, subjective warrants, and motivations. Journal of Teaching in Physical Education, 29, 312-331.

Zehr, M. (1997). Teaching the teachers. Education Week. [Online] Retrieved March 11, 2011 from http://www.edweek.org/sreports/tc/misc/tctoc.htm.

Zeichner, K. M., \& Tabachnick, B. R. (1981). Are the effects of university teacher education “washed out” by school experience? Journal of Teacher Education, 32(3), 7-11. 
Zeichner, K. M., \& Gore, J. M. (1990). Teacher Socialization. In W.R. Houston (Ed.), Handbook of research on teacher education (pp. 329-348). New York, NY: Macmillan.

Zhao, Y., \& Frank, K. (2003). Factors affecting technology use in schools: An ecological perspective. American Education Research Journal, 40(4), 807-840.

Zhou, G., \& Xu, J. (2007). Adoption of educational technology: How does gender matter? International Journal of Teaching and Learning in Higher Education, 19(2), 140-153. 
Appendix C

Consent Form 


\section{Dear Participant,}

This letter is a request for you to take part in a research project to examine a strategy to integrate technology into a physical education teacher education curriculum. This project is being conducted by James Wyant in the College of Physical Activity and Sport Sciences at WVU with supervision of Dr. Emily Jones and Dr. Sean Bulger, assistant professors in the College of Physical Activity and Sport Sciences, for completion of my dissertation. Your participation in this project is greatly appreciated and will take approximately 10-15 minutes to fill out the attached questionnaire. You will be asked to complete this questionnaire two times during the study. Also, I will recruit some of you to participate in a 15 minute interview.

Your involvement in this project will be kept as confidential as legally possible. All data will be reported in the aggregate. You must be 18 years of age or older to participate. I will not ask any information that should lead back to your identity as a participant. Your participation is completely voluntary. You may skip any question that you do not wish to answer and you may discontinue at any time. Your class standing will not be affected if you decide either not to participate or to withdraw. West Virginia University's Institutional Review Board acknowledgement of this project is on file.

I hope that you will participate in this research project, as it could be beneficial in understanding the impact of grades on student life. Thank you very much for your time. Should you have any questions about this letter or the research project, please feel free to contact James Wyant at (304)534-1600 or by e-mail at jwyant2@ mix.wvu.edu.

Thank you for your time and help with this project.

Sincerely, 
Appendix D

Quantitative Instruments 


\section{$\underline{\text { Introduction }}$}

Dear instructional technology student,

Thank you for your willingness to assist me in completing my dissertation. I really appreciate you taking the time to complete this survey. Your knowledge and insight is very much needed to complete this project. I am currently involved in studying the process of change in physical education teachers relative to technology, what happens to individuals and why.

You are being asked to fill out a survey that attempts to measure your present concerns and level of adoption with technology.

The survey will ask you to answer a series of questions that addresses your feelings and use of technology. The entire survey should be completed before you submit the survey. I will be the only person that will have access to the information you provide in the survey. Your information will be kept confidential.

It is estimated that it will take you 10-15 minutes to complete the survey.

Thank you,

James Wyant 


\section{Background Information}

1. Name

2. Gender (Please Circle)

Male

Female

3. Age

4. Check the box that you feel best represents your involvement in sport while you were a high school student.

$\square$ Extensive Involvement

$\square$ Moderate Involvement

$\square$ Limited Involvement

5. Was a career in physical education your first choice?
$\square$ Yes
$\square$ No

6. When did your involvement in organized sport begin?

$\square$ Before the age of 10

$\square$ Between the ages of 11-15

$\square$ After the age of 15

$\square$ I was never really involved in organized sport

7. My desire to coach when I become a physical education teacher is ?
$\square$ Strong
$\square$ Moderate
$\square$ Minimal 
8. How many college-level technology courses have you taken? (not including this one)
$\square 0$
$\square 1$
$\square 2$
$\square 3$

9. Where have you learned the most about using technology? (select one)

$\square \mathrm{K}-12$ years as a student

$\square$ Courses in college

$\square$ At work

$\square$ Self-taught

$\square$ Family/friends

10. Do you have a computer at home?

$\square$ Yes

$\square$ No

11. What has exposure to technology been like as physical education student? (K-12 and college)

$\square$ High

$\square$ Moderate

$\square$ Minimal 


\section{$\underline{\text { SoCQ Technology Survey }}$}

The purpose of this questionnaire is to determine what people who are using or thinking about using various technologies are concerned about at various times during the innovation adoption process. Some of the items may be of little relevance or irrelevant to you at this time. For the completely irrelevant items, please circle ' 0 ' on the scale. Other items will represent those concerns you do have, in varying degrees of intensity, and should be marked higher on the scale, according to the explanation at the top of each of the following pages.

For example:

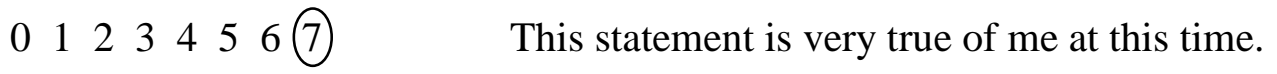

$\begin{array}{lllllll}0 & 1 & 2 & 3 & 4 & 5 & 67\end{array} \quad$ This statement is somewhat true of me now.

0(1) 234567 This statement is not all true of me at this time.

(0) 1234567 This statement seems irrelevant to me.

Please respond to the items in terms of your present concerns, or how you feel about your involvement or potential involvement with instructional technology. Also, when you read the term student in a question that refers to the students you could be interacting with during your student teaching practicum or when you become a physical education teacher. We do not hold any one definition of instructional, so please think of it in terms of your own perception of what it involves. Please respond to each item in terms of your present concerns about your involvement or potential involvement with instructional technology.

Again, thank you for taking the time to complete this survey. 
0

Not true of me now
2 Somewhat true of me now
5

6

7

$\begin{array}{lllllllll}0 & 1 & 2 & 3 & 4 & 5 & 6 & 7\end{array}$ I am concerned about students' attitudes toward instructional technology.

$\begin{array}{lllllllll}0 & 1 & 2 & 3 & 4 & 5 & 6 & 7\end{array}$ Inow know of several other approaches for how I might integrate instructional technology into my teaching.

$\begin{array}{lllllllll}0 & 1 & 2 & 3 & 4 & 5 & 6 & 7\end{array}$ I don't even know what instructional technology is.

$\begin{array}{lllllllll}0 & 1 & 2 & 3 & 4 & 5 & 6 & 7\end{array}$ I am concerned about not having enough time to learn about instructional technology so that I can integrate it effectively.

$\begin{array}{lllllllll}0 & 1 & 2 & 3 & 4 & 5 & 6 & 7\end{array}$ I would like to help other teachers in their use of instructional technology.

$\begin{array}{lllllllll}0 & 1 & 2 & 3 & 4 & 5 & 6 & 7\end{array}$ I have very limited knowledge about instructional technology.

$\begin{array}{lllllllll}0 & 1 & 2 & 3 & 4 & 5 & 6 & 7\end{array}$ I would like to know how instructional technology might affect me when I am teaching.

$\begin{array}{lllllllll}0 & 1 & 2 & 3 & 4 & 5 & 6 & 7\end{array}$ I am concerned about what my cooperating teacher and or university supervisor might expect me to know about instructional technology and how those expectations might be in conflict with what I like to do.

$\begin{array}{lllllllll}0 & 1 & 2 & 3 & 4 & 5 & 6 & 7\end{array}$ I am concerned about revising my use of instructional technology.

$\begin{array}{lllllllll}0 & 1 & 2 & 3 & 4 & 5 & 6 & 7\end{array}$ I would like to develop working relationships with both my classmates and other teachers using instructional technology.

$\begin{array}{lllllllll}0 & 1 & 2 & 3 & 4 & 5 & 6 & 7\end{array}$ I am concerned about how instructional technology affects students.

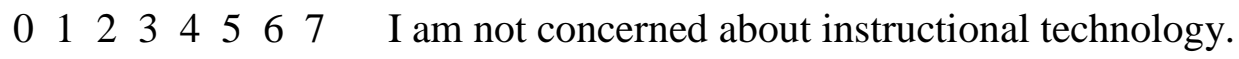

$\begin{array}{lllllllll}0 & 1 & 2 & 3 & 4 & 5 & 6 & 7\end{array}$ I would like to know who will make the decisions about me integrating instructional technology.

$\begin{array}{lllllllll}0 & 1 & 2 & 3 & 4 & 5 & 6 & 7\end{array}$ I would like to discuss the possibility of using instructional technology.

$\begin{array}{lllllllll}0 & 1 & 2 & 3 & 4 & 5 & 6 & 7\end{array}$ I would like to know what resources are available if I decide to adopt instructional technology.

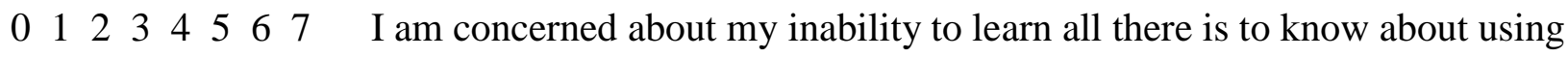
instructional technology effectively. 
$0 \quad 1$

Not true of me now
$2 \quad 3 \quad 4$ Somewhat true of me now
5

6

7

$\begin{array}{lllllllll}0 & 1 & 2 & 3 & 4 & 5 & 6 & 7\end{array}$ I would like to know how my teaching or administration is suppose to change because of instructional technology.

$\begin{array}{lllllllll}0 & 1 & 2 & 3 & 4 & 5 & 6 & 7\end{array}$ I would like to familiarize other teachers about integrating instructional technology into their teaching.

$\begin{array}{lllllllll}0 & 1 & 2 & 3 & 4 & 5 & 6 & 7\end{array}$ I am concerned about evaluating my impact on students.

$\begin{array}{lllllllll}0 & 1 & 2 & 3 & 4 & 5 & 6 & 7\end{array}$ I would like to revise how instructional technology might be used as I learn more about it.

$\begin{array}{lllllllll}0 & 1 & 2 & 3 & 4 & 5 & 6 & 7\end{array}$ I am completely occupied with other things besides instructional technology.

$\begin{array}{lllllllll}0 & 1 & 2 & 3 & 4 & 5 & 6 & 7\end{array}$ I would like to modify my use of instructional technology based on the experiences of my students.

$\begin{array}{lllllllll}0 & 1 & 2 & 3 & 4 & 5 & 6 & 7\end{array}$ Although I don't know about instructional technology, I am concerned about things in the area.

$\begin{array}{lllllllll}0 & 1 & 2 & 3 & 4 & 5 & 6 & 7\end{array} \quad$ I would like to excite my students about their part in using instructional technology.

$\begin{array}{lllllllll}0 & 1 & 2 & 3 & 4 & 5 & 6 & 7 & \text { I am concerned about time spent working with nonacademic problems }\end{array}$ related to instructional technology.

$\begin{array}{lllllllll}0 & 1 & 2 & 3 & 4 & 5 & 6 & 7\end{array}$ I would like to know what the use of instructional technology will require in the immediate future.

$\begin{array}{lllllllll}0 & 1 & 2 & 3 & 4 & 5 & 6 & 7\end{array}$ I would like to coordinate my effort with others to maximize instructional technology's effects.

$\begin{array}{lllllllll}0 & 1 & 2 & 3 & 4 & 5 & 6 & 7\end{array}$ I would like to have more information on time and energy commitments required by instructional technology.

$\begin{array}{lllllllll}0 & 1 & 2 & 3 & 4 & 5 & 6 & 7\end{array}$ I would like to know how other teachers are using instructional technology.

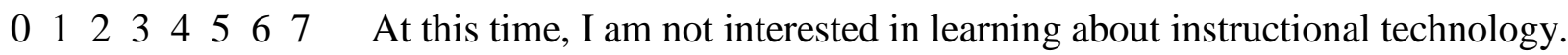

$\begin{array}{lllllllll}0 & 1 & 2 & 3 & 4 & 5 & 6 & 7\end{array}$ I would like to determine how to supplement, enhance or replace instructional technology. 
$0 \quad 1$

Not true of me now
2 Somewhat true of me now
5

6

7

$\begin{array}{lllllllll}0 & 1 & 2 & 3 & 4 & 5 & 6 & 7\end{array}$ I would like use feedback from students to change how I use instructional technology.

$\begin{array}{lllllllll}0 & 1 & 2 & 3 & 4 & 5 & 6 & 7\end{array}$ I would like to know how my role as a teacher will change when I am using instructional technology.

$\begin{array}{lllllllll}0 & 1 & 2 & 3 & 4 & 5 & 6 & 7\end{array}$ My present schedule is preventing me from learning too much about instructional technology.

$\begin{array}{lllllllll}0 & 1 & 2 & 3 & 4 & 5 & 6 & 7\end{array}$ I would like to know how instructional technology is better than methods I currently use.

\section{Stages of Adoption of Technology}

Please read the descriptions of each of the six stages related to adoption of technology. Check the stage that best describes where you are in the adoption of technology.

Stage 1 - Awareness - I am aware that technology exists but have not used it. Perhaps I'm even avoiding it.

Stage 2 - Learning the Process - I am currently trying to learn the basics. I am often frustrated using technology. I lack confidence about technology.

$\square$ Stage 3 - Understanding and Application of the Process - I am beginning to understand the process of using technology and can think of specific tasks in which it might be useful.

$\square$ Stage 4 - Familiarity and Confidence - I am gaining a sense of confidence using technology for specific tasks. I am starting to feel comfortable using technology.

$\square$ Stage 5 - Adaptation to other Contexts - I think about technology as a tool to help me. I can use it in many applications and as an instructional tool.

$\square$ Stage 6-Creative Applications to other Contexts - I can apply what I know about technology in the classroom. I am able to use it as an instructional tool and integrate it into my curriculum. 
Dear instructional technology student,

Your completion of the survey is greatly appreciated. I look forward to working with you in the technology course. Hope you are having a great summer. I will be asking you to complete this survey one more time following the instructional technology course.

Once again I really appreciate you taking the time to complete the survey.

If you have any questions please feel free to contact me at jwyant2@mix.wvu.edu.

Thanks,

James 
Appendix E

Journal Entry Questions 
Directions: Read each question carefully and provide an answer in the box below. Be sure to answer each question separately. (Questions will be embedded into an electronic journal)

\section{$\underline{\text { Week } 1}$}

1. All physical education teachers have beliefs about teaching. It could be beliefs about the curriculum you want to use, the activities you want to teach, and just an overall philosophy about teaching. What would you say are your beliefs about teaching physical education?

2. We have been hearing a lot about technology in education. Based on your prior experience as a student and as a future teacher what is your opinion of technology's role in education and your teaching?

3. At this point in time how concerned are you about instructional technology?

a. What concerns do you have about having to teach with technology?

b. What concerns do you feel need to be addressed in order for you to be able to use technology in your technology?

4. What are your expectations about how this course will affect your teaching philosophy?

a. What changes do you hope will result from your participation in the instructional technology course?

b. What do you hope to get out of the experience?

\section{Week 2}

1. To what extent has the course been what you expected it to be?

a. How was it different from what you expected?

b. To what extent did the concerns you had about technology before the course come true?

2. Do you feel the class has increased your awareness about the role technology could potentially play in your teaching?

a. What questions do you have about technology in your teaching?

\section{$\underline{\text { Week } 3}$}

1. What was the most important experience you had in the class?

a. Why do you feel that it was important?

2. How did the course affect your personally?

a. What changes do you see or feel as a result of the course?

b. What would you say you got out of the class? 
Appendix F

Semi-Structured Interview Protocol 
The following protocol represents the protocol for the semi-structured interview to gain further insight into the perceptions of pre-service teachers with different levels of concern toward instructional technology.

Reminder: Be sure to read script to participant before starting questions.

"First, I want to thank you for volunteering to participate in this interview today. Your insight is very important and I appreciate you taking the time to visit with me. I will be asking you questions about your perceptions of the instructional technology course, technology, and your thoughts about technology going forward. The information you provide can help to improve the instructional technology course, and also provide ideas on how other PETE programs across the country might integrate technology."

"I will be using a digital recorder today to capture our conversation. The digital recorder will be used to make sure all the information we talk about gets recorded. However, you should be confident that all that we discuss today will remain confidential. Any information that you disclose will not be connected back to you or impact your grade in the class. At any time you can decide to not answer a question, just let me know and we will skip to the next. It is expected that the interview will last about 15 minutes. “

"Do you have any questions?" I will wait a few seconds to give the participant time to process all that we just discussed. "If not, let's go ahead and begin."

"I am going to first ask you several questions about your experiences in PET 441"

1. "First, please describe your experience in PET 441 Technology in Physical Education." a. "What do you remember most about the class?" 
2. "Please think about the concerns about instructional technology that you had upon entering PET 441. During the three weeks spent in PET 441, was there a critical point during the class where your concerns about instructional technology shifted - either for better or worse?"

a. If yes, could you please tell me more about that?"

b. If no, what would have needed to happen in PET 441 to address your concerns about instructional technology in PE?

3. "Now that you have finished the course in instructional technology, what, if anything, will you do now as a teacher that you might not have done before this class?"

a. "Why do you think that is?"

b. "Have other PETE courses that you have taken here at WVU changed the way you think about or do things as a teacher? If so, how have your teaching behaviors been altered as a result of taking the instructional technology course in comparison to other courses you have taken? About the same amount; A lot more than other courses; or A lot less than other courses?"

i. What do you think it was about the PET 441 course that makes you think that (e.g., was it the way the course was organized? Delivered? Hands-on? New content, etc.)?

ii. "Is there anything else you could add to that?"

"Those were questions that focused on your experience during the class. Now I am going to ask you some questions about how you now feel about technology based on your experience in the class." 
4. "Based on what your experiences and perspective as a WVU pre-service teacher and now having taken the instructional technology course, what are your thoughts about technology's role in physical education?"

a. "What about technology's role in your teaching?"

i. "Do you feel as though you will be able to integrate technology into your teaching? If yes, why and please explain. If no, why and please explain."

ii. "Based on your experiences teaching physical education, do you feel that it is feasible to make technology a meaningful component of your teaching? If yes, how do you (or how can you) envision using technology in your teaching? If no, what makes you feel that way?"

iii. "Do you think technology is a tool that could make you a better teacher? Why or why not?"

iv. "If you could think ahead for a moment, I'd like to know the types of challenges you anticipate in using technology in your teaching."

"The last two questions relate to your use of technology in your upcoming BIP and student teaching placements"

5. "When you think about you using technology during your BIP and student teaching placements what is the first thing that comes to mind?"

a. "Why do you think that is at the forefront of your mind?"

b. "Can you envision being successful in using technology in your teaching (BIP / student teaching placements)?

i. "If yes, can you pinpoint what makes you feel that way?" 
ii. "If no, can you think of any resources or people that you will use to help you be successful in this?"

"That last question was the last I have for you. Is there anything that you can think of that you would like to add - either about PET 441, the role of technology in PE, or your use of technology in your student teaching placement? (Wait for a few seconds) Okay, again thank you for your willingness to participate in the interview.

Over the next few days if you think of anything that you would like to add to what we discussed today please write it down and contact me by email and I will add it to our discussion notes. In the next few days you will be receiving an e-mail from me that will contain all of the information you shared with me today in our interview. Please read through the information to make sure that I captured your thoughts and responses to the questions I asked today in a manner that is accurate of how you feel. If you have concerns about the content, please email me back with specific clarifications and those edits will be made. . Please remember that none of this conversation or your feelings will be connected to you and any identifiable information that could link back to your comments will be removed."

“Thank you again! It was a pleasure working with you. Please be sure to keep an eye open for that email from me- I will have additional instructions in the email for you. 


\section{Appendix G}

Participant Profiles 


\section{Participant One Profile}

\section{Background Information}

Participant One was a male pre-service teacher. Coming into the class he cited that his exposure to technology as a physical education student had been minimal. During his collegiate years he attended one technology course. He also attributed most of his knowledge about technology to a course he attended during college.

Table 1

SoCQ Data

\begin{tabular}{ccccccccc}
\hline Timing & $\begin{array}{c}\text { Stage } \\
\text { Zero }\end{array}$ & $\begin{array}{c}\text { Stage } \\
\text { One }\end{array}$ & $\begin{array}{c}\text { Stage } \\
\text { Two }\end{array}$ & $\begin{array}{c}\text { Stage } \\
\text { Three }\end{array}$ & $\begin{array}{c}\text { Stage } \\
\text { Four }\end{array}$ & $\begin{array}{c}\text { Stage } \\
\text { Five }\end{array}$ & $\begin{array}{c}\text { Stage } \\
\text { Six }\end{array}$ & $\begin{array}{c}\text { Total } \\
\text { Score }\end{array}$ \\
\hline Pre & 99 & 90 & 89 & 77 & 43 & 48 & 65 & 73 \\
Post & 96 & 80 & 95 & 77 & 71 & 52 & 94 & 81 \\
\hline
\end{tabular}

Participant One

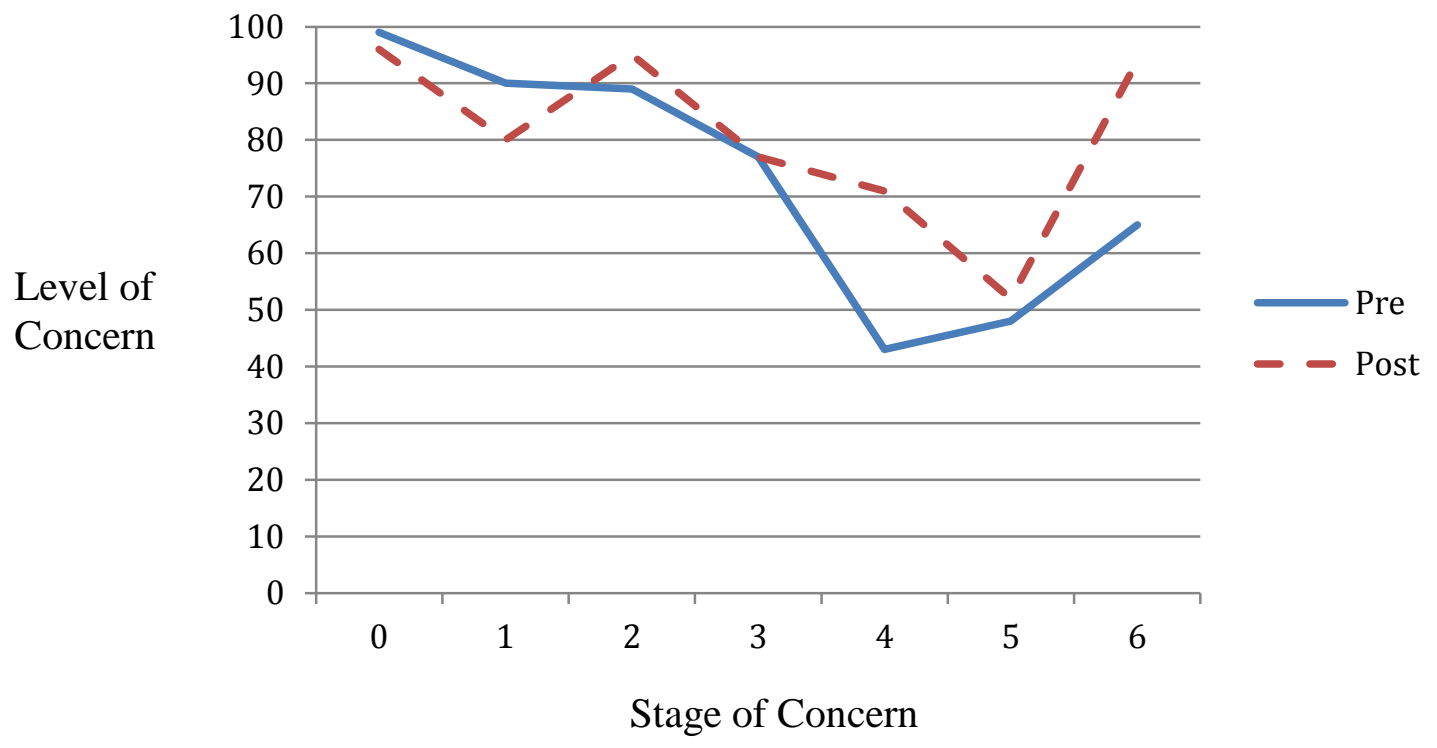

Figure 1. Participant One's pre and post-course levels of concern. 


\section{Quantitative Case Profile}

SoCQ data profile. Examination of the SoCQ data, which served as the focal point of the quantitative data revealed two emergent trends in Participant One's data. First and foremost, Participant One's internal concerns toward instructional technology's role in physical education remained at a dominant level. Awareness (Stage Zero), Informational (Stage One), and Personal's (Stage Two) level of intensity remained over $80 \%$ from pre to post assessment. As Hall, George, and Rutherford (1979) point out high scores on these stages typically indicate that the person is a nonuser of the innovation, which in this case was use of technology in the physical education context. Participant One acknowledged that he had minimal exposure to technology as a physical education student. Therefore, coming into the class and after leaving the class similar questions remained for Participant One. A high Awareness (Stage Zero) level of concern suggests that the user is still in the early process of gaining knowledge and information about instructional technology in physical education. Similarly, a high Informational (Stage One) level of concern indicates that the user still needs more information about instructional technology. A high Personal (Stage Two) level of concern score which in Participant One's case, actually increased on the post assessment highlights how the user has a general uneasiness toward the innovation.

While the internal concerns remained high for Participant One, a second trend also emerged from the data. Examination of the SoCQ data revealed positive changes in his external concerns, specifically Consequence (Stage Four) and Refocusing (Stage Six). Coming into the class Participant One scored a $41 \%$ intensity level toward Consequence (Stage Four), but exited the class at a $71 \%$. Consequence (Stage Four) is characterized by the user possessing concerns toward how instructional technology will impact his teaching and learners. This indicated that 
the user was thinking about how the use of the innovation would impact entities beyond themselves. The second increase in an external concern was at Refocusing (Stage Six), which increased from $65 \%$ to $94 \%$. The increase in Refocusing (Stage Six) indicated that Participant One left the course with a lot more ideas about how he could potentially use instructional technology in his teaching. Increased knowledge and ideas toward the innovation is also supported with the decrease that was present in the data in his Informational concern (Stage One), which dropped from $90 \%$ to $80 \%$. The drop in stage one highlighted that Participant One received more information about the innovation. However, as Hall, George, and Rutherford (1979) point out an increased Informational concern (Stage Six) for a nonuser indicates that the individual has more ideas about the innovation, but still may possess a negative disposition of toward technology.

Stages of Adoption data profile. Similar to the SoCQ instrument the Stages of Adoption instrument was administered two times during the study, pre and post. Coming into the class Participant One identified Stage Four, Familiarity and Confidence, as the stage of adoption that most accurately characterized his current perception toward technology. Stage Four describes a technology user that is starting to gain confidence and increased comfort level toward instructional technology. Following the three week course and administration of the post assessment Participant One again identified Stage Four as the adoption status that most accurately captured his perception of comfort level with instructional technology.

Analysis of the Stages of Adoption instrument supports what the data showed from the SoCQ. Participant One's Stage of Adoption remained at Stage Four, Familiarity and Confidence from pre to post assessment. Again Stage Four highlights that the individual is still gaining confidence and knowledge toward instructional technology, physical education, and fusing the 
two components. The SoCQ identified Participant One as a nonuser toward instructional technology and physical education. Adoption of technology results showed that Participant One is still in the early process of gaining familiarity toward instructional technology in physical education.

\section{Qualitative Case Profile}

Analysis of Participant One's qualitative data mirrored what his quantitative data showed, that is he possessed positive and negative feelings toward instructional technology. One interesting aspect about Participant One was that his positive feelings relative to instructional technology appeared to emerge as he progressed through the course. Coming into the course when asked about what he would like to get out of the instructional technology course he responded by saying:

I would like to be aware of IT and its practical uses, but I am also realistic. I know the probability of me using technology in a physical education classroom is unlikely because it is both costly and an unproven method of teaching in the classroom. (P1-J1-L23) His apprehension and skepticism with instructional technology were again expressed the following week in his second journal entry. When asked about his concerns toward instructional technology and how the class may have addressed them he replied:

As far as my concerns regarding the class, they were unfortunately verified. I did not believe technology would be a practical addition to a physical education classroom. This I still believe to be true. Although there are many practical benefits to its usage within a classroom for economic reasons it is most likely impossible to incorporate. (P1-J2-L7) 
While his concerns about the class and instructional technology remained, he voiced a new perception of the potential benefits of technology. His feelings about the potential positives of technology emerged during his week two journal. When asked about if the course exceeded his expectation he responded by saying:

I can say this course has exceeded my expectations. I have learned quite a lot about the technologies that are currently available. This is truly the opposite from what I expected because I thought I would not learn much practical information about technology. (P1$\mathrm{J} 2-\mathrm{L} 4)$

According to Participant One, a primary influence as to why the class exceeded his expectations was due to the hands-on learning experiences with technology threaded throughout the class. When asked what he remembered most about the class during the post-course interview, he stated, "You know you have more fun when you are actually in front of the technology doing it than when you are thinking about doing it." (P1-I-L14) He further elaborated on the benefit of hands-on learning when he discussed a reason why the instructional technology course may change his teaching behaviors. "Actually sitting down and using the technology and having it front of you and being available. Hands-on learning was big for me" (P1-L78-I). The value and product of hands-on learning for Participant One was also voiced when he cited specific uses that technology could enhance his teaching effectiveness. Specifically, when he was asked if technology could make him a better teacher he provided the following response: "The advantage of technology is that you can measure goals a lot easier like I said. Some of the goals that I find are really hard to measure without technology is health related fitness goals" (P1-I-L-119). His exposure to technology and experience of using technology provided him with the knowledge to articulate how the use of technology could make him a better teacher. 
The concerns Participant One voiced about instructional technology remained consistent throughout the course. He was concerned that instructional technology is an unproven and unrealistic tool for the physical education setting. However, as the course progressed the handson learning experiences opened his eyes to the possibilities of instructional technology in the physical education setting. When asked about the impact the course had on him personally his response may best capture his perception of instructional technology:

I would have to say the course has had a positive effect on me personally. I walked into the course with a very pessimistic view of using technology in the physical education setting. I can now say I am less skeptical and do see the potential effects that technology can have in the classroom. I am still not $100 \%$ sold on the issue, but do feel more educated on the topic. (P1-J3-L11)

\section{Mixed-Data Case Narrative}

Examination of Participant One's holistic profile revealed a duality of trends. His quantitative and qualitative data illustrated that the instructional technology course enhanced his knowledge base relative to instructional technology. His Refocusing concern (Stage Six) as measured by the SoCQ, increased from $65 \%$ to $94 \%$. This jump echoed the statements he shared in his journal entries and interview that the course provided him knowledge and ideas for how he could potentially use instructional technology in his teaching. As Posner, Strike, Hewson, and Gertzong (1982) posit one of the first steps in meaningful learning is for an individual to gain knowledge about the innovation. A key factor for Participant One's increased knowledge base was his ability to use different technologies throughout the instructional technology course. However, as Ertmer and Ottenbreit-Leftwich (2010) emphasize simply knowing how to use technology does not guarantee that a teacher will integrate technology into their teaching. So 
while his knowledge base did increase, his quantitative and qualitative data also showed that his personal concerns about instructional technology remained. Specifically, for Participant One his internal concern about cost and how realistic of an instructional tool technology is for the physical education context persisted. Hall, Rutherford, and George (1979) exacerbate an individual's personal concerns must first be addressed. In Participant One's case his internal concerns about technology's feasibility for the physical education context must be addressed for meaningful change to occur.

\section{Participant Two Profile}

\section{Background Information}

Participant Two was a male pre-service teacher. Upon entry into the instructional technology course he stated that he had high exposure to technology as a physical education student. He attributed his knowledge of technology to being self-taught. Prior to entry into the instructional technology course he had attended two technology courses as a college student.

Table 2

SoCQ Data

\begin{tabular}{ccccccccc}
\hline Timing & $\begin{array}{c}\text { Stage } \\
\text { Zero }\end{array}$ & $\begin{array}{c}\text { Stage } \\
\text { One }\end{array}$ & $\begin{array}{c}\text { Stage } \\
\text { Two }\end{array}$ & $\begin{array}{c}\text { Stage } \\
\text { Three }\end{array}$ & $\begin{array}{c}\text { Stage } \\
\text { Four }\end{array}$ & $\begin{array}{c}\text { Stage } \\
\text { Five }\end{array}$ & $\begin{array}{c}\text { Stage } \\
\text { Six }\end{array}$ & $\begin{array}{c}\text { Total } \\
\text { Score }\end{array}$ \\
\hline Pre & 98 & 90 & 85 & 27 & 30 & 64 & 77 & 67 \\
Post & 72 & 57 & 45 & 18 & 27 & 31 & 38 & 41 \\
\hline
\end{tabular}




\section{Participant Two}

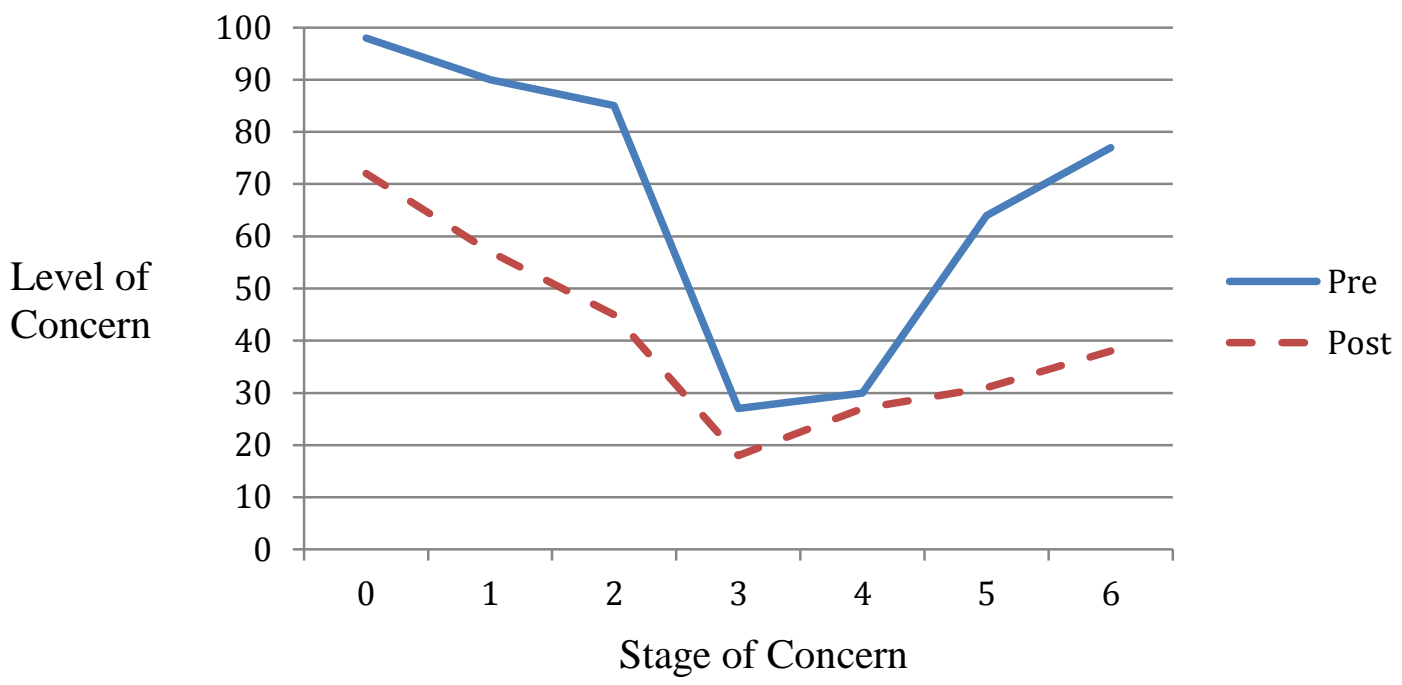

Figure 2. Participant Two's pre and post-course levels of concern

\section{Quantitative Case Profile}

SoCQ data profile. Examination of Participant Two's SoCQ profile revealed one significant trend. First, it was clear coming into the instructional technology course that Participant Two possessed high internal concerns toward technology's role in physical education. This is evident with Participant Two recording a 98\% intensity level of concern on Awareness (Stage Zero) and $90 \%$ on Informational (Stage One). In contrast to the typical interpretation of high internal concerns, Participant Two's profile is not indicative of a nonuser of technology; rather this pattern reflected a user of technology that is more concerned about other things relative to physical education than instructional technology. Illustrating this was a dramatic decrease that was seen in his level of concern across all seven stages of concern. A lack of concern toward instructional technology is also reflected in Participant Two's overall score. According to Hall, George, and Rutherford (1979) the overall score can reflect an individual's 
investment with the innovation. The overall score is simply the average of all seven stages of concern. Participant Two's total score for pre-class administration was $67 \%$. Following the course his total score dropped to $41 \%$. This dramatic drop suggested that Participant Two's investment toward instructional technology's role in physical education dropped significantly following the course.

Stages of Adoption data profile. For pre-class administration of the Stages of Adoption survey Participant Two identified Stage Five, Adaptation to Other Contexts that most accurately captured his perception toward instructional technology. Stage Five is characterized as a technology user that feels confident in their ability to apply technology in a variety of contexts. Following the instructional technology course participant identified Stage Six, Creative Application to New Contexts, as the stage that identified their stage of adoption of technology. Stage Six describes technology users that are not only very confident in their ability to use technology in a variety of contexts, but they also have the confidence to make technology an integral component of his or her curriculum.

Analysis of the Stages of Adoption survey revealed results that seemed to counter what the SoCQ showed. Participant Two entered the course with a Stage Five adoption level, and left the course with a Stage Six adoption level. Both Stage Five and Stage Six indicated that Participant Two was confident in his ability to integrate technology into his teaching.

\section{Qualitative Case Profile}

Analysis of Participant Two's qualitative data reinforced a trend that emerged in his SoCQ data. The trend that emerged from his SoCQ was a lack of investment in instructional technology. What is interesting about Participant Two is that during the first week of the course 
he appeared open to the use of the instructional technology in his teaching. He stated the following in his week one journal entry:

I hope I am open to different types of technology that can be used in the classroom. I also hope that I can become comfortable enough with technology to the point that I wouldn't hesitate using technology in a classroom setting (P2-J1-L25).

While he possessed a tone that appeared to be open to the use of instructional technology during week one, this changed as the course advanced into week two. In his week two journal entry, Participant Two did not voice concerns about lacking confidence toward his ability to use technology, instead he began to question how feasible technology would be in the physical education setting. When asked about what questions he may have about technology he responded, "The only questions I have would deal with cost and how open are administrators to the new ideas of incorporating technology more and more into physical education" (P2-J2-L13). The concerns and doubt he felt about technology were also voiced during his week three journal entry. When asked what he thought was his most important experience he provided the following answer:

I thought the best experience I had was when our project was completely lost at the library when the computer crashed. It showed no matter how good technology is it is not perfect and it is always good to back up your work. (P2-J3-L2)

His frustration with technology was again reiterated when he was asked to describe his experience in the class for his interview. He replied, "It was okay. A couple of times during the class technology actually hurt us." (P2-I-L3) It was clear that the one single negative experience he had with a piece of technology made a lasting impact on him. He again expressed candidly that he thought technology was not feasible in the physical education setting. When asked about 
the challenges of using technology in his teaching he highlighted the following, "I don't think it is ever going to be cost effective" (P2-I-L104). Further highlighting his skepticism was a statement he made when asked about if the class addressed his concerns to which he replied, "No, I stayed about the same the biggest thing was the price of everything. How would you go about doing this" (P2-I-L16)?

Participant Two expressed his concern about the time it would take to make technology a part of his teaching. When he was asked about the potential role technology could play in his teaching he stated the following, "I mean from a time stand point I am planning on coaching so there is not going to be much time outside of school to put all of this together" (P2-I-L72). Further emphasizing his lack of concern about technology was his response to what he thought about using technology during his student teaching practicum. To this question he replied, "I am not going to be concentrating on technology that is going to be the last thing on my mind" (P2-IL116). The points expressed by Participant Two highlights what the occupational socialization literature emphasizes in that a physical education teacher that is focused on coaching has a tendency to lean toward more traditional methods of teaching (Lawson, 1983a).

\section{Mixed-Data Case Narrative}

When examined holistically, Participant Two's data revealed two interesting trends. Similar to Participant One, Participant Two's data revealed a duality of trends. First, Participant Two did not view technology as a feasible instructional tool for the physical education setting. Posner and colleagues (1982) emphasize that an individual must view an innovation as plausible for meaningful learning to occur. When you couple this emergent trend from his qualitative data with the lack of investment that emerged from his SoCQ data it is clear that the instructional technology course did not address the internal concerns that he possessed toward technology. 
Ertmer and Ottenbreit-Leftwich (2010) suggest that the more value an individual places on an instructional tool the more likely they are to use it. In Participant Two's case he did not place a great deal of value on the potential role of technology in his teaching. However, while his concerns about instructional technology persisted one area did seem to improve as a result of the class. Specifically, Participant Two voiced that he felt more comfortable with technology. This elevated sense of comfort supported what his stage of adoption of technology post-assessment revealed in that he rated himself as a Stage Six adopter. Collectively the data indicated that the instructional technology course did make him a more confident technology user, but he still did not view technology as a necessity in his teaching. As Schempp and Graber (1992) suggest teachers rely heavily on personal interests for identifying instructional methods. For Participant Two his personal interests for teaching physical education appeared to exclude instructional technology. Therefore, as Hall, George, and Rutherford (1979) highlight an individual's internal concerns about an innovation must first be addressed before meaningful change can occur.

\section{Participant Three Profile}

\section{Background Information}

Participant Three was a male pre-service teacher. Upon entry into the instructional technology course he cited that his exposure to technology as a physical education student had been moderate. He cited self-taught as the manner the most accurately characterized how he has learned what he knew about technology. Coming into the class he had attended two instructional technology courses as a college student. 
Table 3

SoCQ Data

\begin{tabular}{ccccccccc}
\hline Timing & $\begin{array}{c}\text { Stage } \\
\text { Zero }\end{array}$ & $\begin{array}{c}\text { Stage } \\
\text { One }\end{array}$ & $\begin{array}{c}\text { Stage } \\
\text { Two }\end{array}$ & $\begin{array}{c}\text { Stage } \\
\text { Three }\end{array}$ & $\begin{array}{c}\text { Stage } \\
\text { Four }\end{array}$ & $\begin{array}{c}\text { Stage } \\
\text { Five }\end{array}$ & $\begin{array}{c}\text { Stage } \\
\text { Six }\end{array}$ & $\begin{array}{c}\text { Total } \\
\text { Score }\end{array}$ \\
\hline Pre & 99 & 95 & 89 & 83 & 27 & 48 & 47 & 70 \\
Post & 98 & 93 & 94 & 95 & 59 & 88 & 94 & 89 \\
\hline
\end{tabular}

Participant Three

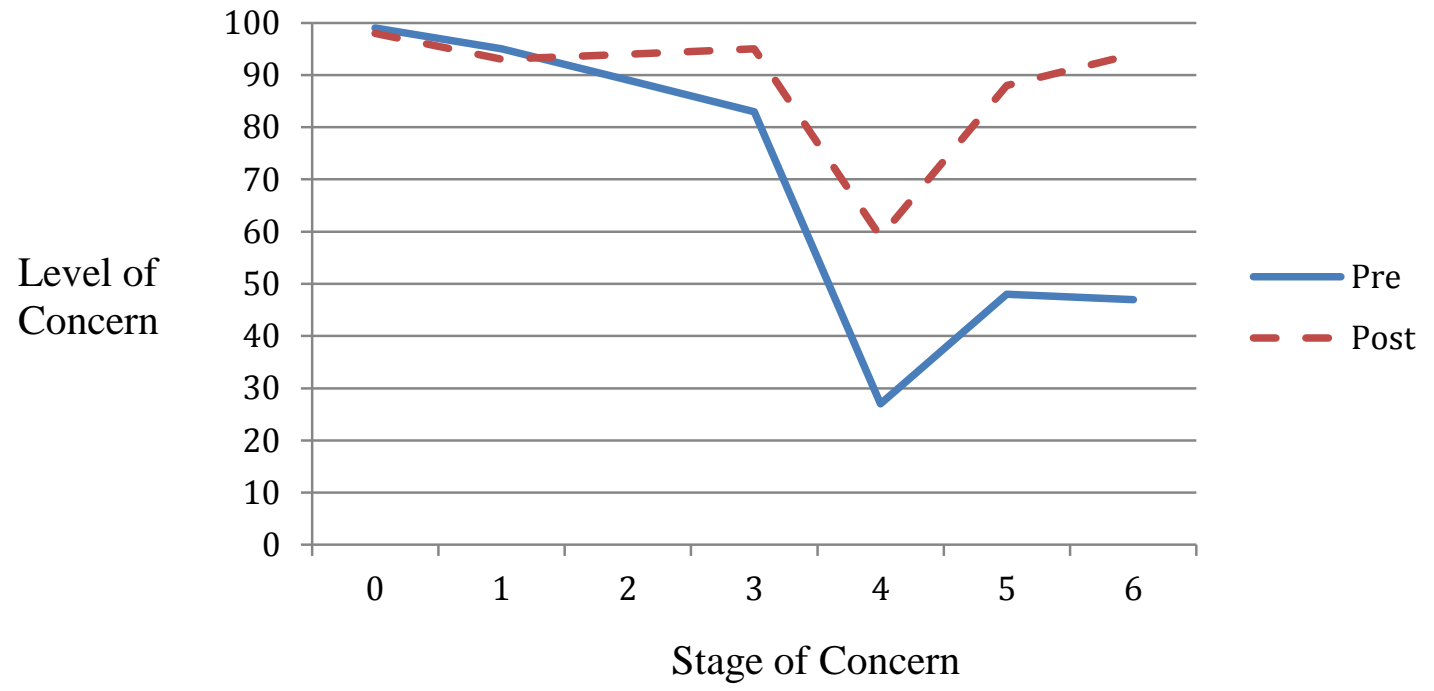

Figure 3. Participant Three's pre and post-course levels of concern.

\section{Quantitative Case Profile}

SoCQ data profile. Examination of Participant Three's SoCQ profile revealed two emergent trends in the data. The first clear trend in the data was the lack of change in Participant Three's internal concerns. Most significant of the internal concerns was Awareness (Stage Zero) where Participant Three reported concerns at $99 \%$ on pre-course administration and $98 \%$ on post-class administration. As Hall, George, and Rutherford (1979) point out such high levels of concern on stage zero are indicative of a non-user of technology. This suggested that Participant Three's concerns and questions toward instructional technology in physical education remained 
throughout the class. Further, Participant Three also had high concerns on Informational (Stage One) for pre and post administration with both being over $90 \%$. High concern on Stage One is indicative of a user that has a lot of questions about the innovation and needs more information. In a similar vein, Participant Three's Personal (Stage Two) and Management (Stage Three) concerns both increased to over $90 \%$ for post-class administration. Collectively Participant Three's SoCQ data indicates that his internal concerns remained at a high level following the instructional technology course.

The second trend that emerged from the data was an evident increase in Participant Three's external concerns, specifically on Collaboration (Stage Five) and Refocusing (Stage Six). His stage five concerns increased from $48 \%$ to $88 \%$. According to Hall, George, and Rutherford (1979) when one couples a high level of concern on Stage One and Stage Five that describes a user that is concerned about learning how to use the innovation from others and getting ideas from other people. Similar to Collaboration (Stage Five), Refocusing (Stage Six) also saw a dramatic increase from $47 \%$ to $94 \%$. Hall, George, and Rutherford (1979) emphasize that an increase in Stage Six coupled with high internal concerns could characterize a nonuser of technology that has more ideas about the innovation, yet negative concerns still exist. In Participant Three's case this seemed to be true because his internal concerns remained high, but it was clear that he left the course with more ideas about how he could potentially use technology in his teaching.

Stages of Adoption data profile. Participant Three labeled Stage One, Awareness, as the stage that characterized his adoption status when he entered the instructional technology course. The Awareness stage describes a technology user that is aware that technology exists, but beyond that they are not very comfortable with using it. Following the instructional 
technology course Participant Three selected Stage Two, Learning the Process, as the stage of adoption of technology that best captured his perception toward his ability to use technology in his teaching. Stage Two describes a technology user that is still consumed about learning the basics relative to technology which leads the individual to being easily frustrated and lacks confidence in their ability to use technology.

Analysis of the Stages of Adoption survey shows that Participant Three's confidence toward technology remained a concern. Coming into the class he identified Stage One as his level of adoption toward technology, which is characteristic of a technology user that is not confident or knowledgeable about his ability to use technology. This supports data trends from the SoCQ data that Participant Three was a nonuser of technology. Following the class Participant Three selected Stage Two as his adoption status; this reflects a user that is still in the early in the process of using technology. Participant Three being a Stage Two adopter of technology also supported the SoCQ data because he had high level of concerns that related to wanting to learn more information about technology and physical education.

\section{Qualitative Case Profile}

Participant Three's qualitative data supported the duality theme that emerged from his quantitative data. He was an individual that entered the course with very little awareness and knowledge about instructional technology in the physical education context. As a result of his lack of awareness of technology he was a user that lacked confidence, comfort, and experience with using technology. These apprehensive feelings were articulated throughout the course. As he stated in his week one journal, "I am very concerned about instructional technology, but not because I believe it will eliminate teachers. I am concerned my instructional technology literacy 
is not up to par" (P3-J1-L15). His concerns about his ability to use technology were seen in week one, but he also expressed an openness to using technology throughout the course. Also in his week one journal when he was asked about his feeling on technology he replied, "Technology is growing rapidly which means it needs to play a major role in not only my teaching but all teaching" (P3-J1-L7). So while he has serious internal concerns related to his ability to use technology he knows that this is a skill that he needs to learn more about.

As the course progressed into week two he again lamented on the fact that he did not feel comfortable with technology. When he was asked about his concerns and whether the course was addressing them he responded with the following statement:

My technology literacy is still awful. I need someone to show me a couple of time before I ever feel comfortable using a piece of technology. So my concerns of not being comfortable with the equipment, especially when it doesn't go as planned are still there (P3-J2-L8).

While he expressed frustration with his ability to use technology in week two he also spoke to an aspect of the course that was addressing this issue. When asked whether the course had exceeded his expectation he pointed to one experience in particular that he really enjoyed. "I've enjoyed the fact that we have got to use some of the pieces outside of the classroom and really get comfortable with the technology" (P3-J2-L4).

Following the course he expressed similar insight about instructional technology in that he is not overly comfortable with technology, but he does see the value in using technology in his teaching. When asked to discuss how his concerns manifested over the course of the class he provided the following statement: 
It definitely shifted for the better like using heart rate monitors and stuff like that just because I think being able to track how active your students are I think that definitely shifted my thoughts after that. There are still a lot of frustrating aspects with technology that I don't like that I get easily frustrated and so that I mean from the negative side I have always had the view toward technology so that really didn't change (P3-I-L12). It was clear throughout his qualitative data that a motive for his eagerness to learn more about technology reinforced his belief that technology was something that he needed to learn and adapt to. When asked to describe his feeling on technology's role in physical education he replied, "I think it is going to end up playing a huge role. There is no doubt about it that technology is pretty much taking over" (P3-I-L40). A similar sentiment was shared again when he was asked if technology could make him a better teacher. To that question he responded, "Definitely it can make you a better teacher because I mean technology has pretty much made everything better" (P3-I-L60).

While Participant Three described his belief that technology is going to play a significant role in physical education and that it needed to be integrated into his teaching this did not alleviate his concerns about his ability to use technology. Best capturing his feelings on his impending use of technology during his student teaching practicum was the following statement, “Crap! Oh no! Yea, it's like what am I going to do? It is definitely a little anxious. I mean I am probably a little nervous because like I am not completely comfortable with anything in technology" (P3-I-L72). When asked why he felt this way and why it was at the forefront of his mind he stated, "You know I really haven’t used technology that much so I am still going to be learning when I first use technology with students" (P3-I-L81). Due to his lack of experience with technology he acknowledged that he needed help to be successful. When asked about 
whether he thinks he can be successful with his use of technology during his student teaching practicum he stated, "I will have to rely on a lot of people until I am more confident" (P3-I-L87). The preceding statements signify that Participant Three has serious concerns and fears about using technology. A result of his intense personal concerns is that he worried that his positive view of technology may be impacted. An example that best described his mindset following the course was an answer he provided when asked what he would do differently as a teacher after experiencing the class participant three stated, "Hopefully it (technology) continues to be something that I view positively" (P3-I-L-24).

\section{Mixed-Data Case Narrative}

A holistic analysis of Participant Three's data revealed a duality of trends. Participant Three's data described a technology user that is in a precarious state. As his quantitative and qualitative data clearly revealed he had intense internal concerns about his ability to use technology in his teaching. Both datasets also showed that the experience in the class made him feel more positive about technology. This was evident when you look at his advanced Refocusing (Stage Six) concern and stage of adoption on his post-class survey. Supporting this in his qualitative data was the positive outcomes he described as a result of the hands-on learning experiences threaded throughout the course. However, both datasets also described a technology user that has intense internal concerns about using technology. Specifically, for Participant Three he possessed serious concerns about his ability to use technology. As Ertmer and Ottenbreit (2010) state, "Evidence suggests that self-efficacy may be more important than skills and knowledge among teachers who implement technology in their classrooms" (p. 261). So naturally Participant Three understood that he was in a vulnerable state relative to technology because he knows it is something that is going to be a challenge for him. Data highlighted that 
his early experiences of using technology are going to be critical to shaping his long term view of technology. As Bandura (1977) emphasized an individual's self-efficacy is a great predictor of behavior. So if Participant Three does not find the necessary people or resources to help him in his use of technology it may erode the positive feelings he left the course possessing. It will be critical for Participant Three to have the resources in place to help alleviate his internal concerns about instructional technology for meaningful change to occur. Hall, George, and Rutherford (1979) echo this sentiment in stating that an individual's internal concerns must first be addressed. While it did appear the course enhanced his knowledge base and improved his comfort level slightly his internal concerns about instructional technology remained a prominent barrier for him.

\section{Participant Four Profile}

\section{Background Information}

Participant Four was a male pre-service teacher. Prior to his enrollment in the instructional technology course he cited his exposure to technology as physical education student as moderate. He attributed most of his knowledge about technology to learning experiences while he was a student during the K-12 years. During his time as a college student he had attended one technology course before entering the instructional technology course.

\section{Table 4}

SoCQ Data

\begin{tabular}{ccccccccc}
\hline Timing & $\begin{array}{c}\text { Stage } \\
\text { Zero }\end{array}$ & $\begin{array}{c}\text { Stage } \\
\text { One }\end{array}$ & $\begin{array}{c}\text { Stage } \\
\text { Two }\end{array}$ & $\begin{array}{c}\text { Stage } \\
\text { Three }\end{array}$ & $\begin{array}{c}\text { Stage } \\
\text { Four }\end{array}$ & $\begin{array}{c}\text { Stage } \\
\text { Five }\end{array}$ & $\begin{array}{c}\text { Stage } \\
\text { Six }\end{array}$ & $\begin{array}{c}\text { Total } \\
\text { Score }\end{array}$ \\
\hline Pre & 98 & 84 & 63 & 69 & 30 & 26 & 77 & 64 \\
Post & 86 & 43 & 41 & 11 & 40 & 30 & 57 & 44 \\
\hline
\end{tabular}




\section{Participant Four}

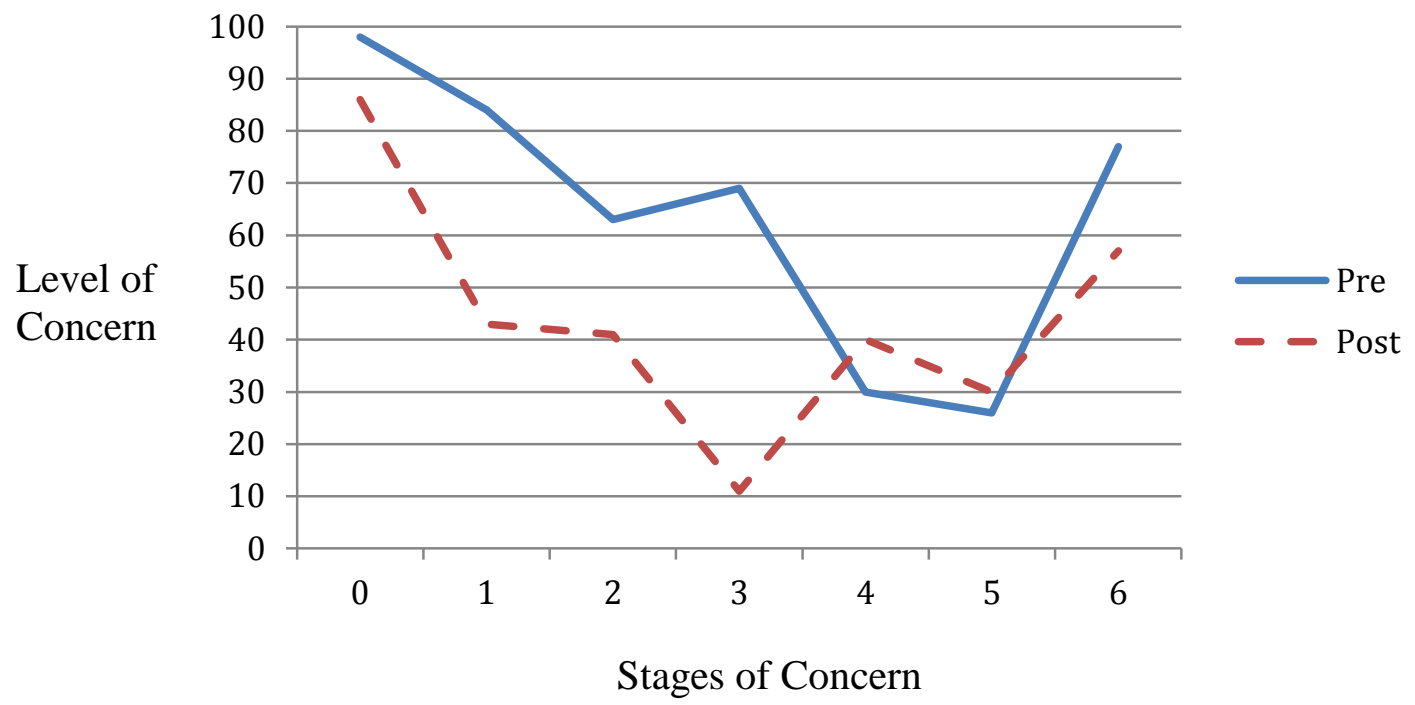

Figure 4. Participant Four's pre and post-course levels of concern.

\section{Quantitative Case Profile}

SoCQ data profile. Analysis of Participant Four's SoCQ data revealed two emergent trends. First a consistent theme that was present during both pre and post administration was that participant had a high level of concern on Awareness (Stage Zero). For pre-class administration he had $98 \%$ level of concern and for post-class administration he had an $86 \%$ level of concern. According to Hall, George, and Rutherford when a user's only high stage score is on Awareness (Stage Zero) it may reflect an unconcern about the innovation.

The second emergent trend in the data seemed to be a lack of unconcern from Participant Four toward technology in physical education. Further supporting this notion is an examination of Participant Four's total score. At the start of the class he had a total score of $64 \%$. Following the class his total score decreased to 44\%. As Hall, George, and Rutherford (1979) point out a low total score may suggest that the user is comfortable with the innovation, but lacks a high degree of investment. 
Stages of Adoption data profile. Participant Four identified Stage One, Awareness, as the stage that characterized his adoption status of technology when he entered the instructional technology course. The Awareness stage describes a technology user that is aware that technology exists, but beyond that they are not very comfortable with using it. For post-class administration of the stage of adoption of technology survey Participant Four identified Stage Five, Adaptation to New Contexts that most accurately captured his perception toward instructional technology. Stage Five is characterized as a technology user that feels confident in their ability to apply technology in a variety of contexts.

Examination of the Stages of Adoption data supported the notion that Participant Four left the class with a degree of comfort toward using technology in his teaching. Highlighting this is his increase in stage of adoption of technology from Awareness (Stage One) to Adaptation to New Contexts (Stage Five). Stage Five characterizes a user that is comfortable in their ability to use technology in a variety of contexts. Therefore, it was safe to assume that the instructional technology course made Participant Four feel more comfortable and confident in his ability to use technology in his teaching.

\section{Qualitative Case Profile}

Analysis of Participant Four's qualitative data supported the theme that emerged from his SoCQ data. A significant theme that emerged from his post-class quantitative assessment was a lack of investment toward instructional technology. A similar theme emerged from his qualitative data. Instructional technology was a tool that did not completely align with his teaching philosophy. From his first week journal entry he made this clear when asked what his opinion of technology was: 
I think technology is a great tool if it is used in the right way. Unfortunately, kids spend hours upon hours in front of a screen each day. I want to pull kids away from their television and computer screens and engage them in activities that promote health (P4-J1L21).

His belief that technology would not promote activity was voiced strongly in week one. However, in his week two journal he did cite two technologies that sparked his interest because he felt they promoted physical activity. When asked about how the class was meeting his expectation he stated the following, "I did not expect to learn about hand held GPS navigation. I think that was one of the most unique ideas for a class, but I don't think it is realistic for most schools with a low end budget" (P4-J2-L6). In that statement he mentioned a specific technology that he enjoyed using, but he also voiced his concern on it not being a feasible tool for most schools. He reiterated this sentiment when he was asked about concerns he still had following two weeks of the class. "I just want to know how we can make technology fit into a tight budget" (P4-J2-L18).

Following the course Participant Four's skeptical tone remained consistent during his interview, but he did see value in specific technologies that he felt aligned with his teaching philosophy. His affinity toward certain technologies was articulated when he was asked to describe his experience in the class, "I like hear rate monitors, I like the activity watches, and I like the GPS. Anything that is going outside and doing actual physical activity I am all for that" (P4-I-L6). While he did praise the potential value of certain technologies his skepticism about technology remained strong. When he was asked if the class what impact his teaching behaviors he responded, 'I'm just not an avid fan of it (technology) yet. I don't see the use for technology now. It is just not for me" (P4-I-L37). His lack of belief in technology was further elaborated on 
when he stated the following, "I think we can still use paper and pencil if we really had to do this stuff technology is supposed to accomplish" (P4-I-L41). As to why he lacked the investment his following statement may best describe it:

I think the reason behind this is probably because I have been with the generation of technology. I grew up with all this stuff and it should be common sense to kids. They grew up around the internet and around all of these sources they already know about. I want to pull them away from that (P4-I-L44).

This statement indicated that Participant Four believed that technology promotes the wrong thing. As a result of the skepticism was expressed when he was asked how the course changed him he stated, "The course did not make a monumental change about my views of technology in the classroom. I think that there are plenty of ways to incorporate technology, but not all of them are necessarily useful for student learning" (P4-J3-L8). His negative perception may have been best captured when he discussed the lack of change in his teaching behaviors following the course, "I am not convinced. I think we can still use paper and pencil if we really had to do this stuff that technology is supposed to accomplish" (P4-I-L41).

Participant Four was clearly skeptical of technology, but he did feel comfortable in his ability to use technology. When asked to describe his feelings about using technology during his student teaching practicum he responded by saying, "I'm not scared of the thought I think it can be easily incorporated it is really just how useful it is." (P4-I-L79) As to why he felt confident in his ability to use technology he pointed to his exposure to technology when he grew up. Specifically he cited, "I grew up around technological advances we are all up to date with this kind of stuff so it is nothing new to me it's just extra work" (P4-I-L81). Even in these statements 
about technology he stated that he felt comfortable, but he also made it a point to include his negative views of technology as well.

\section{Mixed-Data Case Narrative}

When you combine Participant Four's quantitative and qualitative data it revealed a duality of trends. First and foremost when you examine his qualitative and SoCQ data it characterized a user that lacks investment in instructional technology. His mindset created a great deal of skepticism for him about instructional technology. Pajares (1992) highlighted that all teachers have beliefs about teaching and beliefs about teaching can be resistant to change. Relative to instructional technology scholars suggest that teachers are not likely to use a tool that they do not value (Ertmer \& Ottenbreit, 2010). While he was skeptical to using technology in his teaching, he was very comfortable with his ability to use technology. He also did express an interest in using technologies that promoted physical activity. On the post-class quantitative assessment he rated himself as a Stage Five adopter. Further, throughout the qualitative data he talked about him feeling comfortable with technology. Even though he is a confident technology user his skepticism and lack of investment in instructional technology were not positively influenced as a result of the course. As Hall, George, and Rutherford (1979) highlight an individual's personal must first be addressed. Therefore, for Participant Four his internal concerns about technology's role in physical education will need to be addressed for meaningful change to occur. 


\section{Participant Five Profile}

\section{Background Information}

Participant Five was a male pre-service teacher. He characterized his exposure to technology as a physical education student as minimal. When it came to how he gained the most knowledge about technology he attributed it to learning experiences during his K-12 years. Prior to enrollment in the instructional technology course he had only attended one technology course during his time as a college student.

\section{Table 5}

SoCQ Data

\begin{tabular}{ccccccccc}
\hline Timing & $\begin{array}{c}\text { Stage } \\
\text { Zero }\end{array}$ & $\begin{array}{c}\text { Stage } \\
\text { One }\end{array}$ & $\begin{array}{c}\text { Stage } \\
\text { Two }\end{array}$ & $\begin{array}{c}\text { Stage } \\
\text { Three }\end{array}$ & $\begin{array}{c}\text { Stage } \\
\text { Four }\end{array}$ & $\begin{array}{c}\text { Stage } \\
\text { Five }\end{array}$ & $\begin{array}{c}\text { Stage } \\
\text { Six }\end{array}$ & $\begin{array}{c}\text { Total } \\
\text { Score }\end{array}$ \\
\hline Pre & 98 & 97 & 92 & 85 & 54 & 72 & 84 & 83 \\
Post & 60 & 84 & 91 & 65 & 43 & 88 & 92 & 75 \\
\hline
\end{tabular}

\section{Participant Five}

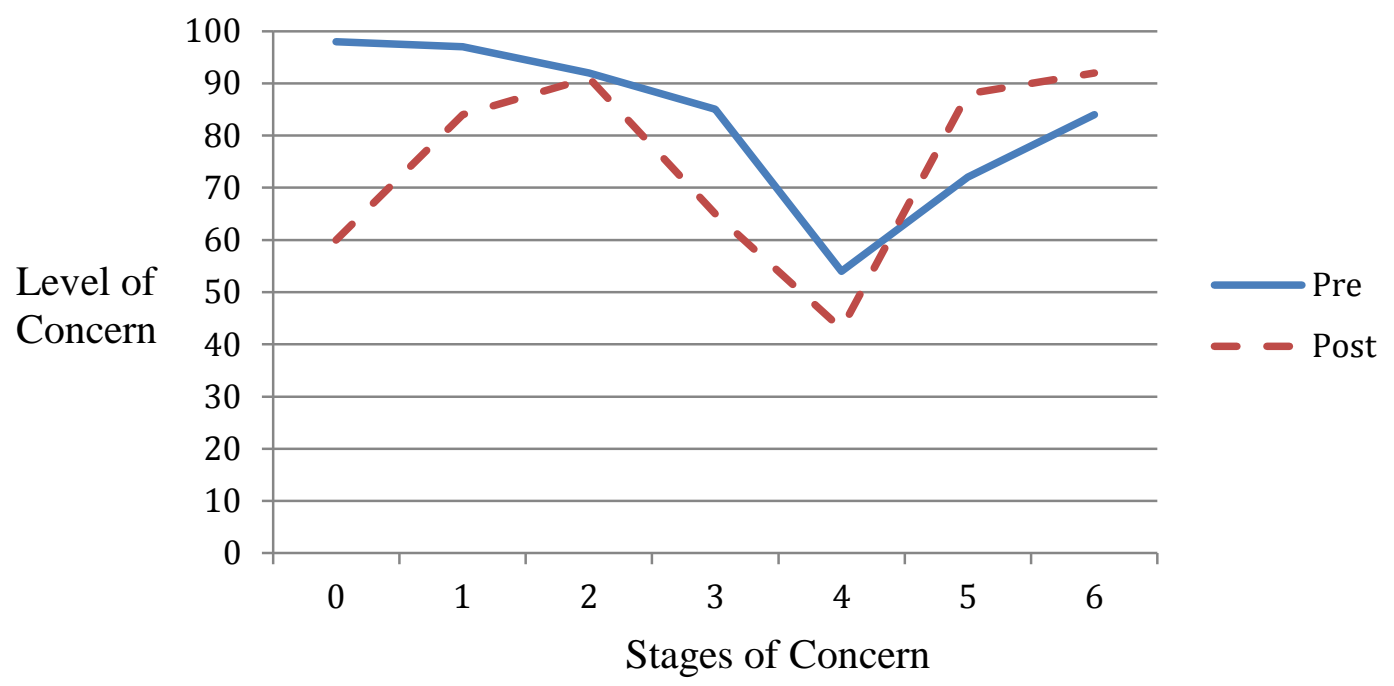

Figure 5. Participant Five's pre and post-course levels of concern. 


\section{Quantitative Case Profile}

SoCQ data profile. Examination of Participant Five's SoCQ data revealed three emergent trends. First, it was clear coming into the instructional technology course Participant Five had a high level of internal concerns toward using technology in his teaching. Specifically, he registered scores over $90 \%$ on Awareness (Stage 0), Informational (Stage 1), and Personal (Stage 2). The high internal concerns suggested that Participant Five needed to know more information about technology and physical education was worried about how using technology would impact him while he was teaching, and had concerns about his current knowledge base toward instructional technology. These high internal concerns echoed what he stated in his background information because he had minimal exposure to technology as a physical education student and had only attended one technology course as a college student.

The second emergent trend focused on the shift in concerns that occurred in Participant Five following participation in the instructional technology course. Primary of the shifts in concerns was the dramatic decrease on his Awareness (Stage Zero) concern. His level of concern decreased from $98 \%$ to $60 \%$. Such a decrease suggested that a lot of his initial fears and concerns about using technology in his teaching were addressed during the course. Further substantiating this shift in concern was an increase on the level of concern for Collaboration (Stage Five) and Refocusing (Stage Six). Collaboration (Stage Five) saw an increase from $72 \%$ to $88 \%$. A high Collaboration (Stage Five) indicated that the user had a strong desire to collaborate with others in their use of technology in the physical education context. In a similar vein, his Refocusing (Stage Six) level of concern increased from $84 \%$ to $92 \%$. According to Hall, George, and Rutherford (1979) when a stage six score is high, 92\%, and is accompanied 
with a lowered stage one, $81 \%$, score it indicates that the user feels that they know more about the innovation and have ideas for how they can implement it.

The third trend was the consistent concern that remained on Personal (Stage Two). Prior to the course his Personal (Stage Two) concern was $92 \%$ and following the course it was $91 \%$. Personal (Stage Two) was the only internal concern that saw little change following the course. Hall, George, and Rutherford (1979) highlight that a high Personal (Stage Two) score is indicative of a user that has intense personal concerns about how the innovation is going to impact them or the consequences of them using it. Therefore, it appeared that he still had a high concern about the personal consequences of using technology in the physical education context.

Stages of Adoption data profile. Participant Five identified Stage One, Awareness, as the stage that characterized his stage of adoption of technology when he entered the instructional technology course. The Awareness stage describes a technology user that is aware that technology exists, but beyond that they are not very comfortable with using it. Following the instructional technology course participant identified Stage Six, Creative Application to Other Contexts, as the stage that identified their stage of adoption of technology. Stage Six describes technology users that are not only very confident in their ability to use technology in a variety of contexts, but they also have the confidence to make technology an integral component of his or her curriculum.

Analysis of the Stages of Adoption data revealed a dramatic shift from pre assessment to post assessment. Coming into the class Participant Five rated himself at a Stage One of adopter of technology. Therefore, he labeled himself as having very little knowledge and confidence in his ability to use technology in the physical education setting. However, following the course his 
adoption status increased to Stage Six. Such a shift indicates that the instructional technology course instilled a great deal of confidence in him to the point that he feels he now has the competencies to use technology in his teaching and use it in a creative manner.

\section{Qualitative Case Profile}

Analysis of Participant Five's qualitative data supported findings that emerged from his quantitative data. His quantitative profile characterized a technology user that lacked confidence in their ability to use technology when he entered the instructional technology course. A representation of this concern was feelings he shared in his week one journal entry. When asked to describe his concerns about technology he responded, “Technology can be extremely intimidating and incorporating it into teaching can seem like a risk if the teacher does not know much about the technology or she is planning to use" (P5-J1-L18). While he did express concerns about using technology in his teaching he also described why he thought technology was a positive for learning environments. Specifically he cited, "Since students are becoming more and more familiar with technology it can be added to a curriculum with very few problems" (P5-J1-L11).

Following the second week of the course he voiced similar concerns about lacking confidence in his ability to use technology. When asked to discuss his concerns about technology he described prior negative experiences he had with technology. However, when he talked about a prior negative experience during week two he mentioned how those concerns have not yet come to fruition:

There were so many experiences where I felt as if throwing the computer out of my dorm's fourth story window was definitely the best option. But there have not been too 
many experiences like that so far in this class. I'm so glad my suspicions were incorrect and that I have had some good experiences so far in class (P5-J2-L16).

He pointed to one specific experience he had with a technology that he really enjoyed. In his week three journal he was asked to describe his most important experience of the class. "I feel like the GPS systems were the most important technology because they seem like the thing that most likely fit into my physical education teaching” (P5-J3-L5). It was his belief that the GPS system matched his teaching philosophy of getting students outside and getting them active. During his interview he further explained the role technology will have in his teaching and why he has an affinity to certain technologies. "If it aligns with that I already think I will be using or what I will probably be using I will definitely be more apt to use it" (P5-I-L60) Therefore, for Participant Five he valued technologies that aligned with his teaching philosophy, which for him focused on getting students outside and promoting physical activity.

Following the course his positive tone toward technology continued to emerge. Illustrating his positive tone about technology was an outcome he described following the course in his week three journal entry. "As a result of the course I feel like incorporating technology into my physical education classroom is not only a good idea but almost a necessity" (P5-J3L16). An important message he articulated in his previous quote was that he felt that technology was a necessity for his teaching. Highlighting why he felt this way was the response he provided to a question of whether technology could make him a better teacher:

Definitely it could make me a better teacher and it can help students learn more. That is the point of teaching is student learning so if I can get the technology and use it then yea it will make me a better teacher (P5-I-L77). 
Another important transformation that was seen following the course was an enhanced level of confidence in his ability to use technology. When he was asked to describe if he feels he will be successful in his use of technology during his student teaching practicum he responded, "I feel pretty confident that I will be successful in my use of technology during the student teaching placement" (P5-I-L101). Not only did Participant Five believe that technology was an effective instructional tool, but he felt confident that he has the ability to use technology in his teaching.

While his tone was positive in nature he did voice a concern that he envisioned would be a challenge for him as a teacher. Specifically he cited that the cost of technology would be a challenge for him to address. When asked about the feasibility of technology he replied, "It's feasible if there is money to do it because with technology money is probably the biggest issue especially in the public school setting" (P5-I-L70). Now while he did mention the challenge of cost he discussed this issue also when asked what he would do differently as teacher after experiencing the class. "Find ways to maybe write grants to get technology because I know a lot of times when you are in public schools you are not going to have a lot of the things that we have here at the university" (P5-I-L24). So while he is concerned about the cost of technology he is already thinking of ways that he can address this challenge.

Participant Five's qualitative data described an individual that entered the course with concerns about his ability to use technology. When asked to describe his concerns entering the course he finished his thoughts by saying, "I just wanted to the class over with coming into it" (P5-I-L18). A reason for his negative feelings about the class spawned from his prior negative experiences he had with technology; however, as Participant Five matriculated through the course his feelings about technology shifted to a more positive tone. A great illustration of this transformation was a response he provided during his week two journal entry when he was asked 
to describe how the class has addressed his concerns. "Before the class I was not comfortable with technology and using it in my classroom was out of the question. Things have changed over the previous three weeks" (P5-I-L14). While Participant Five spoke to a positive change that occurred as his SoCQ data showed he still possessed a concern about the personal consequences of using technology. For Participant Five his concern still seemed to be rooted in the operational aspects of using technology. When asked to discuss that challenges he envisioned in his use of technology he stated, "I'm not good with it first of all so I am not as comfortable teaching people how to use it because I am not that great with it either. So that is a huge challenge" (P5-I-L83). Again this highlighted the duality of feelings that Participant Five possessed following the course. He entered the course as a frustrated, negative technology user. Following the course his outlook changed to a proponent of technology and a more confident technology user, but he still possessed a concern about how challenging the operational aspects of using technology will be for him. For Participant Five it will be critical for him to be comfortable with the technology in order for him to integrate it into his teaching, thus his operational concerns of using technology will need to be addressed for meaningful change to occur.

\section{Mixed-Data Case Narrative}

A holistic view of Participant Five's quantitative and qualitative data described a user that had positive experiences and outcomes from the instructional technology course. Representing this positive change was that he entered the course as a stage one adopter and left the course as a stage six adopter. Pierson's (2001) research on the importance of knowledge about technology highlights that it is critical for teachers to know how to use different technologies and how to effectively integrate them into their teaching. For Participant Five 
learning how to use the different technologies appeared to fuel the positive change he experienced. It is clear following analysis of Participant Five's data that intense personal concerns he possessed about technology were greatly alleviated as a result of his experience in the instructional technology course. However, as his SoCQ Personal (Stage Two) concern revealed and when he spoke to challenge of using technology Participant Five still possessed a personal concern about the operational challenge of using technology. Addressing his concern about the operational challenges of using technology is important because an individual's selfefficacy toward an instructional tool ultimately plays a significant role on whether or not they will use it (Ertmer \& Ottenbreit, 2010). Participant Five received perceived outcomes from the class ranging from an enhanced knowledge base, increased confidence, and a belief that technology can benefit his teaching. A critical factor for Participant Five to continue to maintain his positive view of technology it will be important that he is fully comfortable with technology that he uses in the instructional setting.

\section{Participant Six Profile}

\section{Background Information}

Participant Six was a male pre-service teacher. Coming into the class he cited that his exposure to technology as a physical education student had been moderate. During his collegiate years he attended one technology course. He also attributed most of his knowledge about technology to learning experiences he had during the K-12 years as a student. 
Table 6

SoCQ Data

\begin{tabular}{ccccccccc}
\hline Timing & $\begin{array}{c}\text { Stage } \\
\text { Zero }\end{array}$ & $\begin{array}{c}\text { Stage } \\
\text { One }\end{array}$ & $\begin{array}{c}\text { Stage } \\
\text { Two }\end{array}$ & $\begin{array}{c}\text { Stage } \\
\text { Three }\end{array}$ & $\begin{array}{c}\text { Stage } \\
\text { Four }\end{array}$ & $\begin{array}{c}\text { Stage } \\
\text { Five }\end{array}$ & $\begin{array}{c}\text { Stage } \\
\text { Six }\end{array}$ & $\begin{array}{c}\text { Total } \\
\text { Score }\end{array}$ \\
\hline Pre & 99 & 80 & 83 & 52 & 27 & 16 & 81 & 63 \\
Post & 93 & 90 & 80 & 88 & 43 & 44 & 87 & 75 \\
\hline
\end{tabular}

\section{Participant Six}

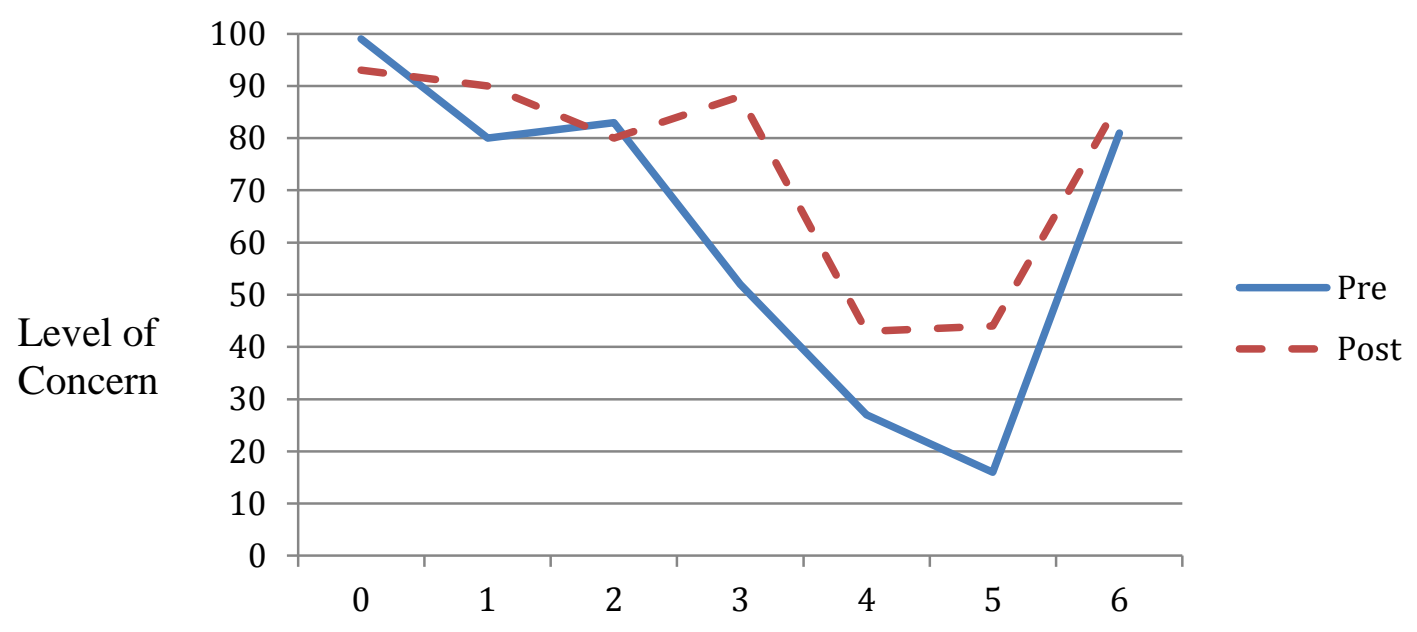

Stages of Concern

Figure 6. Participant Six's pre and post-course levels of concern

\section{Quantitative Case Profile}

SoCQ data profile. Examination of Participant Six's SoCQ data identified three emergent trends. The first trend was the high level of concern on Awareness (Stage Zero) that was present prior to and following the course. Prior to the course he scored a $99 \%$ on Awareness (Stage Zero) and following the course his level of concern was 93\%. There was a slight decrease from pre to post assessment but a high level of concern remained. According to Hall, George, and Rutherford (1979) this is indicative of a user that is just becoming aware of the innovation. 
The second trend that was of importance from the SoCQ data was an increase in two of the internal concerns. His Informational (Stage One) level of intensity increased from $80 \%$ to 90\%. This means that he left the class wanting to have more information about technology and physical education. Similarly, his Management (Stage Three) level of concern increased from $52 \%$ to $88 \%$. High levels of concern on Management (Stage Three) are indicative of users that have intense concerns about the management of the innovation (Hall, George, \& Rutherford, 1979). Therefore, it appears that following the course that Participant Six left the class with enhanced concerns toward technology and physical education as it relates to wanting more information and the logistics of using it.

The third trend related to an increase in his Refocusing (Stage Six) level of concern. When he entered the course he scored an $81 \%$ and following the course he had an $87 \%$ level of concern. The increase in stage six indicated that he left the course with more ideas about how he could potentially use technology in the physical education setting. However, as Hall, George, and Rutherford (1979) point out a Refocusing (Stage Six) increased level of concern that is accompanied with high levels of internal concerns could indicate that the user has more ideas about the innovation but negative feelings may still persist.

Stages of Adoption data profile. Participant Six selected Stage Three, Understanding the Application of the Process, as his adoption status that most accurately captured his perception toward technology when he entered the course. Stage Three describes a user that is beginning to understand the process of applying technology and can even cite specific ways in which they could apply it. Following the course Participant Six again identified Stage Three as his adoption status. Therefore, he felt that the instructional technology course did not enhance his stage of adoption of technology. 
Examination of the Stages of Adoption data was fairly straightforward. Participant Six entered the course at a Stage Three and left the class at a Stage Three. Stage Three, Understanding the Application of the Process describes a user that is beginning to understand how the process of implementing technology. Therefore, it appears that the course did not enhance confidence in his ability to implement technology into his teaching in more creative and diverse manners.

\section{Qualitative Case Profile}

Analysis of Participant Six's qualitative data supported the results that emerged from his quantitative data. A prominent theme that emerged from his quantitative data was that his internal concerns relative to instructional technology remained an issue following the course. What is interesting about Participant Six is that during his weekly journal entries he spoke positively about instructional technology. In his week one journal he was asked to describe what his opinion of technology his response was the following:

Technology wasn't really a big part of my physical education, but I found that using technology could be a great help. With so many students becoming engaged with technology on an everyday basis it seems appropriate to integrate it into the classroom (P6-J1-L12).

One aspect of this statement that developed into a trend in his qualitative data was his mention of technology not playing a big role in his past as a physical education student. During his week three journal entry he was prompted to write about his most important experience in the class. He stated the following, "Coaching is something that I want to do in the future and I think this course has helped me better understand how to incorporate the video editing technology into my 
coaching effectiveness" (P6-J3-L9). What this highlighted is that Participant Six saw how the technology could enhance his coaching effectiveness instead of his teaching effectiveness.

His lack of desire to utilize technology in his teaching really emerged during his interview. When asked what he would do differently as a result of his experience in the class he responded, "I don't really doubt technology it's just that I don't know if I would actually use the technology it's just I'd rather be more traditional" (P6-I-L18). His affinity to a more traditional approach to teaching was again mentioned when he discussed the role technology would play in his teaching. "I just feel more comfortable with a traditional approach" (P6-I-L41). Clearly, he viewed technology as an approach to teaching physical education that was non-traditional. He discussed a few times in his interview why he viewed technology as a non-traditional approach to teaching physical education. His response to what he would do differently as a teacher following the instructional technology course helped explain his rationale: "Honestly I just think it is easier to go without technology as opposed to using technology" (P6-I-L20). While he mentioned his concern about technology creating more work and making teaching more difficult he also spoke to simply not seeing the value of technology. When asked to describe his feelings about using technology during his student teaching practicum he cited, "It still kind of goes back to I really don't see how technology will benefit me in my teaching" (P6-I-L80). He pointed to one aspect of the course that inhibited him changing his perception of technology greatly was the lack of experience he had of using technology during field placements. "You know we really haven't used any of the technology resources during our teaching placements" (P6-I-L31).

Lack of authentic experience of using technology in the K-12 context may have prevented him from changing his perception of technology greatly, but he did leave the course feeling more comfortable in his ability to use technology. He cited multiple times how he felt 
the class did benefit him. When asked how the class impacted him personally for his week three journal he replied, "I've expanded my knowledge on ways to integrate technology in the classroom" (P6-J3-L14). His enhanced awareness and increased knowledge was also elaborated on during his interview. A prompt that asked him to discuss how the course influenced his concern about technology he stated, "I didn't really know how you could use technology in a physical education setting, but now I have a better idea" (P6-I-L13). He spoke to some positive outcomes he received from the course; however his skepticism about technology remained. When prompted to describe his final thoughts about technology or the technology course he stressed, "The course was beneficial in learning more about technology. I just don't know how effective some of the technology will be in the physical education classroom" (P6-I-L91). Participant Six benefitted from an enhanced awareness of technology, but he simply did not see the value of using technology in his teaching.

Participant Six's qualitative data characterized an individual that prefers a traditional approach to teaching physical education. What is interesting about his qualitative data are that when you connect a few of his trends is that it suggested that he possessed a coaching warrant. Lawson (1983a) describes a teacher that possesses a coaching warrant prefers a traditional approach to teaching physical education. He mentioned early in his journal responses that technology was something that he was not exposed to as a physical education student. Therefore, as Lortie $(1975,2002)$ suggests teachers are often socialized to teach in a similar manner that they were taught. Now while Participant Six did not value technology's role in his teaching he did feel more confident that he could use technology. When asked if he would be able to integrate technology into his teaching he candidly replied, "I mean I would be able to if I wanted to. I know how to use different technologies and it would just a matter of whether I 
wanted to apply it to my teaching" (P6-I-L48). His knowledge of technology and confidence in his ability to use technology is not an issue for him. The real concern for Participant Six is that he does not value technology. His response to a challenge he thinks he will face with his use of technology as a teacher may best capture his perception of technology when left he the instructional technology course. "I just don't really have the desire to use technology" (P6-IL68).

\section{Mixed-Data Case Narrative}

A holistic view of Participant Six's quantitative and qualitative data revealed an individual that has intense personal concerns about instructional technology. For him his personal concerns are squarely rooted in a lack of desire to use technology. The intense internal concerns are evident in his post-class SoCQ and throughout his interview responses. As Lawson (1983a) highlighted pre-service teachers beliefs about teaching have been well established by the time they enter formal preparation. For Participant Six it was clear that his lack of change seemed to be rooted in instructional technology not aligning with his established beliefs about teaching physical education. Lack of change was also present with his stage of adoption of technology because he rated himself as a stage three adopter for pre and post administration. When an individual does not believe that instructional technology will benefit their teaching they are likely not going to use it (Ertmer \& Ottenbreit, 2010). One area that did see a slight increase was his Refocusing (Stage Six) concern on the SoCQ that increased from 81\% to 87\%. This increase suggested that he left the course with more ideas and knowledge about instructional technology. This finding was also supported in his qualitative data. Participant Six felt more knowledgeable and confident about technology; however he did not believe that technology was a necessity. Again this highlighted the duality of feelings that Participant Six experienced. He 
gained knowledge about technology, but his internal concerns about technology's role or lack thereof in his teaching remained consistent. Therefore, as Hall, George, and Rutherford (1979) emphasize an individual's internal concerns must first be addressed before meaningful change can occur.

\section{Participant Seven Profile}

\section{Background Information}

Participant Seven was a male pre-service teacher. He characterized his exposure to technology as a physical education student as high. When it came to how he gained the most knowledge about technology he attributed it to learning experiences during his K-12 years. Prior to enrollment in the instructional technology course he had only attended one technology course during his time as a college student.

Table 7

SoCQ Data

\begin{tabular}{ccccccccc}
\hline Timing & $\begin{array}{c}\text { Stage } \\
\text { Zero }\end{array}$ & $\begin{array}{c}\text { Stage } \\
\text { One }\end{array}$ & $\begin{array}{c}\text { Stage } \\
\text { Two }\end{array}$ & $\begin{array}{c}\text { Stage } \\
\text { Three }\end{array}$ & $\begin{array}{c}\text { Stage } \\
\text { Four }\end{array}$ & $\begin{array}{c}\text { Stage } \\
\text { Five }\end{array}$ & $\begin{array}{c}\text { Stage } \\
\text { Six }\end{array}$ & $\begin{array}{c}\text { Total } \\
\text { Score }\end{array}$ \\
\hline Pre & 60 & 84 & 91 & 65 & 71 & 91 & 90 & 79 \\
Post & 66 & 80 & 94 & 65 & 90 & 93 & 98 & 84 \\
\hline
\end{tabular}




\section{Participant Seven}

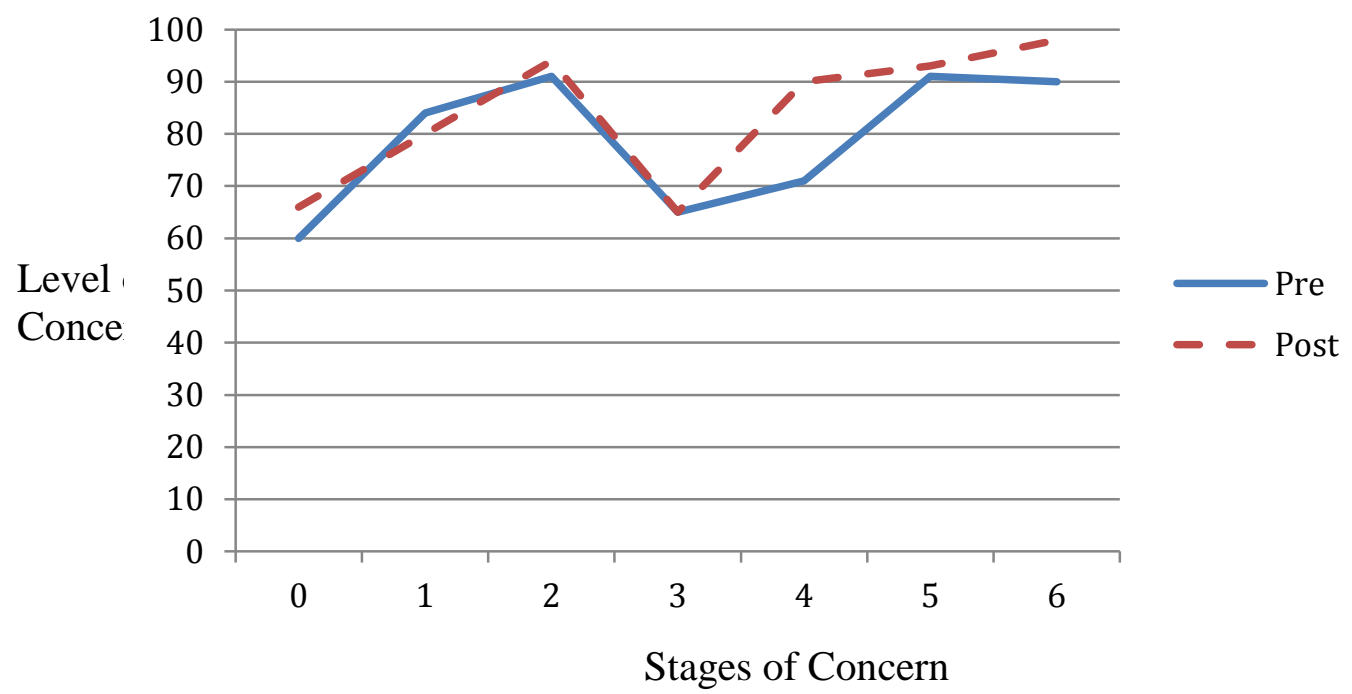

Figure 7. Participant Seven's pre and post-course levels of concern

\section{Quantitative Case Profile}

SoCQ data profile. Examination of Participant Seven's SoCQ revealed two trends in the data. The first trend in the data was the high level of external concerns that Participant Seven possessed coming into the course and following the course. He entered the course with a $91 \%$ on Collaboration (Stage Five) and left the course with an increased level concern at 93\%. Hall, George, and Rutherford (1979) suggest that a user that has level of concern on Collaboration (Stage Five) are concerned about and are interested in collaborating with others in relation to the innovation. A similar trend was also present with his Refocusing (Stage Six) scores. Coming into the course he had a $90 \%$ level of concern and left the course with an increased level of concern of $98 \%$. Such a high level of concern on Refocusing (Stage Six) indicated that he had ideas about how he could not only use the innovation but ways in which he could potentially 
improve its use (Hall, George, \& Rutherford, 1979). Given that he entered the course with high exposure to technology as a physical education student may provide a reason for such high external concerns. Another positive trend in Participant Seven's external concerns was a dramatic increase in his level of concern for Consequence (Stage Four) which jumped from $71 \%$ to $90 \%$. A high Consequence (Stage Four) concern score emphasizes that the user is thinking beyond their internal concerns and are concerned about how the innovation will impact his or her students in the learning environment (Hall, George, \& Rutherford, 1979).

The second trend that emerged in his SoCQ data was that his high level of concern for Personal (Stage Two) remained present. He entered the class with a $91 \%$ level of concern on Personal (Stage Two) and left with a 94\% level of concern. The high level of concern on Personal (Stage Two) indicated that he is highly concerned about the personal consequences of using technology in his teaching. As Hall, George, and Rutherford (1979) highlight while a person with a high Personal (Stage Two) level of concern may worry about the personal consequences of using the innovation it does not necessarily mean that they will resist using it. This sentiment supported Participant Seven's profile because he possessed such high levels of external concerns when he left the course.

Stages of Adoption data profile. For pre-class administration of the Stages of Adoption survey Participant Seven identified Stage Five, Adaptation to Other Contexts that most accurately captured his perception toward instructional technology. Stage Five is characterized as a technology user that feels confident in their ability to apply technology in a variety of contexts. Following the instructional technology course Participant Seven also identified Stage Five as the adoption status that best characterized his perception of instructional technology and 
using it in his teaching. Therefore, he felt that the instructional technology course did not enhance his stage of adoption of technology.

Analysis of the Stages of Adoption data was straightforward. He entered the class with a Stage Five adoption status. Following the course his adoption status remained the same. Stage Five, Adaptation to Other Contexts users are confident that they have the ability to use technology in a variety of contexts and are able to use it in their teaching. Therefore, it appeared the course did not enhance his stage of adoption of technology, but it also did not negatively impact his stage of adoption of technology.

\section{Qualitative Case Profile}

Analysis of Participant Seven's qualitative data reinforced the themes that emerged from his quantitative data. Two themes emerged from his quantitative data. One theme was characterized as him being a confident technology user that felt comfortable with his ability to integrate technology into his teaching. Throughout his qualitative data he also described himself as a confident technology user. He also spoke to the potential value technology could bring to the physical education setting in his week one journal. When asked to describe how concerned he was about technology he responded, "I am very concerned about using technology in my classroom. It would be waste to ignore resources that can help our teaching process" (P7-J1L14). His concern about using technology in the physical education setting was also clearly expressed in his week three journal. When prompted to describe his most important experience of the class he replied:

I feel the most important experience that I have had in class is figuring out ways to implement technology into my teaching. Prior to class I felt comfortable in my 
knowledge of what the technology was, however I wasn't completely sure how it would help me become a better teacher (P7-J3-L2).

The question of how technology could make him become a better teacher was also addressed during his interview. When he discussed his experience in the class he stated the following, "So far I mean have known all of the forms of technologies. However I feel that I have gained some appreciation on how to use it and implement it into my teaching to improve my effectiveness" (P7-I-L3). Participant Seven emphasized that he felt comfortable with technology just that the course helped him better understand how he can integrate different technologies into his teaching. An ideal illustration of his mindset was when he was asked if he thought he could be successful using technology: "More or less the class helped to put all of the pieces of the puzzle together" (P7-I-L80). Participant Seven is comfortable using technology, but needed more information on how he could integrate technology in the physical education context. This increased comfort level is reflected when he was asked what he got out the class, "Overall, I thought that I got a lot out of this class. I learned how to best use these forms of technologies and learned how to use technologies that I thought could never be used in physical education" (P7-J3-L9). His increased awareness on how to integrate technology was further articulated in his interview when he was asked to describe how the class would potentially change his teaching behaviors: "I was a little narrow minded about using technology, like using videos or music. I never really thought about podcasting so the class broadened my view of technology" (P7-IL33).

The second theme that emerged from his quantitative data, specifically his SoCQ profile was that he had a high degree of concern on the potential consequences of using technology. While this concern did not emerge in his journal entries they did emerge in his interview. When 
asked to share his opinion on the role technology should have in physical education he provided an interesting answer. "I would never want my instruction to be technology you understand what I am saying. Like for instance I heard in Florida they changed most of their schools physical education to technology-based instead of teacher delivered" (P7-I-L39). While he described his fear that technology could replace teacher-based physical education he still felt that technology had a role in physical education. "You should use technology in my opinion but if you become too reliant on technology it could replace us" (P7-I-L42). He further articulated on this concern when asked to describe the role of technology in his teaching, "My personal philosophy is that technology should not be a huge role of physical education" (P7-I-L48). His fear of the potential consequences seemed to stem from his belief that if technology is emphasized too much it could result in him losing his job.

\section{Mixed-Data Case Narrative}

For Participant Seven his qualitative data provided a background on the themes that emerged from his quantitative data. It was believed after analysis of his quantitative data that he entered the course a confident technology user. Illustration of this was the fact that he identified himself as a Stage Five adopter at the beginning of the class. His comfort level with technology was also voiced in his interview. In addition to a high degree of comfort and confidence with technology it was believed that the course provided him with more knowledge about how he could potentially use technology in his teaching. This belief was derived from his increased level of concern on Refocusing (Stage Six) for his post-class SoCQ. His concern increased from $90 \%$ to $98 \%$. Increased knowledge relative to instructional technology and physical education was also evident in qualitative data. 
It was also believed following analysis that he had concerns about the personal consequences of using technology. What his qualitative data informed us was that he is concerned about technology potentially replacing teachers. As a result, it appears this concern about technology negatively impacting physical education needs to be addressed before he fully embraces technology as an instructional resource. Posner and colleagues (1982) emphasized that a person's beliefs or conceptions act as a filter to newly introduced ideas. For Participant Seven he possessed a belief that technology could potentially negatively impact his ability to teach physical education. A result of this belief was that he does not intend on having technology play a huge role in his teaching. As Hall, George, and Rutherford (1979) emphasize lower stages of concern must first be addressed. Therefore, for Participant Seven his concern about the potential negative personal consequences of using technology will need to be alleviated. However, when you couple his SoCQ level of concern on Refocusing (Stage Six) and the themes that emerged from his qualitative data it is clear that the course made him more knowledgeable on how he can integrate different technologies into his teaching. So while the course did help enhance his knowledge and confidence his internal concern about the negative consequences of using technology will need to be addressed for meaningful change to occur.

\section{Participant Eight Profile}

\section{Background Information}

Participant Eight was a male pre-service teacher. Coming into the class he cited that his exposure to technology as a physical education student had been moderate. During his collegiate years he attended zero technology courses. He also attributed most of his knowledge about technology to learning experiences he had during the K-12 years as a student. 
Table 8

SoCQ Data

\begin{tabular}{ccccccccc}
\hline Timing & $\begin{array}{c}\text { Stage } \\
\text { Zero }\end{array}$ & $\begin{array}{c}\text { Stage } \\
\text { One }\end{array}$ & $\begin{array}{c}\text { Stage } \\
\text { Two }\end{array}$ & $\begin{array}{c}\text { Stage } \\
\text { Three }\end{array}$ & $\begin{array}{c}\text { Stage } \\
\text { Four }\end{array}$ & $\begin{array}{c}\text { Stage } \\
\text { Five }\end{array}$ & $\begin{array}{c}\text { Stage } \\
\text { Six }\end{array}$ & $\begin{array}{c}\text { Total } \\
\text { Score }\end{array}$ \\
\hline Pre & 81 & 90 & 92 & 80 & 71 & 76 & 90 & 83 \\
Post & 81 & 95 & 99 & 43 & 76 & 91 & 97 & 83 \\
\hline
\end{tabular}

Participant Eight

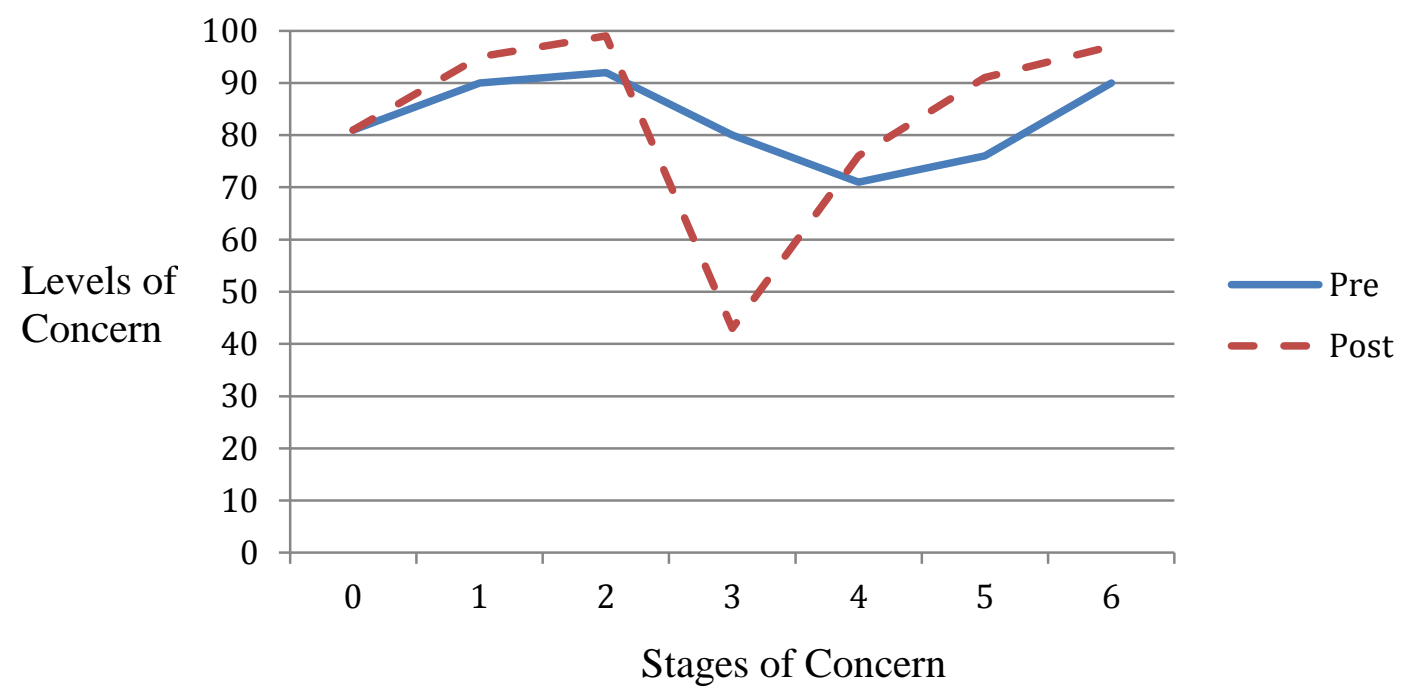

Figure 8. Participant Eight's pre and post-course levels of concern

\section{Quantitative Case Profile}

SoCQ data profile. Analysis of Participant Eight's SoCQ revealed three trends in the data. The first trend that emerged in his SoCQ data was that his Informational (Stage One) and Personal (Stage Two) levels of concern were at a high level when he entered the course and increased following the course. His Informational (Stage One) score was $90 \%$ and increased to $95 \%$ following the course. Such high level of concerns on Informational (Stage One) is indicative of a user that still needs to have more information about the innovation (Hall, George, \& Rutherford, 1979). A similar trend was present with Participant Eight's score on Personal 
(Stage Two) because his score started at $92 \%$ and increased to 99\%. Personal (Stage Two) concern highlights a user that has concerns about the personal consequences of using the innovation, which in his case a $99 \%$ score suggests he has intense concerns about this issue (Hall, George, \& Rutherford, 1979).

While two of Participant Eight's internal concerns increased following the course one concern saw a dramatic decrease. His Consequence (Stage Three) level of concern decreased from $80 \%$ to $43 \%$. A low level of concern on Consequence (Stage Three) is characteristic of users that has little to no concerns relative to the management of the innovation (Hall, George, \& Rutherford, 1979). Therefore, it appears that the course decreased the concerns he had about the potential management issues related to using technology in his teaching.

The third trend that was of importance in Participant Eight's SoCQ data was the increased level of concerns that were present in two of his external concerns. His Collaboration (Stage Five) score increased from $76 \%$ to $91 \%$. Hall, George, and Rutherford (1979) emphasize that a user that has both high level of concern on Informational (Stage One) and Collaboration (Stage Five) are indicative of a person that has a strong interest in learning how to use the innovation from others and wants to receive more ideas about how they could use innovation from other people. Participant Eight's Refocusing (Stage Six) score saw a similar increase from 90\% to 97\%. The high level of concern on Refocusing (Stage Six) highlighted that he entered the course with ideas about how he could use technology, but left the course possessing ever more knowledge relative to instructional technology and physical education. However, as Hall, George, and Rutherford (1979) emphasize a high Refocusing (Stage Six) level of concern that is accompanied with a high level of internal concerns suggest that the user may have ideas about how to use the innovation, but may still possess some negative feelings toward it as well. 
Stages of Adoption data profile. Participant Eight identified Stage Three, Understanding the Application and Process, as the stage that characterized his stage of adoption of technology when he entered the instructional technology course. Understanding the Application and Process stage describes a user that is beginning to understand the process of using technology and even knows specific ways in which they could implement technology in their teaching. For post-class administration of the stage of adoption of technology survey participant four identified Stage Five, Adaptation to Other Contexts that most accurately captured his perception toward instructional technology. Stage Five is characterized as a technology user that feels confident in their ability to apply technology in a variety of contexts.

Analysis of the Stages of Adoption data showed that he left the course with more positive feelings about his ability to use technology. He entered the course as a Stage Three adopter, but left the course at a Stage Five. A Stage Five, Understanding the Application and Process user believes they have the competencies to use technology in a variety of contexts. Similar to the increased levels of his external concern seen on Collaboration (Stage Five) and Refocusing (Stage Six) from the SoCQ his stage of adoption of technology also saw a positive trend in the data.

\section{Qualitative Case Profile}

Analysis of Participant Eight's qualitative date reinforced the themes that emerged from his quantitative profile. His quantitative data showed that he left the course feeling more knowledgeable and confident in his ability to use technology. What the qualitative data further shed light on was that he entered the course feeling comfortable about his ability to use technology. In his week one journal he discussed how he did not have any great concerns about 
technology: "At this time I really have no concerns about technology as I am pretty tech savvy with a lot of technology" (P8-J1-L18). This level of comfort and confidence with technology was also reiterated in his week two journal. When asked to describe if any concerns have emerged about technology he responded, “I myself haven't had any concerns come out because when I deal with technology I am able to learn fast which is why I don't get concerned easy" (P8-J2-L5). Clearly he felt quite comfortable about his ability to use technology and learn how to use new technologies.

Another theme that emerged in his qualitative data that also emerged in his quantitative data was that he left the course with more knowledge for how to use technology in his teaching. For him it appeared a critical factor that attributed to this positive change was his opportunity to use different technologies during the course. There were several points throughout his qualitative data where he described how important being able to use technology was for him. In his week three journal entry he was prompted to describe his most important experience in the class to which he stated the following, "I feel the most important experience that I had in class was actually getting to do hands-on activities with all of the technology we learned about" (P8J3-L2). As to why he felt this was so important he provided the following rationale, "I feel it is important for student teachers to actually get to use the tools they are being introduced to so they are able to learn about them and actually get a feel for them" (P8-J3-L5). The importance of this hands-on experience for Participant Eight was that it further instilled confidence in him that he could use the technology in his teaching. In his interview he eloquently articulated what he would do differently as a teacher following his experience in the class:

Probably use the forms of technology that I probably didn't want to use before and kind of a little weary about. Like is that really going to be beneficial? Are the students really 
going to like it? Then we used it during the class and we had a good time with it so then you feel like if I like it then there is a pretty good chance the kids are going to like it (P8I-L16).

For Participant Eight being able to use the technology was a beneficial learning experience.

A second theme that emerged from his qualitative data was a concern that he had on staying abreast with all the advancements in technology. He first mentioned this concern in his week one journal entry, "My concern would come in the future as I get older and might not be able to stay up to date with all of the different technology out there" (P8-J3-L19). He further elaborated on this point when he was asked to discuss the challenge he envisioned of using technology during his teaching he responded, "Technology actually advancing and changing all the time" (P8-I-L66). Another concern that he discussed was making sure technology did not overshadow him as a teacher. He wanted to ensure that technology was only a tool that helped him as a teacher. When asked to describe technology's role in physical education he stated, "I think that technology is a great assistant, but it will never actually get rid of the teacher" (P8-IL36). His insistence on making sure technology remained as an assistant to the teacher may have been articulated best in his week one journal. "I feel technology will be an important part of physical education in the future, but that does also not mean it can replace a teacher" (P8-J1L13). He also spoke to this concern when he discussed the role of technology in his teaching. "I never want technology to trump me, but I would like to have it as a tool to help me when I am teaching" (P8-I-L57). So while he did have concerns about keeping up to date with technology and ensuring that technology did not overshadow his teaching he believed that technology had the potential to be a positive asset for physical education teachers. 
Collectively Participant Eight's qualitative data highlighted a technology user that had enhanced knowledge, a good level of confidence, a fear of technology constantly changing, and concern about making sure technology does not overshadow his teaching. A key experience that led to his increased comfort and confidence was his ability to use technology. "Being able to use technology was something I really liked about the class" (P8-I-L7). Being able to use all of the different technologies may have also led to his next concern of staying abreast with all the different technologies in the future. Another concern that he mentioned as one that he was focused on was ensuring that technology served only as an assistant to his teaching. For him he believed this was critical for technology to be an asset. "I think as long as you use technology and you don't overuse technology you can be successful with it” (P8-I-L80). He feels that if technology is used appropriately it can be an effective tool for teachers to use. Hall, George, and Rutherford (1979) lament that an individual's internal concerns must be addressed before meaningful change can occur relative to the innovation. His duality of feelings illustrated that he is a more knowledgeable and confident technology user, but he still possessed internal concerns about using technology in his teaching.

\section{Mixed-Data Case Narrative}

When you look holistically at Participant Eight's quantitative and qualitative data it described a user that became more comfortable with using technology in his teaching. His confidence level of using technology was high when he entered the course, but learning experiences embedded within the course enhanced his knowledge of how to use technology that related to physical education. Supporting his enhanced level of confidence in using technology was his advanced stage of adoption of technology, which increased from Stage Three to Stage Five. It seemed the experience that stimulated this change was the opportunity to use the 
technology. Further supporting the advance of knowledge was the increase seen on his SoCQ stage six concern from $90 \%$ to $97 \%$. As a result of this positive change he felt confident that he could use technology in his teaching. For Participant Eight having success and positive experiences with the technology during the class provided him with enhanced confidence. Bandura (1977) reiterates why this is important because successful early experiences are critical to building one's self-efficacy.

Following post-class administration of his SoCQ two internal concerns increased. His Information (Stage One) and Personal (Stage Two) concerns increased to higher levels. These increases suggested that he had concerns about wanting more information and the potential consequences of using technology. At various points in his qualitative data he highlighted how he was concerned about staying up to date with technologies advances. This concern aligned with his SoCQ Informational (Stage One) concern of wanting more information about instructional technology. His increased Personal (Stage Two) concern of potential personal consequences of using technology was also found throughout his qualitative data. He emphasized that he did not want technology to overshadow his teaching.

Collectively the data showed that the instructional technology course increased his knowledge base relative to technology. The class also increased his confidence in his ability to use technology in his teaching. While the course did clearly advance these two areas it is also evident that his personal concerns remained. He is worried that it will be a challenge as a teacher to stay current with all of the advances in technology. Further, he wants to make sure technology is only an assistant to his teaching and does not overshadow him. He is a more confident technology user, but did possess internal concerns that he feels will be challenging in his use of technology. Hall, George, and Rutherford (1979) emphasize that an individual's internal 
concerns must first be addressed. Participant Eight's duality of feelings highlighted that his personal concerns about technology will first need to be addressed for meaningful change to occur.

\section{Participant Nine Profile}

\section{Background Information}

Participant Nine was a male pre-service teacher. Coming into the class he cited that his exposure to technology as a physical education student had been moderate. During his collegiate years he attended two technology courses. He also attributed most of his knowledge about technology to being self-taught.

Table 9

SoCQ Data

\begin{tabular}{ccccccccc}
\hline Timing & $\begin{array}{c}\text { Stage } \\
\text { Zero }\end{array}$ & $\begin{array}{c}\text { Stage } \\
\text { One }\end{array}$ & $\begin{array}{c}\text { Stage } \\
\text { Two }\end{array}$ & $\begin{array}{c}\text { Stage } \\
\text { Three }\end{array}$ & $\begin{array}{c}\text { Stage } \\
\text { Four }\end{array}$ & $\begin{array}{c}\text { Stage } \\
\text { Five }\end{array}$ & $\begin{array}{c}\text { Stage } \\
\text { Six }\end{array}$ & $\begin{array}{c}\text { Total } \\
\text { Score }\end{array}$ \\
\hline Pre & 27 & 96 & 95 & 56 & 71 & 95 & 99 & 77 \\
Post & 10 & 66 & 95 & 30 & 96 & 98 & 38 & 62 \\
\hline
\end{tabular}




\section{Participant Nine}

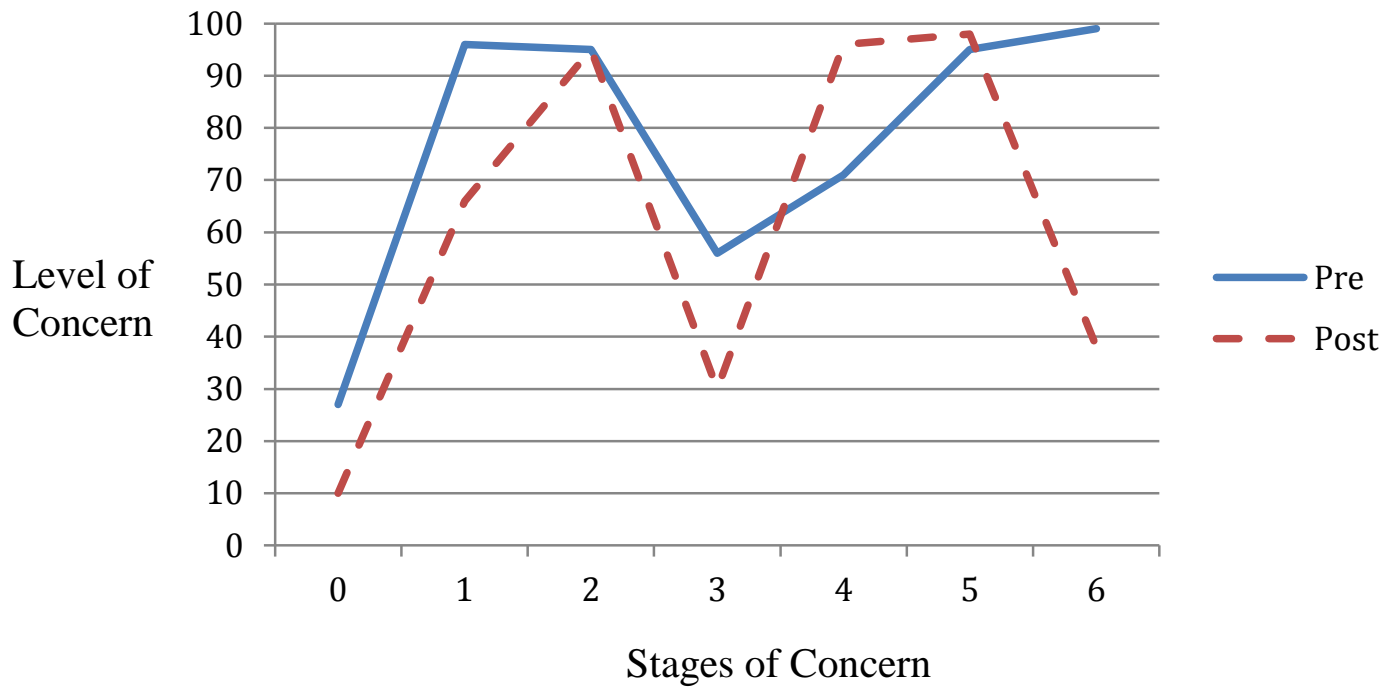

Figure 9. Participant Nine's pre and post-course levels of concern.

\section{Quantitative Case Profile}

SoCQ data profile. Analysis of Participant Nine's SoCQ provided two interesting trends in the data. The first theme that emerged was a dramatic shift from pre to post assessment in three stages. For Participant Nine Informational (Stage One) and Refocusing (Stage Six) both saw level of concerns make a dramatic decrease. His Informational (Stage One) score for preassessment was at $96 \%$, while his post-assessment fell to $66 \%$. The lowered level of concern for Informational (Stage One) indicated that he felt more confident in his knowledge about the innovation (Hall, George, \& Rutherford, 1979). A similar decrease was also present in his Refocusing (Stage Six) score which decreased from $99 \%$ to $38 \%$. Upon entry into the course Participant Nine appeared to feel that he had a lot of ideas about technology and ways in which they could enhance its use in the physical education setting (Hall, George, \& Rutherford, 1979). However, the data showed that Participant Nine's concerns about enhancing the use of technology in the physical education setting and his presumption of possessing creative ideas 
about technology were tempered following the course. While two stages saw dramatic decreases one stage saw a similar shift in the other direction. His Consequence (Stage Four) level of concern increased from $71 \%$ to $96 \%$. The high Consequence (Stage Four) level of concern indicated that he had intense concerns about how instructional technology will impact his students in the learning environment (Hall, George, \& Rutherford, 1979).

Changes from pre to post assessment were seen, but two stages of concern remained consistent. Participant Nine's Personal (Stage Two) level of concern remained over 90\% for pre and post assessment. A high Personal (Stage Two) level of concern is indicative of a user that has intense personal concerns about how technology will impact them personally, but does not indicate that they are resistant to the idea of using the innovation (Hall, George, \& Rutherford, 1979). Participant Nine's Collaboration (Stage Five) level of concern also remained at a high level. The high level of concern for Collaboration (Stage Five) is characteristic of a user that has concern about collaborating with others in relation to the innovation (Hall, George, \& Rutherford, 1979).

Stages of Adoption data profile. For pre-class administration of the Stages of Adoption survey Participant Nine identified Stage Five, Adaptation to other Contexts that most accurately captured his perception toward instructional technology. Stage Five is characterized as a technology user that feels confident in their ability to apply technology in a variety of contexts. Following the instructional technology course participant identified Stage Six, Creative Application to New Contexts, as the stage that identified his adoption status. Creative Application to Other Contexts (Stage Six) describes technology users that are not only very confident in their ability to use technology in a variety of contexts, but they also have the confidence to make technology an integral component of his or her curriculum. 
Analysis of the Stages of Adoption was not as convoluted as the SoCQ data. Participant Nine entered the course with a Stage Five adoption level, and left the course with a Stage Six adoption level. Both Stage Five and Stage Six indicated that Participant Nine felt confident in their ability to integrate technology into their teaching. Such confidence in his ability to use technology could be a result of his high exposure to technology as a physical education student and also due to him attributing his knowledge of technology stemming from being self-taught.

\section{Qualitative Case Profile}

Participant Nine's qualitative data added credence to the themes that emerged from his quantitative data. His quantitative data described a user whose concerns about technology evolved following his experience in the course, while certain concerns remained consistent. Following the course he was characterized as a knowledgeable, confident technology user that possessed some personal concerns about how technology will impact him personally and how technology will impact his students. Similar trends emerged from his qualitative data as well.

Starting in his week one journal entry his interest and affinity toward technology emerged. When asked about to provide his opinion on technology and physical education he stated, "I believe technology in the physical education realm can be very beneficial" (P9-J1-L6). It seemed a reason for his positive view as to why physical education should be included within physical education programming stemmed from its emerging role in society. "Technology is very involved in everyone's lives, even children" (P9-J1-L9). From the outset of the course he spoke positively about technology and its potential role in physical education.

His positive feelings about technology may have been rooted in the high degree of interest and comfort he possessed toward technology. In his week two journal he was prompted 
to describe if the course had changed his feelings about technology to which he responded, "The rate of which I wanted to use technology has not changed. I have always wanted to use it more in the classroom" (P9-J2-L8). His comfort toward technology was reiterated during his interview as well. "Like I said coming in I was pretty familiar with all of the technologies" (P9-I-L12). The positive feelings about technology and physical education may be best explained with a thought he expressed when he discussed his experience in the technology course during the interview. "Like I consider myself pretty knowledgeable about technology and I have always wanted to do something that could align with physical education" (P9-I-L5).

He described that he felt comfortable and knowledgeable about technology prior to entry into the instructional technology, but he also elaborated on how the course broadened his horizon as to all of the technological options that are available to teachers. During his week three journal entry he discussed the changes the class had on him:

A change that I feel that I have through with this class would be more confidence in implementing technologies into the classroom. I know how to use the majority of them, but how to use it in my instruction was lacking (P9-J3-L9).

His belief that the class had a positive change on him was also elaborated on during his interview. When asked if the class would change his teaching behaviors he responded, "The class definitely changed my teaching behaviors I didn't really have to many ideas with how I could bring technology in" (P9-I-L34). A component of the class that helped participant nine with getting more ideas was being able to use the technology. When asked to describe why the class would have a change on his teaching behaviors he pointed to hands-on learning. "The instructor is letting us practice with it even though I might not enjoy some of the aspects I now 
know how to do them" (P9-I-L42). Opportunities to practice with different and new technologies exposed him to technology that he particularly liked. "I gravitated to blogging because it was something different" (P9-I-L13). He even cited that blogging was the most important experience he had in the class. "Blogging to me was the most important experience I had in the class. I really look forward to using that form of technology in my teaching" (P9-J3L2). Being exposed and opportunities to use different technologies served as an important learning experience for Participant Nine.

While his tone was positive about technology's potential role in his teaching he also expressed concerns about how technology's impact on him and his students. These concerns were also evident in his SoCQ data with the high levels of concern on Personal (Stage Two) and Consequence (Stage Four). A high Personal (Stage Two) score illustrates a user that possesses concern on how the technology will impact him personally. This theme also emerged in his qualitative data. When asked during his interview if he thought he would be able to used technology in his teaching he replied, "I do think I will be able to do it like I just haven't had any experiences with it yet" (P9-I-L66). The doubt in his mind was further articulated when he discussed the challenges he thought he would face in his use of technology. "Because I have not used it in the classroom at all like maybe if we started using technology earlier I wouldn't have much of a worry about it" (P9-I-L84). One interesting theme that emerged from both datasets was he expressed an interest in wanting to collaborate with others in their use of technology. On his post-class SoCQ administration he had a high Collaboration (Stage Five) level of concern. This indicated that he had an interest in seeing how other professionals are using the innovation. During his interview he mentioned a desire to see technology in action while he discussed 
whether he would be able to use technology. "I still want to see it in action before I feel real comfortable" (P9-I-L60).

His concern about technology extended beyond himself as well. During his interview he expressed concern about how the use of technology would impact his students. Illustrating this mindset was a concern he described that he had entering the course. "I guess my concern was kind of like more toward how to use it toward an age group. Like which technologies do you use with certain age groups" (P9-I-L20)? He was also cognizant of the fact that he has had very little practical experience of using technology with children in the K-12 setting. As a result he is concerned about how technology will impact his students. "It is about the students to me I want to make sure it benefits them" (P9-I-L80). His focus on technology's impact on his students was artfully described when he discussed if he thought he would be able to use technology.

I hope I have learned enough about this to then use it in high school health or physical education. I hope that I can use it correctly and hope the kids respond to it well so my view on technology stays as positive as it is (P9-I-L62).

One important thought discussed in the previous quote was that he was hopeful that he can use technology to his advantage. He also discussed that his students' response to the technology will influence his view on technology.

\section{Mixed-Data Case Narrative}

A holistic view of Participant Nine's quantitative and qualitative data characterized an individual that values technology and is cautiously optimistic that he will be able to use technology to his advantage. His value and comfort with technology is represented in both 
datasets. In his quantitative data he rated himself as a stage six adopter when he left the course. This suggested that he felt he could use technology as a tool in an innovative manner to enhance his teaching. Within his qualitative data he also spoke in a manner that highlighted his confidence. His guarded optimism is also represented in both datasets. In his post-class SoCQ he expressed concern about technology's impact on him and his students. This message was also well represented in his qualitative data. His lack of experience in the K-12 setting increased the concern he had for technology's impact on his students. Gunter's (2001) research on a singlecourse strategy to integrate technology supported his claim in identifying an inherent weakness of this strategy is that learners do not get field experience. Therefore as Hall, George, and Rutherford (1979) stress an individual's internal concerns about an innovation must first be addressed before meaningful change can occur. Participant Nine is concerned about technology's impact on the learning environment, but his experience in the course provided him more ideas, knowledge, and confidence that he will be able to use technology to his advantage.

\section{Participant Ten Profile}

\section{Background Information}

Participant Ten was a female pre-service teacher. Coming into the class she cited that her exposure to technology as a physical education student had been minimal. During her collegiate years she attended three technology courses. She also attributed most of her knowledge about technology to being self-taught.

\section{Table 10}

\section{SoCQ Data}

\begin{tabular}{ccccccccc}
\hline Timing & $\begin{array}{c}\text { Stage } \\
\text { Zero }\end{array}$ & $\begin{array}{c}\text { Stage } \\
\text { One }\end{array}$ & $\begin{array}{c}\text { Stage } \\
\text { Two }\end{array}$ & $\begin{array}{c}\text { Stage } \\
\text { Three }\end{array}$ & $\begin{array}{c}\text { Stage } \\
\text { Four }\end{array}$ & $\begin{array}{c}\text { Stage } \\
\text { Five }\end{array}$ & $\begin{array}{c}\text { Stage } \\
\text { Six }\end{array}$ & $\begin{array}{c}\text { Total } \\
\text { Score }\end{array}$ \\
\hline Pre & 53 & 99 & 96 & 80 & 59 & 84 & 94 & 81 \\
Post & 29 & 84 & 87 & 47 & 66 & 86 & 94 & 70 \\
\hline
\end{tabular}




\section{Participant Ten}

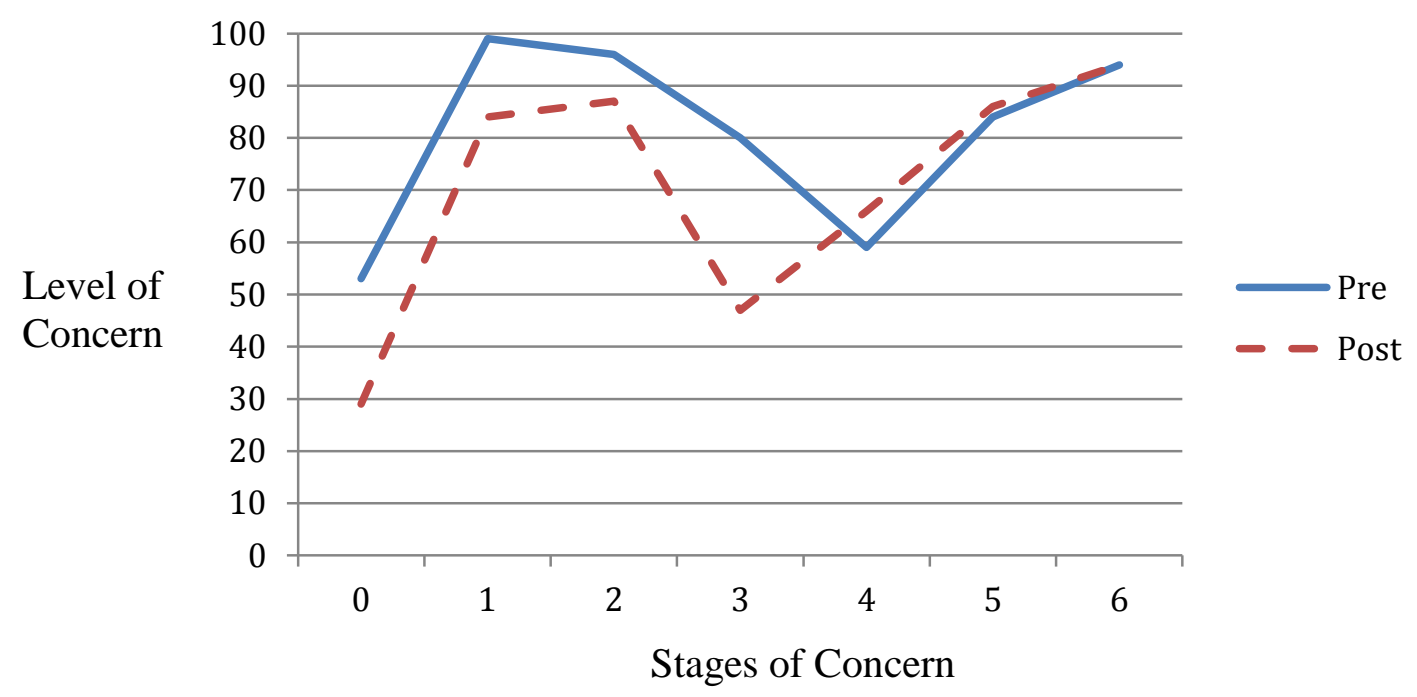

Figure 10. Participant Ten's pre and post-course levels of concern.

\section{Quantitative Case Profile}

SoCQ data profile. Analysis of Participant Ten's SoCQ identified two trends in the data. First, upon entry into the course her internal concerns were all at higher levels including Informational (Stage One) at 99\%, Personal (Stage Two) at 96\%, and Management (Stage Three) at $80 \%$. Concerns on these stages suggested that she was worried about her current knowledge relative to technology in the physical education context, how using technology would impact her personally, and management issues related to technology (Hall, George, \& Rutherford, 1979). Following the course her level of concern decreased for Informational (Stage One) to 84\%, Personal (Stage Two) to 87\%, and on Management (Stage Three) to 47\%. The dramatic decrease on Management (Stage Three) indicated that her concerns about management of technology in the physical education setting were greatly alleviated (Hall, George, \& Rutherford, 1979). 
The second trend that emerged from analysis of the SoCQ was a consistent level of concern on Collaboration (Stage five) and Refocusing (Stage Six). Her Collaboration (Stage Five) level of concern was $84 \%$ on pre-assessment and $86 \%$ on post-assessment. The consistent level of concern on Collaboration stage five combined with a similar level of concern on Informational (Stage One) of $84 \%$ suggested that she was concerned about getting ideas from other people about how to use the innovation (Hall, George, \& Rutherford, 1979). A similar consistency was also visible with her Refocusing (Stage Six) level of concern with pre and post assessment registering at 94\%. The higher level of concern on Refocusing (Stage Six) indicated that she had positive feelings toward the innovation and possessed ideas for how she could use it in her teaching (Hall, George, \& Rutherford, 1979).

Stages of Adoption data profile. Participant Ten selected Stage Three, Understanding the Application of the Process, as her adoption the status that most accurately captured his perception toward technology when she entered the course. Understanding the Application of the Process (Stage Three) describes a user that is beginning to understand the process of applying technology and can even cite specific ways in which they could apply it. Following the course Participant Ten identified Stage Four, Gaining Confidence and Familiarity as her adoption status. Stage Four describes a technology user that is starting to gain confidence and increased comfort level toward instructional technology.

Analysis of the Stages of Adoption data also highlighted that she left the class with more positive feelings about instructional technology. She assessed herself as a Stage Four adopter following the course. This increased from a stage three adopter when she entered the course. A Stage Four adopter characterizes a user that is starting gain more confidence and feels more comfortable about their ability to use technology. 


\section{Qualitative Case Profile}

Analysis of Participant Ten's qualitative data revealed an individual that was open to the thought of using technology. She believed that technology could fill a positive role in her curriculum. The data also showed that her lack of experience with technology created some doubts about using technology in the field with children. Even though she did have concerns that stemmed from her lack of experience of using technology in the K-12 context the course instilled a greater sense of knowledge and confidence toward her ability to use technology.

Starting in her week one journal she cited that some of her doubts about technology were rooted in her lack of personal experience of seeing and using technology in the physical education context. In her week one journal she discussed some of her concerns about technology:

As a student in physical education class, I never really had any experience with technology at all besides the occasional movie that was shown when classes were shortened. As a future teacher though I now think that using technology can be beneficial to education and teaching (P10-J1-L10).

Why she believed in technology was also artfully described in her interview. "So if you're not staying up to date with what is going on today and integrating that into your classroom then I think in a sense, yea you fall behind and you won't be the best teacher that you could be" (P10-IL76). Even though she acknowledged that technology in physical education was a new concept to her she believed that technology can be a positive tool to use in her teaching. Her lack of knowledge and experience with technology also created some concerns that she had about the reliability of technology. In her week two journal she again cited how she had a concern about the reliability of technology. "Before the class I was concerned about the reliability of 
technology, especially with large groups of students. I've seen that not all technology is reliable, and doesn't always pickup the different activities that the students may do" (P10-J2-L11). Again, due to her limited experience and knowledge with technology she had developed a perception that technology is not reliable.

As the class progressed it appeared that she found one component of the class to be extremely valuable. Starting in her week two journal she discussed how hands-on learning experiences were enjoyable. "It's nice to be able to take some of the different equipment home and really get to experience how it works" (P10-J2-L9). Her enjoyment of hands-on learning was further articulated when she discussed her experience in the instructional technology course during her interview.

It's been a positive experience. Just trying the different technology like having the opportunity instead of just like sitting there and reading about it on the PowerPoint or something like actually getting to see the positive, like the pros and cons of different technologies. Especially the hands-on learning experiences like taking them getting to see how to use them outside of class (P10-I-L3).

She pointed out that hands-on learning was important to her because she felt that she learned better that way. When asked why the class experience changed her future teaching behavior she pointed to hands-on learning. "I really liked it hands-on because I learn better that way" (P10-IL41).

A result of the hands-on learning experience was that it appeared to alleviate some of the concerns she had about technology. When asked to discuss how the class addressed her concerns about technology she stated the following, "Well I went in thinking that technology was kind of unreliable and I guess throughout the class having other peoples' opinion in how they used 
technology the margin of error was not as much as I thought it would have been" (P10-I-L15). Her experience in the course also addressed her internal concerns that she had about the reliability of technology. "Now having learned more about it and having used them and seeing other people's use of them I now see there is not as much of a risk of an error" (P10-I-L18). Another outcome of her hands-on learning experiences was that it enhanced her confidence to use technology. "Personally I feel as though the course affected me very positively. I would say that it has really increased my confidence in integrating technology in the physical education health settings" (P10-J3-L7). The ability to use different technologies helped to enhance her self-efficacy that she could use technology in her teaching.

Hands-on learning increased her confidence and comfort level with technology, but her lack of experience still left doubt in her mind. She referred to this doubt when she was asked about her feelings of using technology during her student teaching practicum. "Really just my lack of experience of applying it in the field just makes me nervous" (P10-I-L89). While she did refer to feeling nervous she still felt fairly confident. When asked if she thought she would be successful in her use of technology she stated, “I don't feel 100\% confident in it but probably like $80-90 \%$ and rest of that I could definitely rely on my university supervisor or professor to help me get through it" (P10-I-L92). One learning experience that she felt would help to enhance her confidence and comfort level with technology would be to see how teachers are using them in the field with children. "I would like to see how teachers have actually used them. I think that would make me feel more comfortable with using some technologies" (P10-I-L55). Again, her lack of experience has created a sense of concern about her ability of applying technology in the field with children. It appeared one area that the class did not fully address was the concerns she had about lack of experience of using technology in the K-12 setting. As 
she stated, "Honestly it makes me a little nervous because I still don't have that much experience with technology in the classroom or even with a small group of students" (P10-I-L86).

One additional concern that emerged in her interview about using technology in the K-12 setting was securing technologies for her to actually use. This was an issue for her because she cited her desire to work in rural or urban areas. She felt that these places would not have enough financial resources to purchase technology. As she stated, "I want to teach more rural areas or urban area that like a lot them won't really have the technology available" (P10-I-L80). Her lack of seeing and experience with technology in the field created another doubt that would be challenging for her to address.

\section{Mixed-Data Case Narrative}

Trends that emerged from Participant Ten's quantitative data revealed that she possessed some internal concerns about technology, but it also suggested that she was more comfortable and confident with technology. Similar duality of feelings was present in her qualitative data. Her increased level of confidence was also present in the quantitative data. Through her handson learning experiences and seeing other people's use of technology she highlighted that these concerns were somewhat alleviated. One stage of concern that did remain high on her SoCQ was Personal (Stage Two), which focuses on the consequences of using technology. Her lack of experience probably contributed to this concern remaining at a higher level. This lack of experience had created some concern for her about using technology in the K-12 context. Gunter (2001) emphasized that not having field experiences in the K-12 setting is a weakness of the single-course strategy. However, it is clear that her experience in the course has made her more knowledgeable and enhanced her comfort level with technology. What may be even more important to her future use of technology is her willingness and openness to trying new 
instructional tools. "I am willing to try new things in teaching so I think the more confident you are going into something the more successful you will be instead if you go in feeling weary about it because you are setting yourself up for failure" (P10-I-L94). The mindset she has adopted made her receptive to technology, which translated into her learning more information about technology even though it was a new instructional tool for her to learn. Following the course she was a more knowledgeable technology user that is willing to integrate technology into her teaching. However, her internal concerns about using technology in the K-12 context will need to be addressed going forward. As Hall, George, and Rutherford (1979) assert an individual's internal concerns must first be addressed before meaningful change can occur. In Participant Ten's case her concern about lacking experience of using technology in the physical education context will need to be addressed.

\section{Participant Eleven Profile}

\section{Background Information}

Participant Eleven was a male pre-service teacher. Coming into the class he cited that his exposure to technology as a physical education student had been moderate. During his collegiate years he attended one technology course. He also attributed most of his knowledge about technology to information he learned from family and friends.

\section{Table 11}

SoCQ Data

\begin{tabular}{lcccccccc}
\hline Timing & $\begin{array}{c}\text { Stage } \\
\text { Zero }\end{array}$ & $\begin{array}{c}\text { Stage } \\
\text { One }\end{array}$ & $\begin{array}{c}\text { Stage } \\
\text { Two }\end{array}$ & $\begin{array}{c}\text { Stage } \\
\text { Three }\end{array}$ & $\begin{array}{c}\text { Stage } \\
\text { Four }\end{array}$ & $\begin{array}{c}\text { Stage } \\
\text { Five }\end{array}$ & $\begin{array}{c}\text { Stage } \\
\text { Six }\end{array}$ & $\begin{array}{c}\text { Total } \\
\text { Score }\end{array}$ \\
\hline Pre & 81 & 99 & 99 & 43 & 82 & 97 & 87 & 84 \\
Post & 77 & 91 & 89 & 52 & 30 & 98 & 96 & 76 \\
\hline
\end{tabular}




\section{Participant Eleven}

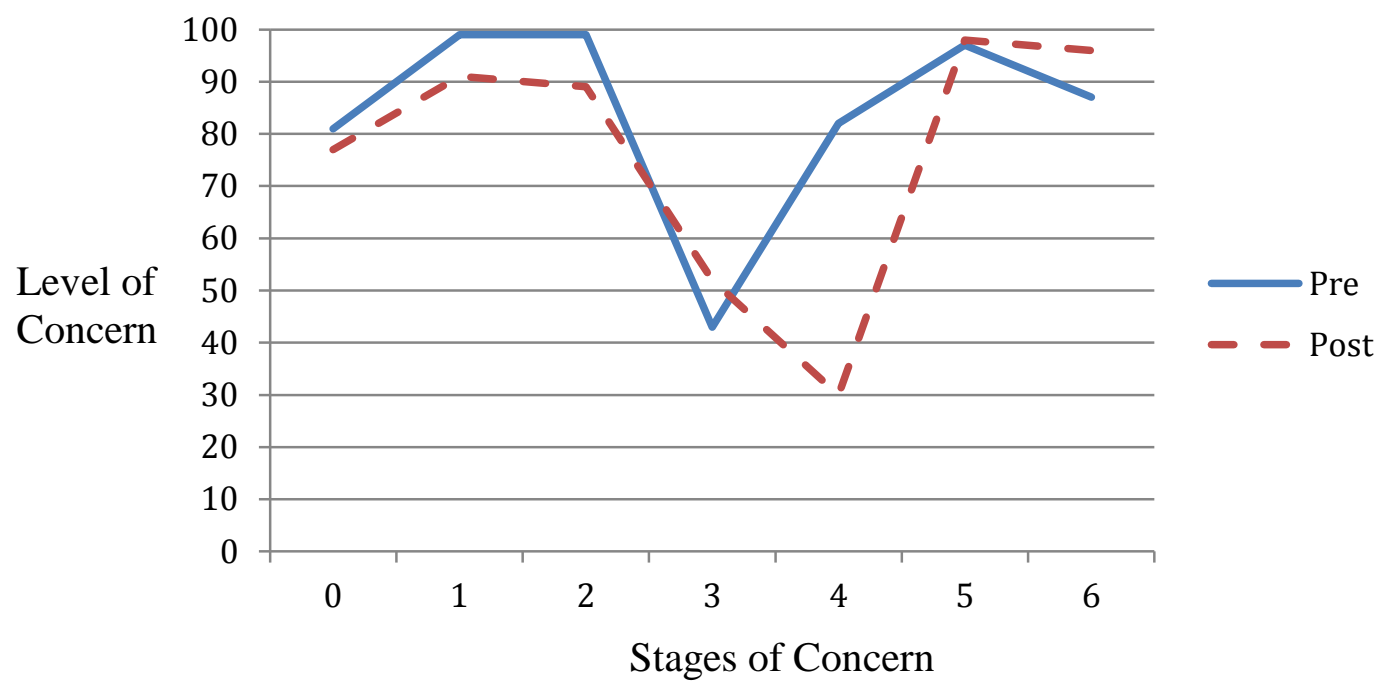

Figure 11. Participant Eleven's pre and post-course levels of concern.

\section{Quantitative Case Profile}

SoCQ data profile. Analysis of Participant Eleven's SoCQ identified three trends in the data. The first trend in his data was the high level of concern he possessed on entry on two of his internal concerns. His Informational (Stage One) level of concern registered at $99 \%$ for preassessment. Similarly, his Personal (Stage Two) level of concern came in at $99 \%$. Such high levels of concern on these two stages posit that he had intense concerns about wanting to have more information about the innovation and he also was worried about how the innovation will personally impact him (Hall, George, \& Rutherford, 1979). Following the course his level of concern for Informational (Stage One) decreased to 91\%, while his Personal (Stage Two) decreased to $89 \%$. The decline in these two stages suggest that the intensity of concerns he possessed for these two stages were somewhat tempered following the course, but they still remained at a high level. 
The second trend that was of interest in his SoCQ data was the consistent high level of intensity for his Collaboration (Stage Five) and Refocusing (Stage Six) concerns. Participant Eleven's Collaboration (Stage Five) score for pre-assessment was $97 \%$ and increased to $98 \%$ on post-assessment. Hall, George, and Rutherford (1979) highlight that users that have high level of concerns on Collaboration (Stage Five) and Informational (Stage One) describe a user that is highly concerned about looking for ideas from other people and possess a desire to know how other people are using the innovation. Mirroring this trend was the level of concern seen on his Refocusing (Stage Six). For pre-assessment his level of concern was $87 \%$ and increased to $96 \%$ for post-assessment. As Hall, George, and Rutherford (1979) emphasize a user that has higher level of concerns on Refocusing (Stage Six) that also possess higher level of concerns with their internal concerns are users that possess more ideas about the innovation but they also may harbor negative feelings toward the innovation as well.

The third trend that emerged in Participant Eleven's SoCQ data was a dramatic decrease in his Consequence (Stage Four) concern. When he entered the course his level of concern was $82 \%$. After the course this level of concern dropped to 30\%. Consequence (Stage Four) users that have higher level of concerns are worried about how the innovation will impact their students in the learning environment (Hall, George, \& Rutherford, 1979). Therefore, it appeared his concerns about how technology would impact his students were not as much of a concern following the course.

\section{Stages of Adoption data profile. Participant Eleven selected Stage Four, Familiarity} and Confidence, as his adoption status when he entered the course. Stage Four describes an adopter that starting to feel more comfortable and gaining more confidence in relation to technology. Following participation in the instructional technology course he identified himself 
as a Stage Three adopter. A Stage Three adopter, Understanding the Application of the Process, describes a user that feels they are just beginning to learn the process of using technology.

Analysis of Participant Eleven's Stages of Adoption data revealed an interesting finding. His stage of adoption status decreased from a Stage Four adopter when he entered the course to a Stage Three adopter following the course. A Stage Four adopter feels that they are starting to gain confidence and familiarity with technology. While a Stage Three adopter is characterized by a user the feels that they are just beginning to understand the process of applying technology and can even cite specific ways in which they could apply it. It appeared that following the course he felt that he overstated what his adoption status was when he entered the course and that technology is still something he is becoming familiar with as an instructional tool.

\section{Qualitative Case Profile}

Analysis of Participant Eleven's qualitative data revealed an individual that viewed technology as a positive tool, but he also harbored some internal concerns about technology that stemmed from his lack of experience of seeing and using technology in the physical education context. This mental struggle that emerged in his data was first described in his week one journal. When he described his concerns about technology he stated, "Technology is both a benefit and a problem in our world" (P11-J1-L14). In his week one journal he also described how it was going to be important for teachers to use technology because of its emerging role in society. "We must understand that technology is on the move and there is no way of stopping it. So we must keep that in mind, we must learn to adapt and utilize technology for what it's worth" (P11-I-L17). In his mind he viewed technology's growth and importance as inevitable so 
teachers might as well accept it. "Technology cannot be stopped from growing. So we need to just accept it and make it work for us" (P11-I-L31).

One reason why he viewed technology as a bad thing at least in his mind seemed rooted in his belief that he was not a technological person. This belief was mentioned in his week one journal. When he discussed his concerns about technology he mentioned, “As I am not a technologically savvy person I fear not being able to stay current with the technology" (P11-J2L34). As the course progressed into week two it appeared that some of the personal concerns he possessed about being able to use technology were somewhat alleviated. "As we have been introduced to these technologies I have come to find out that most of them are in fact quite simple to use" (P11-J2-L9). This notion was further elaborated on when he discussed about how the course had addressed his concerns that he possessed upon entry. "The main concerns I have had coming into this course were in regards to if I would be able to use those technologies with ease. I am not a technologically savvy person, but as I stated previously these technologies are easy to use" (P11-J2-L13). For him the realization of understanding that the technologies were not that difficult was a major relief for him. When he discussed how the technologies were fairly simple to use he stated, "This excited me as I want to implement a great deal of technology in my classroom" (P11-J2-L16). Being able to use the technology and see the technology used showed him that it was not as difficult to do as he thought.

His tone toward technology remained positive during the first two weeks. This trend continued into his week three journal as well. When asked to describe what he learned from the class he stated, "Before the class I was unaware and somewhat uninterested of the technology that I could use. Now I can say that I do not feel the same" (P11-J3-L3). However, one issue that he spoke to during his week three journal indicated that his lack of previous experience with 
technology served as a barrier for him personally. When he further discussed how the course changed him personally he added, "Before the class I was somewhat uninterested about using technology in my classroom. Part of why this was because of my knowledge and experience using technology before. I now am much more confident about using technology in my classroom and look forward to implementing it" (P11-J3-L16). For him his lack of experience with technology appeared to be a barrier for him because he was more comfortable with a traditional approach to physical education. When he elaborated on the role technology should have in physical education he again pointed to his affinity for a traditional approach: "I will always be more toward the traditional way of physical education" (P11-I-L57). Perhaps a statement that best captured his mental struggle with technology was a response he mentioned when he talked about the role technology would have in his teaching: "Like I said it's good because technology is becoming that important, but I would rather stick to a traditional method" (P11-I-L67). In that statement he described technology being a positive entity because of its emerging role in education he also highlighted that he personally prefers a tradition approach. His preference to a traditional approach to education seemed to stem from his lack of experience and exposure to technology. When asked if technology could make him a better teacher he stated, "Not at this current time in my life do I feel it could make me a better teacher because it's not what I grew up on and it's not what I learned here" (P11-I-L85). His statement here was of great importance because he spoke to his biography as a physical education teacher. Technology was not an instructional tool that he witnessed a lot when he was a student. Therefore, as Lortie $(1975,2002)$ suggests teachers have a tendency to reproduce teaching behaviors that they were exposed to as students. For Participant Eleven it appeared that he is more inclined to adopt a teaching approach that embraces traditional methods to physical education programming. 
Participant Eleven's qualitative data revealed an individual that had conflicting views of technology. Part of him knows that technology is important and that it has the potential to positively influence the learning environment. When he discussed technology's role in physical education he described this mindset accurately.

Unfortunately or fortunately however you want to look at it technology is taking over the world, like in every aspect. So if technology is going to be that big we might as well utilize it for its benefits. It's unstoppable, it's inevitable, it's going to happen it just keeps growing, growing, and growing. So as we are moving into this technological, screenbased world we might as well use it and kind of flip the bad into good (P11-I-L58).

As this statement highlighted he feels strongly that technology is a big part of our lives and its role is going to continue to grow. In a similar vein, he also expressed throughout his data how the course helped to improve his confidence and comfort level with technology. When he entered the course he had concerns that technology was going to be difficult for him to learn because he is not a big technology person. When asked how the class addressed his concerns he stated:

Once I was introduced to the technology my main concern was being able to use it because I am not that technologically savvy person, but once the instructor showed us how easy they are made and created it really was a piece of cake because I realized anybody could use it (P11-I-L15).

He believed that the course enhanced his comfort level and increased his confidence level relative to technology. Participant Eleven also acknowledged that the process of integrating technology into his teaching remained a challenge for him going forward. When asked about his 
biggest challenge of using technology he responded, "My biggest weakness is the actual operation of the technology itself" (P11-I-L94). His confidence improved following his experience in the instructional technology course, but he still feels that being able to operate the technology will be a challenge.

Operation of the technology was a challenge that he described. Another issue that may be of greater importance for him to address going forward is his preference to a traditional approach of teaching physical education. His resistance to technology was described well when he discussed his feelings about using technology during his student teaching practicum.

If you base if off my education here the majority was not involved with technology so I am more comfortable with everything else. Now they are throwing technology in the mix. It's whoa this is new. I have been taught so many other things and I am actually starting to become comfortable with it. How am I just going to use it or throw technology into it? (P11-I-L101)

Again his lack of experience with technology in the physical education context has led to him being more comfortable with traditional methods to teaching.

He believes technology has a prominent role in society. The instructional technology course somewhat alleviated his concern about operational challenges of using technology. Even though his concerns have somewhat been alleviated he still believes it will be a challenge for him going forward. While those are positive outcomes that he received from the course a lingering issue for him is that he still prefers a traditional approach to teaching physical education. This sentiment was shared when he talked about the role of technology in his teaching, "Well I am not going to use it really unless I feel that it is absolutely necessary" (P11-I-L64). His lack of 
experience with technology as a physical education student and pre-service teacher seems to be the culprit as to why he has adopted his current perception of technology. This point was further elaborated on when he talked about if he would be able to integrate technology into his teaching he stated the following, "Not right now I need a little more experience. I just don't have that much experience with it. I barely have enough experience. I am just getting introduced to technology” (P11-I-L73).

\section{Mixed-Data Case Narrative}

A holistic view of Participant Eleven's quantitative and qualitative data highlights that he possesses conflicting perceptions of instructional technology. Trends in both datasets support the mental struggle participant eleven has in regards to technology. One important trend that emerged from his SoCQ post-class analysis was that he possessed high levels on his internal concerns and a higher level of concern on his Refocusing (Stage Six). According to Hall, George, and Rutherford (1979) a user that possesses this combination of concerns has positive views of the innovation, but also harbors personal concerns about the innovation. Participant Eleven described throughout hid qualitative data how the course helped to alleviate his concerns about the operational challenges of technology. This sentiment also was present in his SoCQ data following the class. His Informational (Stage One) concern that focused on wanting more information decreased from $99 \%$ to $91 \%$. Similarly his Personal (Stage Two) concern that deals with the consequences of using technology also saw a similar decrease dropping from $99 \%$ to 89\%. When you couple these decreases with an increase that was seen on SoCQ his Refocusing (Stage Six) concern from $87 \%$ to $96 \%$ this suggests that he gained more knowledge and ideas for how he could use technology in his teaching. Both quantitative and qualitative datasets indicated that he left the course feeling more comfortable about technology. 
The data also highlighted that Participant Eleven still possessed some personal concerns about technology. Highlighting these personal concerns from his quantitative data was that his stage of adoption of technology decreased from Stage Four to Stage Three. His concern about using technology was also expressed throughout his qualitative data. Participant Eleven's feeling of lacking the skill to use technology and lack of experience seemed to manifest into a mindset that preferred to use a traditional approach to programming. As Bandura (1977) highlighted the confidence or self efficacy an individual possesses toward an innovation will ultimately impact their behavior.

Clearly Participant Eleven possessed views of technology that appeared to counter one another. At some points in the data he mentions that he intended to use technology. It seemed that a large reason why he felt that he would use technology was because the operational concerns he had about using technology were alleviated. While he shared these thoughts about his intention to use technology he also described how he had internal concerns about technology. Even though he felt more comfortable with technology his prior experience with technology still seemed to permeate his thoughts when it came to technology. When you couple the negative thoughts he shared about technology failures with his lack of experience it may help to explain why part of him is still hesitant toward technology. Participant Eleven left the class in a precarious position relative to technology. He possessed an enhanced level of comfort toward technology, but still had doubts about operating technology. He knows technology is experiencing an emerging role in education, but due to his lack of experience with technology he still preferred a traditional approach to physical education. The class did appear to somewhat alleviate the internal concerns he possessed, but they still remain at the forefront of his mind. As Hall, George, and Rutherford (1979) stress an individual's personal concerns about an innovation 
must first be addressed. For Participant Eleven his preference to a traditional approach will need to be addressed for meaningful change to occur relative to instructional technology.

\section{Participant Twelve Profile}

\section{Background Information}

Participant Twelve was a female pre-service teacher. Coming into the class she cited that her exposure to technology as a physical education student had been minimal. During her collegiate years she attended one technology course. She also attributed most of her knowledge about technology from learning experiences during her K-12 years as a student.

\section{Table 12}

SoCQ Data

\begin{tabular}{ccccccccc}
\hline Timing & $\begin{array}{c}\text { Stage } \\
\text { Zero }\end{array}$ & $\begin{array}{c}\text { Stage } \\
\text { One }\end{array}$ & $\begin{array}{c}\text { Stage } \\
\text { Two }\end{array}$ & $\begin{array}{c}\text { Stage } \\
\text { Three }\end{array}$ & $\begin{array}{c}\text { Stage } \\
\text { Four }\end{array}$ & $\begin{array}{c}\text { Stage } \\
\text { Five }\end{array}$ & $\begin{array}{c}\text { Stage } \\
\text { Six }\end{array}$ & $\begin{array}{c}\text { Total } \\
\text { Score }\end{array}$ \\
\hline Pre & 46 & 72 & 55 & 47 & 54 & 68 & 92 & 62 \\
Post & 46 & 93 & 89 & 34 & 82 & 91 & 94 & 76 \\
\hline
\end{tabular}

\section{Participant Twelve}

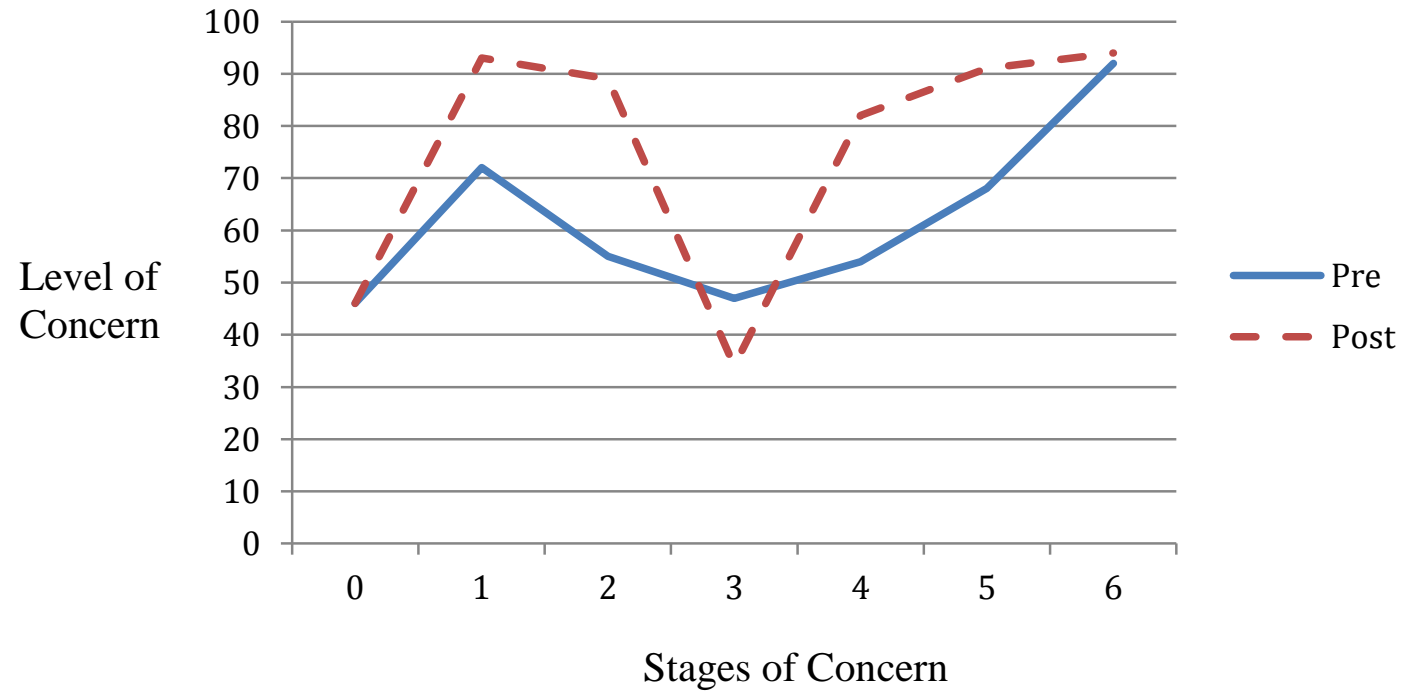

Figure 12. Participant Twelve's pre and post-course levels of concern 


\section{Quantitative Case Profile}

SoCQ data profile. Analysis of Participant Twelve's SoCQ identified two themes in the data. The first theme was a dramatic increase that was seen in both her internal and external concerns toward instructional technology. The two internal concerns that jumped on post assessment for Participant Twelve were her Informational (Stage One) and Personal (Stage Two) concerns. Her pre-class assessment for stage one was $72 \%$, while her post-class assessment jumped to 93\%. A similar increase was also seen in her Personal (Stage Two) score with an increase from $55 \%$ to $89 \%$. Such an increase indicated that her concerns about wanting more information and concerns about the personal consequences of using the innovation increased following the course (Hall, George, \& Rutherford, 1979). Increase in level of concern was also seen in two of her external concerns. Her Consequence (Stage Four) level of concern increased from $54 \%$ to $82 \%$. The increased level of concern suggested that her concern about the relationship between how technology will impact her students increased following the course. A similar trend was also present with her Collaboration (Stage Five) level of concern with an increase from $68 \%$ to $91 \%$. The elevated increase on Collaboration (Stage Five) in conjunction with the elevated Informational (Stage One) concern highlighted that she is concerned about looking for ideas from other people and learning more about the innovation from how other people are using it (Hall, George, \& Rutherford, 1979).

A second important trend in Participant Twelve's data was a consistent high level of concern on Refocusing (Stage Six). Her pre-class level of concern was 92\% and post-class level of concern was 94\%. Her consistent high levels of concern on Refocusing (Stage Six) indicated that she maintained positive feelings toward the innovation. The high level of concern on 
Refocusing (Stage Six) also suggested that she felt comfortable with her knowledge about the innovation (Hall, George, \& Rutherford, 1979).

Stages of Adoption data profile. For pre-class administration of the Stages of Adoption survey Participant Twelve identified Stage Five, Adaptation to other Contexts that most accurately captured her perception toward instructional technology. Stage Five is characterized as a technology user that feels confident in their ability to apply technology in a variety of contexts. Following the instructional technology course Participant Twelve identified Stage Six, Creative Application to New Contexts, as the stage that identified her stage of adoption of technology. Stage Six describes technology users that are not only very confident in their ability to use technology in a variety of contexts, but they also have the confidence to make technology an integral component of his or her curriculum.

Analysis of the Stages of Adoption data highlighted a user that entered with positive feelings toward instructional technology and left the course feeling even better. She entered the course with as a Stage Five adopter and left as a Stage Six adopter. These results coincide with the consistent high level of concern she registered on stage six on the SoCQ. Her positive feelings about instructional technology were high coming into the class and were enhanced following participation in the class.

\section{Qualitative Case Profile}

Participant Twelve's qualitative data described an individual that viewed technology in a positive light. The data also showed that the instructional technology course provided her with more knowledge and confidence to use technology in her teaching. Her positive view of 
technology was stated early in her week one journal entry. As she stated in her week one journal about concerns relative to instructional technology:

I am concerned about instructional technology. As I start to complete my final year of undergraduate work and student teach, I feel that it is important to learn a lot concerning technologies that I can use in my classrooms whether they are student based or teacher based (P12-J1-L20).

She had a mindset early in the class that she wanted to learn more about how she can use technology in her teaching. "Being a student of today, technology has been a part of my learning" (P12-J1-L11). In addition to describing how technology has been a part of her learning she expressed how technology could positively impact her students learning. "Technology can have a positive impact on student learning and in teaching" (P12-J1-L18). Her views were predominately positive toward technology even though she admitted that her exposure to technology as a physical education student was limited. "In elementary, middle, and high school I have had no exposure to technology in the physical education classroom" (P12-J10-L11). As a result when she discussed her concerns about technology she expressed that she hoped to become more comfortable with technology. "I am concerned that I may not know how to use technology correctly. I am also afraid that students will misuse the technology" (P12-J1-L25). Her concern about lacking comfort with technology did not deter her from being open to using technology. "I hope to open up to the use of technology in the physical education setting" (P12-J1-L33). She expressed willingness to learn more about technology and stated technology's value to the learning environment early in her qualitative data. She also admitted that technology in the physical education context was a new concept to her. 
As she progressed into the second week of the course her positive view of technology continued to emerge. In her week two journal she was asked if the class increased her awareness of technology. To which she responded, "The class has broadened my scope of technology that can be used in the physical education setting from a teaching, assessment, and professional standpoint" (P12-J2-L13). Similarly in her week three journal she described that her most important experience in the class was learning how to use different technologies. "The most important experience I had in this class was learning different technologies to use in lesson delivery" (P12-J3-L2). A result of her experience of using different technologies was that it gave her new ideas for how she could use technology and the benefits of using technology:

Technology can also be used to adapt to students' needs, such as exergaming. If a student cannot physically hold a ball, but can make the correct arm movement, he or she can use a game such as an Xbox Kinnect to be involved in a throwing lesson. It is important that all students in the physical education setting learn and technology can help with student learning (P12-J3-L7).

In her week three journal she was able to describe a specific aspect of teaching that technology could enhance her instructional effectiveness.

Her positive view of technology was also seen throughout her interview data. When she discussed her concerns that she had upon entry to the course and how they evolved during the class she provided an interesting answer:

During the first week while we were learning how to incorporate technology into the lesson I really didn't know before that. I didn't think technology really belonged in the 
physical education setting, and after learning the different technologies I can definitely see a place for technology now (P12-I-L11).

A result of her increased knowledge relative to technology she felt that technology definitely had a place in physical education. A direct result of her learning new ways to put technology into her lesson delivery was that it enhanced the confidence she had in her ability to be successful. "I do feel like I can be successful because I know how to use the technology and how it can be used in the physical education setting" (P12-I-L58). Her affinity toward technology was further articulated on when she talked about what she would do differently as a teacher following her experience in the course. "Definitely incorporate technology into my lessons because I have a better understanding of the technology and how it works and how it could be put into the lesson and used" (P12-I-L19). Her belief that technology definitely has a role in physical education was further spurred on because of technology's involvement with learners of today. When she talked about if she felt technology would be feasible for her to use in her teaching she stated, "Yes, because with students today being brought up with technology so their more aware of technology at home, in the classroom now, and it needs to be incorporated into the gymnasium (P12-I-L41).

Her concerns about knowing how to use technology seemed to erode as a result of the class. One challenge she spoke about relative to technology was the challenge of securing technologies for her program. In her week two journal she stated that a question she has about technology is how to purchase technologies with a tight budget. "I am concerned about using technology in the classroom with the respect to budgets. Technology is expensive and some schools do not have the money to purchase the necessary equipment" (P12-J2-L14). She spoke to this barrier again when she discussed a challenge to using technology in her teaching during her interview. "Obtaining technology if the school does not have it especially if the school does 
not have a lot of money finding a way to purchase the technology to put into the classroom" (P12-I-L50). In her mind the challenge will not involve being able to know how to use a certain technology, instead for her actually obtaining the technologies for her program will be the challenge.

\section{Mixed-Data Case Narrative}

A holistic analysis of Participant Twelve's quantitative and qualitative data highlighted that one trend that emerged in each dataset lend support to one another. Analysis of her quantitative data suggested that participant twelve was a more confident and knowledgeable technology user. One trend that emerged from her quantitative data, specifically her SoCQ was that her personal concerns on Informational (Stage One) and Personal (Stage Two) increased on post-class administration. Concerns on these stages suggested that she had internal issues about how technology is going to impact her personally and the consequences of using technology. These trends did not emerge in her qualitative data. The one personal concern that she spoke to was that she felt it would be difficult to obtain technology for her physical education program. While the personal concerns did not emerge in her qualitative there may be a reason that describes why her personal concerns increased following the course. Hall, George, and Rutherford (1979) direct researchers to examine the total score of an individual as well. For Participant Twelve her total score increased from $62 \%$ to $76 \%$ suggested that her personal involvement and investment with the innovation increased. She openly admitted that she lacked experience, knowledge, and was skeptical when she entered the class. Following the class she expressed how these concerns were alleviated because she felt more knowledgeable, confident, and believed that technology would play a role in her teaching. Therefore, it appeared that the 
instructional technology course enhanced her knowledge, comfort level, and addressed her concern about technology's role in physical education. 
Appendix G

Curriculum Vitae 


\section{James D. Wyant, Ph.D \\ West Virginia University \\ College of Physical Activity and Sport Sciences}

807 Vermont Ave.

Fairmont, WV 26554

304.534.1600

jwyant12@gmail.com

https://sites.google.com/site/jdwyantportfolio/

\section{$\underline{\text { Summary of Qualifications }}$}

\section{Scholarship of Teaching}

- Received highly positive reviews in the area of teaching effectiveness at the higher education and K12 contexts

- Planned, delivered, assessed, and fostered effective learning environments in Physical Education Teacher Education and Physical Education contexts

- Supervised pre-service teachers during early field experiences and student teaching placements to enhance teaching effectiveness

- Assisted faculty with the delivery of Physical Education Teacher Education courses

- Established expertise in a variety of domain-specific curriculum models, instructional methods, instructional technology, and systematic observation tools to enhance the teaching-learning environment

- Assisted faculty with data collection for NCATE/NASPE accreditation

- 2010-2011 College of Physical Activity and Sport Sciences graduate student of the year

\section{Scholarship of Research}

- Collaborated with faculty on research projects ranging from school-based physical activity to instructional technology

- Served as lead investigator of a project that examined Physical Education Teacher Education technology integration strategies

- Delivered three presentations at national and state conferences

- Presented two poster presentations at national and state conferences

- Co-authored 2 articles that have been accepted for publication

Scholarship of Service

- Served as Live Text trainer to assist PETE candidates and faculty with data entry

- West Virginia Physical Activity Symposium technology consultant 
Academic Preparation:

West Virginia University, Morgantown, WV

Ph.D Kinesiology-Physical Education Teacher Education

August 2012

Cognate area-Instructional Design and Technology

Dissertation Defense: July 11, 2012

Dissertation Topic: A mixed methods analysis of a single- course strategy to integrate technology into a PETE.

Comprehensive Areas: Health-Related Physical Education, Applied Behavior Analysis, Instructional Technology, Supervision, Curriculum Design, Physical Education Research Methods, and Statistics

M.S. Kinesiology-Athletic Coaching Education

May 2009

Emphasis: Sport psychology, exercise prescription, and coaching techniques

Fairmont State University, Fairmont, WV

B.S. Kinesiology- Physical Education, Health Education

May 2007

$\underline{\text { Research and Teaching Interests }}$

Research: Instructional technology integration into PETE, instructional technology integration into the K-12 context, Occupational Socialization, and Social Networking

Teaching: Introductory courses in physical education, elementary methods, pedagogical content knowledge courses, supervision of practicum and field placements, and athletic coaching education

$\underline{\text { Academic Honors and Certifications }}$

Graduate Student of the year award, West Virginia University, College of Physical Activity and Sport Sciences award presented for excellence in teaching and research for the 2010-2011 academic year.

West Virginia Department of Education Certified Physical Education and Health Education teacher certification is valid for teaching physical education preK-Adult and 5-12 for health education 
West Virginia Association of Health, Physical Education, Recreation and Dance Bea N. Orr Student Award Nominee the nomination acknowledged excellence in teaching for young professionals

\section{Employment History}

Graduate Teaching Assistant, West Virginia University, WV

2007-2012

Taught and assisted in teaching undergraduate pre-service physical education teachers. I served as primary teacher for a variety of activity courses in West Virginia University's PETE and Basic Instruction Programs. Responsible for syllabi creation, assessment, lesson planning, and grading. Additional responsibility included managing and entering student data for NCATE accreditation.

University Supervisor for Student Teachers, West Virginia University, WV

2009-2012

I was responsible for supervising pre-service teachers during culminating field placements. An integral component of this experience was to conduct systematic observations of student teachers throughout field placements to help promote teacher growth and monitor progress.

West Virginia University Supervisory Responsibilities

Fall 2009 responsible for supervising six student teachers

Spring 2011 responsible for supervising six student teachers

Fall 2011 responsible for supervising one student teacher

\section{$\underline{\text { Public School Experience }}$}

Mylan Park Elementary, Morgantown, WV

2011-2012

I worked as an elementary physical education practitioner in the K-12 setting. I was responsible for creating and delivering unit plans, lesson plans, and authentic assessments to $4^{\text {th }}$ and $5^{\text {th }}$ grade students. Additional responsibility included serving as the fitness testing coordinator for the school.

Mylan Park Elementary, Morgantown, WV

2009-2010

A highlight of this experience was serving as primary contact for a school-based physical activity promotion research project that focused on increasing school-based physical activity opportunities for sedentary children. I was responsible for interacting with research participants, classroom teachers, and administrators. 
East Fairmont High School, Fairmont, WV

2004-2008

I was required to fill a variety of roles during time spent at the school. Responsibilities included: freshmen boys basketball coach, varsity boys basketball assistant coach, summer strength and conditioning coordinator, and summer basketball camp instructor.

\section{$\underline{\text { Research and Scholarship }}$}

Ongoing Research and Scholarship

Wyant, J.D. (2012). “A mixed methods analysis of a strategy to integrate technology into a pete program.” Status - Dissertation defense in July 2012

Jones, E.J., Bulger, S.M., DiGiacinto, K., \& Wyant, J. D. (2011). “Recess-based incentive program on physical activity levels of elementary students." Status - submitted for publication

Jones, E.J., Bulger, S.M., Wyant, J.D., \& Illg, K. (2012). A modified delphi investigation of instructional technology use in physical education teacher education. Status Manuscript accepted for publication

Jones, E.J., Wyant, J. D., \& Bulger, S. (2012). Moving beyond the stopwatch and whistle: Examining technology use in teacher training. Status - Manuscript accepted for publication

National Presentations

Jones, E., Bulger, S., DiGiacinto, K., \& Wyant, J. D. (2011). Recess-based incentive program On physical activity levels of elementary students. Paper presented at AAHPERD National Conference. San Diego, California. 
Wyant, J. D. (2011). A pete program's strategy to integrate technology into the student teaching practicum. Presentation at the National Student Teaching \& Supervision Conference. Slippery Rock, Pennsylvania.

State Presentations

Wyant, J. D. (2011) Strategies to integrate technology into pete. Presentation at the WVAHPERD State Conference. Flatwoods, West Virginia.

Wyant, J. D. (2011) Life after the party. Presentation at the WVAHPERD State Conference. Flatwoods, West Virginia.

Wyant, J. D. (2010). Technology in physical education: A look at what is new. Presentation at the WVAHPERD Conference. Canaan Valley, West Virginia.

DiGiacinto, K., Wyant, J. D., \& Jones, E. (2010). Mylan park adventure challenge: Results of a semi-structured recess program. Presentation at the West Virginia Physical Activity Symposium. Charleston, West Virginia

West Virginia University Teaching Responsibilities

*Served as teaching assistant

$\begin{array}{llll}\text { Course } & \text { Title } & \text { Semester/Year } & \text { Enrollment } \\ \text { PE 103 } & \text { Beginning Basketball } & \text { Fall 2007/2008 } & 25 \\ \text { PE 103 } & \text { Beginning Basketball } & \text { Fall 2007/2008 } & 25 \\ \text { PE 104 } & \text { Intermediate Basketball } & \text { Fall 2007/2008 } & 25 \\ \text { PE 104 } & \text { Intermediate Basketball } & \text { Fall 2007/2008 } & 25 \\ \text { PE 164 } & \text { Weight Training } & \text { Fall 2007/2008 } & 25 \\ \text { PE 103 } & \text { Beginning Basketball } & \text { Spring 2008/2009 } & 25 \\ \text { PE 103 } & \text { Beginning Basketball } & \text { Spring 2008/2009 } & 25 \\ \text { PE 104 } & \text { Intermediate Basketball } & \text { Spring 2008/2009 } & 25 \\ \text { PE 104 } & \text { Intermediate Basketball } & \text { Spring 2008/2009 } & 25 \\ \text { PE 164 } & \text { Weight Training } & \text { Spring 2008/2009 } & 25 \\ \text { PET 340 } & \text { Teaching Soccer } & \text { Fall 2009 } & 22 \\ \text { PET 344 } & \text { Teaching Hockey } & \text { Fall 2009 } & 22 \\ \text { PET 233 } & \text { Pedagogy \& Theory } & \text { Fall 2009 } & 21 \\ \text { PE 158 } & \text { Indoor Soccer } & \text { Fall 2009 } & 25 \\ \text { PET 340 } & \text { Teaching Soccer } & \text { Spring 2010 } & 18 \\ \text { PET 344 } & \text { Teaching Hockey } & \text { Spring 2010 } & 18\end{array}$




$\begin{array}{lllr}\text { PET 233* } & \begin{array}{l}\text { Pedagogy \& Theory } \\ \text { PE 158 }\end{array} & \begin{array}{l}\text { Spring 2010 } \\ \text { Spring 2010 }\end{array} & 22 \\ \text { PET 483 } & \begin{array}{l}\text { Issues in Physical } \\ \text { Education } \\ \text { PET } 441^{*}\end{array} & \text { Summer 2010 } & 18 \\ \text { PET } 441^{*} & \begin{array}{l}\text { Education } \\ \text { Technology in Physical }\end{array} & \text { Summer 2010 } & 18 \\ \text { PET 460 } & \text { Education } & \\ \text { PET 233* } & \text { Teaching Tennis } & \text { Fall 2010 } & 18 \\ \text { PE 131 } & \text { Pedagogy \& Theory } & \text { Fall 2010 } & 21 \\ \text { PE 131 } & \text { Frisbee } & \text { Fall 2010 } & 25 \\ \text { PE 131 } & \text { Frisbee } & \text { Fall 2010 } & 25 \\ \text { PE157 } & \text { Frisbee } & \text { Spring 2011 } & 25 \\ \text { PET 369* } & \text { Slow Pitch Softball } & \text { Spring 2011 } & 22 \\ \text { PET 379* } & \text { Elementary Methods } & \text { Spring 2011 } & 21 \\ & \text { Elementary Methods } & \text { Spring 2011 } & 21\end{array}$

Professional Affiliations $*$ Currently active

American Alliance for Health, Physical Education, Recreation and Dance*

West Virginia Association of Health, Physical Education, Recreation and Dance*

Service to the College

West Virginia Physical Activity Symposium Technology Consultant 2010

West Virginia University College of Physical Activity and Sport Sciences 2011

Live Text Trainer

College of Physical Activity and Sport Science Dean's Student

Advisory Committee

References Furnished Upon Request 